Portland State University

PDXScholar

\title{
A Scoring Model to Evaluate Offshore Oil Projects: Case of Eni and Mellitah Oil \& Gas
}

Abdulhakim Giadedi

Portland State University

Follow this and additional works at: https://pdxscholar.library.pdx.edu/open_access_etds

Part of the Petroleum Engineering Commons

Let us know how access to this document benefits you.

\section{Recommended Citation}

Giadedi, Abdulhakim, "A Scoring Model to Evaluate Offshore Oil Projects: Case of Eni and Mellitah Oil \& Gas" (2020). Dissertations and Theses. Paper 5601.

https://doi.org/10.15760/etd.7473

This Dissertation is brought to you for free and open access. It has been accepted for inclusion in Dissertations and Theses by an authorized administrator of PDXScholar. Please contact us if we can make this document more accessible: pdxscholar@pdx.edu. 
A Scoring Model to Evaluate Offshore Oil Projects: Case of Eni and Mellitah Oil \& Gas

by

Abdulhakim Giadedi

A dissertation submitted in partial fulfillment of the requirements for the degree of

\author{
Doctor of Philosophy \\ in \\ Technology Management
}

Dissertation Committee:

Tugrul U. Daim, Chair

Ramin Neshati

Richard C. Sperry

Birol Yesilada

Portland State University

2020 


\begin{abstract}
Offshore oil projects have many different and unique characteristics, such as larger project size, higher number of scopes, and higher complexity. In fact, offshore oil projects described as mega projects are ones that require significant assessment and acquisition methods in order to reduce risks and failures. Traditionally, cash flow analysis and return on investment are the most known factors to evaluate offshore oil projects. However, there are several other internal and external factors that affect the overall performance of offshore oil projects. A comprehensive approach and advanced tools are required to evaluate these factors that can have a significant impact before any investment decisions are made.

This study emphasizes some critical and challenging factors that affect the successful implementation of offshore oil projects and scores these factors to highlight their weight of impact on offshore oil projects using a hierarchical decision model (HDM). A comprehensive literature review was conducted to recognize the complexities of these factors. Four perspectives were identified in order to assess the attributes that are necessary for successful offshore projects. These perspectives are economical, technical, political, and safety and environmental. Under each perspective, there are multiple criteria that are linked to each other with complex processes and unique challenges. A hierarchical decision model, along with desirability curves, was implemented to evaluate offshore oil projects in order to improve investment decisions and reduce failure.
\end{abstract}




\section{DEDICATION}

I dedicate my dissertation work to my family for their endless love, support and encouragement.

To my beloved parents, Abdussalam and Sabria

To my lovely wife, Rowida Milad

To my kids, Abdulssalam, Aisha and Atika 


\section{ACKNOWLEDGMENTS}

I would like to thank the following people, without whom I would not have been able to complete this research, and without whom I would not have made it through my doctoral degree!

First of all, I would like to express my sincere gratitude to my adviser and committee

chair Dr. Tugrul U. Daim for the continuous support of my Ph.D study and research, for his patience, motivation, enthusiasm, and immense knowledge. Without his guidance and persistent help this research would not be possible.

I would also like to express my deepest appreciation to my committee members, Dr. Ramin Neshati, Dr. Richard Sperry, and Dr. Birol Yesilada, for their encouragement and insightful comments. I am grateful for all the time, effort and advice they have offered me during this research.

This research would not have been achievable without the active participation, input, and feedback from dozens of subject matter experts, who took time from their busy schedules to understand the research and to help in the validation, quantification, and application of the research model. My sincere thanks also goes to all of them.

Last but not the least, I would also like to acknowledge the support and dedication of Mohamed Swesi, Kosha Amin and Shalah Ghumiem as well as all of ETM department faculty members, staff, and friends who have been a great source of support. 


\section{TABLE OF CONTENTS}

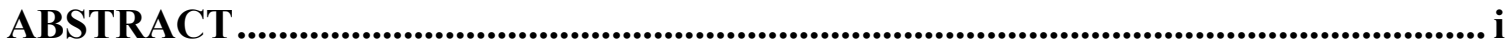

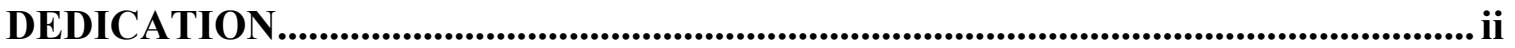

ACKNOWLEDGMENTS .................................................................................................ii

LIST OF TABLES ……...........................................................................................ii

LIST OF FIGURES ....................................................................................................

LIST OF ABBREVIATIONS ........................................................................................ xiii

CHAPTER 1: INTRODUCTION................................................................................... 1

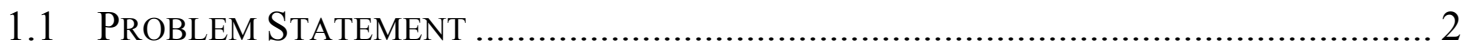

CHAPTER 2: LITERATURE REVIEW ....................................................................... 4

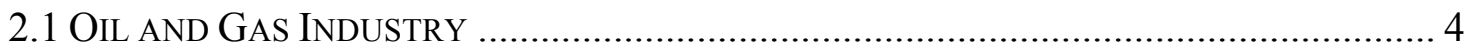

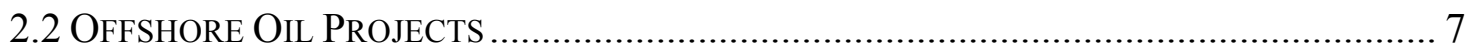

2.3 OfFshore OIL Projects Performance ………............................................ 10

2.4 Root CAUSES OF OfFSHORE OIL PRoJeCt FAILURES.............................................. 13

2.5 Offshiore Oil Portfolio Management and Project Selection ...................... 15

CHAPTER 3: FACTORS AFFECTING OFFSHORE OIL PROJECTS................... 17

3.1 ECONOMICAL PERSPECTIVE ............................................................................. 17

3.1.1 Oil Price Behavior ............................................................................. 17

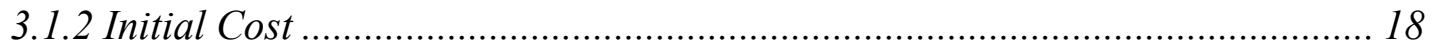

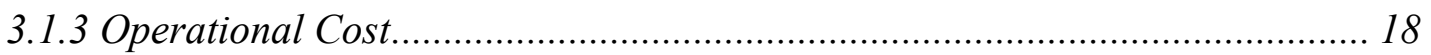

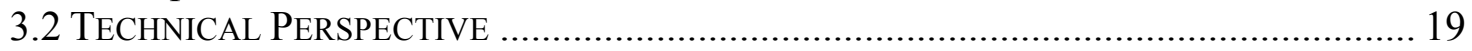

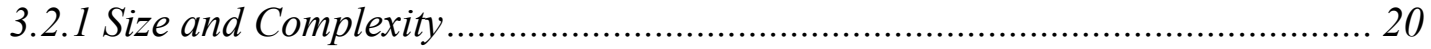

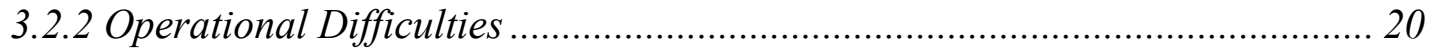

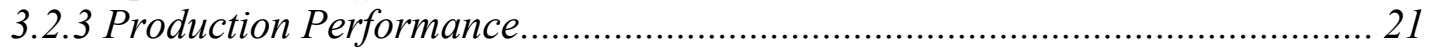

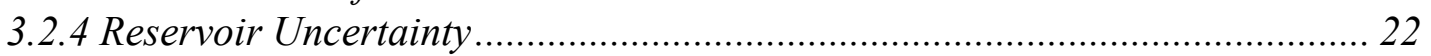

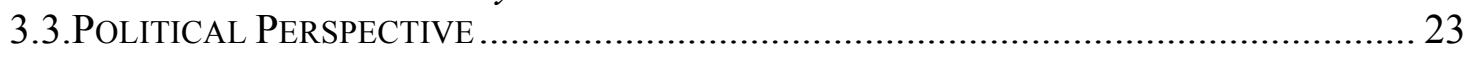

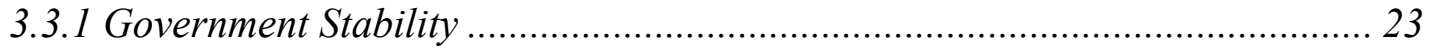

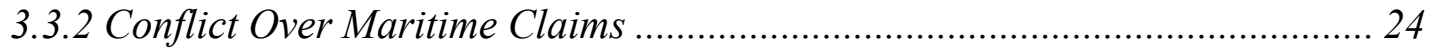

3.3.3 Policies, Regulations and Governance Standards......................................... 25

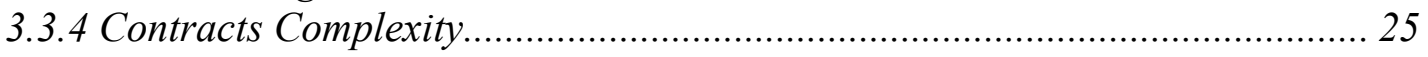

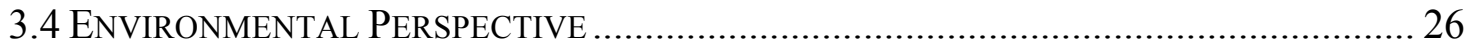

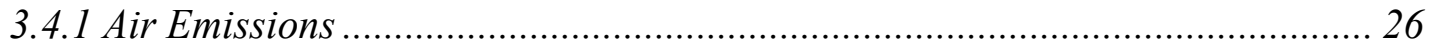

3.4.2 Solid \& Liquid Waste Management ............................................................ 27

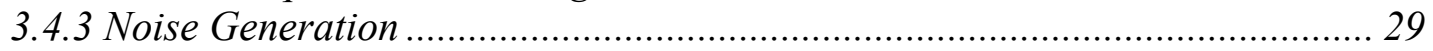

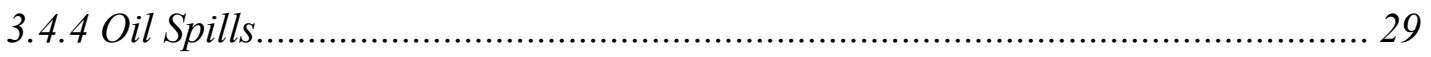

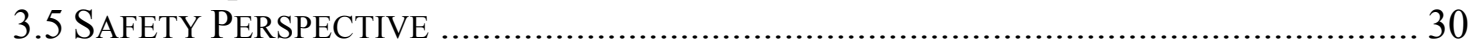

3.5.1 Hazard Identification and Risk Management .............................................. 30

3.5.2 Implementing Health, Safety and Environmental (HSE) ................................ 31

CHAPTER 4: RESEARCH APPROACH AND METHODOLOGY ........................... 33 


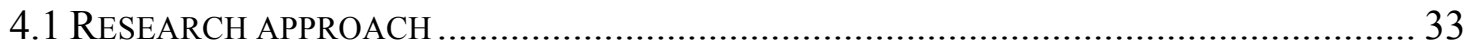

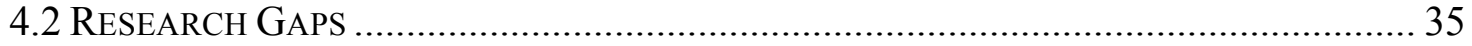

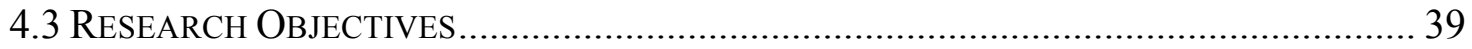

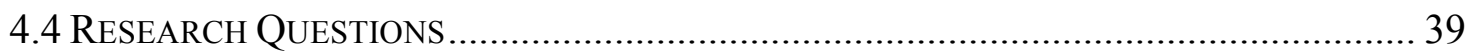

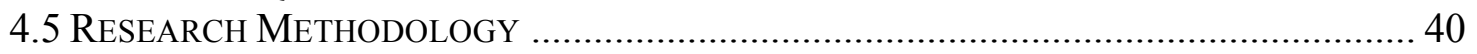

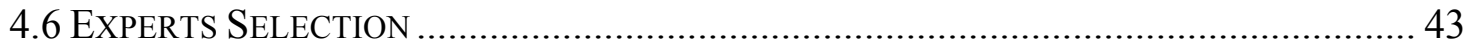

4.6.1 Challenges Associated with Expert Panels Formation................................... 45

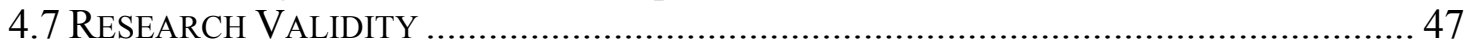

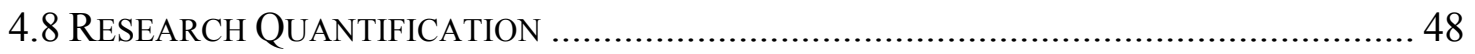

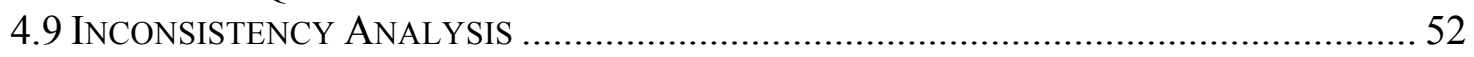

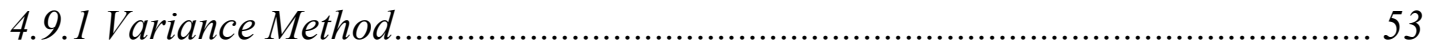

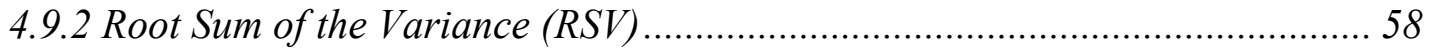

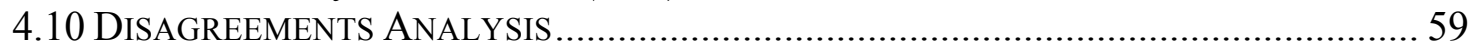

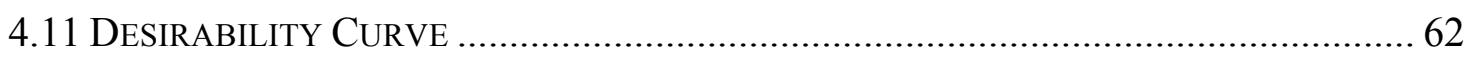

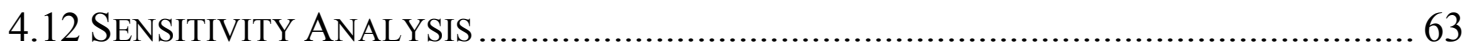

CHAPTER 5: MULTI CRITERIA DECSION MAKING METHODOLOGIES.... 66

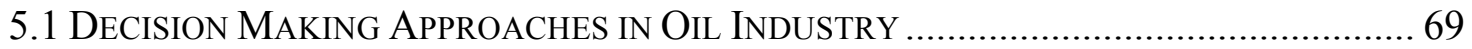

5.1.1 Decision Trees Analysis (DTA).............................................................. 70

5.1.1.1 Strengths of Using Decision Tree Analysis (DTA) ............................ 73

5.1.1.2 Limitations of Decision Tree Analysis (DTA) ..................................... 73

5.1.2 Monte Carlo Simulations ............................................................................ 75

5.1.2.1 Strengths of Using Monte Carlo Simulations ...................................... 76

5.1.2.2 Limitation of Using Monte Carlo Simulations.................................... 77

5.2 WHY THE HDM APPROACH IS IMPLEMENTED IN THIS RESEARCH .............................. 77

CHAPTER 6: MODEL DEVELOPMENT AND PANELS FORMAT ....................... 79

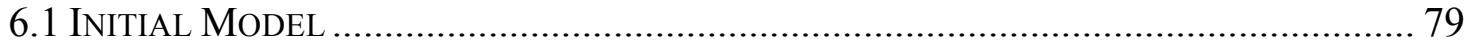

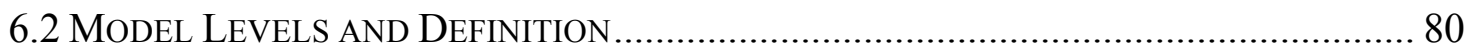

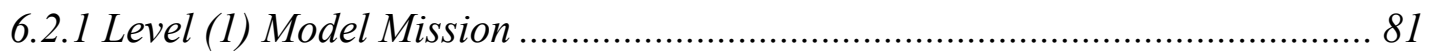

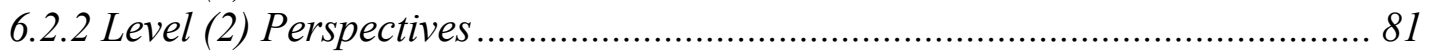

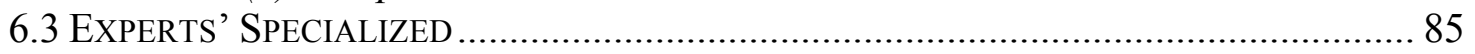

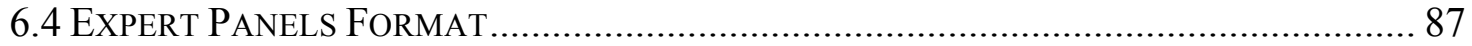

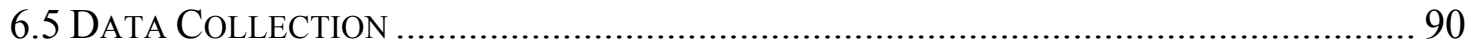

CHAPTER 7: MODEL VALIDATION, QUANTIFICATION AND DESIRABILTY

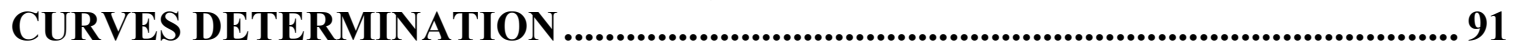

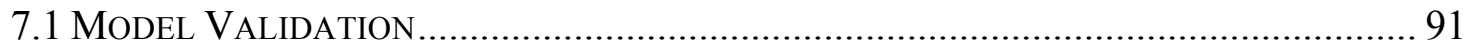

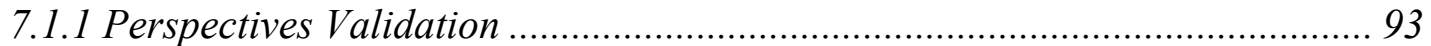

7.1.2 Economical Criteria Validation.................................................................... 94

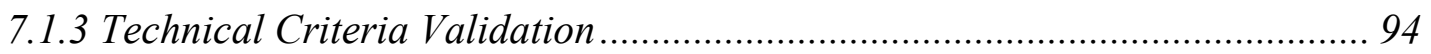

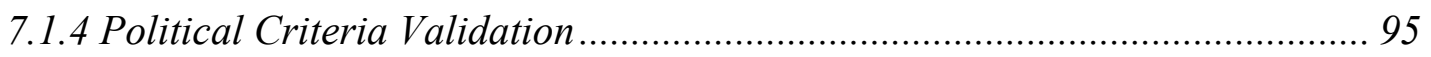

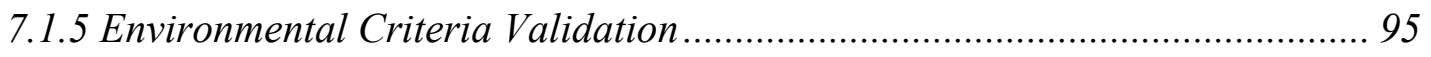

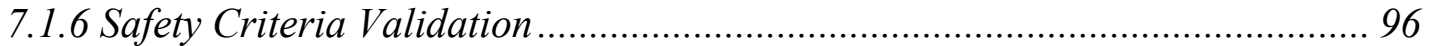

7.2 SECOND Round OF THE VALIDATION PhaSe ......................................................... 96 


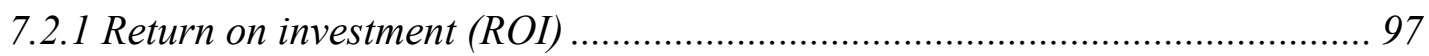

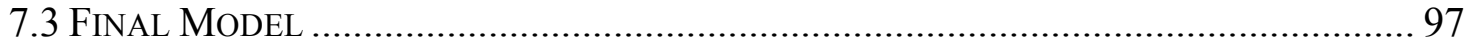

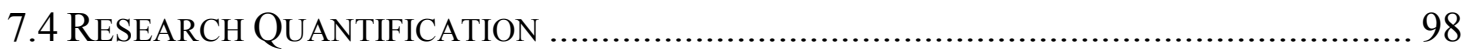

7.4.1 Perspectives Quantification .......................................................................... 100

7.4.2 Economical Quantification ........................................................................ 102

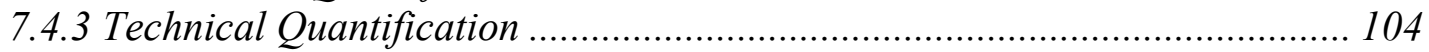

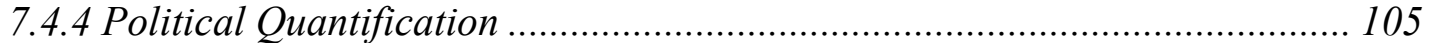

7.4.5 Environmental \& Safety Quantification................................................... 107

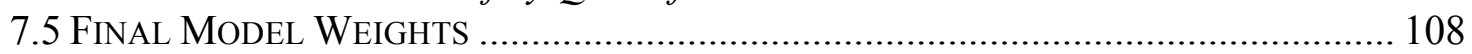

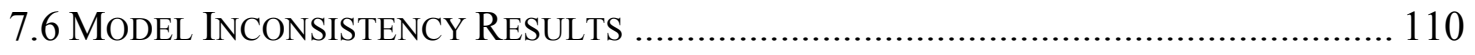

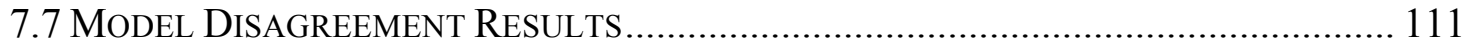

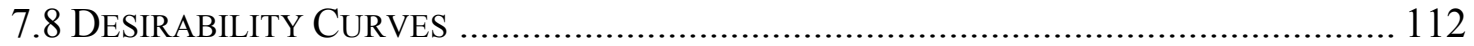

7.8.1 Economical Perspective Desirability Value .................................................. 113

7.8.2 Technical Perspective Desirability Value ................................................ 117

7.8.3 Political Perspective Desirability Value....................................................... 121

7.8.4 Environmental \& Safety Perspective Desirability Value .............................. 125

CHAPTER 8: RESEARCH APPLICATION .................................................. 131

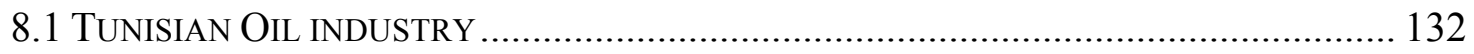

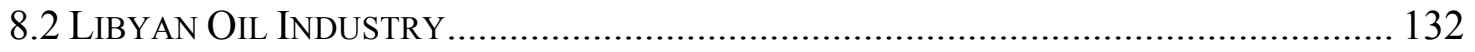

8.3 ENI AND MELLITAH OIL \& GAS ....................................................................... 134

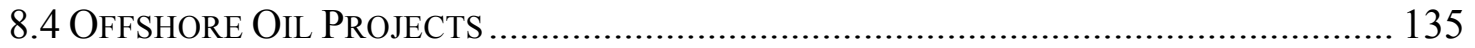

CHAPTER 9: ANALYSIS OF CASE AND SENSITIVITY ANALYSIS............... 136

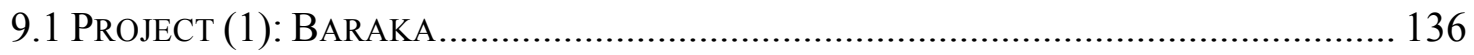

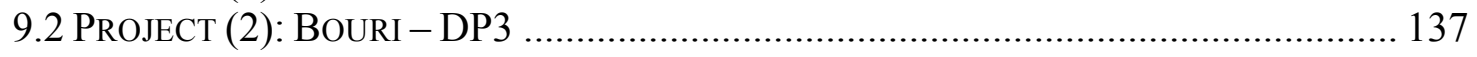

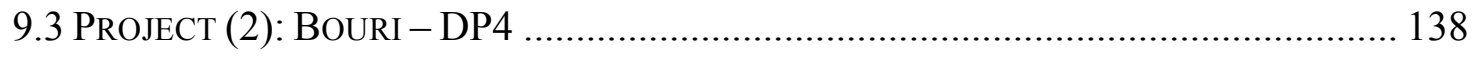

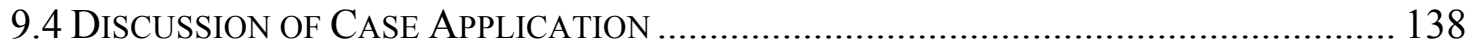

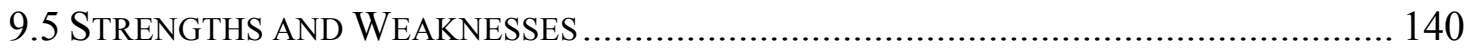

9.6 SCENARIO ANALYSIS ............................................................................... 141

CHAPTER 10: RESEARCH VALIDITY .......................................................... 156

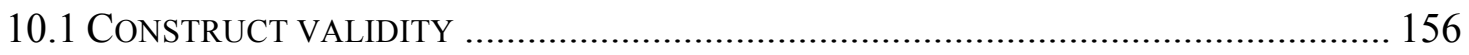

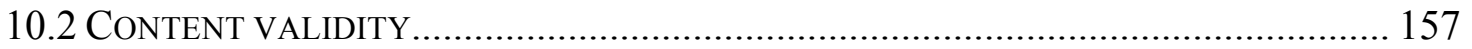

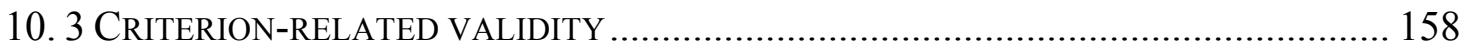

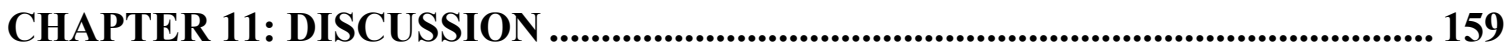

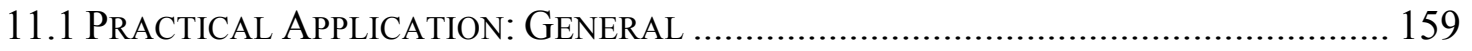

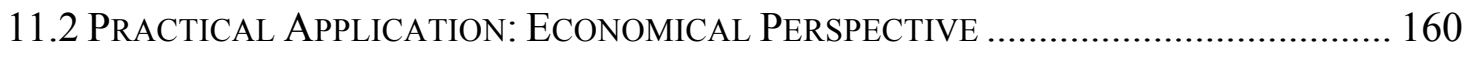

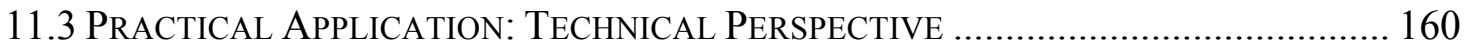

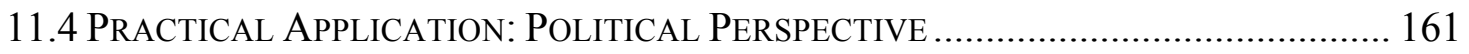

11.5 Practical Application: EnVironmental \& Safety Perspective................. 162

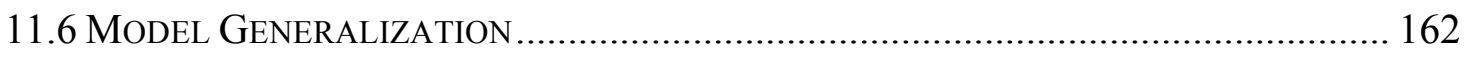

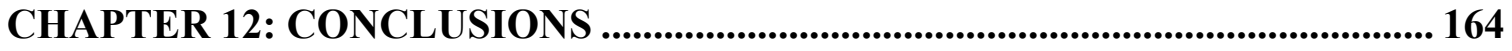

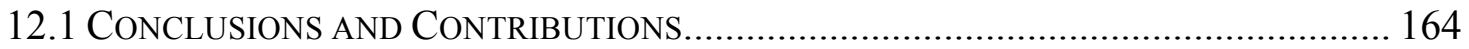




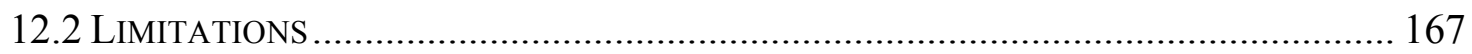

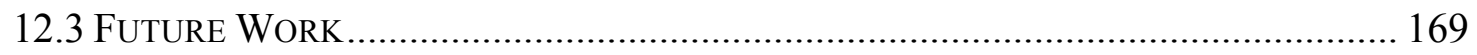

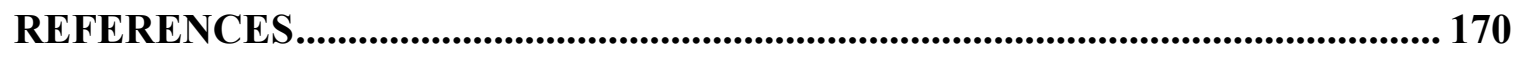

APPENDIX A: LETTERS OF INVITATION TO EXPERTS.................................... 185

APPENDIX B: QUALTRICS SURVEYS TO VALIDATE THE MODEL ............. 186

APPENDIX C: QUALTRICS SURVEYS TO QUANTIFY THE MODEL............. 191 APPENDIX D: QUALTRICS SURVEYS TO QUANTIFY THE DESIRABILITY

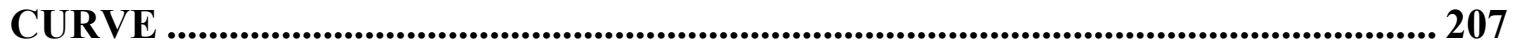

APPENDIX E: HDM SOFTWARE TOOL................................................................. 215 


\section{LIST OF TABLES}

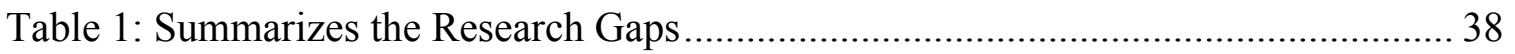

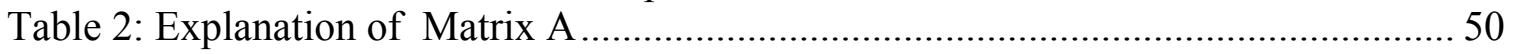

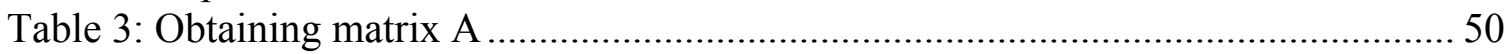

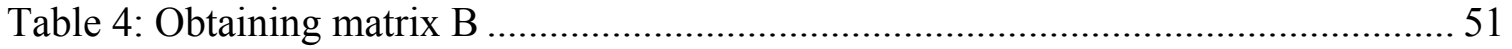

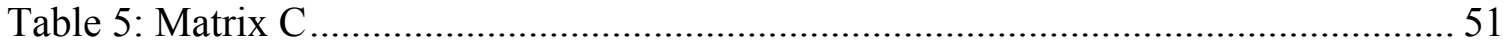

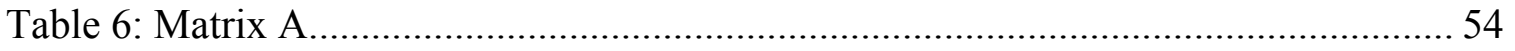

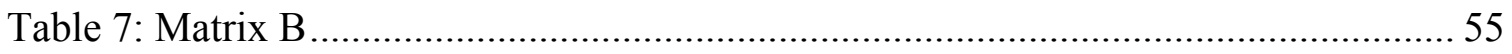

Table 8: Construction of the Orientation Table Before Normalized ................................ 57

Table 9: Construction of the Orientation Table After Normalized.................................... 57

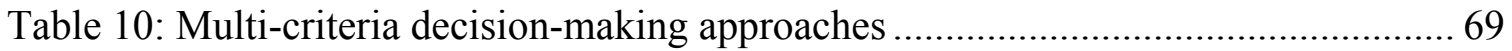

Table 11: Definition of Economical Perspective and Criteria ........................................... 81

Table 12: Definition of Technical Perspective and Criteria ........................................... 82

Table 13: Definition of Political Perspective and Criteria ................................................ 83

Table 14: Definition of Environmental Perspective and Criteria ...................................... 84

Table 15: Definition of Safety Perspective and Criteria .................................................. 85

Table 16: Required Experiences Each Panel ............................................................. 87

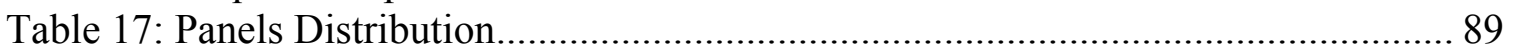

Table 18: List of Experts in Validation Panel............................................................ 93

Table 19: Quantification Expert Panels Breakdown................................................... 100

Table 20: Expert in Panel 2................................................................................... 101

Table 21: Perspectives Quantification Results .......................................................... 101

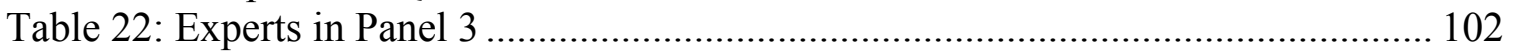

Table 23: Economical Criteria Quantification Results .................................................. 103

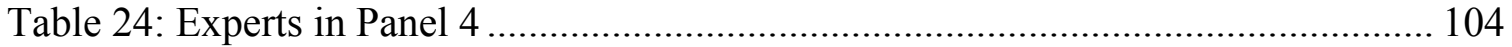

Table 25: Technical Criteria Quantification Results ..................................................... 104

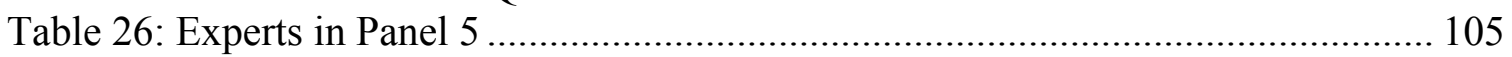

Table 27: Political Criteria Quantification Results ....................................................... 106

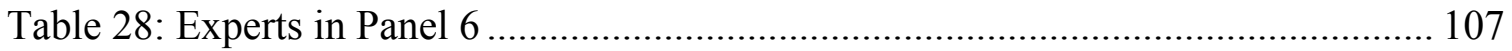

Table 29: Environmental \& Safety Criteria Quantification Results ............................... 107

Table 30: Experts' Judgment Quantification Output..................................................... 109

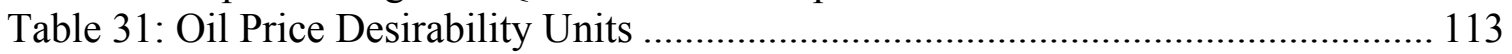

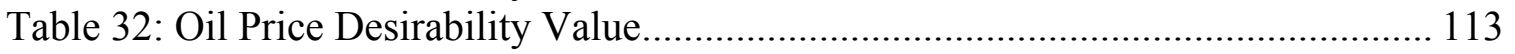

Table 33: Initial Cost Desirability Units .................................................................... 114

Table 34: Initial Cost Desirability Value .................................................................. 114

Table 35: Operational Cost Desirability Units............................................................ 115

Table 36: Operational Cost Desirability Value .......................................................... 115

Table 37: Return on Investment Desirability Units ................................................... 116

Table 38: Return on Investment Desirability Value ..................................................... 116

Table 39: Operational Difficulties Desirability Units..................................................... 117

Table 40: Operational Difficulties Desirability Value............................................... 117

Table 41: Project Size \& Complexity Desirability Units................................................. 118 
Table 42: Project Size \& Complexity Desirability Value........................................... 118

Table 43: Production Performance Desirability Units ................................................... 119

Table 44: Production Performance Desirability Value .................................................... 119

Table 45: Subsurface \& Reservoir Desirability Units ................................................... 120

Table 46: Subsurface \& Reservoir Desirability Value ................................................... 120

Table 47: Government Stability Desirability Units ..................................................... 121

Table 48: Government Stability Desirability Value ................................................... 121

Table 49: Conflict Over Maritime Claims Desirability Units ..................................... 122

Table 50: Conflict Over Maritime Claims Desirability Value....................................... 122

Table 51: Policies, Regulations \& Governance Standards Desirability Units................ 123

Table 52: Policies, Regulations \& Governance Standards Desirability Value............... 123

Table 53: Contracts Complexity Standards Desirability Units................................... 124

Table 54: Contracts Complexity Standards Desirability Value ...................................... 124

Table 55: Hazard Identification \& Risk Management Desirability Units ..................... 125

Table 56: Hazard Identification \& Risk Management Desirability Value ...................... 125

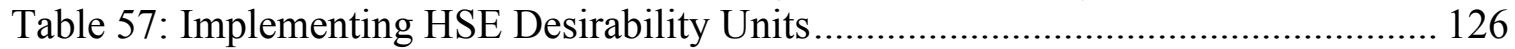

Table 58: Implementing HSE Desirability Value ....................................................... 126

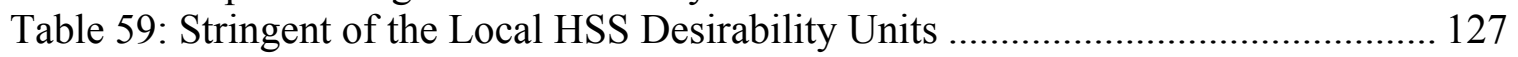

Table 60: Stringent of the Local HSS Desirability Value............................................. 127

Table 61: Environmental Risk Management Integration Desirability Units ................. 128

Table 62: Environmental Risk Management Integration Desirability Value ................ 128

Table 63: Unit of Measurements Value On Desirability Curve ................................... 130

Table 64: Advantages and Disadvantages of Case Studies Method .............................. 131

Table 65: Evaluation Scores for Project 1 ................................................................. 137

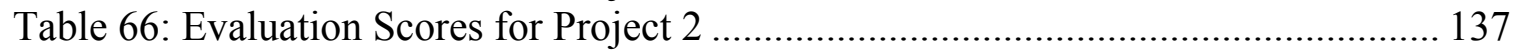

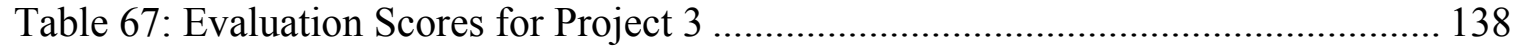

Table 68: Strengths and Weaknesses of Project 1 .................................................... 141

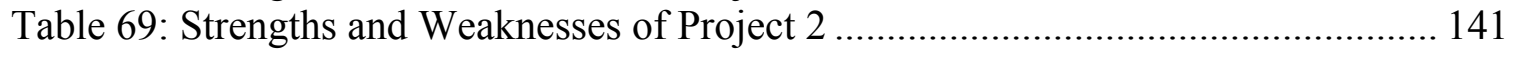

Table 70: Strengths and Weaknesses of Project 3 ..................................................... 141

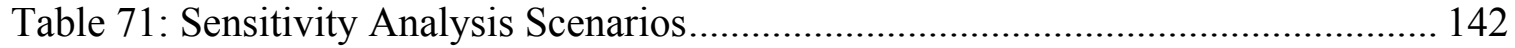

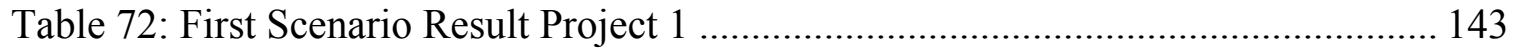

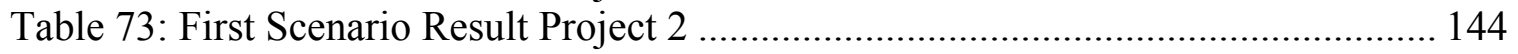

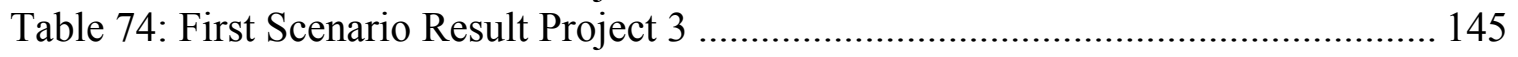

Table 75: Summarizes First Scenario Changes of Scores ......................................... 145

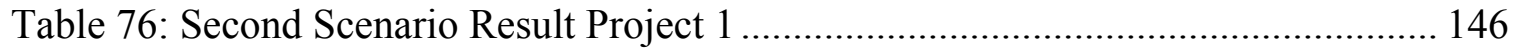

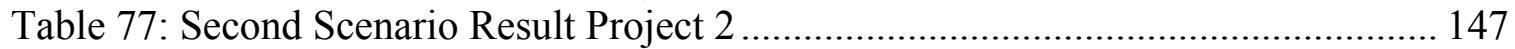

Table 78: Second Scenario Result Project 3 ............................................................... 148

Table 79: Summarizes Second Scenario Changes of Scores ....................................... 149

Table 80: Third Scenario Result Project 1 ................................................................... 150

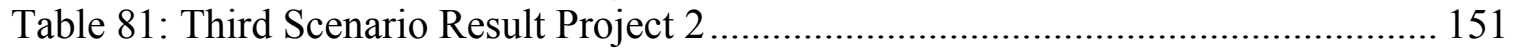

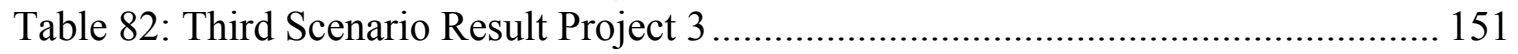

Table 83: Summarizes Third Scenario Changes of Scores .......................................... 152

Table 84: Forth Scenario Result Project 1 ............................................................... 153 


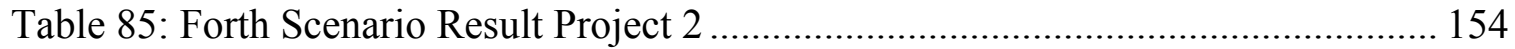

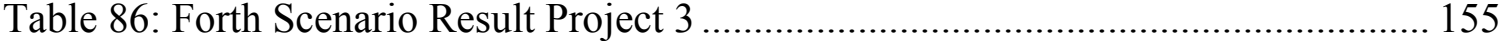

Table 87: Summarizes Forth Scenario Changes of Scores ........................................ 155

Table 88: Summarizes the Gaps and the Contributions ................................................ 166

Table 89: Summarizes Research Questions and How Were Addressed........................ 167 


\section{LIST OF FIGURES}

Figure 1: Oil production \& Consumption \% of Global 20 Nations Production .................. 4

Figure 2: Regional Cumulative Oil Investment Between 2014 and 2035 (US\$) ............... 5

Figure 3: Average Cost to Produce One Barrel of Oil in Top Oil Producing Countries in

2015 (U.S dollars per barrel) ………………………................................................ 6

Figure 4: Top 20 Nations By Oil Reserves (\% of global).............................................. 7

Figure 5: Global Offshore Oil Production By Water Depth (Million barrel per day) ........ 8

Figure 6: Global Offshore Gas Production By Water Depth $(\mathrm{bcm})$.................................... 9

Figure 7: Annual Average Offshore Oil Investment By Water Depth and Scenario........ 10

Figure 8: Hierarchical Structure Offshore Oil Projects ................................................ 11

Figure 9: Global Distribution of the Offshore Oil Performance........................................ 12

Figure 10: Root Causes of Offshore O\&G Project Failures ............................................... 13

Figure 11: Internal Factors Responsible for Offshore Oil Projects Failures .................... 14

Figure 12: External Factors Responsible for Offshore Oil Projects Failures .................... 15

Figure 13: General Project Phases of Offshore Oil Projects.............................................. 15

Figure 14: Research Processes Flow Chart............................................................... 34

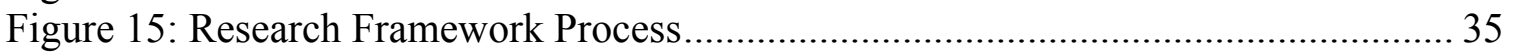

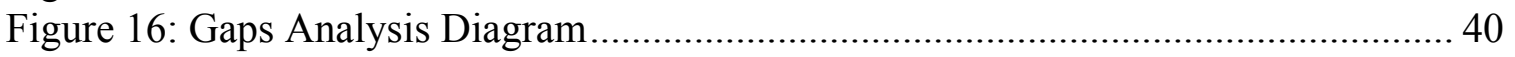

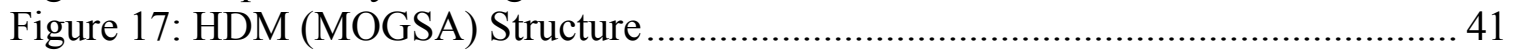

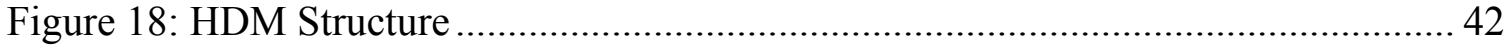

Figure 19: Pair-Wise Comparisons Technique ............................................................ 49

Figure 20: Processes of Applying Multi-Criteria Decision-Making.................................. 66

Figure 21: DTA Implementation in Oil Industry ......................................................... 72

Figure 22: Monte Carlo Equation to Calculate the NPV for a Simplified Oil Project ..... 76

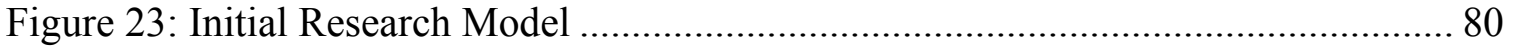

Figure 24: Validation Processes Chart................................................................... 92

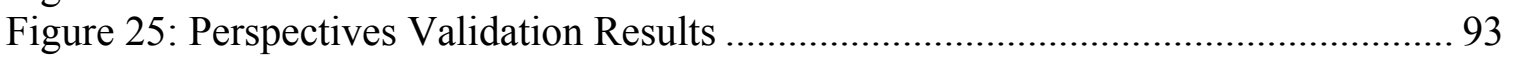

Figure 26: Economical Validation Results ……………….......................................... 94

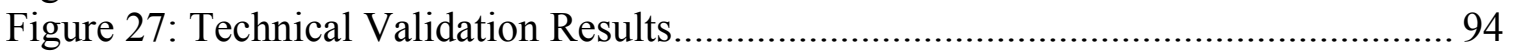

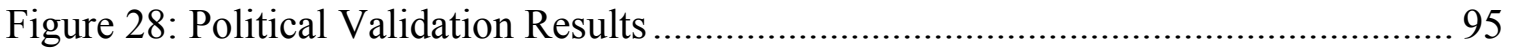

Figure 29: Environmental Validation Results............................................................. 95

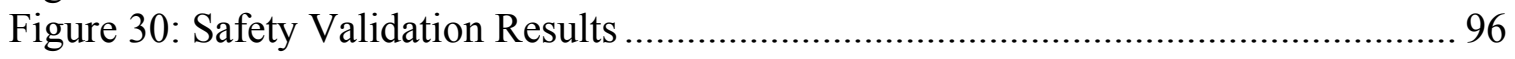

Figure 31: Second Round Validation Results ................................................................ 97

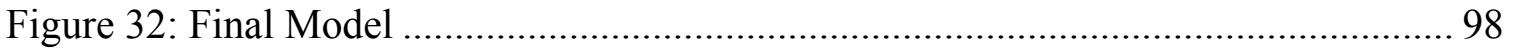

Figure 33: Perspectives Quantification ................................................................. 102

Figure 34: Economical Quantification..................................................................... 103

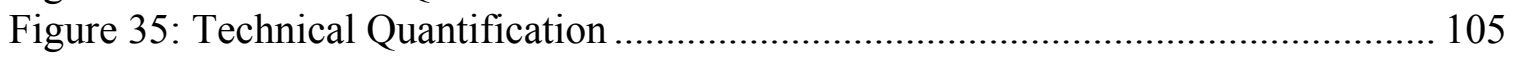

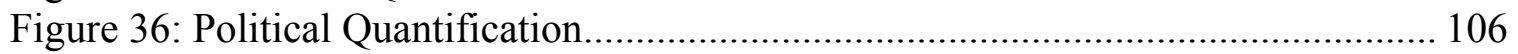

Figure 37: Environmental \& Safety Quantification...................................................... 108

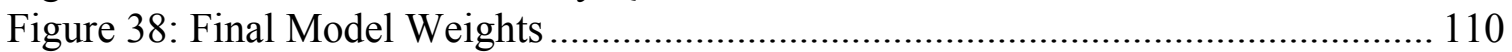

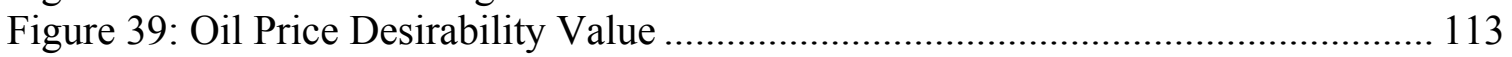

Figure 40: Initial Cost Desirability Value.................................................................. 114 
Figure 41: Operational Cost Desirability Value 115

Figure 42: Return on Investment Desirability Value................................................. 116

Figure 43: Operational Difficulties Desirability Value ................................................. 117

Figure 44: Project Size \& Complexity Desirability Value ........................................... 118

Figure 45: Production Performance Desirability Value................................................ 119

Figure 46: Subsurface \& Reservoir Desirability Value ................................................. 120

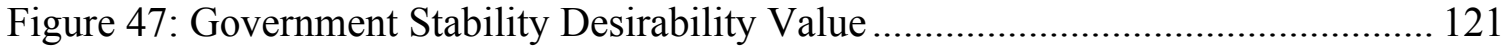

Figure 48: Conflict Over Maritime Claims Desirability Value ...................................... 122

Figure 49: Policies, Regulations \& Governance Standards Desirability Value............... 123

Figure 50: Contracts Complexity Standards Desirability Value...................................... 124

Figure 51: Hazard Identification \& Risk Management Desirability Value ..................... 125

Figure 52: Implementing HSE Desirability Value..................................................... 126

Figure 53: Stringent of the Local HSS Desirability Value .............................................. 127

Figure 54: Environmental Risk Management Integration Desirability Value ................ 128

Figure 55: Top African Nation Oil Reserves (Billion Barrels)........................................ 133

Figure 56: Projects Evaluation Results ................................................................... 139

Figure 57: Perspectives Evaluation Results ............................................................ 139 


\section{LIST OF ABBREVIATIONS}

AHP

ANP

BWM

$\mathrm{CO}$

DEMATEL

DTA

DCF

EEZs

ELECTRE

FPSO

HAC

HSE

HDM

ICC

IEA

$\mathrm{mb} / \mathrm{d}$

MCDM

NPV

NOx

O\&G

OOGPs

PAHs

RSV

TLPs

TOPSIS

UNCLOS

VOC

HSE
Analytical Hierarchy Process

Analytical Network Process

Best Worst Method

Carbon Monoxide

Decision Making Trial and Evaluation Laboratory

Decision Trees Analysis

Discounted Cash Flow

Exclusive Economic Zones

Elimination and Choice Expressing Reality

Floating Production, Storage, and Offloaders

Hierarchical Agglomerative Clustering

Health, Safety and Environmental

Hierarchical Decision Model

Intraclass Correlation Coefficient

International Energy Agency

Million Barrels Per Day

Criteria Decision-Making

Net Present Value

Nitrogen Oxides

Oil and Gas

Offshore Oil and Gas Platforms

Polycyclic Aromatic Hydrocarbons

Root Sum of the Variance

Tension-Leg Platform

Technique for Order of Preference by Similarity to Ideal Solution

United Nation Convention on the Law of the Sea

Volatile Organic Compounds

Health Safety Environmental 


\section{CHAPTER 1: INTRODUCTION}

With the global energy demand rising every single day, offshore oil production remains a key source of energy for meeting the worldwide energy demand. A recent report by the National Petroleum Council in the United States indicates that this sector has seen great levels of growth in the late 20th century to today, with offshore oil growing from $1 \%$ of total production in 1954 to up to $25 \%$ in 2008 , and offshore natural gas observing a more steady growth, with a less dramatic rise from $1 \%$ to $11 \%$ in the same time frame [1][2]. In these days, offshore hydrocarbon projects have produced about $30 \%$ of the world's oil production and $27 \%$ of the world gas production since 2000 [3][4]. There are now over 7000 oil and gas installations and platforms on continental shelves in over 53 countries around the world [5][6]. Among the $30 \%$ of the world's oil production that is coming from developing offshore fields, there is around $9 \%$ that is coming from deep-water reserves projects contributions [7][8][9].

Compared to capital projects in other industries, offshore oil projects have many different and unique characteristics that can be challenging, such as a larger project size, higher number of scopes, and higher complexity. In general, offshore oil projects tend to be significant in terms of their capital size. So called "multibillion dollar offshore oil megaprojects" are common in industry today. Typical offshore projects also usually have a larger number of individual sub-scopes. These individual project sub-scopes are also quite large themselves with costs in the hundreds of millions of dollars. As such, these individual project sub-scopes are usually implemented or managed by multiple 
contractors. To develop offshore oil projects, a large project team is formed that comprises various functional groups. Furthermore, regulatory requirements and the political climate can significantly influence the performance of oil projects [4]. Because most new hydrocarbon reservoirs are discovered in ultra-deep remote waters, companies are faced with unprecedented physical, environmental, technical and project management challenges. Moreover, companies lose billions of dollars in revenues each year due to oil spills resulting from tanker leaks, drilling well blowouts and oil spills [10]. All of these factors combined affect offshore oil projects and lead to higher project complexity. However, as long as oil remains the lifeblood of the economy, investment in offshore exploration and production will continue, but better evaluation methods are needed to overcome all of these challenges and improve the offshore hydrocarbon projects performance.

\subsection{Problem Statement}

Offshore oil projects are very large in size and complexity, and they require financial investments, hence they are often referred to as multibillion-dollar offshore oil megaprojects. The nature and size of megaprojects mean that participating companies must commit enormous amounts of resources and take on significant risk. Therefore, missing targets in one or more of these multibillion-dollar projects can have major implications for any company's financial performance, either through increased demand on capital (potentially leading to lost opportunities and increased cost of borrowing) or loss of revenue through missed production dates [11]. It has been observed that global 
offshore projects have not performed well. More than $60 \%$ of the projects have experienced a cost overrun of $33 \%$ or more, schedule delays of $30 \%$ or longer, and lower than expected hydrocarbon production [12][4]. Traditionally, cash flow analysis and return on investment are the most known methods to evaluate offshore oil projects. However, there are several other internal and external factors that affect the overall performance of offshore oil projects. Evaluation and selection of the right project in the offshore oil sector is characterized by a high volatile price setting market, increasing pressure to minimize cost structures, political concerns, and safety and environmental risks. The combinations of these characteristics provide a motivation for development of new tools to allocate capital and improve the quality of overall decision making in the exploration and production decisions. A comprehensive approach and advanced tools are required to evaluate these factors that can have a significant impact before any investment decisions are made. 


\section{CHAPTER 2: LITERATURE REVIEW}

The focus of this chapter is to understand the numerous complex characteristics of offshore oil projects. The literature review started with an overview of the oil and gas industry and then navigated to highlighting the classification of oil projects. Next, offshore oil project's performance was discussed along with the root causes of project failures. Finally, this chapter introduced the methodology of offshore oil portfolio management and project selection.

\subsection{Oil and Gas Industry}

Average annual global oil \& gas $(\mathrm{O} \& \mathrm{G})$ projected capital investment is about US\$1 trillion per year between 2011 and 2035 [13][14]. Based on the CIA World Factbook, the top 20 nations' oil productions are listed in the figure below. Based on this information, Saudi Arabia produces the most at $11.6 \%$ of the world's oil production. Moreover, United States consumes the most at $19,650,000.00$ bbl per day, a full $25 \%$ of the world's oil consumption [15].

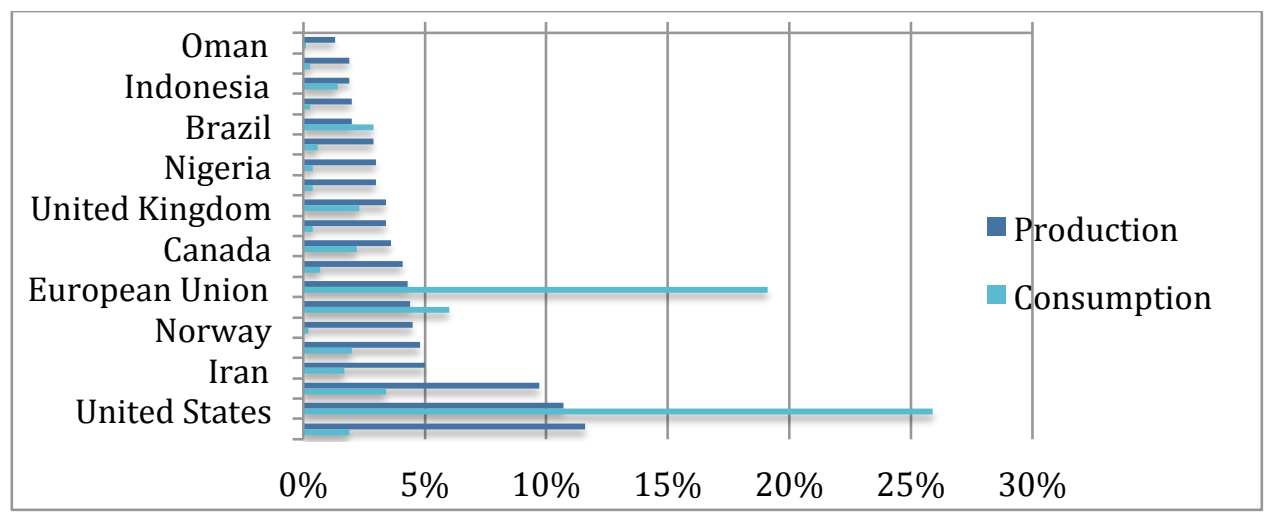

Figure 1: Oil production \& Consumption \% of Global 20 Nations Production 
The oil and gas industry is witnessing an unprecedented wave of capital spending, driven by the need to build capacity to meet growing energy demand from emerging markets and to replace depleting supply sources. This capital expenditure has, to date, been underpinned by consistently higher oil prices, globally and gas prices outside North America. This trend is expected to continue. In its World Energy Investment Outlook 2014, the International Energy Agency (IEA) estimates a cumulative investment of US\$22.4t in the global oil and gas sector between 2014 and 2035 [16]. Average annual global investment in oil project capital is about US\$1 trillion per year (IEA, 2011). However, the performances of the oil projects did not get any attention until the recent oil price crashes [14]. The figure below shows the oil investment and spending that will be dominated by North America around 5.8 US \$ trillion between 2014 and 2035 [16].

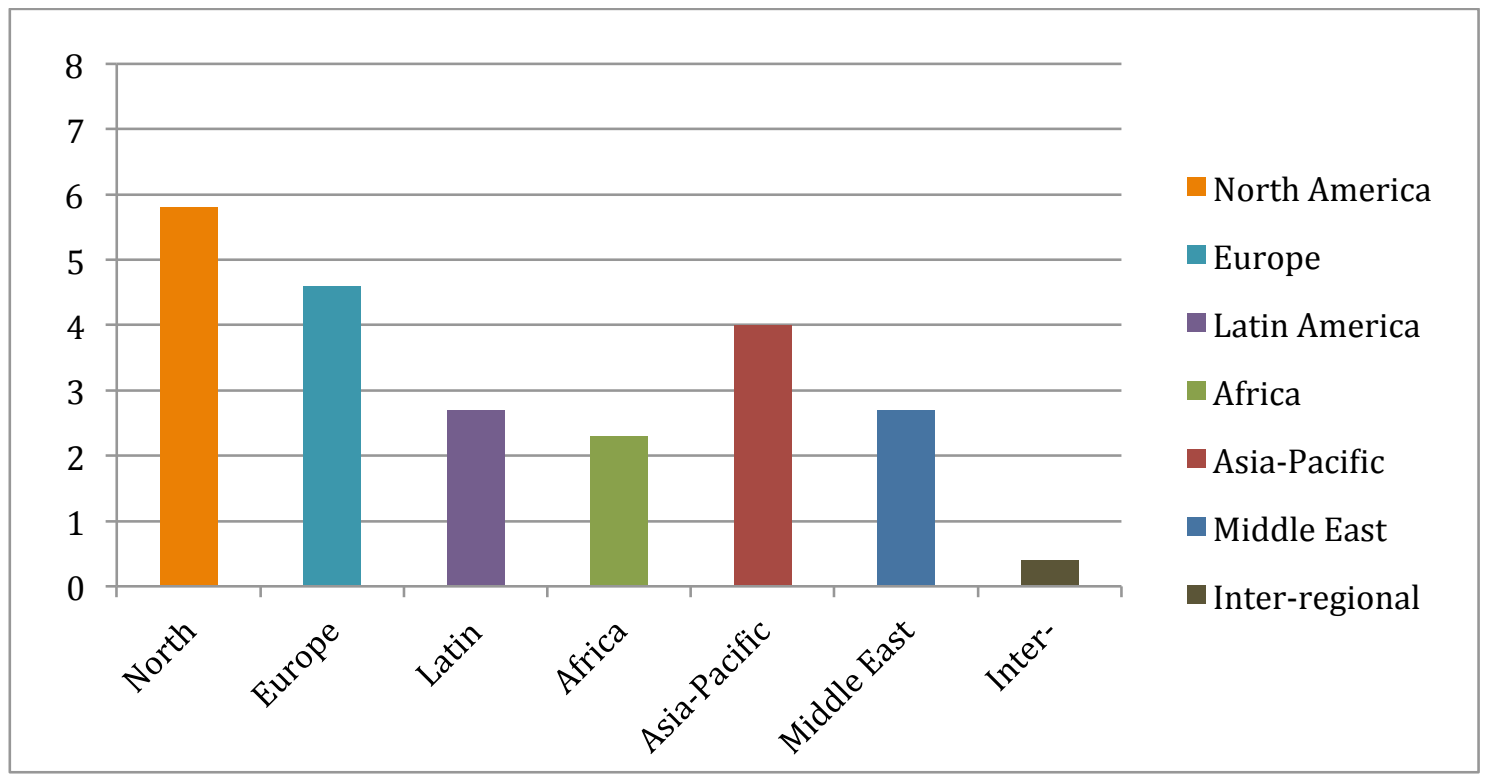

Figure 2: Regional Cumulative Oil Investment Between 2014 and 2035 (US\$) 
However, the total oil capital investment is mainly affected by many factors such as the global price of the oil and its operational cost. Based on data that was collected from more than 15,000 oil fields across 20 countries, Kuwait had the lowest production costs per barrel of oil, at a total cost of 8.5 U.S. dollars per barrel of oil followed by Saudi Arabia of 9.9 dollars total cost per barrel of oil. The production costs were calculated by including a mix of capital expenditures and operational expenditures [17][18]. Capital expenditures included the costs involved with building oil facilities, pipelines and new wells. Operational expenditures included the costs of lifting oil out of the ground, paying employee salaries and general administrative duties.

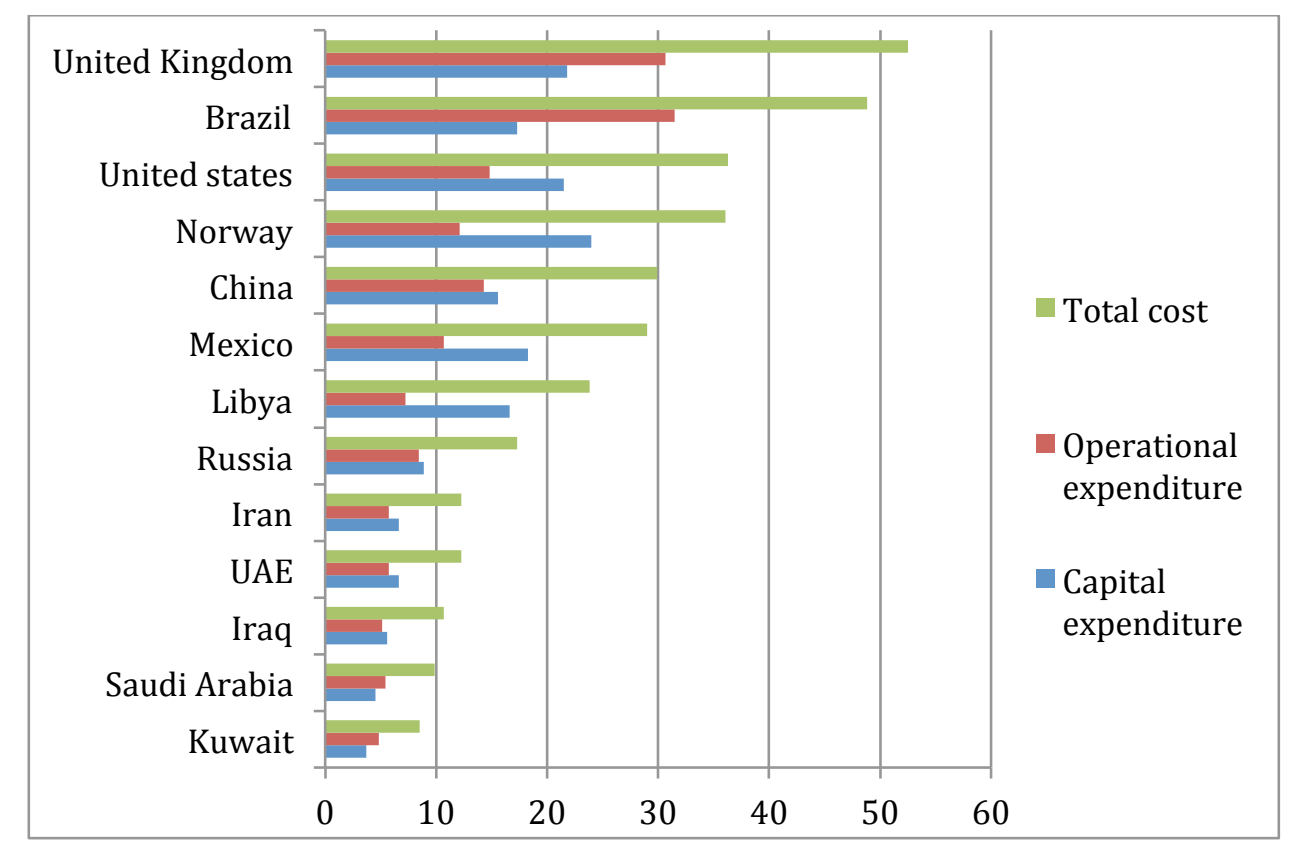

Figure 3: Average Cost to Produce One Barrel of Oil in Top Oil Producing Countries in 2015 (U.S dollars per barrel)

The figure below illustrates the top 20 nations by oil reserves. Saudi Arabia has almost $25 \%$ oil reserves of the world followed by Iraq more than $10 \%$. The total 
estimated amount of oil in an oil reservoir, including both producible and non-producible oil, is called oil in place. However, because of reservoir characteristics and limitations in petroleum extraction technologies, only a fraction of this oil can be brought to the surface, and it is only this producible fraction that is considered to be reserves [15].

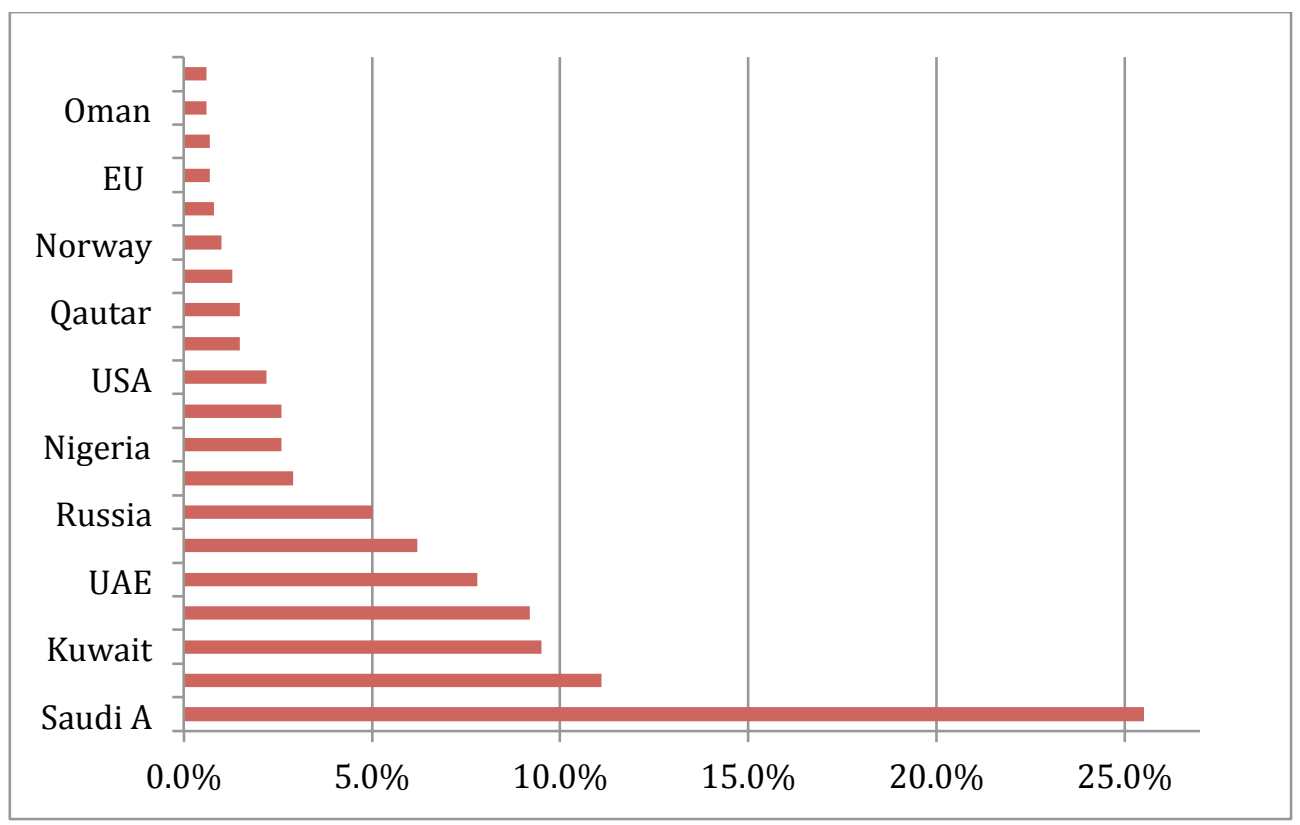

Figure 4: Top 20 Nations By Oil Reserves (\% of global)

\subsection{Offshore Oil Projects}

Offshore fields are considered as an important source of oil reserves. There are over 7270 offshore oil installations and platforms distributed in more than fifty-three countries [19]. Offshore oil resources also serve as a major source for meeting the global energy demand. According to Maribus (2014), offshore projects have produced about 30 percent of the world's oil production and 27 percent of world gas production since the start of the new millennium [20]. According to the International Energy Administration (IEA), global offshore oil and gas fields would account for about a third of the anticipated one 
hundred and twenty million barrels per day consumption rate by 2030 [13][21]. Offshore oil and gas sector is unarguable one of the world's most viable sectors since revenue from its investment have prospects of generating huge revenue annually [21]. In 2016 the contribution of offshore oil production to global oil and gas sector was around 26-27 million barrels per day $(\mathrm{mb} / \mathrm{d})$ and offshore gas production has grown by almost $30 \%$ to more than 1000 billion cubic $(\mathrm{bcm})$ per year over the same period. Figures 5 and 6 illustrate the global offshore oil and gas production over the period $2000-2016$. Offshore oil production are in many parts of the world, with the top producing areas being the Middle East, the North Sea, Brazil, the Gulf of Mexico and the Caspian Sea [22].

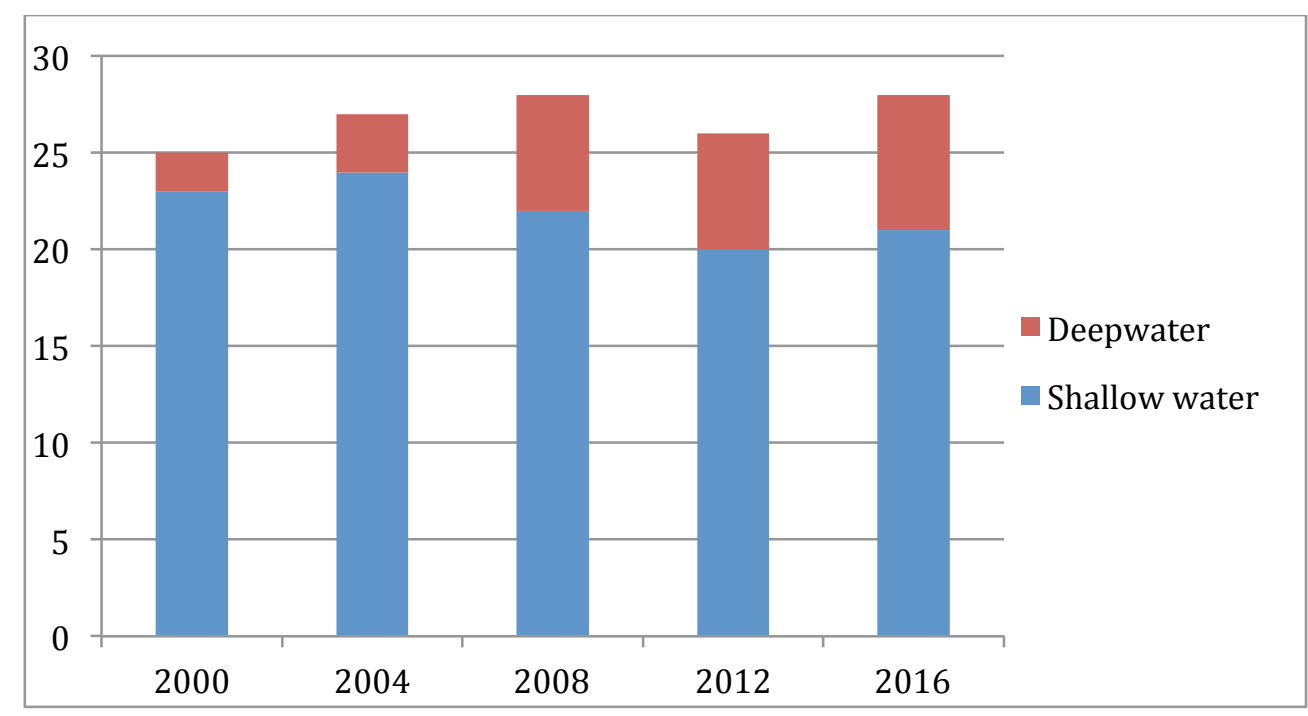

Figure 5: Global Offshore Oil Production By Water Depth (Million barrel per day) 


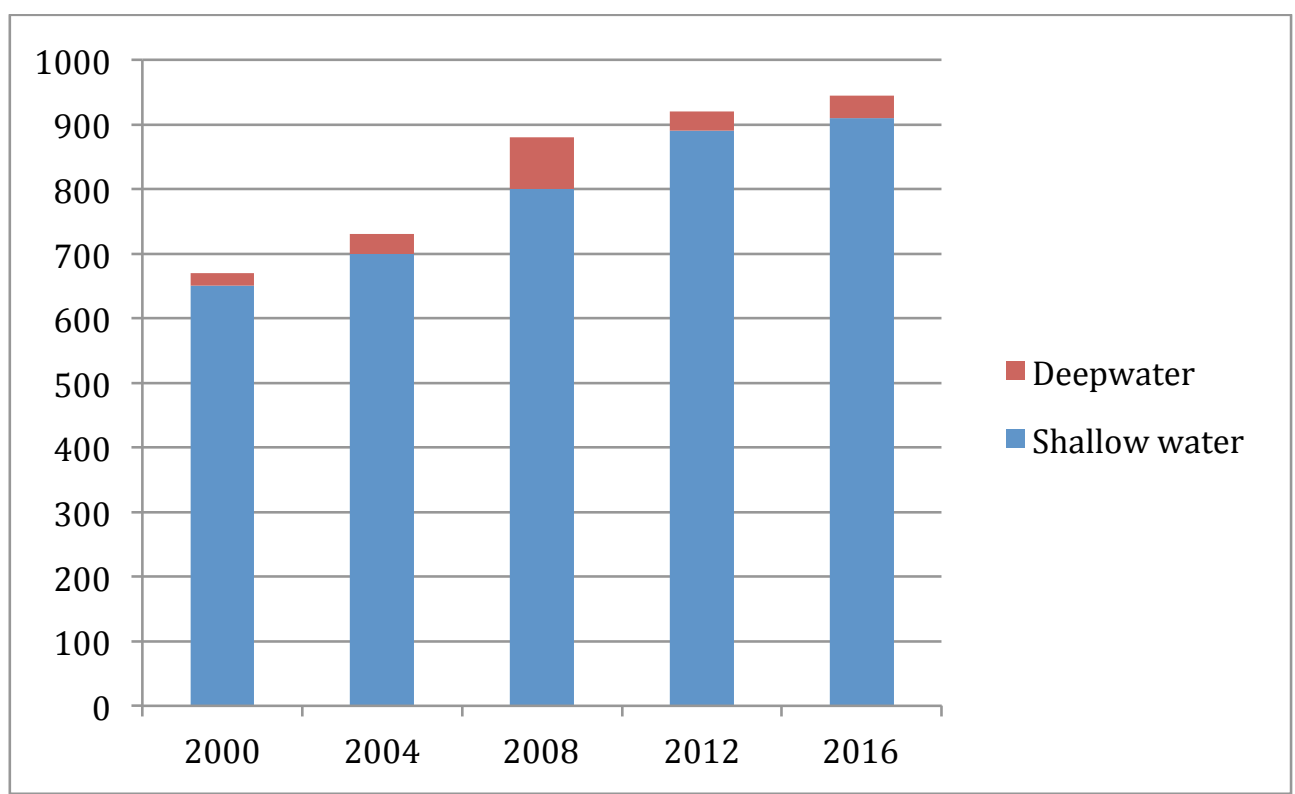

Figure 6: Global Offshore Gas Production By Water Depth (bcm)

Although the record of discoveries over the last ten years has been impressive, offshore exploration activity has fallen sharply since 2014. The number of exploration and appraisal wells drilled globally (both onshore and offshore) peaked in 2008 at more than 2000 wells by 2014 , this was down by some $20 \%$ (with most of the decline exhibited onshore). With the fall in prices since 2014, activity levels have plummeted across the board; there were only around 700 exploration and appraisal wells drilled globally in 2016. The count of active offshore rigs declined from an average of 320 in 2013 and 2014 to around 220 at the end of 2016 [22]. 


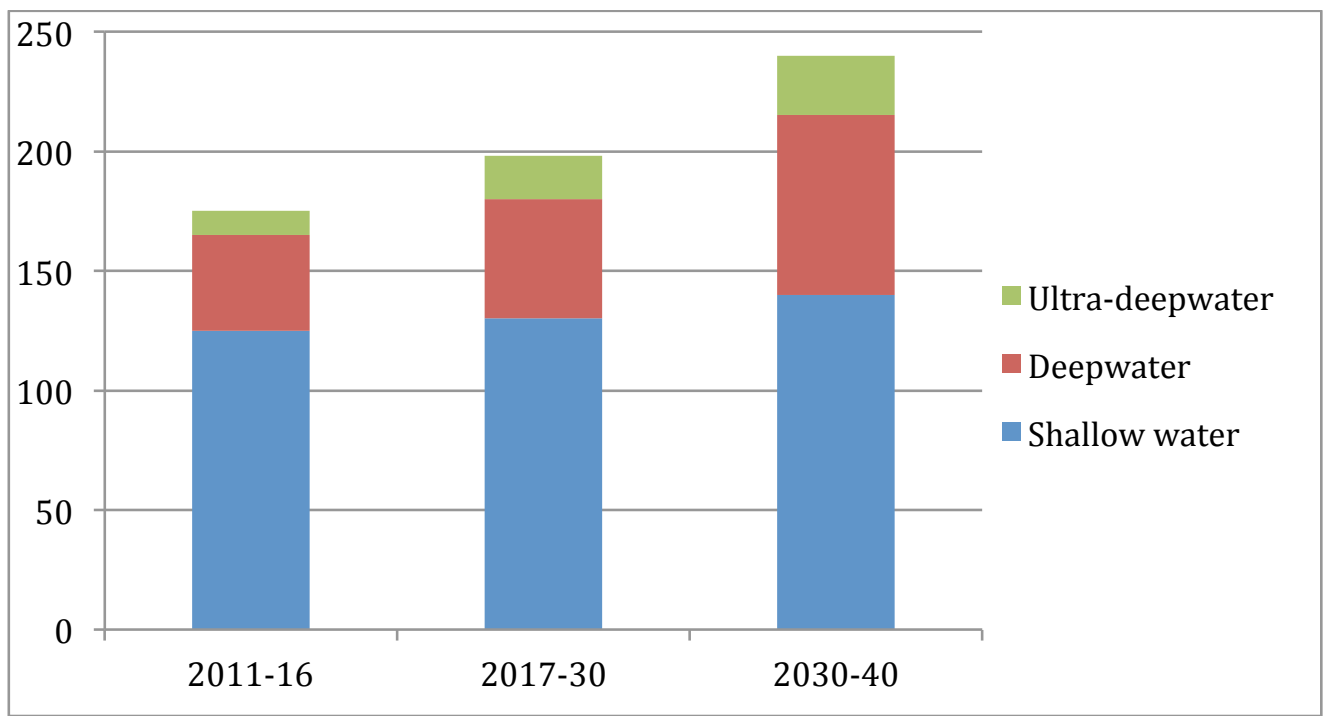

Figure 7: Annual Average Offshore Oil Investment By Water Depth and Scenario

\subsection{Offshore Oil Projects Performance}

Offshore oil projects tend to have a large number of project sub-scopes and sub-scope components. A general hierarchical structure for an offshore oil project is shown in figure 8. This hierarchical structure is based on a typical offshore oil project scope based on an industry standard. The first level typically contains well, subsea system, fixed or floating platform, and pipeline system. First level mainly called the project level and under each system of the first level there are sub-scope and sub-scope components on the second and third levels. Offshore oil projects often involve various sub-scopes and sub-scope components. A typical oil project includes well, subsea system, fixed or floating platform, and pipeline scopes. In addition, they often involve major types of floating platforms, including tension-leg platform (TLPs); spars and semi-semisibles; floating storage and offloading systems (FPSs); and floating production, storage, and offloaders (FPSO). Each sub-scope of an offshore oil project is also very large in terms of its size 
and often costs hundreds of millions or even billions of dollars to build. Furthermore, sub-scopes have their own key components. For example, a platform has two major parts: the topsides and substructure [23].

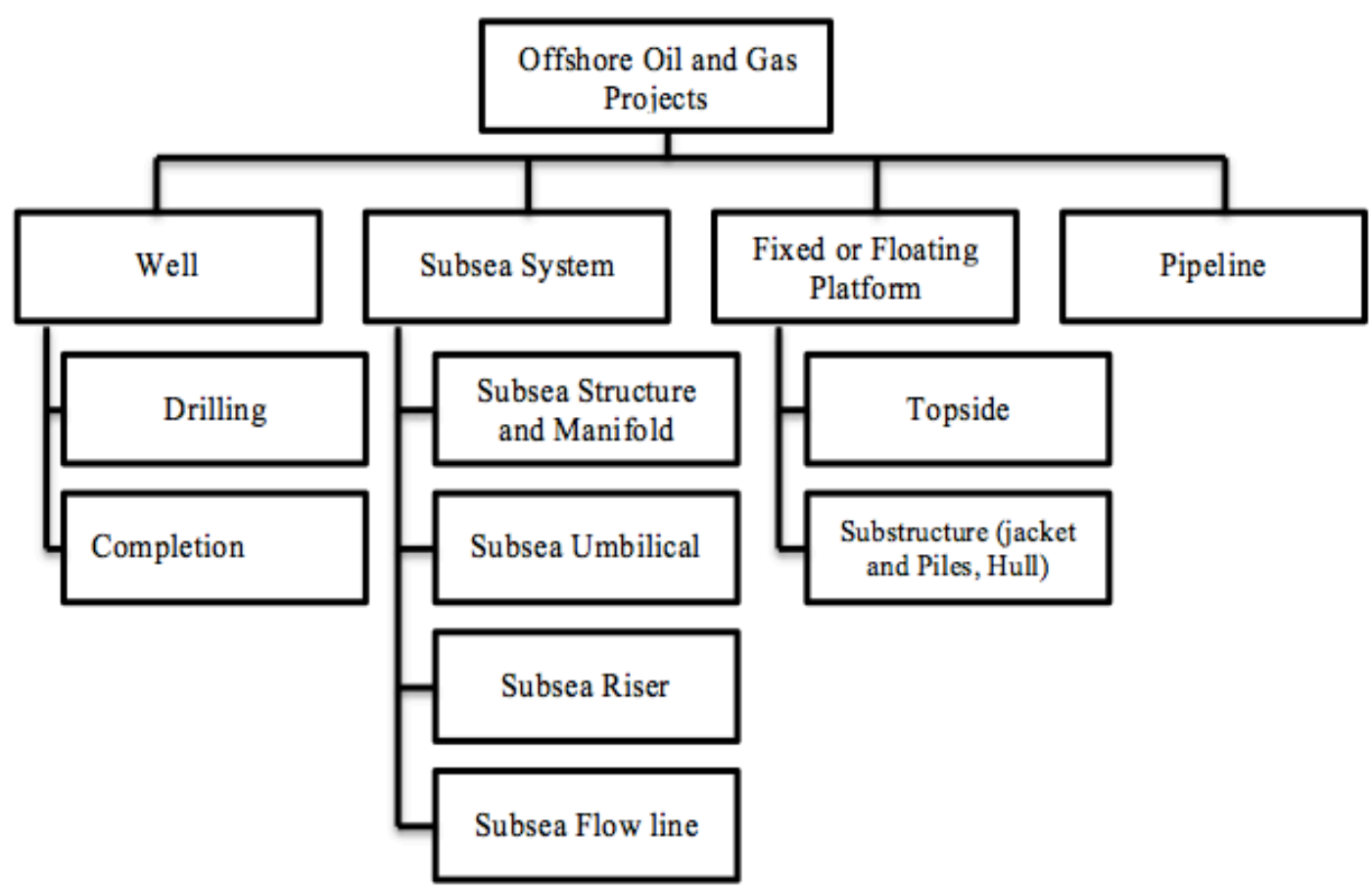

Figure 8: Hierarchical Structure Offshore Oil Projects

Though, historical records on the performances of global offshore oil and gas oil projects show that most did not meet industry expectations [23]. The majority of these projects are facing cost overruns and schedule delay. Based on a 2014 repot generated by EY's Global Oil \& Gas Center, the majority of oil projects are facing schedule delays and/or cost escalations and these overruns are prevalent in all of the segments and geographies. $64 \%$ oil and gas projects are facing cost overruns and $73 \%$ of the projects are reporting schedule delays [16]. Figure 9 shows the global distribution of the offshore 
oil performance. As the data showed, the Middle East has the worst project performance in term of cost and schedule among other regions. $89 \%$ of the projects in Middle East had cost overruns and $87 \%$ of them faced schedule delay. Even though North America had the best oil projects' performance compared to other places, $58 \%$ of its proportion projects faced cost overruns and $55 \%$ of them faced schedule delay. In the aftermath of the oil price fall in 2014, proposed new deep-water projects were generally among the first to be delayed or cancelled as the industry moved towards shorter cycle investments $[22]$.

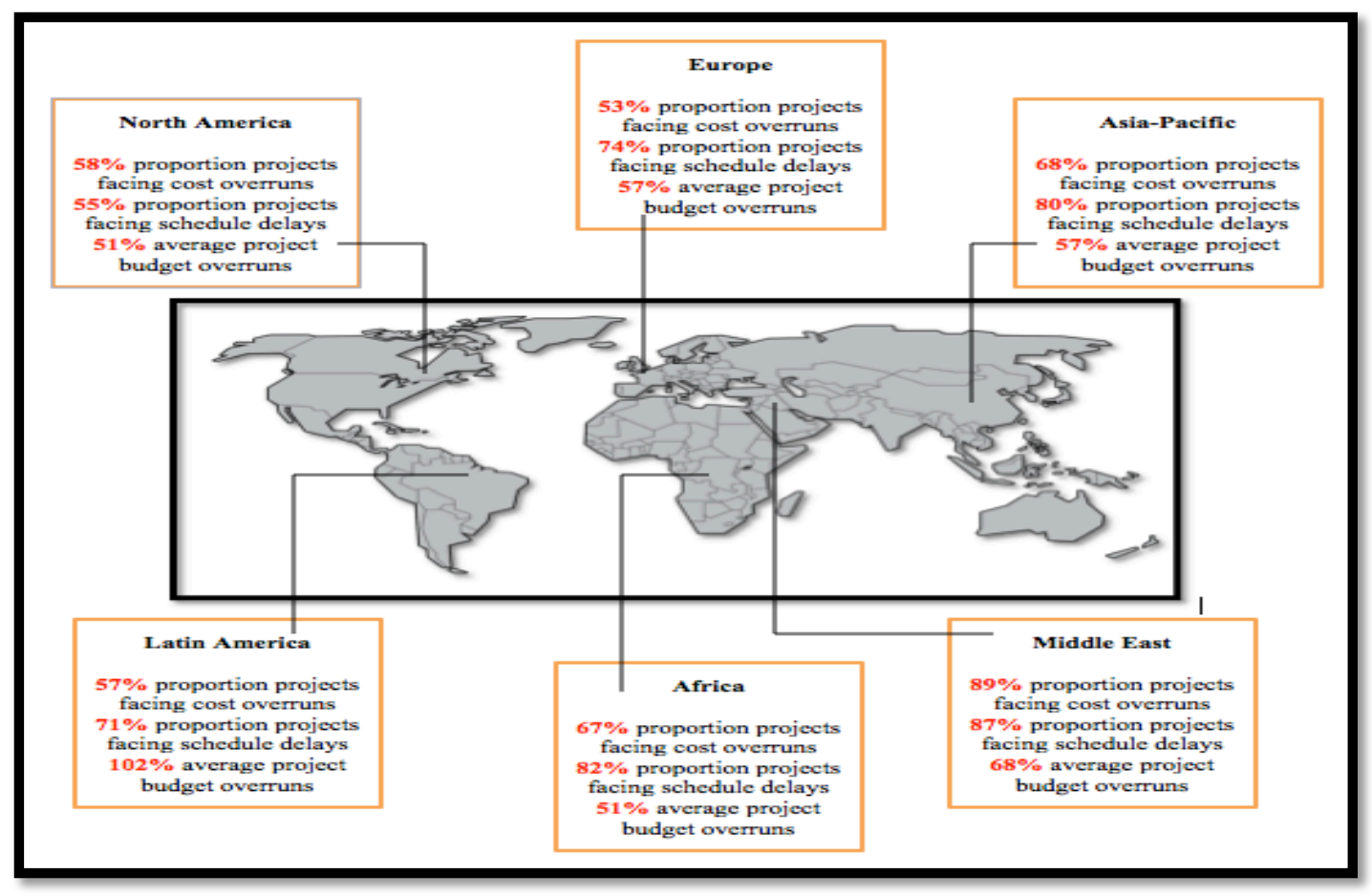

Figure 9: Global Distribution of the Offshore Oil Performance 


\subsection{Root Causes of Offshore oil Project Failures}

Industry performance data suggests that the factors that result in budget overruns or schedule delays are common across oil and gas projects; however, due to their scale, complexity and cost, the impact is more profound on megaprojects. Industry research suggests that non-technical issues are responsible for the majority of the overruns. According to data provided in Offshore Technology Conference 2013, 65\% of project failures were due to softer aspects such as people, organization and governance. $21 \%$ were caused by management processes and contracting and procurement strategies, with the remaining $14 \%$ of the failures due to external factors such as government intervention and environment-related mandates [24][16].

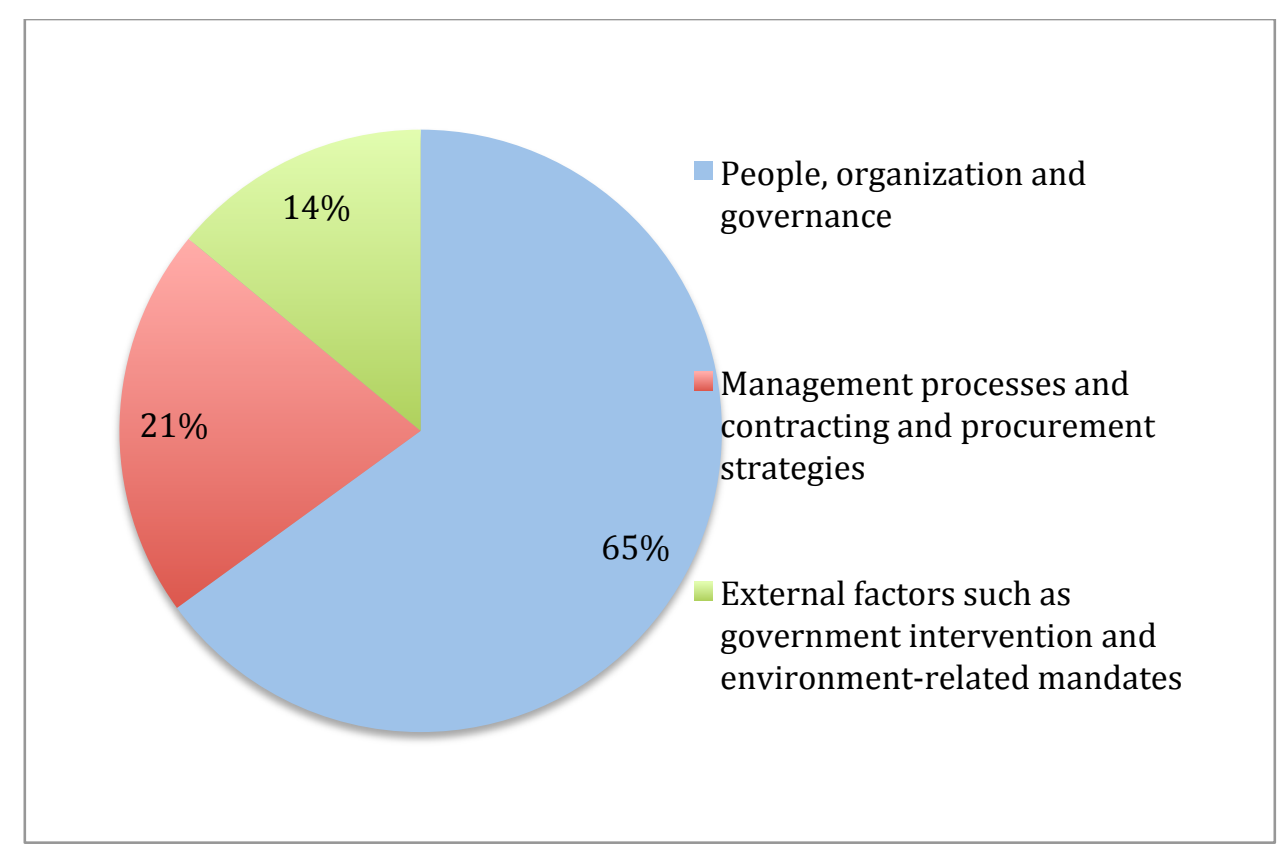

Figure 10: Root Causes of Offshore O\&G Project Failures

To elaborate, often there are internal and external factors that can lead offshore O\&G projects to fail. Internal factors including portfolio and project commercial context, 
project development and project delivery. The figure 11 shows the most common internal factors that affect the offshore O\&G projects as well as the key challenges associated with each factor.

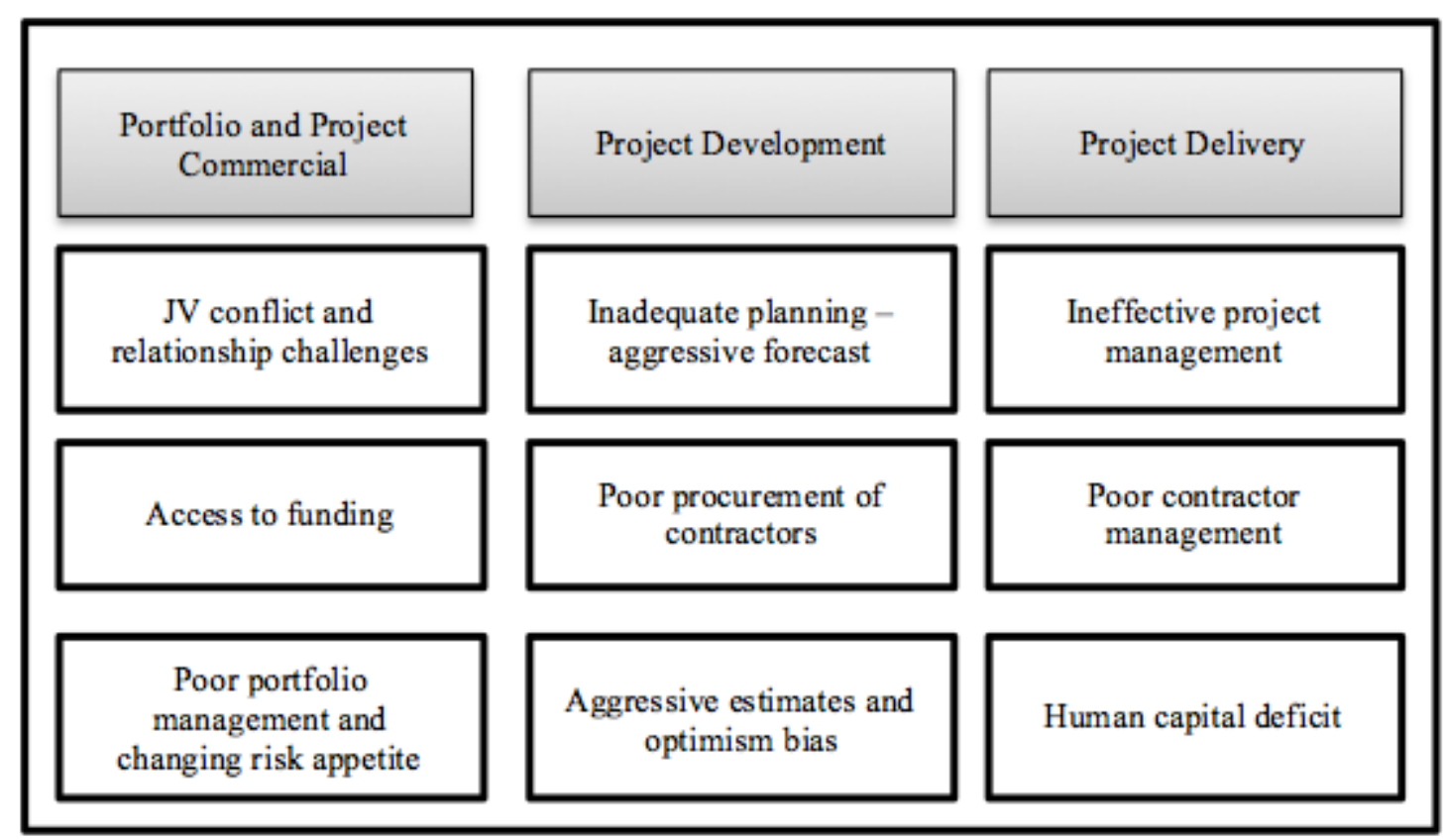

Figure 11: Internal Factors Responsible for Offshore Oil Projects Failures

Moreover, the external factors such as regulatory geopolitical challenges play a significant role in the offshore O\&G project's overall performance. The figure 12 illustrates some of the external factors that affect the offshore O\&G projects as well as key challenges associated with each factor. 


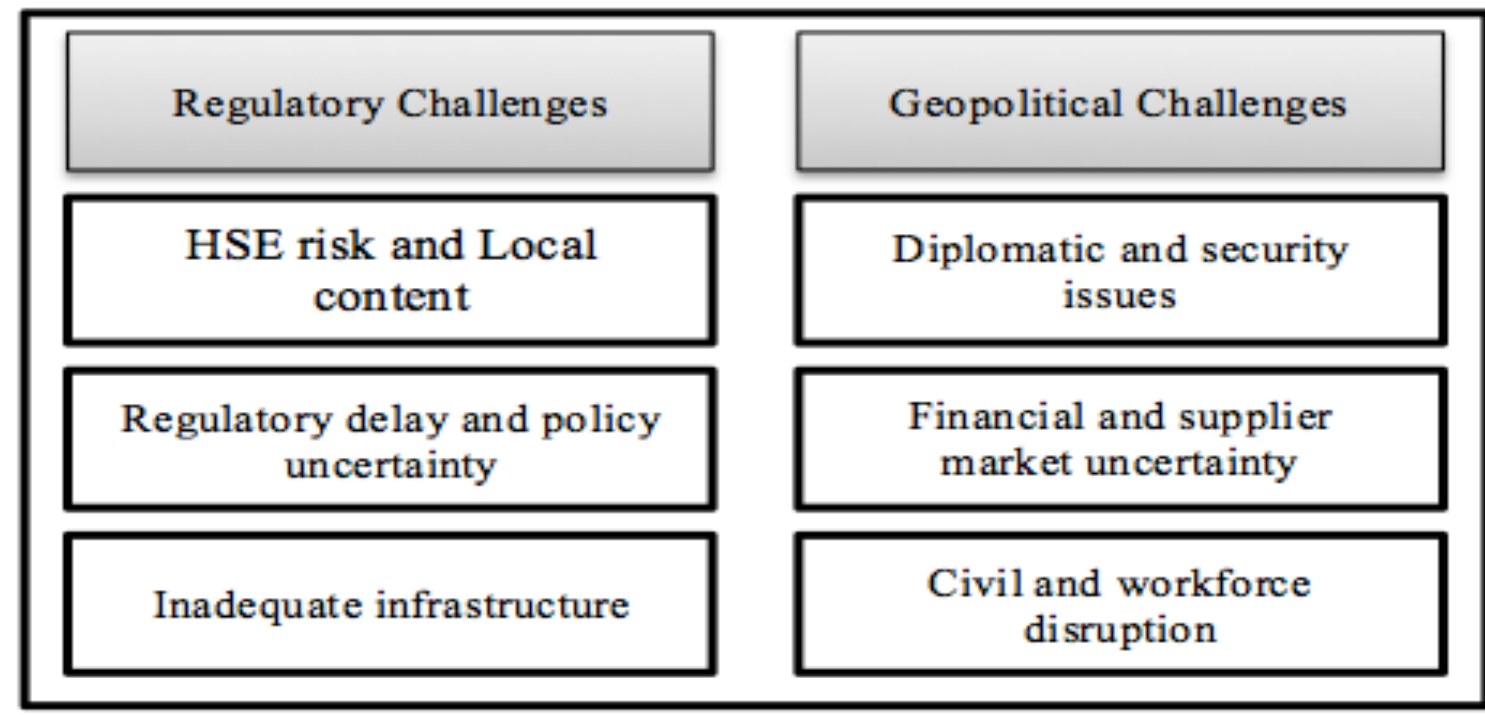

Figure 12: External Factors Responsible for Offshore Oil Projects Failures

\subsection{Offshore Oil Portfolio Management and Project Selection}

Selecting the right project that fits within the company's strategy is critical in the oil sector. The life cycle of offshore oil project has different phases where at the end of each project phase a review of its performance evaluation is held [23]. The figure 13 shows the whole project life cycle that includes the six significant phases: assess, select, define, execute, operate, and decommission, although these may have different names across various organizations.

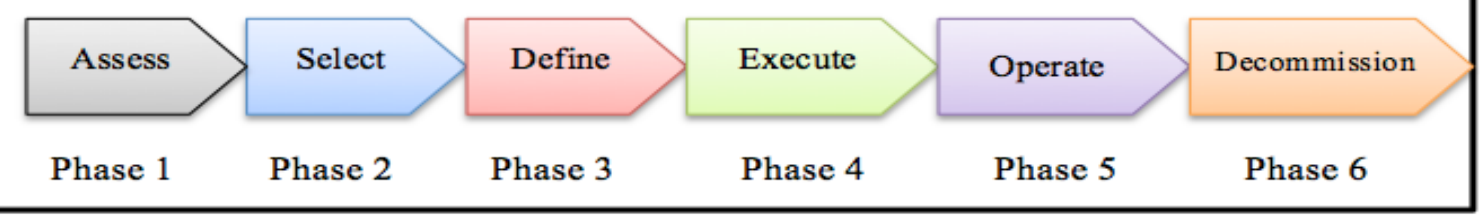

Figure 13: General Project Phases of Offshore Oil Projects 
However, selection phase is a process to assess each project idea and select the project with the highest priority. Frequently a lack of clear strategic direction and project selection criteria means that over time, organizations develop overly diverse and poorly aligned project portfolios, which often unnecessarily stretch resources, increase portfolio risk and dilute the potential value of inter-project linkages. It is therefore critical to select and subsequently approve appropriate projects that align to company capability, experience and strategy [16]. Most of the decision-making in the selection phase in oil sector can be resumed as a balance between the costs and profits. Nevertheless, oil industry has a large set of risks, uncertainties and also opportunities, which make the decision-making processes difficult. Today, there are several available methodologies which can be used to support the decision making process in oil and gas industries [25]. In particular, net present value (NPV) calculations, discounted cash-flow analysis, Monte Carlo simulation, portfolio theory, decision-tree analysis and preference theory can be used [25][26][27][28]. However, historical records on the performances of global offshore oil projects show that most of these projects did not meet industry expectations [23]. 


\section{CHAPTER 3: FACTORS AFFECTING OFFSHORE OIL PROJECTS}

Through the literature review, seventeen challenge factors have been highlighted. These factors play an important role in identifying an offshore hydrocarbon project's overall performance. The seventeen factors have been captured under five perspectives including economical, technical, political, environmental, and safety perspectives.

\subsection{Economical Perspective}

The economic evaluation underlying the investment decision is based on the entity's reasonable forecast of future conditions, including capital cost, operational cost and oil prices, which will exist before and during the life of the project.

\subsubsection{Oil Price Behavior}

The price of a barrel of oil is one of the most important variables in determining an oil company's capital investment strategy, and oil prices have gone through many major swings since its discovery in the latter half of the nineteenth century [10]. In the history of the oil prices, there are various factors that affect the overall oil price and the industry's performance such as wars, increased production, decrease in demand and the discovery of oil shale. The history of oil price shows that the price movement is hard to predict. The oil price dropped more than $30 \%$ in a seven-month time frame in the last three decades for five times (1985- 1986, 1990-1991, 1997-1998, 2001, 2008) [29]. In the period between June 2014 and January 2015 the oil price fell by $60 \%$, which is considered as one of the quickest and largest declines in oil history [29]. Since the 
offshore hydrocarbon projects cost billions of dollars, oil price remains the most important factor that affects the overall performance and yields of these projects.

\subsubsection{Initial Cost}

Oil exploration is an expensive, high-risk operation. Since, offshore projects cost a huge amount of money and deep-water wells can even cost hundreds of millions dollars, only very large corporations or national governments are capable to invest and undertake offshore and remote area exploration [30]. The capital investment for individual O\&G projects has increased considerably due to the development of more challenging oil fields. The Gorgon project in Australia, which was one of the largest completed offshore projects, was estimated to cost more than $\$ 57$ billion, which was almost more than double the initially estimated cost [4]. The major cost categories include engineering and project management, equipment, bulk materials, fabrication, installation, construction, startup and commissioning costs as well as the estimated cost contingency. Gaining an understanding of each cost category will help to understand the project's overall cost

performance. Investments in O\&G offshore projects require large monetary investments and tremendous amount of resources; hence a failure in any of its various categories can lead to a disaster. A complete and thorough analysis of all factors must be completed before pursuing a project of this sort to ensure success.

\subsubsection{Operational Cost}

Traditionally, companies have responded to low oil prices, high costs and weak margins by cancelling or postponing projects, laying off staff and freezing spending. 
Once the capital investments have been made, the wells have been drilled, platforms are installed, facilities commissioned and pipelines placed in service, much more remains to be done. It needs to be assured that adequate returns are being generated to match the operating expenses as this is the key to maintain production and stay in business [31]. Operational cost include staff expenditure, subsea, pollution control, water injection, maintenance, insurance, transport charges, miscellaneous etc. Operation costs are primarily comprised of the lease operating expenses, which can be highly variable depending on product mix, water depth, distance from the shore, facility size and configuration [32]. When market conditions change, such as in the case of the 2014/15 downshift in crude oil prices, the challenge for operators and service companies is to realign their cost structures, while making the minimum negative impact on the other components of operational excellence. Success in achieving this is usually the main factor if new resource development can continue or if it should be deferred. The challenge for the upstream sector is to take a more strategic view of cost structures so the necessity for tactical and reactive cost reduction measures as oil prices drop is minimized [33]. In O\&G offshore projects operational expenses cost the companies hundreds of millions of dollars. Evaluating these operational costs in early stages and managing them effectively can significantly reduce chances of failure.

\subsection{Technical Perspective}

Technical implications are one of the other challenging factors that are faced by project managers and decision makers in offshore hydrocarbon projects such as, 
operational difficulties, large size \& multiple scopes, production and reservoir performance.

\subsubsection{Size and Complexity}

Offshore oil projects tend to be significant in terms of their capital size. So called "multibillion dollar offshore oil megaprojects" are common in the industry today. Typical offshore projects have a larger number of sub-scopes, such as well, subsea system, production system, transportation system, etc. These individual project sub-scopes are also quite large with costs in the hundreds of millions of dollars. As such, these individual project sub-scopes are usually implemented or managed by multiple contractors [4]. With rising project complexity, pressure to deliver on schedule and within budget simultaneously increase, there is a high chance for things to be missed, done incorrectly or simply not accomplished [10]. Large project size and multiple scopes is one of the more important technical factors that must be assessed and evaluated with the appropriate approach to reduce the risk of the complexity and chance of failure.

\subsubsection{Operational Difficulties}

Deep-water drilling is one of the high-risk operations in the oil and gas sector due to large uncertainties and extreme operating conditions [34]. Since 1994, 2,500 to 3,700 wells have been drilled each year. The number of deep-water $(>400 \mathrm{~m})$ wells has grown over the past 15 years while the number of shallow water $(<400 \mathrm{~m})$ wells has fluctuated [35]. In some cases, the operation drilling occurs for extremely deep wells, whose depth is more than 9000 meters which can increase the operation costs and risks [36]. 
Operational complications force companies to increase their spending on the project that will lead to cost overrun and schedule delays. Offshore petroleum projects face different types of operational difficulties such as, complex working equipment, harsh weather conditions, limited access to safety points, hydrocarbon releases, fire, high degrees of temperature and pressure, fatigue, etc. Therefore, deep-water drilling consists of complex operations in which engineering and commissioning mistakes, along with major work overs, can cost tens of millions of dollars [37][38]. Moreover, The remote geographic locations and complexity of upstream operations in deep water locations has led to great distances for the supply chain partners. This in turn has resulted in large in-transit inventories and inventory carrying costs as the companies need to keep a greater amount of safety stock at the final location [39][40][41]. As a result of the operational difficulty, drilling rigs and oil production platforms in offshore rigging are arguably the most hazardous workstations in the world. An operational difficulty is another significant factor that can cause substantial delays to the overall project and lead to a significant loss of money and investments.

\subsubsection{Production Performance}

The main objective of offshore oil projects is to extract oil from the subsea underground. If the project fails to produce the planned production, it should be considered a failure because the production volume of the oil and gas is one of the key factors to determine a project's profitability and future [4]. However, production performance is often omitted when evaluating an O\&G project's performance. The main 
reason is the fact that it usually takes $2-5$ years of operations to collect enough production records to generate a production index metric. By that time, the project has been totally completed and the project team dismissed, so there is no one to take responsibility for the low production rate. Based on historical record, on average, an O\&G project produces just $75 \%$ of the planned production due to various reasons, which means it lost $25 \%$ of the revenue due to project production failure [42]. In addition to other factors such as, cost, schedule, and safety, actual O\&G production performance is also a measure of project success. The O\&G reserve is the total amount of O\&G that can be technically and economically produced from subsurface through project development. The high average reserve per well implies that fewer wells will be drilled to produce the given amount of reserves, which will lead to greater well production and higher project profitability [4]. Even though the O\&G companies use advanced technology in drilling operation, there is still no clear way to evaluate the production performance before the well has been drilled which can cost the project a fortune if it fails.

\subsubsection{Reservoir Uncertainty}

Enhanced understanding of the geological environment is needed in order to identify potential geo-hazards and develop technological countermeasures to hazardous precursors [43]. However, in order for the geologists to discover the oil, a process that involves shock waves or seismic waves is used in creating a picture of deep rock structures. Even though, geological and geophysical clues can be reassuring, but drilling is the only way to confirm if an oil or gas field actually exists in that location [30]. The 
geologic and seismic uncertainty can cause the company to lose money and waste time and resources. Today, the average wildcat well has only one chance in ten of finding an economic accumulation of hydrocarbons. So even though oil and gas prospectors of today have better tools than their predecessors, luck remains a significant factor in the search for oil and gas [14]. Moreover, because of reservoir characteristics and limitations in petroleum extraction technologies, only a fraction of this oil can be brought to the surface, and it is only this producible fraction that is considered to be reserves. Reservoir quality is a key component in determining the value of an oil and gas asset. Failing to measure the reservoir quality accurately is a major contribution for field development failure [44]. However, as the geology of the subsurface cannot be examined, direct or indirect techniques must be used to estimate the size and recoverability of the resource. While new technologies have increased the accuracy of these techniques, significant uncertainties still remain [14].

\subsection{Political Perspective}

Politics is a central concern for the O\&G sector and can be viewed as a source of both risk and opportunity. It is no coincidence that one of the top risks facing offshore oil project, as identified by most recent risk studies, was geopolitics.

\subsubsection{Government Stability}

Oil and gas companies tend to prefer countries with stable political systems and a history of granting and enforcing long-term leases [45]. However, in the past companies simply go where the oil and gas is, even if a particular country doesn't quite match their 
preferences. The main driving factors of investment decisions were made based on sites that were financially beneficial, leading in oil quality and their availability. Numerous issues may arise from this, including sudden nationalization and/or shifting political winds that change the regulatory environment. Depending on what country the oil is being extracted from, the deal a company starts with it is not always the deal it ends up with, as the government may change its mind after the capital is invested, in order to make more profits [46][47]. An important approach that a company takes in mitigating this risk is careful analysis and building sustainable relationships with its international oil and gas partners, if it hopes to remain in there for the long run.

\subsubsection{Conflict Over Maritime Claims}

The United Nation Convention on the Law of the Sea (UNCLOS), established by the United Nations (UN) in 1984, is a quasi-constitutional treaty that grants certain areas of the Arctic seafloor to the five circumpolar nations [48]. The UNCLOS states that exclusive economic zones (EEZs) shall not extend beyond 200 nautical miles (nm) from which the breadth of the territorial sea is measured [49][50]. Based on new research "Offshore oil development and maritime conflict in the 20th century: A statistical analysis of international trends" by Elizabeth Nyman shows that the independent variable is positive and significant at the $95 \%$ confidence level, indicating that the threat or use of conflict over maritime claims with offshore oil is indeed more likely to occur in the wake of successful offshore drilling [2]. The conflict over maritime most likely occurs when the high production performance has been achieved which means that a lot of money and 
effort have already been put on the project, so any cancellation or delay can lead to a disaster.

\subsubsection{Policies, Regulations and Governance Standards}

Various policies governing the regulations for offshore hydrocarbon drilling have been radically changing due to fluctuating public and governmental values. Industry regulations aim at stabilizing the conditions for production and efficiency, while the fairly new paths of social regulation deal with external factors of material production,

workplace health, safety and environmental security [51]. The success of a petroleum project is also greatly influenced by political uncertainty, such as changing taxes, public service announcement terms, government stability in the developing countries, etc. for example since the 1970s, the offshore oil and gas industry has been subjected to multiple environmental regulations. The biggest regulation impact occurred based on climate change-a new global policy [52][42]. However, since the United States has now decided to walk away from the Paris international agreement for controlling climate change, the offshore petroleum industry may face a regulatory uncertainty, which will in turn affect the whole industry until relevant regulations are established. Offshore petroleum projects have a lifetime of about 40 to 50 years, so any regulation and policy change during this time can increase the cost and cause delays.

\subsubsection{Contracts Complexity}

O\&G companies are required to have a license to explore for hydrocarbons [14]. Finding the right contract that fits within the company's vision is a complicated process 
and requires tremendous experience in dealing with offshore $O \& G$ contracts in order for the project to be successful. However most governments have their own policies to manage bidding and contracts of O\&G offshore projects. Firms have to fulfill the government regulations and policies such as environmental protection, health and safety and public opinion etc. Such processes and others make offshore O\&G contracts very complicated and they require the firm to have extended experiences and strong assessment capabilities to go through this long and tedious contract and leasing process. In addition, many of the larger oil and gas companies participate in megaprojects through complex operator or non-operator joint venture agreements to limit risk exposure. This added complexity, combined with the high-risk, high-value nature of the projects, presents a challenge for companies in managing their total portfolio risk [11].

\subsection{Environmental Perspective}

Environmental impacts of oil and gas operations may influence species, populations, assemblages, or ecosystems by modifying a variety of ecological parameters (e.g., biodiversity, biomass, productivity, etc.). Potential environmental issues associated with offshore oil and gas development projects include the following: Air emissions, Wastewater discharges, Solid and liquid waste management, Noise generation and Spills.

\subsubsection{Air Emissions}

In recent years, particular attention has been directed towards the impacts caused by the offshore oil and gas industry $[53][54][55][56]$. Whilst the industry has inevitably yielded substantial economic rewards, it has also been a major cause of marine pollution 
and degradation. Activities such as flaring, drilling, construction, transportation and discharge have all played a role in disturbing marine ecosystems [57][58]. Nevertheless, air emissions from hydrocarbon offshore activities considering as a one of the main source of environmental pollution. Gaseous waste released to the air can potentially affect humans, animals, and plant life through inhalation or dermal contact. Indirectly, gaseous waste may alter the comical balance in the atmosphere [59]. The main sources of air emissions continuous or non-continuous resulting from offshore activities include: combustion sources from power and heat generation, and the use of compressors, pumps, and reciprocating engines (boilers, turbines, and other engines) on offshore facilities including support and supply vessels and helicopters; emissions resulting from flaring and venting of hydrocarbons; and fugitive emissions [60]. Principal pollutants from these sources include nitrogen oxides (NOx), sulfur oxides (SOx), carbon monoxide (CO), and particulates. Additional pollutants can include: hydrogen sulfide (H2S); volatile organic compounds (VOC) methane and ethane; benzene, ethyl benzene, toluene, and xylenes (BTEX); glycols; and polycyclic aromatic hydrocarbons (PAHs) [32].

\subsubsection{Solid \& Liquid Waste Management}

The marine environment is host to a diverse set of highly productive and complex ecosystems. In addition to playing a central role in climatic regulation, it also contributes significantly towards biodiversity maintenance, food and energy provision, and the creation of economic and cultural benefits [61][62]. Yet whilst marine systems are highly adaptive they are also vulnerable [63][64]. Typical non-hazardous and hazardous wastes 
routinely generated at offshore facilities include general office and packaging wastes, waste oils, oil contaminated rags, hydraulic fluids, used batteries, empty paint cans, waste chemicals and used chemical containers, used filters, fluorescent tubes, scrap metals, and medical waste, among others [60]. These waste materials should be segregated offshore into non- hazardous and hazardous wastes at a minimum, and shipped to shore for re-use, recycling, or disposal. Moreover, oil and gas reservoirs contain water (formation water) that becomes produced water when brought to the surface during hydrocarbon production. Oil reservoirs can contain large volumes of this water whereas gas reservoirs typically produce smaller quantities. In many fields, water is injected into the reservoir to maintain pressure and / or maximize production. The total produced water stream can be one of the largest waste products, by volume, disposed of by the offshore oil and gas industry. Produced water contains a complex mixture of inorganic (dissolved salts, trace metals, suspended particles) and organic (dispersed and dissolved hydrocarbons, organic acids) compounds, and in many cases, residual chemical additives (e.g. scale and corrosion inhibitors) that are added into the hydrocarbon production process. Feasible alternatives for the management and disposal of produced water should be evaluated and integrated into production design. These alternatives may include injection along with seawater for reservoir pressure maintenance, injection into a suitable offshore disposal well, or export to shore with produced hydrocarbons for treatment and disposal [60]. 


\subsubsection{Noise Generation}

As the offshore industry expands into the world, the oil and gas exploration activities generate all kinds of waste, varying from contaminated runoff water to material packaging [65][66][67]. Primary concerns relate to marine pollution and toxicity, benthic disturbance, biological depletion, and the loss of archaeological heritage [56][68][25]. Nevertheless, Offshore hydrocarbon activities noise generation has a significant impact on marine environment that get the scientists attention in the last few years. Offshore hydrocarbon activities generating marine noise include seismic operations, drilling and production activities, offshore and near-shore structural installation and construction activities, and marine traffic. Noise from these activities can affect fish and marine mammals [60]. The loudest noises generated by the offshore petroleum industry specially that produced by seismic survey equipment could kill fish at a range of some hundreds of meters [69]. Based the marine impact there are two important potential health problems arising from exposure to noise offshore: noise-induced hearing loss and the potential for sleep disturbance with resultant fatigue and stress that could affect the workers [70].

\subsubsection{Oil Spills}

Many marine species (e.g., marine mammals, birds and fish) are highly vulnerable to oil spill impacts because they are highly localized and seasonally more abundant near offshore petroleum drilling areas [71][72]. Spills from offshore facilities can occur due to leaks, equipment failure, accidents, or human error. A significant oil spill in marine waters could have extensive and long-term impacts. Abilities to respond to oil spills are 
extremely limited, posing significant challenges for implementing pollution prevention techniques [73]. Spills are an important environmental performance indicator for the oil and gas industry since they can have a significant and visible impact on the environment. The degree of environmental impact is highly dependent on the nature of the release, where it occurred and how it was subsequently managed [74]. Based on environmental impacts and climate change, the offshore O\&G industry is subjected to new policies and regulations that will increase investment costs and delay production productivity.

\subsection{Safety Perspective}

Health and safety are important elements of the industry and its working standards. Offshore petroleum projects function in unsafe environments and constantly deal with risky products. Potential safety factors associated with offshore oil and gas development projects including hazard identification and implementing health, safety and environmental (HSE).

\subsubsection{Hazard Identification and Risk Management}

Safety performances cost companies a huge amount of money and lead to delays to the whole project. A recent example is the Deep-water Horizon accident in 2010. The gas blowout-induced explosion killed 11 workers and injured another 17 of the 126 on board [75]. The Deep-water Horizon accident is the largest blowout catastrophe on record in deep-water oil drilling history and it has already cost about $\$ 62$ billion for just British Petroleum (BP) [76][77]. A project's safety performance has become a priority in determining whether an offshore O\&G project is successful [4]. Existing data shows that 
there were 1183 fatality cases in the U.S. O\&G industry between 2003 and 2013. The fatality rate is 29.1 deaths per 100,000 workers, which is eight times higher than the rate for the overall U.S. worker [78]. Hazard identification is an essential step before project implementation and during the project lifecycle phases. Issues potentially impacting safety and environmental stewardship are promptly identified, fully evaluated, and promptly addressed or corrected commensurate with their significance [79]. Accidents on offshore oil and gas platforms (OOGPs) usually cause acute fatalities [80] and financial losses as OOGPs have demanding environment and oil and gas production is a difficult and potentially dangerous operation. The demanding environment includes limited accessibility and danger of encountering hurricanes, massive waves, and storms. Drilling and processing oil and gas turn offshore platforms into a high-pressure, inflammable, and dangerous environment with frequent accidents, including a gas leak, fire, explosion, blow out, structural failure, and adverse weather condition [81][82][83]. By evaluating and identifying such risks and hazards will increase the awareness of safety implementation.

\subsubsection{Implementing Health, Safety and Environmental (HSE)}

Due to the nature of the work environment and the properties of the products, offshore O\&G projects pose more serious safety threats to the workers than their counterparts in other industries. The fatality rate between 2003 and 2013 in the U.S. O\&G industry is 29.1 deaths per 100,000 workers, which is eight times higher than the rate for the fatality overall U.S. worker [4]. Early evaluation of implementing health, 
safety and environmental (HSE) principles is essential to the success of the project. HSE principles contain the performance levels and measures that are generally considered to be achievable in new facilities by existing technologies at reasonable costs [84]. Proper assessment can prevent negative consequences such as schedule delays and cost increases [85]. Decision makers should take into consideration the project specification factors that could affect HSE implementation such as the complexity of the project, site of the project, number of operations required, depth of the water, size of the project, etc. Such factors that are related to the operation of O\&G facilities within harsh environments and situations that pose difficulties in emergency response may represent critical situations and project failure [86]. 


\section{CHAPTER 4: RESEARCH APPROACH AND METHODOLOGY}

This chapter highlights the research approach that was implemented to identify the research gap. Moreover, research objectives, research questions and research methodology sections were presented in this chapter. Though, this study relies on the experts and their willingness to contribute, various challenges associated with expert panels' formation were investigated.

\subsection{Research approach}

The research starts with a literature review in order to identify and investigate the main factors that affect the performance and success the offshore hydrocarbon projects. The literature review has been conducted with the help of three independent study papers. The first paper provides a broad overview of offshore oil projects and their opportunities and challenges. The purpose of the second paper is to identify and assess key factors impacting the performance of offshore hydrocarbon projects. In the third paper an academic research from an industry point of view has been conducted. Seven experts who have extensive experience not less than 10 years of working in the offshore oil projects were involved in the elaboration of this paper. The main purpose of this paper is to capture the experts' recommendations and feedback in order to assess key factors impacting the performance of offshore oil projects. Figure 14 shows the research processes flow chart. 


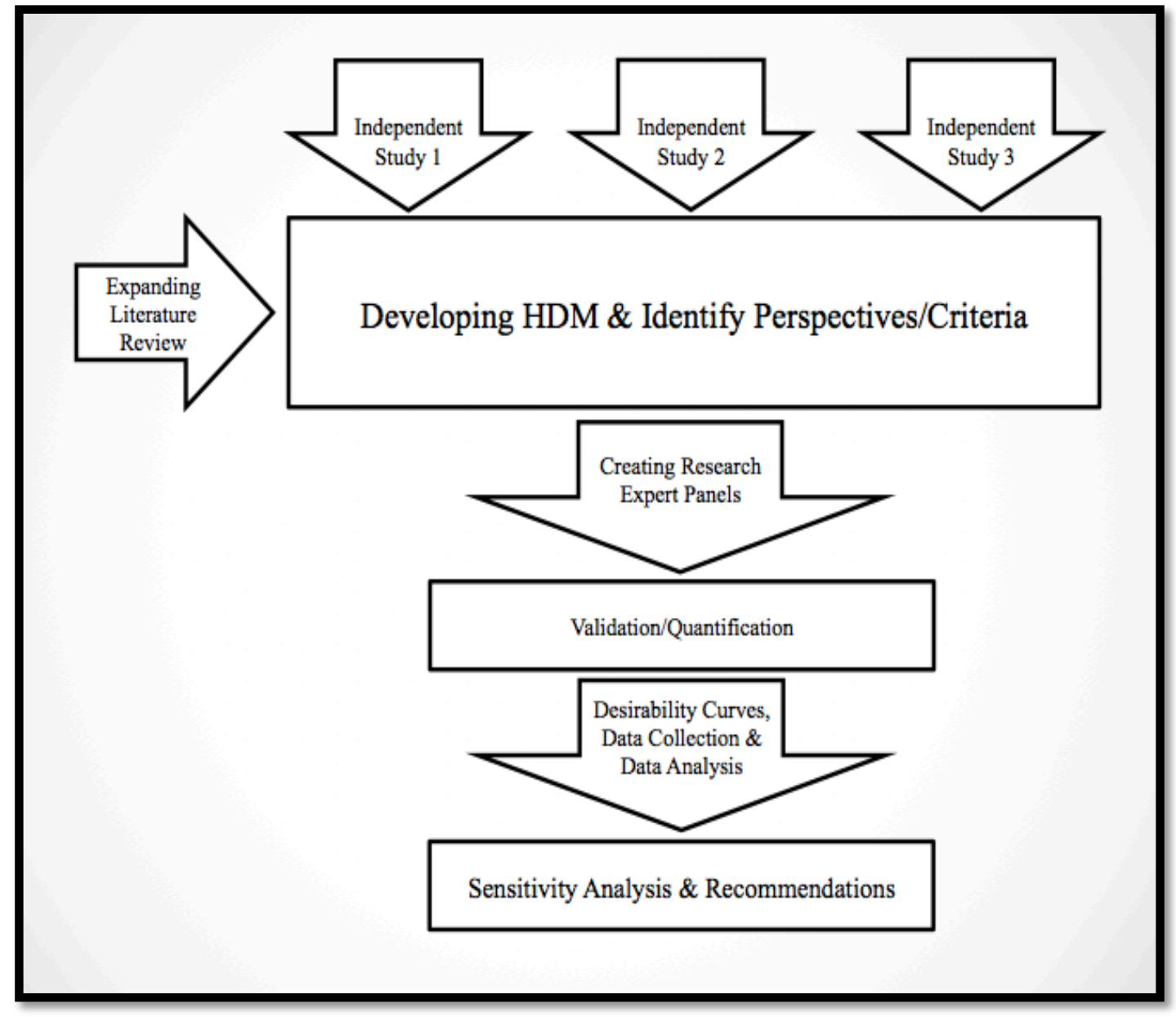

Figure 14: Research Processes Flow Chart

Figure 15 illustrates the research framework process that would start with evaluating the investment opportunities using a hierarchical decision model. The next step is assigning scores value to each factor and builds the value cures. Last step is to provide index value for each project. 


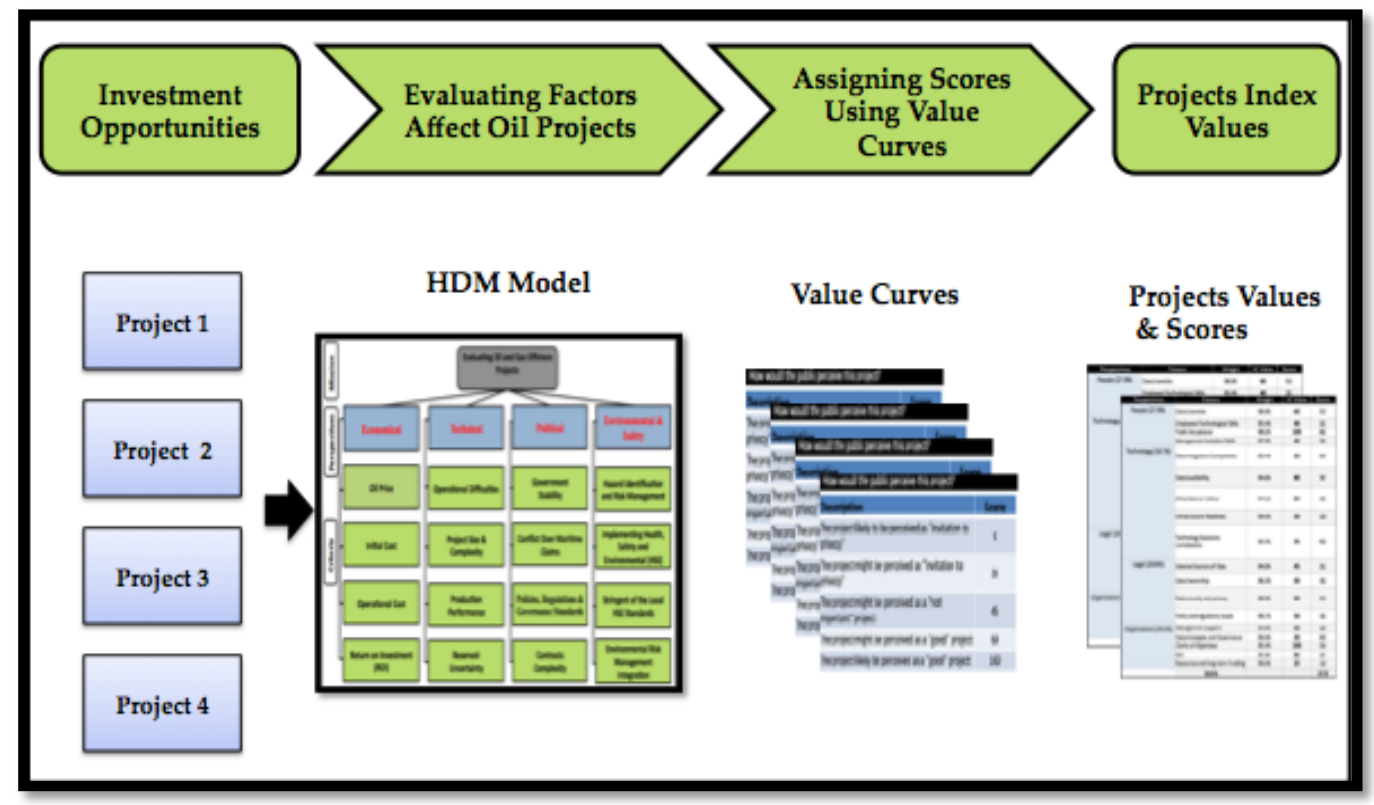

Figure 15: Research Framework Process

\subsection{Research Gaps}

Numerous researchers have shown that global offshore oil projects have not performed well, including within the three constituents of project management capability: scope, schedule, and budget capabilities [4][12]. Research demonstrates that the majority of offshore oil projects are facing delays, cost escalations, and lower than expected hydrocarbon production [12]. Merrow (2012) shows that $64 \%$ of the projects are facing cost overruns. These projects are reporting schedule delays at 73\% [87]. EY (2014) reported similar findings with $64 \%$ of oil megaprojects experiencing a cost overrun [16]. A new study in 2016 investigated the cost performance of oil projects by analyzing the data of approximately 200 public oil projects in terms of project size, company type and region, showing that the overall average cost overrun of oil projects is $18 \%$ with an SD of 
$29 \%$ [88]. Kegang Ling (2017) reported that more than $60 \%$ of the offshore oil projects experienced a cost overrun of $33 \%$ or more and schedule delays of $30 \%$ or longer [4]. Kolltveit and Gronhaug (2004) concluded that Norwegian offshore projects have experienced overruns ranging from $6 \%$ to $160 \%$ [88][89]. Moreover, Cunningham \& Scheck (2016) reported that 68 major projects were scrapped in 2015, which accounts for around 27 billion barrels of oil. All of these studies revealed that the majority of the hydrocarbon offshore projects were delayed and/or faced cost overruns when measured against estimates made during the initial stages of the project life cycle. According to data provided in the Offshore Technology Conference 2013, 65\% of project failures were due to softer aspects such as people, organization and governance. Another $21 \%$ were caused by management processes as well as contracting and procurement strategies, with the remaining $14 \%$ of the failures due to external factors such as government intervention and environment-related mandates [24][16]. However, project portfolio has been highlighted as one of critical factors that leads to project failures [16]. Frequently, a lack of clear strategic direction and project selection criteria means that over time, organizations develop overly diverse and poorly aligned project portfolios, which often unnecessarily stretch resources, increase portfolio risk, and dilute the potential value of inter-project linkages. The capital investment for individual oil projects has, therefore, increased significantly to develop more and more challenging oil fields. The largest completed offshore project, the Gorgon project in Australia, cost more than $\$ 57$ billion, which more than doubled the estimated cost [90]. Elsewhere, the Pearl GTL project in Qatar rose nearly 300\% from its 2003 budget of $\$ 5$ billion [91], while Norway's offshore 
oil projects are running roughly $20 \%$ above original cost estimates [92]. All findings indicate that the overall cost performance of oil projects is worse than expected, implying that project teams fail to incorporate the risks in the planning phase.

Traditionally, cash flow analysis and return on investment are the most known methods to evaluate offshore oil projects [93]. One of the traditional methods of investment analysis is based on discounted cash flow (DCF). This approach considers an investment as a decision of the now-or-never type. If the net present value (NPV) is positive, the investment must be done without delay, and if the NPV is negative, the investment should be cancelled. However, the DCF method requires detailed assumptions to develop reliable cash flow forecasts. In a typical evaluation, the firm's analysts use sensitivity analysis to identify the key uncertainties, assess probabilities for these key uncertainties, and construct decision trees or simulation models of the project cash flows. They use these models to calculate expected NPVs and distributions on NPVs, which then serve as important inputs into the decision making process. Though management is generally pleased with decision analysis processes, there are typically two concerns. First, there is concern that analyses frequently do not capture some of the flexibilities associated with projects. Decision models typically assume that management makes an initial investment decision, and then the project uncertainties are resolved and cash flows are determined [11]. A second issue that has long concerned many firms is the way cash flows are discounted. Many investments have time horizons as long as 30 or 40 years, and the NPVs for these investments are extremely sensitive to the discount rate used. There is concern, particularly among managers in the exploration and new ventures parts 
of a business, that the blanket use of such a risk-adjusted discount rate causes them to undervalue projects with long time horizons [11]. In reality, firms make a series of investment decisions as uncertainties resolve over time. For example, when considering the development of a new oil field, if oil prices, production rates, or reserves exceed their expectations, or if production technology improves, the firm might be able to develop more aggressively or expand to nearby fields. Similarly, if prices, rates, or reserves are below expectations, the firm might be able to scale back planned investments and limit their downside exposure [11]. According to Suslick \& Furtado (2001), exploring and producing oil involves risky investments. The authors affirmed that when petroleum executives make investment decisions on petroleum projects, they face several uncertainties including future oil prices, reserves, environmental concerns, the chances of finding petroleum, fiscal terms, current degree of exploration, and operational peculiarities [94]. As the data show, improving offshore oil capital project efficiency is critically needed. Relying on financial assessments alone will not solve the problems that arise later on, and a comprehensive approach is needed to measure project outcomes and identify gaps for future improvements.

\begin{tabular}{|l|l|l|}
\hline 1 & \multicolumn{1}{|c|}{ Gap Description } & \multicolumn{1}{|c|}{ References } \\
\hline 1 & $\begin{array}{l}\text { There is not a specific study, which is aimed to identify the most } \\
\text { factors that impact oil offshore projects' investment decision as } \\
\text { well as assessing their weights. }\end{array}$ & $\begin{array}{l}{[4][12][48][49]} \\
{[50][51][52][5} \\
3][54][55][56]\end{array}$ \\
\hline 2 & $\begin{array}{l}\text { As the data shows, improving oil offshore capital project } \\
\text { efficiency is critically needed. Companies rely only on financial } \\
\text { analysis approach and there is a lack of a comprehensive } \\
\text { approach to evaluate oil offshore projects before and after the } \\
\text { investment decision. }\end{array}$ & $\begin{array}{l}{[11][50][57][5} \\
8][24][16]\end{array}$ \\
\hline
\end{tabular}

Table 1: Summarizes the Research Gaps 


\subsection{Research Objectives}

It has been observed that global offshore projects have not performed well. More than $60 \%$ of the projects experienced a cost overrun of $33 \%$ or more, schedule delays of $30 \%$ or longer, and lower than expected hydrocarbon production [4]. Traditionally, cash flow analysis and return on investment are the most known methods to influence the decision in hydrocarbon offshore projects. However, in current times there are many factors that play a more important role in evaluating oil offshore projects and influencing investment decisions. The main purpose of this research is to identify the key challenging factors that affect oil offshore projects as well as assess their impact on the investment decision. Also, to provide a comprehensive approach to evaluate offshore oil projects before and after the investment decision takes place. Specific objectives of this research include:

1. To identify the major challenging perspectives as well as associated sub-criteria impacting oil offshore projects.

2. To evaluate and score these factors, and highlight their weight of impact on offshore oil projects.

3. To provide a comprehensive framework that can be used for assessing and evaluating offshore oil projects to select the right project.

\subsection{Research Questions}

1. Which attributes are most important for evaluating offshore oil projects?

2. Is the assessment framework appropriate for evaluating offshore oil projects? 
3. To what extent could the developed model results help project managers and decision makers to evaluate offshore oil projects and select the right project?

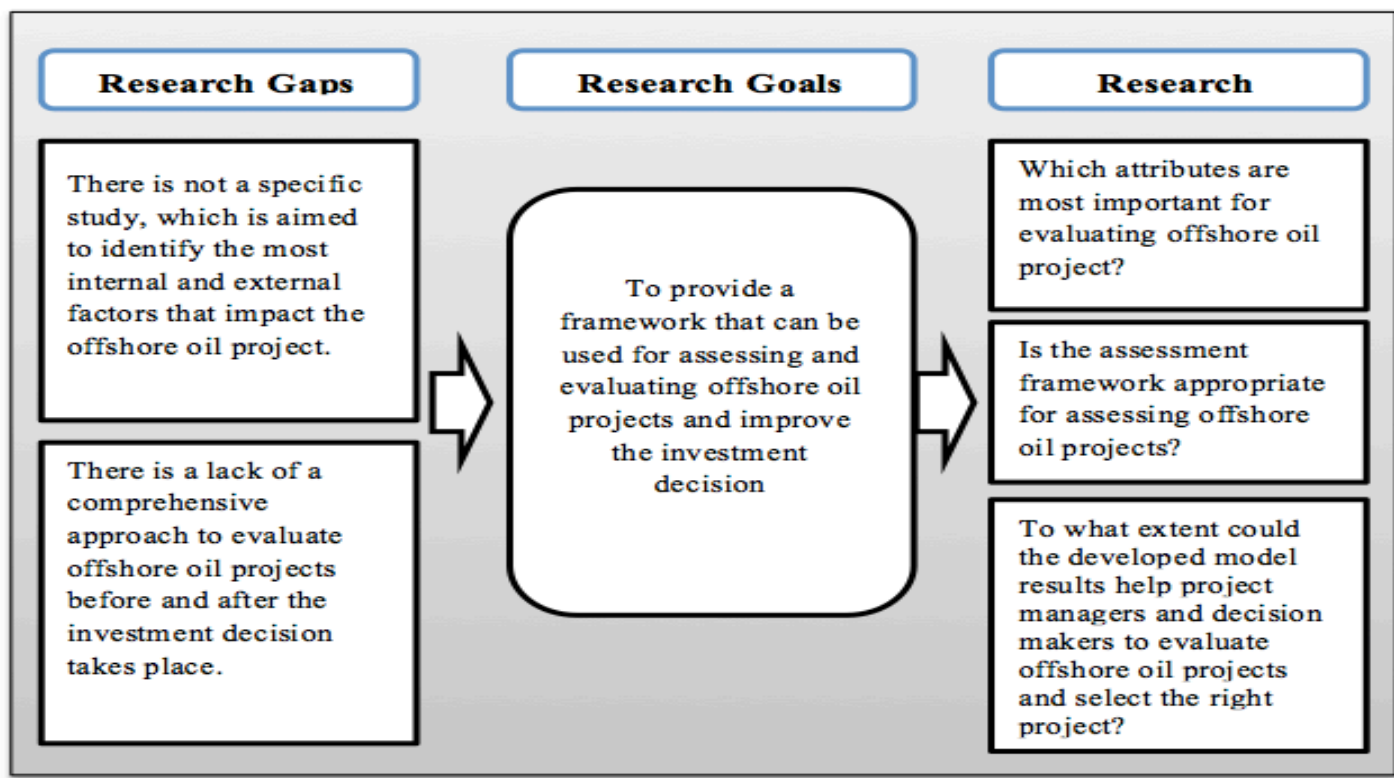

Figure 16: Gaps Analysis Diagram

\subsection{Research Methodology}

The main purpose of this research is to emphasize the key challenge factors that affect oil offshore projects as well as to assess their impact on the project. Also, to provide a comprehensive approach evaluating oil offshore projects the investment decision has taken place. The methodology that has been used in this research is the Hierarchical Decision Model (HDM) that was introduced by Cleland and Kocaoglu [95]. The model can be used as a network of relationships among decision hierarchies, where subjective judgments are provided in a comprehensive evaluation [96]. The HDM has adopted by decision makers in various industries [97][98]. The HDM process likes other multicriteria decision tools such as AHP. Its steps include structuring the decision problem into 
levels, followed by pairwise comparison among all variables, calculating the priorities of the objectives, and checking the consistency. The HDM process is more comfortable to the experts related to the relative and absolute preference [99].

In HDM, the subjective judgments expressed in pairwise comparisons are converted to relative weights in ratio scale. This is done by a series of mathematical operations. The methodology can be used for quantifying the judgment of a single decision maker, or multiple decision makers [95]. The basic structure of HDM can vary depending on the needs of each application. Based on Kocaoglu HDM structure contains five levels: Mission, Objectives, Goals, Strategies, and Actions (MOGSA), as shown in Figure 17.

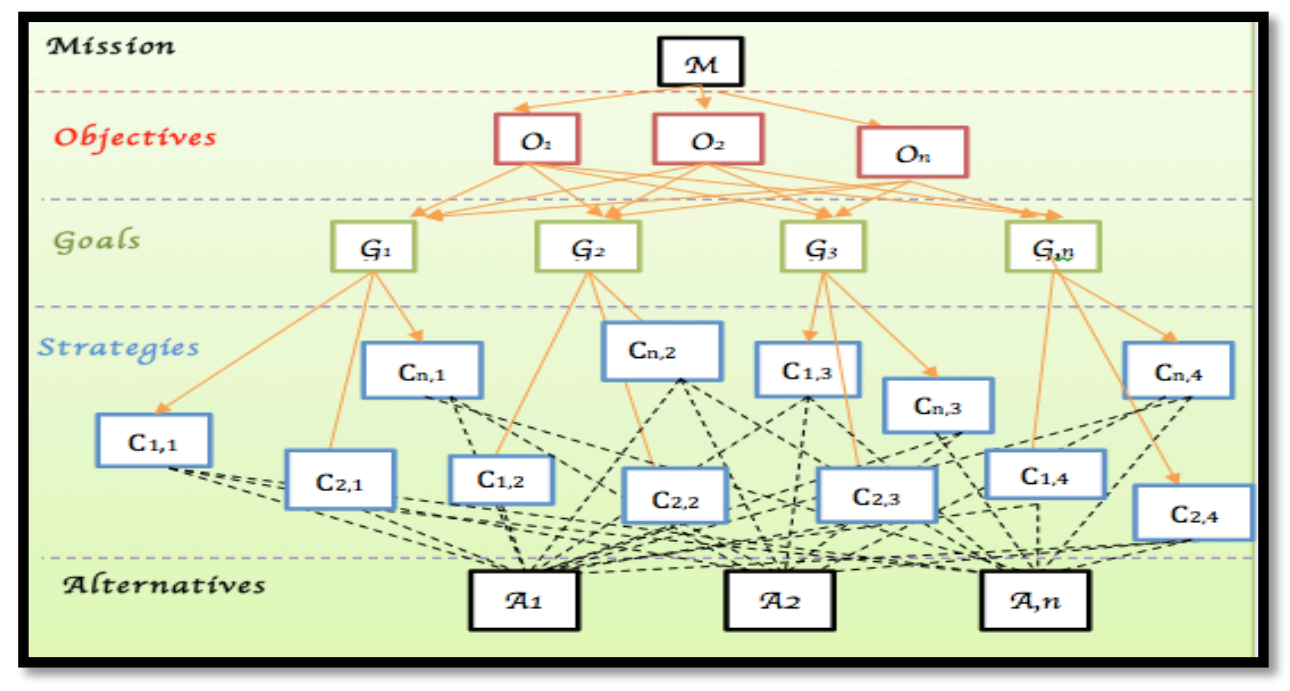

Figure 17: HDM (MOGSA) Structure

However, other structures can be applied under four-level model that will include Mission, Perspectives, Criteria, and Alternatives as it's showing in Figure 18. 


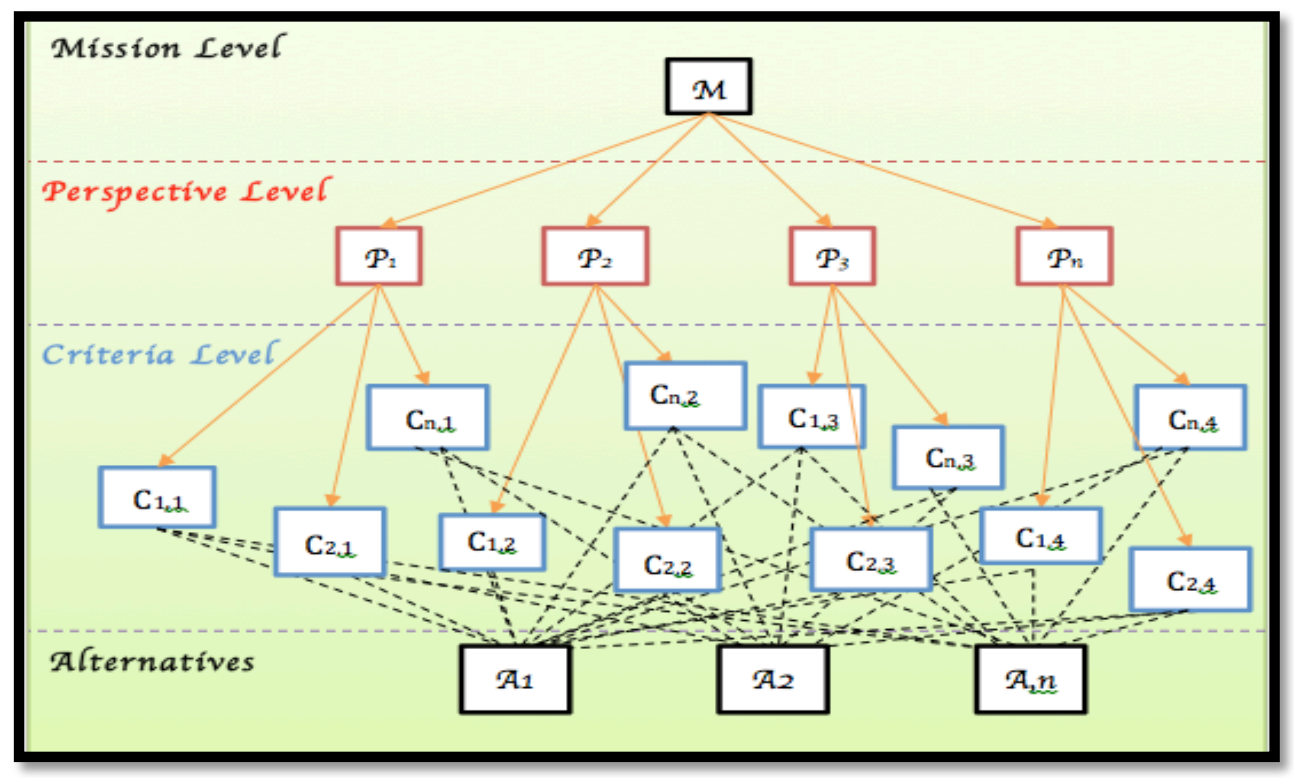

Figure 18: HDM Structure

However, during the data collection phase, it is important to consider inconsistency and disagreements among the judgments' of experts. Inconsistency is a disagreement within an individual's evaluation, which in other words shows how an expert could have an inconsistent judgment within his/her comparisons. Disagreements amongst experts can show different quantifications and different perspectives to the same analysis. Nevertheless, HDM has been used in a variety of cases and for several purposes, especially in technology management, to evaluate and understand which technology alternative is the best option in a particular setting, given the criteria established to evaluate the alternatives [101]. Moreover, HDM has been applied in several different settings and fields, proving that it is, indeed, an effective method. The fields and areas that were explored using HDM are, but not limited to, computer selection [102], agriculture [103], university housing [100], transportation options [104], solar 
photovoltaic technologies [105], energy [106], health technology assessment [107], selection of graduate school [108], and technology transfer [114], big data projects and smart cities selection [109].

\subsection{Experts Selection}

HDM relies on the experts and their willingness to contribute. However, selecting experts and formatting panels is the most critical part in these types of research. In this study the experts will be involved in two main steps; (1) validate the model and the desirability metrics. (2) Quantify the model and the desirability metrics. Numerous studies and researches provide a significant amount of information for defining the experts and what characteristics they should have. According to Sternberg (1997), expertise can be seen as a multidimensional prototype that includes seven characteristics [110]:

1. Advanced problem-solving processes.

2. A great amount of knowledge.

3. Advanced knowledge organization.

4. An ability to use knowledge effectively.

5. Creating new knowledge on the basis of knowledge that one already has.

6. Automatized actions.

7. Practical ability, which involves knowing how to get ahead in one's field. 
Moreover, other studies have been introduced about the nature and different constituents of expert knowledge. Despite their differences in details, all of these analyses mainly divide expert knowledge into three main components [110]:

1. Formal knowledge.

2. Practical knowledge.

3. Self-regulative knowledge.

According to the Cambridge dictionary, an expert is "a individual who has a high level of knowledge or skill in a particular field" [111]. Based on Cambridge Handbook of Expertise and Expert Performance, Press and edited by K. Anders Ericsson, "Consistently and overwhelmingly, the evidence showed that experts are always made, not born" [112].

In 2005 study represented by Hubert L. Dreyfus and Stuart E. Dreyfus classified the acquisition of expertise into five-stage as following [113]:

Stage 1: Novice: In this stage, an individual is able to recognize and decompose the task without the desired skill.

Stage 2: Advanced Beginner: In this stage, an individual begins to develop an understanding of the relevant context, he or she begins to note, or an instructor points out, perspicuous examples of meaningful additional aspects of the situation or domain.

Stage 3: Competence: In the third stage, the individual gains more experience and the learner is now able to recognize and follow. 
Stage 4: Proficiency: In this stage only if the detached, information-consuming stance of the novice, advanced beginner, and distance learner is replaced by involvement, is the student set for further advancement. Then the proficiency will start to develop.

Stage 5: Expertise: In the fifth stage, the individual becomes a proficient expert. He/she is able to recognize how to achieve the goal. Also, the ability to make more subtle and refined discriminations is what distinguishes the expert from the proficient performer.

Based on Hubert L. Dreyfus and Stuart E. Dreyfus definitions, it will be clear that it takes time to become an expert. In addition, research introduced by K. Ericsson, M. Prietula, and E. Cokely, shows that even the most gifted performers need a minimum of ten years (or 10,000 hours) of intense training before they win international competitions. In some fields the apprenticeship is longer: It now takes most elite musicians 15 to 25 years of steady practice, on average, before they succeed at the international level [112].

"It takes time to become an expert. Even the most gifted performers need a minimum of ten years of intense training before they win international competitions" [112].

\subsubsection{Challenges Associated with Expert Panels Formation}

Expert panels can be defined as a group of experts who agree to provide service, feedback or recommendations on the same task [114]. The expert panel method is a commonly used in foresight to elicit expert knowledge. Expert panels are engaged when highly specialized input and opinion is required for a project [135]. Generally, a variety of experts are engaged based on various fields of expertise to debate and discuss various courses of action and make recommendations. The objective of formatting expert panels 
is to allow stakeholders and decision makers to hear a variety of informed (expert) viewpoints from which to decide on recommendations or courses of action in relation to an issue or proposal [116]. It's important to consider primarily technical ability and experience of the expert during the expert panel formatting. Furthermore, ensure that the panels have the broadest possible universal representation in terms of diversity of knowledge, experience and approaches in the fields for which the panels are established.

Meanwhile, numerous studies have identified how many experts required for each panel. Based on "Effective Engagement: building relationships with community and other stakeholders - Book 3 the engagement toolkit" that was published in 2005, number of people required in each panel ranges from 2-12 experts [115]. Successful studies have introduced groups of experts as small as five members [117]. Another study defined the panels as groups of 12-20 individuals who are given specific amount of time to deliberate upon the future of a given topic [118]. However, identifying the size of the panel would be one of the critical issues associated with formatting the expert panel. The number of individuals within the panel is mainly affected by the qualification of these experts and the purpose of formatting this panel. Different successful dissertations and studies show that having 6-12 individual per panel is more reliable and efficient to achieve a significant outcomes [119]. Although, there will always be different considerations and weaknesses associated with formatting expert panels.

- Qualified experts should typically have at least 10 years of experience in the field, which will increase their responsibility and dependability in their work. Due to this, finding the right expert can be challenging and expensive sometimes. 
- A long lead-time may be needed to book appropriate experts.

- A highly skilled moderator is required to ensure a positive communication and understanding the panel's objective.

Moreover, it is important to mention some of the characteristics of the group or individual behaviors that are exhibited by panels during their work. These characteristics that may prevent the panel to work effectively include [118]:

1. Expert shares different basic values and goals of the research objective. Sharing a common goal between the expert and the study is an important factor to achieve the expected results.

2. Individuals are unwilling to commit themselves on an issue.

3. Committee members are not necessarily familiar with the needs of the foresight process and may fall into a conventional mode inappropriate to developing a longer-term view of the topics under discussion.

\subsection{Research Validity}

The main purpose of the validation phase is to answer these questions:

- Does the model capture the necessary elements needed to satisfy the research goal?

- Does the model valid to apply?

Following previous $\mathrm{PhD}$ dissertations [105][120][121][101], the research validity has been guaranteed to answer these questions. However, the validity of the research should 
be tested by adopting three measures applied at different phases of the research: construct validity, content validity and criteria-related validity.

- Construct validity refers to the degree to which a research approach complies with its underlying theories. Construct validity of the model will be tested by a group of ETM doctoral students, who have significant amount of research experience in both the energy field and hierarchical decision modeling.

- Content validity refers to the degree to which a measure represents a given domain of interest. Content validity will be tested during the model development phase. After the preliminary model is constructed based on the literature, Subject matter experts who are familiar with decision models will be asked to provide their feedback using the content of the model.

- Criterion-related validity refers to the degree of effectiveness of a model in predicting real-life phenomenon. Criterion-related validity will be implemented after the analysis is completed. The quantified model will be tested against a case study and subject matter experts will determine if the results are acceptable. Also, these experts will be asked to verify if the model could be generalized to other than the case study application.

\subsection{Research Quantification}

The graph below shows how the Hierarchical Decision Model approach uses the pairwise comparisons technique through each level to determine the weights of each factor. 


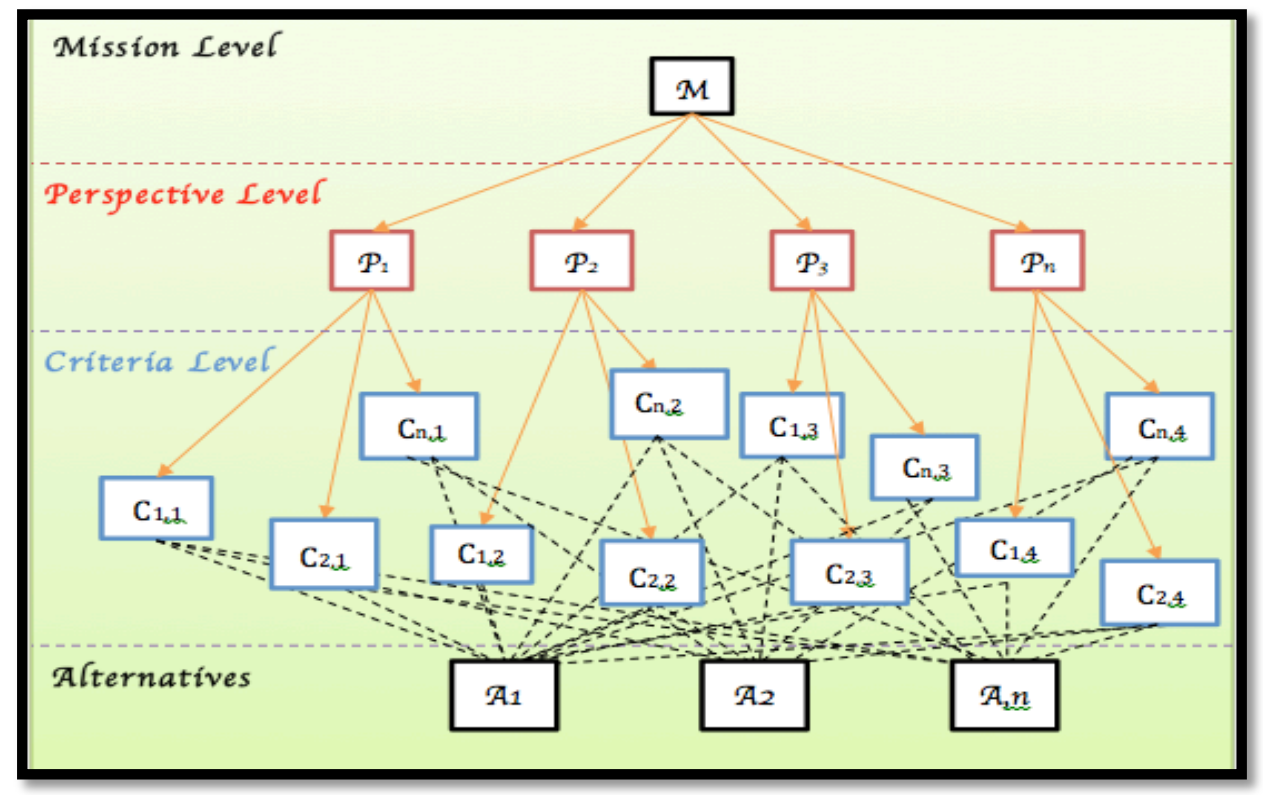

Figure 19: Pair-Wise Comparisons Technique

The respondent divides 100 points between the pair to reflect his judgment of each element's relative importance in comparison with the other element of the pair [122]. In HDM, the subjective judgments expressed in pairwise comparisons are converted to relative weights in ratio scale. This is done by a series of mathematical processes divided on three different matrices.

The first step is to obtain matrix- A. Starting with define $V_{i}^{(j)}$ as the perceived value of element when compared with element $X_{i}$, the $\frac{n(n-1)}{2}$ pairwise comparisons for $\mathrm{n}$ elements results in an $\mathrm{n} x \mathrm{n}$ matrix.

$$
\begin{aligned}
& \text { Let } \quad a_{i j}=V_{j}^{(i)} \\
& \text { Where } a_{j i}=100-a_{i j}
\end{aligned}
$$

As such the matrix-A can be described as following: 


\begin{tabular}{|c|c|c|c|c|}
\hline $\mathrm{i} j$ & $x_{1}$ & $x_{2}$ & ......... & $x_{n}$ \\
\hline$x_{1}$ & $a_{11}=50$ & $a_{12}=V_{2}^{(1)}$ & ........ & $a_{1 n}=V_{n}^{(1)}$ \\
\hline$x_{2}$ & $a_{11}=V_{1}^{(2)}$ & $a_{22}=50$ & 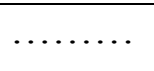 & $a_{2 n}=V_{n}^{(2)}$ \\
\hline$\vdots \quad \vdots$ & $\vdots \quad \vdots$ & $\vdots$ & & $\vdots \quad \vdots \quad \vdots$ \\
\hline$x_{n}$ & $a_{n 1}=V_{1}^{(n)}$ & $a_{n 2}=V_{2}^{(n)}$ & $\cdots$ & $a_{n n}=50$ \\
\hline
\end{tabular}

Table 2: Explanation of Matrix A

Within this we can develop Matrix-B as the following equation:

$$
b_{i j}=\frac{a_{i j}}{a_{j i}}=\frac{V_{j}^{(i)}}{V_{i}^{(j)}} \quad \text { for all } \mathrm{i}, \mathrm{j} \text { except } \mathrm{i}=\mathrm{j}
$$

The next step is to calculate Matrix-C by dividing the elements of each column of Matrix-B by the corresponding elements of the next column.

The following example explains how the weights of the perspective level have been calculated. Let's say expert 1 entered the value of the pairwise comparisons of the perspective level as following:

Economical $=\mathrm{E} \quad$ Technical $=\mathrm{T} \quad$ Political $=\mathrm{P} \quad$ Environmental $=\mathrm{N}$

\begin{tabular}{|c|c|c|c|c|c|}
\hline $\mathrm{E}: 60$ & $\mathrm{~T}: 40$ & P: 60 & $\mathrm{~N}: 40$ & $\mathrm{~N}: 30$ & $\mathrm{E}: 70$ \\
\hline $\mathrm{T}: 45$ & P: 55 & $\mathrm{E}: 55$ & P: 45 & $\mathrm{~T}: 55$ & $\mathrm{~N}: 45$ \\
\hline
\end{tabular}

Matrix A - Symbolic Representation: Based on the information that been collected from expert (1) we can obtain Matrix A as a following:

\begin{tabular}{|c|c|c|c|c|}
\hline & $\mathrm{E}$ & $\mathrm{T}$ & $\mathrm{P}$ & $\mathrm{N}$ \\
\hline $\mathrm{E}$ & $\mathrm{X}$ & 40 & 45 & 30 \\
\hline $\mathrm{T}$ & 60 & $\mathrm{X}$ & 55 & 45 \\
\hline $\mathrm{P}$ & 55 & 45 & $\mathrm{X}$ & 40 \\
\hline $\mathrm{N}$ & 70 & 55 & 60 & $\mathrm{X}$ \\
\hline
\end{tabular}

Table 3: Obtaining matrix A

The next step is develop Matrix B as showing in equation number (6): 


\begin{tabular}{|c|c|c|c|c|}
\hline & $\mathrm{E}$ & $\mathrm{T}$ & $\mathrm{P}$ & $\mathrm{N}$ \\
\hline $\mathrm{E}$ & 1 & 0.67 & 0.82 & 0.43 \\
\hline $\mathrm{T}$ & 1.5 & 1 & 1 & 0.82 \\
\hline $\mathrm{P}$ & 1.2 & 1 & 1 & 0.67 \\
\hline $\mathrm{N}$ & 2.3 & 1.22 & 1.5 & 1 \\
\hline
\end{tabular}

Table 4: Obtaining matrix $B$

By dividing the elements of each column of Matrix-B by the corresponding elements of the next column we can obtain Matrix-C and calculate the mean for each element of Matrix-C: Orientation for: (E) Economical, (T) Technical, (P) Political and (E) Environmental

\begin{tabular}{|c|c|c|c|}
\hline & $\mathrm{E} / \mathrm{T}$ & $\mathrm{T} / \mathrm{P}$ & $\mathrm{P} / \mathrm{N}$ \\
\hline $\mathrm{E}$ & 1.5 & 0.8 & 1.9 \\
\hline $\mathrm{T}$ & 1.5 & 1.0 & 1.2 \\
\hline $\mathrm{P}$ & 1.2 & 1.0 & 1.5 \\
\hline $\mathrm{N}$ & 1.9 & 0.8 & 1.5 \\
\hline MEAN & 1.5 & 0.9 & 1.5 \\
\hline
\end{tabular}

Table 5: Matrix C

Then, a value of 1 is assigned to $\mathrm{N}$ (the element missing from the table 5), and other elements values are calculated based on it, by the ratios indicated as the mean of each column in Matrix $\mathrm{C}$ as follow:

$\mathrm{N}=1$

$\mathrm{P}=1 * 1.5=1.5$

$\mathrm{T}=1 * 1.5 * 0.9=1.4$,

$\mathrm{E}=1 * 1.5 * 0.9 * 1.5=2$

Next, we can calculate the sum of Orientation E-T-P-N from the mean of Matrix-C

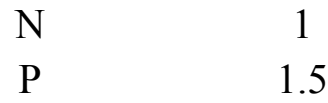




$\begin{array}{cc}\mathrm{T} & 1.4 \\ \mathrm{E} & 2.0 \\ \mathrm{SUM} & 5.9\end{array}$

Now we are able to find the normalized value of each perspective.

$\begin{array}{cc}\text { Environmental } & 0.17 \\ \text { Political } & 0.25 \\ \text { Technical } & 0.23 \\ \text { Economical } & 0.35 \\ \text { Sum } & 1.00\end{array}$

By following the same steps for each expert we are able to obtain the over all value for each perspective and the contribution value of the four perspectives to the overall research objective of Oil offshore projects evaluation. Moreover, following the same calculation will provide the value of the criteria level.

\subsection{Inconsistency Analysis}

Inconsistency is one of the critical factors that could affect the result of the model and it should be calculated and controlled in order to achieve reliable outcomes. The definition of inconsistency has been highlighted in many studies that used HDM methodology. According to Abotah, "inconsistency is a measure that explains how reliable and homogeneous the answer of the expert through the whole questionnaire" [120]. Moreover, Estep described inconsistency as disagreement within an individual's evaluation, which in other words shows how an expert could have an inconsistent judgment within his/her comparisons [105]. Based on Abbas study, there are two types of inconsistency that could occur through the individual's judgment within the HDM, these are 1- ordinal, 2- cardinal. Ordinal consistency requires order of preference of the ranked 
elements to be maintained. For instance, if the expert preferred A over B, and preferred B over C. It will be violated to the ordinal consistency if he/she preferred C over A [123]. The second type of inconsistency is cardinal that requires preservation of preference proportions. For example, if A is preferred twice over $\mathrm{B}$, and $\mathrm{B}$ is preferred thrice over $\mathrm{C}$, then A must be preferred 6 times over C. It will be violated to the cardinal consistency if the expert chooses A to be 5 times preferred over C [123]. According to Gibson, "inconsistency occurs when experts face multiple decisions and have to judge items" [117]. Studies introduce different methods to calculate and control the inconsistency. However, there are two methods that have been used widely in the past few years.

\subsubsection{Variance Method}

This method of measuring the inconsistency is widely referenced in recent dissertations by Chan, Phan, and Sheik [105][117][124][121][98]. The processes start by calculating the mean.

rij $=$ relative value of the ith element in the jth orientation for an expert.

$\bar{r} \mathrm{i}=$ mean relative value of the ith element for that expert.

$$
\frac{1}{n i} \sum_{j=1}^{n i} r i j
$$

After we obtained the mean within the individual data, we measure the standard deviation for the same data.

$$
\sqrt{\frac{1}{n i} \sum_{j=1}^{n i}\left(r_{i}^{-}-r_{i j}\right)^{2}}
$$


By calculate the standard deviation, we are able to define the inconsistency as a mean standard deviation of $\mathrm{n}$ elements

$$
\frac{1}{n i} \sum_{j=1}^{n} \sqrt{\frac{1}{n i} \sum_{j=1}^{n i}\left(r_{i}^{-}-r_{i j}\right)^{2}}
$$

Kocaoglu recommends 0.10 as the limiting value for the inconsistency for any value of $n$ [122]. The following example shows how to measure inconsistency using the variance method.

Where:

$\mathrm{E}=$ Economical $\quad \mathrm{T}=$ Technical

$\mathrm{P}=$ Political $\quad \mathrm{N}=$ Environmental

Perspective Level

Number of comparisons $=[n *(n-1)] / 2]=4(4-1) / 2=6$ pairwise comparisons

Number of perturbations $=4 !=4 * 3 * 2 * 1=24$

Constant Sum Matrices:

Matrix A - Symbolic Representation:

\begin{tabular}{|c|c|c|c|c|}
\hline & $\mathrm{E}$ & $\mathrm{T}$ & $\mathrm{P}$ & $\mathrm{N}$ \\
\hline $\mathrm{E}$ & $\mathrm{X}$ & 40 & 45 & 30 \\
\hline $\mathrm{T}$ & 60 & $\mathrm{X}$ & 55 & 45 \\
\hline $\mathrm{P}$ & 55 & 45 & $\mathrm{X}$ & 40 \\
\hline $\mathrm{N}$ & 70 & 55 & 60 & $\mathrm{X}$ \\
\hline
\end{tabular}

Table 6: Matrix A 
Matrix B:

\begin{tabular}{|c|c|c|c|c|}
\hline & $\mathrm{E}$ & $\mathrm{T}$ & $\mathrm{P}$ & $\mathrm{N}$ \\
\hline $\mathrm{E}$ & 1 & 0.67 & 0.82 & 0.43 \\
\hline $\mathrm{T}$ & 1.5 & 1 & 1 & 0.82 \\
\hline $\mathrm{P}$ & 1.2 & 1 & 1 & 0.67 \\
\hline $\mathrm{N}$ & 2.3 & 1.22 & 1.5 & 1 \\
\hline
\end{tabular}

Table 7: Matrix B

Matrix C: Orientation E-T-P-N

Find the Means for Matrix "C" Under Different Orientations:

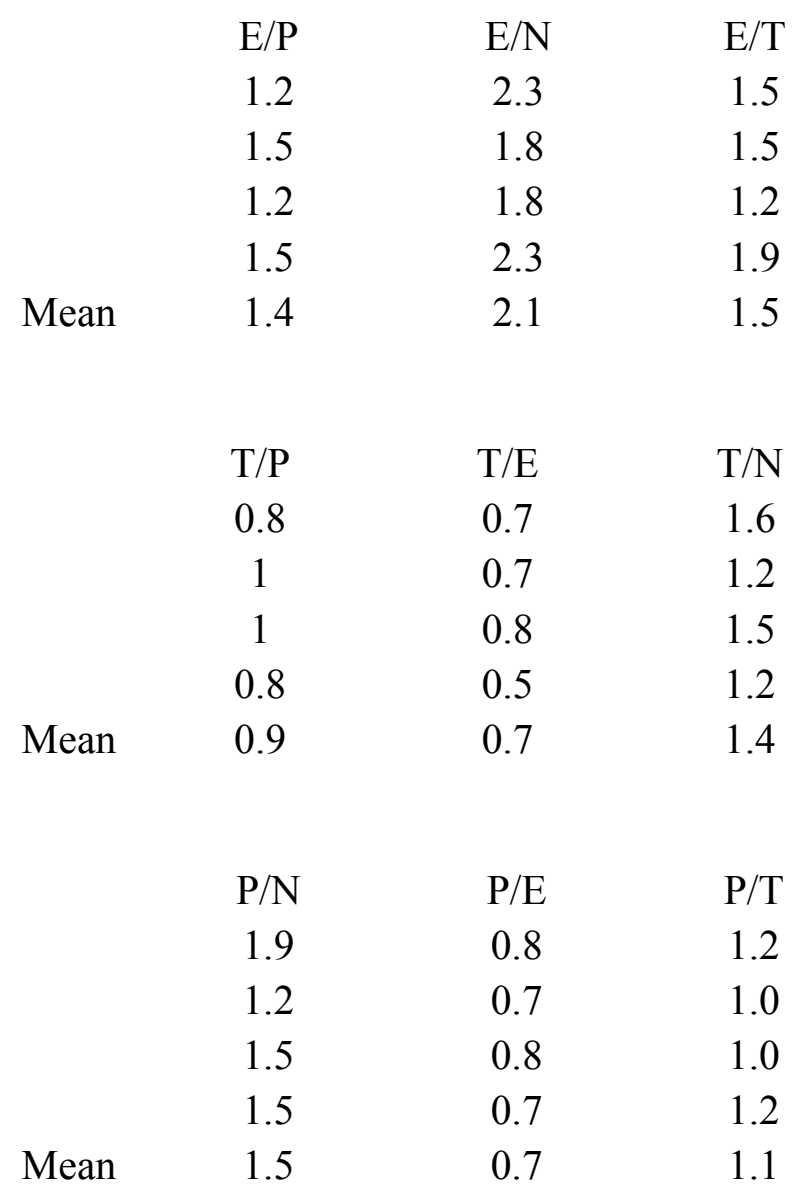




$\begin{array}{cccc} & \mathrm{N} / \mathrm{E} & \mathrm{N} / \mathrm{T} & \mathrm{N} / \mathrm{P} \\ & 0.4 & 0.6 & 0.5 \\ & 0.5 & 0.8 & 0.8 \\ & 0.6 & 0.7 & 0.7 \\ & 0.4 & 0.8 & 0.7 \\ \text { Mean } & 0.5 & 0.7 & 0.7\end{array}$

After we determined the means under different orientations, we are able to measuring the value of each perspective under different orientations.

Number of permutation $=4 !=4 * 3 * 2 * 1=24$

Measuring the value of each perspective Under Different Orientations:

\begin{tabular}{|c|c|c|c|c|c|}
\hline Orientation & & & & & SUM \\
\hline E T P N & 2.03 & 1.35 & 1.50 & 1 & 5.9 \\
\hline E T N P & 1.36 & 0.91 & 0.67 & 1 & 3.9 \\
\hline E P T N & 2.04 & 1.51 & 1.36 & 1 & 5.9 \\
\hline E P N T & 1.51 & 1.12 & 0.74 & 1 & 4.4 \\
\hline E N T P & 1.37 & 0.67 & 0.90 & 1 & 3.9 \\
\hline E N P T & 3.65 & 1.78 & 1.11 & 1 & 7.5 \\
\hline T E P N & 1.35 & 2.03 & 1.50 & 1 & 5.9 \\
\hline T E N P & 0.92 & 1.37 & 0.67 & 1 & 4.0 \\
\hline T P E N & 1.37 & 1.52 & 2.05 & 1 & 5.9 \\
\hline T P NE & 0.66 & 0.74 & 0.49 & 1 & 2.9 \\
\hline T N P E & 0.67 & 0.50 & 0.74 & 1 & 2.9 \\
\hline T N E P & 0.90 & 0.66 & 1.35 & 1 & 3.9 \\
\hline P E T N & 1.51 & 2.03 & 1.36 & 1 & 5.9 \\
\hline P E N T & 1.14 & 1.53 & 0.74 & 1 & 4.4 \\
\hline P T E N & 1.52 & 1.37 & 2.05 & 1 & 5.9 \\
\hline P T N E & 0.74 & 0.67 & 0.49 & 1 & 2.9 \\
\hline P N E T & 1.10 & 0.74 & 1.50 & 1 & 4.3 \\
\hline P N T E & 0.75 & 0.50 & 0.67 & 1 & 2.9 \\
\hline N E T P & 0.66 & 1.35 & 0.90 & 1 & 3.9 \\
\hline N E P T & 0.74 & 1.50 & 1.11 & 1 & 4.3 \\
\hline N T E P & 0.67 & 0.90 & 1.35 & 1 & 3.9 \\
\hline N T P E & 0.50 & 0.67 & 0.74 & 1 & 2.9 \\
\hline
\end{tabular}




\begin{tabular}{|l|l|l|l|l|l|} 
N P E T & 0.75 & 1.12 & 1.50 & 1 & 4.4 \\
N P T E & 0.50 & 0.74 & 0.67 & 1 & 2.9 \\
\hline
\end{tabular}

Table 8: Construction of the Orientation Table Before Normalized

Normalized Value:

\begin{tabular}{|c|c|c|c|c|c|}
\hline Orientation & Economical & Technical & Political & Environmental & SUM \\
\hline E T P N & 0.34 & 0.23 & 0.26 & 0.17 & 1.00 \\
E T N P & 0.35 & 0.23 & 0.17 & 0.25 & 1.00 \\
E P T N & 0.35 & 0.26 & 0.23 & 0.17 & 1.00 \\
E P N T & 0.35 & 0.26 & 0.17 & 0.23 & 1.00 \\
E N T P & 0.35 & 0.17 & 0.23 & 0.25 & 1.00 \\
E N P T & 0.48 & 0.24 & 0.15 & 0.13 & 1.00 \\
T E P N & 0.23 & 0.34 & 0.26 & 0.17 & 1.00 \\
T E N P & 0.23 & 0.35 & 0.17 & 0.25 & 1.00 \\
T P E N & 0.23 & 0.26 & 0.34 & 0.17 & 1.00 \\
T P NE & 0.23 & 0.25 & 0.17 & 0.35 & 1.00 \\
T N P E & 0.23 & 0.17 & 0.26 & 0.34 & 1.00 \\
T N E P & 0.23 & 0.17 & 0.35 & 0.26 & 1.00 \\
P E T N & 0.26 & 0.34 & 0.23 & 0.17 & 1.00 \\
P E N T & 0.26 & 0.35 & 0.17 & 0.23 & 1.00 \\
P T E N & 0.26 & 0.23 & 0.34 & 0.17 & 1.00 \\
P T N E & 0.26 & 0.23 & 0.17 & 0.35 & 1.00 \\
P N E T & 0.25 & 0.17 & 0.35 & 0.23 & 1.00 \\
P N T E & 0.26 & 0.17 & 0.23 & 0.34 & 1.00 \\
N E T P & 0.17 & 0.35 & 0.23 & 0.26 & 1.00 \\
N E P T & 0.17 & 0.35 & 0.26 & 0.23 & 1.00 \\
N T E P & 0.17 & 0.23 & 0.34 & 0.25 & 1.00 \\
N T P E & 0.17 & 0.23 & 0.26 & 0.34 & 1.00 \\
N P E T & 0.17 & 0.26 & 0.34 & 0.23 & 1.00 \\
N P T E & 0.17 & 0.26 & 0.23 & 0.34 & 1.00 \\
\hline MEAN & 0.26 & 0.25 & 0.25 & 0.24 & \\
\hline ST.DV & 0.08 & 0.06 & 0.07 & 0.07 & \\
\cline { 1 - 3 } Table 9: Construction of the Orientation Table After Normalized
\end{tabular}

Table 9: Construction of the Orientation Table After Normalized

From the Normalized Value we are able to calculate the inconsistency.

Inconsistency $=(1 / 4)[(0.08)+(0.06)+(0.07)+(0.07)]=0.069$ 
The inconsistency is below the rejection limit 0.1 .

\subsubsection{Root Sum of the Variance (RSV)}

(RSV) method in measuring the inconsistency was introduced by Abbas.

$$
\text { Inconsistency }(\mathrm{RSV})=\sqrt{\sum_{i=1}^{n} \sigma_{i}^{2}}
$$

Abbas' approach to measure the inconsistency is to apply the root-sum of the variances (RSV) instead of the sum of the standard deviations [117]. According to Kocaoglu, if the variances were higher than threshold value of 0.10 , discrepancies are explained to the respondents and new measurements are needed [105]. Nevertheless, the respondents at the end of each measurement session should be given the opportunity to modify their comparisons. Even though they were not given any information concerning the variance value, the respondents typically accepted the results without modification when variance was small, opted for a new measurement when it was high. The following example shows how the inconsistency can be measured within the perspective level, using the same input data that we used in the first example.

Determining inconsistency using the Root Sum of the Variance (RSV) method.

$$
\begin{array}{lcccc}
\multicolumn{4}{r}{\text { Inconsistency }(\mathrm{RSV})=\sqrt{\sum_{i=1}^{n} \sigma_{i}^{2}}} & \multicolumn{2}{c}{(8)} \\
\text { MEAN } & \text { Economical } & \text { Technical } & \text { Political } & \text { Environmental } \\
\text { MEAN } & 0.26 & 0.25 & 0.25 & 0.24 \\
\text { d. Deviation } & 0.08 & 0.06 & 0.07 & 0.07 \\
\text { Variance } & 0.006 & 0.004 & 0.005 & 0.005 \\
& & & \\
\multicolumn{2}{l}{\text { Inconsistency }=\sqrt{(0.006)+(0.004)+(0.005)+(0.005)}}
\end{array}
$$

$\begin{array}{lllll}\text { MEAN } & 0.26 & 0.25 & 0.25 & 0.24\end{array}$

$\begin{array}{lllll}\text { Std. Deviation } & 0.08 & 0.06 & 0.07 & 0.07\end{array}$

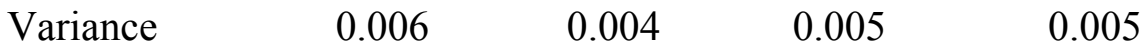




$$
\text { Inconsistency }=0.141(\mathrm{RSV})
$$

Using table 4.1 provided by Dr. Abbas for $n=4$, this RSV value corresponds to $\sigma=$ 0.094. This value is somewhat high considering $n=4$. Therefore, it is recommended for the DM to revise the pairwise comparison assignments.

For $n n=4$, the $10 \%$ fixed limit corresponds to $\sigma=0.03$

\subsection{Disagreements Analysis}

Disagreements amongst experts can show different quantifications and different perspectives to the same analysis. There is group disagreement if the disagreement exceeds a value of 0.10 and a value of 0 would imply complete agreement among the experts [125]. Experts have different backgrounds and experiences that most likely will increase the level of disagreements amongst them. However, Acceptable disagreement has a value of 0.1 or less. According to Kocaoglu disagreement can be measuring by the following equations [126]:

Let $m$ be the number of experts and $n$ be the number of decision variables.

$r_{i k}$ be mean relative value of the $i^{t h}$ decision variable for $k^{t h}$ expert.

Group relative value of the $i^{t h}$ decision variable for $m$ experts is

$$
R_{i}=\sum_{k}^{m} r_{i k} \cdot \frac{1}{m} \quad \text { for } \mathrm{i}=1,2, \ldots, \mathrm{n}
$$

The standard deviation of the relative value of the $i^{\text {th }}$ decision variable is:

$$
\mathrm{STDi}=\sqrt{\frac{1}{m}} \sum_{k=1}^{m}\left(R_{i}-r_{i k}\right)^{2}
$$


Disagreement for $m$ experts is calculated as the mean standard deviation of the group $n$ relative values of variables.

$$
\mathrm{D}=\frac{1}{n} \sum_{i=1}^{n} S T D i
$$

Another common approach has been used in several studies to measure the disagreement levels is the intraclass correlation coefficient (ICC) [127][128]. The intraclass correlation coefficient (ICC) is claimed to be suitable method for the assessment of observer agreement [130]. The ICC is supported by the analysis of variance (ANOVA) [131]. Higher ICC values achieved when applied to a more heterogeneous population as compared with a more homogeneous one despite similar levels of agreement [127]. ICC assesses agreement by comparing the variance of different measurements of the same subject made by different observers with the total variance across all measurements and subjects [131]. These variances are derived from ANOVA, and the ANOVA model (one way or two way with random or fixed effects) depends on the agreement study design. The ICC ranges from 0 to 1 and ICC equal 0 means no agreement on the other hand ICC equal 1 means perfect agreement. However, the ICC value can also be negative. The interpretation of negative ICC values remains unclear [129]. Nevertheless, Burdock proposed that ICC values of 0.75 signify good agreement [127]. Based on Terry and Mae study the 95\% confident interval of the ICC estimate, values less than 0.5 , indicative of poor agreement, ICC value between 0.5 and 0.75 , indicative of moderate agreement, ICC value between 0.75 and 0.9 , indicative of good agreement and ICC value greater than 0.90 indicative of excellent agreement [128]. 
According to Shrout and Fleiss (1979) formula that use for calculating ICC as following [129]:

$$
\mathrm{ICC}=\frac{M S_{R}-M S_{E}}{M S_{R}+(K-1) M S_{E}+\frac{k}{n}\left(M S_{C}-M S_{E}\right)}
$$

Where:

$\mathrm{MSR}=$ mean square for rows.

$\mathrm{MSE}=$ mean square for error.

$\mathrm{MSC}=$ mean square for columns.

$\mathrm{n}=$ number of subjects.

$\mathrm{k}=$ number of raters/measurements.

Different studies have used the value of $10 \%$ to control the disagreement and according to these researches if the expert panels disagreement acceded the 0.10 value there are several steps that should be taken to treat this disagreement. If the variances were higher than threshold value of 0.10 , discrepancies are explained to the respondents and new measurements are needed. However, if second round has been taken and the threshold value still remains higher than 0.10 , the respondent who led to higher disagreement should be taken out of the panel [105][120]. In addition, different studies used Hierarchical agglomerative clustering (HAC) method to measure and interpret the disagreement among the experts. The objective is for clustering to discover natural groupings. Hierarchical clustering was defined as, obtains homogeneous clusters of cases based on measured characteristics. In other words, to identify the similarities amongst the experts' evaluation in cluster and gathering new cluster by comparing it with the old one. 
Repeat the same process until one cluster will be left out [134]. Moreover, F-test can provide more information if there is significant disagreement among the experts [133]. The Null Hypothesis (H0) for the F-test is that there is a significant disagreement among the expert panel judgment quantification, or $\mathrm{H} 0$ : ric $=0$. The F-value of a pairwise comparison procedure is calculated and compared against the F-critical value of the procedure to determine whether the Null Hypothesis can be rejected or not. If we reject the Null Hypothesis, this means that there is no a significant disagreement in the experts' judgments [105].

\subsection{Desirability Curve}

Development of a desirability curve is a method to convert either qualitative or quantitative data used for measuring a decision element to a scaled quantitative value [97]. In this research desirability curves will be used to identify how desirable or valuable a metric is for a decision maker. There are several ways to determine the value of a metric. These include standard gamble, constant-sum method, and graphically representing the relative value of the metric [101]. Calculating the importance of each factor through the perspectives with respect to the mission can be done using the following equation:

$$
S_{n, j n}^{M}=\sum_{n=1}^{N} \sum_{j n=1}^{J n}\left(P_{n, j n}^{M}\right)\left(F_{n, j n}^{P}\right)
$$

Where:

$S_{n, j n}^{M}$ : Relative value of the $j n^{\text {th }}$ factor under the $n^{\text {th }}$ perspective with respect to the mission (Offshore Oil Project Evaluation). 
$\boldsymbol{P}_{\boldsymbol{n}, \boldsymbol{j} \boldsymbol{n}}^{\boldsymbol{M}}$ : Relative value of the $j n^{t h}$ success attribute under the $n^{\text {th }}$ perspective with respect to the mission. $\mathrm{n}=1,2,3, \ldots \mathrm{N}$. $\boldsymbol{F}_{\boldsymbol{n}, j \boldsymbol{n}}^{\boldsymbol{P}}$ : Relative contribution of the $j n^{\text {th }}$ factor under the $n^{\text {th }}$ perspective. jn= $1,2,3, \ldots \mathrm{N}$. However, after having the importance of each factor relative to the mission using the HDM, the determination of the over all offshore oil project score will be given by multiplying the global importance of each factor by its desirability value and making the total summation that can be computed using the following mathematical representation [99]:

$$
\text { Project Score }=\sum_{n=1}^{N} \sum_{j n=1}^{J n}\left(S_{n, j n}^{M}\right)\left(D_{n, j n}\right)
$$

$S_{n, j n}^{M}$ : Relative value of the jnth factor under the nth perspective with respect to the Project score.

$D_{n, j n}$ : Desirability value of the performance measure corresponding to the $j n^{t h}$ success attribute under the $n^{\text {th }}$ perspective.

\subsection{Sensitivity Analysis}

Sensitivity analysis method will be used to analyze the impacts of potential changes in the values at any level of the model. This method has been used widely in several studies [105][120]. In HDM, the local contributions of decision elements at one level to decision elements on the next higher level, derived from different judgment quantification methods, are supplied as intermediate input to the hierarchical model. Decisions obtained by evaluating the final ranking of alternatives are based on the local contributions. However, values of the local contributions are seldom known at a $100 \%$ 
confidence level and are subject to variations as the environment changes. Besides, the various pairwise comparison scales and judgment quantification techniques employed in HDM usually yield different local contribution values, and thus different results for the same problem [135] and various group-opinion combining methods may change the current decision [136][137]. Therefore, the solution of a problem is not complete with the mere determination of a rank order of decision alternatives. Sensitivity analysis (SA) will be conducted with the HDM results to develop an overall strategy to meet the various contingencies [138]. The main objective of using the sensitivity analysis is to illustrate how strong the decisions and the results providing form the model [120]. It is performed to test and assure the robustness of both the model and the results [134]. Moreover, using the sensitivity will give a clear picture of how each level of the model and its components relate to each other [121]. In cases where the model's output is the ranking of different alternatives, the sensitivity analysis is specially useful to tell if and how much that original ranking would change due to changes in the priorities of model's components [98].

The preferred information associated with the decision-making on the evaluation components varies from person to person. Meanwhile, different relative criteria weights have a significant effect on the selection of the most appropriate alternatives. The ranking results are very sensitive to the changes in attribute weights. The presence of different attribute weights may result in different ranking orders [139][132]. Often data in multiple criteria decision-making (MCDM) problems are not exact and changeable. Therefore, an important step in many applications of multiple criteria decision-making is to perform 
sensitivity analysis according to the input data [140]. In order to implement sensitivity analysis multiple scenarios can be used to test how much the ranking would be altered in a particular setting. According to Chen and Kocaoglu conducting sensitivity analysis in multiple scenarios will calculate the tolerance of the model to changes [101]. This approach has been implemented in several dissertations [98][105][117] [121].

The original ranking of the model will not be changed if:

$$
\lambda \geq P_{i}^{c} \cdot \lambda^{C}
$$

For the perturbation $P_{l *}^{C}$ where

$$
-C_{l *}^{c} \leq P_{l *}^{c} \leq 1-C_{l *}^{c}
$$

and

$$
\lambda=C_{r}^{A}-C_{r+n}^{A}
$$

and

$$
\lambda^{C}=C_{r+n, l}^{A-C}-C_{r l *}^{A}-\sum_{l=1, l \neq l *}^{L} C_{r+n, l *}^{A-C} \cdot \frac{C_{l}^{C}}{\sum_{l=1, l \neq l *}^{L} C_{l}^{O}}+\sum_{\mathrm{l}=1, l \neq l *}^{L} \frac{C_{r l}^{A-O}}{\sum_{l=1, l \neq l *}^{L} C_{l}^{O}}
$$

The allowance range of perturbations $C_{i}^{C}$ to maintain the original ranking is given by:

$$
\begin{aligned}
& {\left[\delta_{i-}^{C}, \delta C_{i+}^{O}\right]} \\
& 1 /\left|\delta_{i+}^{C}, \delta_{i-}^{C}\right|
\end{aligned}
$$

Nevertheless, scenario method has been used in this research to assess the robustness of the model and its behavior under different and extreme cases. Under different scenario one factor will be boosted to the max score to test the effect of that factor is if it turned out to be the most important factor in reality. 


\section{CHAPTER 5: MULTI CRITERIA DECSION MAKING METHODOLOGIES}

The multi-criteria decision-making (MCDM) method is a rational mathematical approach that is widely used by the decision makers to help them in evaluating and selecting the appropriate alternative [141][142][143]. The methods generally have been developed in order to facilitate the selection of an alternative with respect to multiple criteria [144]. In general to achieve the expected result using MCDM approaches, decision makers collect and integrate the required data from the sources. MCDM relies on the availability of several components, including databases and other data resources, a data integration component, a decision support tool and a tool for presenting the results. The figure below shows the processes of applying MCDM [145].

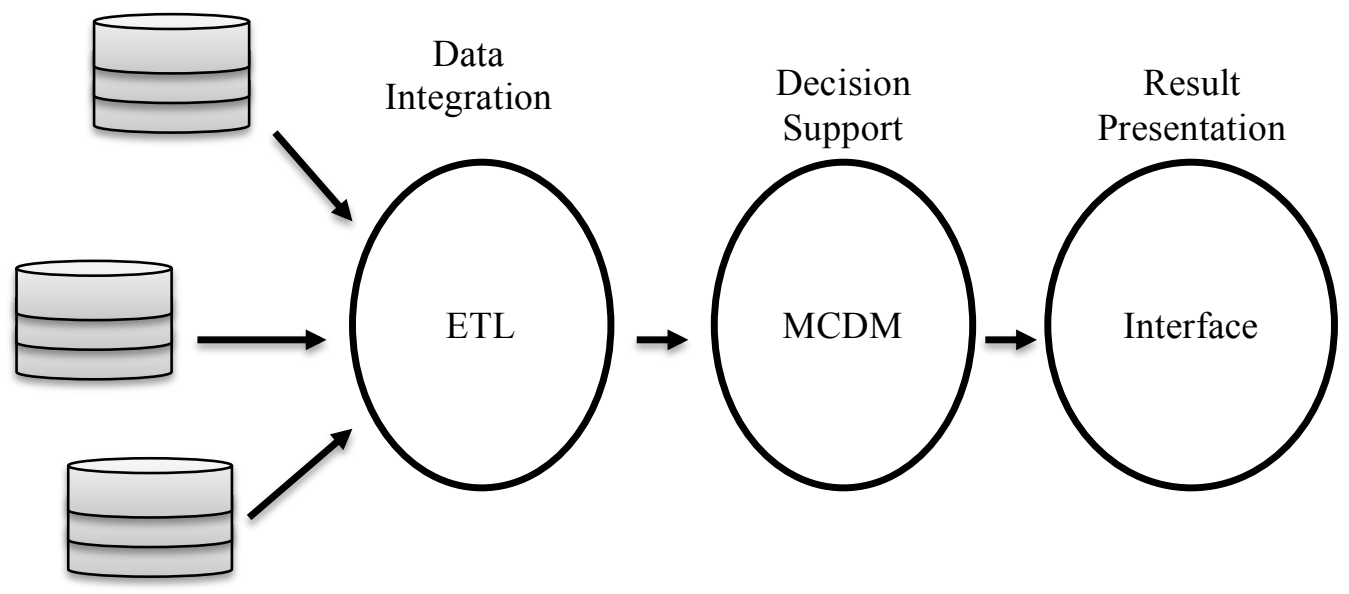

Figure 20: Processes of Applying Multi-Criteria Decision-Making 
MCDM methods provide mathematical models to weigh criteria, score alternatives and synthesize the final results. The process of decision making with several criteria is characterized by the following phases [146]:

- Objective identification.

- Criteria development.

- Alternative generation, evaluation and selection.

- Implementation and monitoring [147].

Nevertheless, the multi-criteria decision-making approaches have been integrated with many other tools and techniques in the last few decades. The integrations are mainly with the aim of strengthening and empowering MCDM methods to address various decision problems more effectively [144]. There are currently several MCDM approaches in use. The more frequently employed are listed in the table below.

\begin{tabular}{|c|c|c|c|}
\hline No & MCDM & Definition & References \\
\hline 1 & $\begin{array}{l}\text { Analytical Hierarchy } \\
\text { Process (AHP) }\end{array}$ & $\begin{array}{l}\text { AHP was proposed by Saaty in } 1980 \text { as a } \\
\text { method that has been used to solve a wide } \\
\text { range of socio-economic decision making } \\
\text { problems. AHP is a comprehensive } \\
\text { framework, which is designed to cope with } \\
\text { the intuitive, the rational, and the irrational. } \\
\text { In general, AHP has three steps: } \\
\text { 1. Structuring the hierarchy between } \\
\text { criteria and alternatives. } \\
\text { 2. Producing pair-wise comparison } \\
\text { matrix. } \\
\text { 3. Calculating weight values of } \\
\text { criteria and scores of alternative } \\
\text { performance. }\end{array}$ & $\begin{array}{l}{[147][148]} \\
{[150][149]} \\
{[151][152]}\end{array}$ \\
\hline 2 & Analytical Network & The ANP, also introduced by Saaty, is a & {$[153][154]$} \\
\hline
\end{tabular}




\begin{tabular}{|c|c|c|c|}
\hline & Process (ANP) & $\begin{array}{l}\text { generalization of the AHP. ANP allows for } \\
\text { complex interrelationships among decision } \\
\text { levels and attributes. The } \\
\text { ANP feedback approach replaces } \\
\text { hierarchies with networks in which the } \\
\text { relationships between levels are not easily } \\
\text { represented as higher or lower, dominant or } \\
\text { subordinate, direct or indirect. For } \\
\text { instance, not only does the importance of } \\
\text { the criteria determine the importance of the } \\
\text { alternatives in a hierarchy, but also the } \\
\text { importance of the alternatives may have an } \\
\text { impact on the importance of the criteria. }\end{array}$ & $\begin{array}{l}{[155][156]} \\
{[157]}\end{array}$ \\
\hline 3 & $\begin{array}{l}\text { Preference Ranking } \\
\text { Organization Method } \\
\text { for Enrichment of } \\
\text { Evaluations } \\
\text { (PROMETHEE) }\end{array}$ & $\begin{array}{l}\text { PROMETHEE was introduced by Brans in } \\
\text { 1982. The method has been in several } \\
\text { applications, such as tourism, management, } \\
\text { logistics, and financial applications. }\end{array}$ & {$[158][159]$} \\
\hline 4 & $\begin{array}{l}\text { Multi-criteria } \\
\text { optimization and } \\
\text { compromise solution } \\
\text { or (VIKOR) }\end{array}$ & $\begin{array}{l}\text { The VIKOR is one of MCDM methods to } \\
\text { solve multi criteria problems. VIKOR aims } \\
\text { to determine a compromise solution for } \\
\text { ranking and selection considering } \\
\text { conflicting criteria. The compromise } \\
\text { solution is a feasible solution, which is the } \\
\text { closest to the ideal solution. }\end{array}$ & $\begin{array}{l}{[160][161]} \\
{[162][163]} \\
{[164]}\end{array}$ \\
\hline 5 & $\begin{array}{l}\text { Elimination and } \\
\text { Choice Expressing } \\
\text { Reality or } \\
\text { (ELECTRE) }\end{array}$ & $\begin{array}{l}\text { The ELECTRE approach was introduced } \\
\text { by Benayoun, Roy and Sussman in } 1968 . \\
\text { There are different methods of using } \\
\text { ELECTRE I, II, III, IV, IS and TRI } \\
\text { methods. All ELECTRE methods appear to } \\
\text { be similar in describing the concepts but } \\
\text { each approach can be used to solve a } \\
\text { specific type of problem. }\end{array}$ & $\begin{array}{l}{[165][166]} \\
{[167][168]} \\
{[169][170]} \\
{[171]}\end{array}$ \\
\hline 6 & $\begin{array}{l}\text { Best Worst Method } \\
\text { (BWM) }\end{array}$ & $\begin{array}{l}\text { Compared to other MCDM approaches, } \\
\text { BWM requires less data, as it does not } \\
\text { need a full pairwise comparison matrix. }\end{array}$ & $\begin{array}{l}{[172][173]} \\
{[174]}\end{array}$ \\
\hline 7 & Technique for Order & The TOPSIS method, which was proposed & {$[175][176]$} \\
\hline
\end{tabular}




\begin{tabular}{|c|c|c|c|}
\hline & $\begin{array}{l}\text { of Preference by } \\
\text { Similarity to Ideal } \\
\text { Solution (TOPSIS) }\end{array}$ & $\begin{array}{l}\text { by Hwang and Yoon(1981), is one of the } \\
\text { best known classical MCDM. It is based on } \\
\text { the concept that the chosen alternative } \\
\text { should have the shortest distance from the } \\
\text { positive ideal solution (PIS), and the } \\
\text { farthest from the negative ideal solution } \\
\text { (NIS). }\end{array}$ & \\
\hline 8 & $\begin{array}{l}\text { Decision Making Trial } \\
\text { and Evaluation } \\
\text { Laboratory } \\
\text { (DEMATEL) }\end{array}$ & $\begin{array}{l}\text { DEMATEL was introduced by the Science } \\
\text { and Human Affairs Program of the Battelle } \\
\text { Memorial Institute of Geneva in the 1970s } \\
\text { to resolve the complicated and intertwined } \\
\text { problem group. It has been widely used in } \\
\text { many fields such as supply chain and } \\
\text { service quality. The DEMATEL is an } \\
\text { effective approach for analyzing } \\
\text { relationships between factors of concern } \\
\text { with respect to the type and severity. }\end{array}$ & $\begin{array}{l}{[177][178]} \\
{[179][180]} \\
{[181][182]} \\
{[183]}\end{array}$ \\
\hline 9 & $\begin{array}{l}\text { Hierarchical Decision } \\
\text { Model (HDM) }\end{array}$ & $\begin{array}{l}\text { HDM was introduced by Cleland and } \\
\text { Kocaoglu. The model can be used as a } \\
\text { network of relationships among decision } \\
\text { hierarchies, where subjective judgments } \\
\text { are provided in a comprehensive } \\
\text { evaluation. The HDM has been adopted by } \\
\text { decision makers in various industries. }\end{array}$ & $\begin{array}{l}{[107][108]} \\
{[109][110]}\end{array}$ \\
\hline
\end{tabular}

Table 10: Multi-criteria decision-making approaches

\subsection{Decision Making Approaches in Oil Industry}

Oil sector is characterized by high investment decisions and most of these decisions can be seen as a balance between the costs and profits. However, this industry is closely associated with high uncertainties, risks as well as opportunities, which raises the complexity of the decision-making processes. Oil and Gas companies use different techniques and methods to improve performance and make the right decisions [184] in 
particular, net present value (NPV) calculations, discounted cash-flow analysis, Monte Carlo simulation, portfolio theory, decision-tree analysis, and option theory [185][186]. Nevertheless, decision-tree analysis and Monte Carlo simulation are the most appropriate approaches that have been used in $O \& G$ industry to support the investment decisions. The following is a brief introduction of these methods as well as their strengths and weaknesses.

\subsubsection{Decision Trees Analysis (DTA)}

The decision tree methodology is one of the most commonly used data mining methods [187][188][189] and it is widely applied to investment decision-making in Oil and Gas industry [206]. Decision tree provides a clear understanding to the problem and encourages the decision-maker to consider the entire sequential course of action, before the initial decision [189]. The decision tree makes use of conditional probability to determine the best strategy to attain a certain target [191]. It is a method for combining profitability estimates of risk and uncertainty to yield a risk-adjusted decision criterion [189]. Decision tree analysis is sable to identify several scenarios within the framework of management ability to improve the project viability and profitability, tied with their probabilities of success. It also helps analysts form a balanced picture of risks, their associated rewards and possible courses of action [191]. In oil industry decision tree focus on managerial decisions such as whether to drill additional wells, or to develop the field or not [192]. The following is a sample example shows how DTA could be used in oil industry. 
The initial exploration activities of Offshore Oil Company (A) have led to discover a hydrocarbon filed. However, the company has a little information of the size of the reserves and the decision makers should make a decision what size of platform the company should build to start the production. Installing the wrong size platform would be an expensive mistake and will cost the company a huge amount of money.

There are three different scenarios.

- It would be optimal for the company to install a large platform.

- Installing a small platform would be more appropriate decision.

- The company prefers to wait and obtain more information on the reserves before making decision.

The probability of finding large reserve is $60 \%$ and that of finding a small reserve would be about $40 \%$. Moreover, installing a large platform when the reserves prove to be large generates an NPV of 170 and 110 for small field. Moreover, installing a small platform when the reserves prove to be small generates an NPV of 130 and 150 for large field. NPV would be 165 for the large field if additional information is obtained and 125 for the small. 


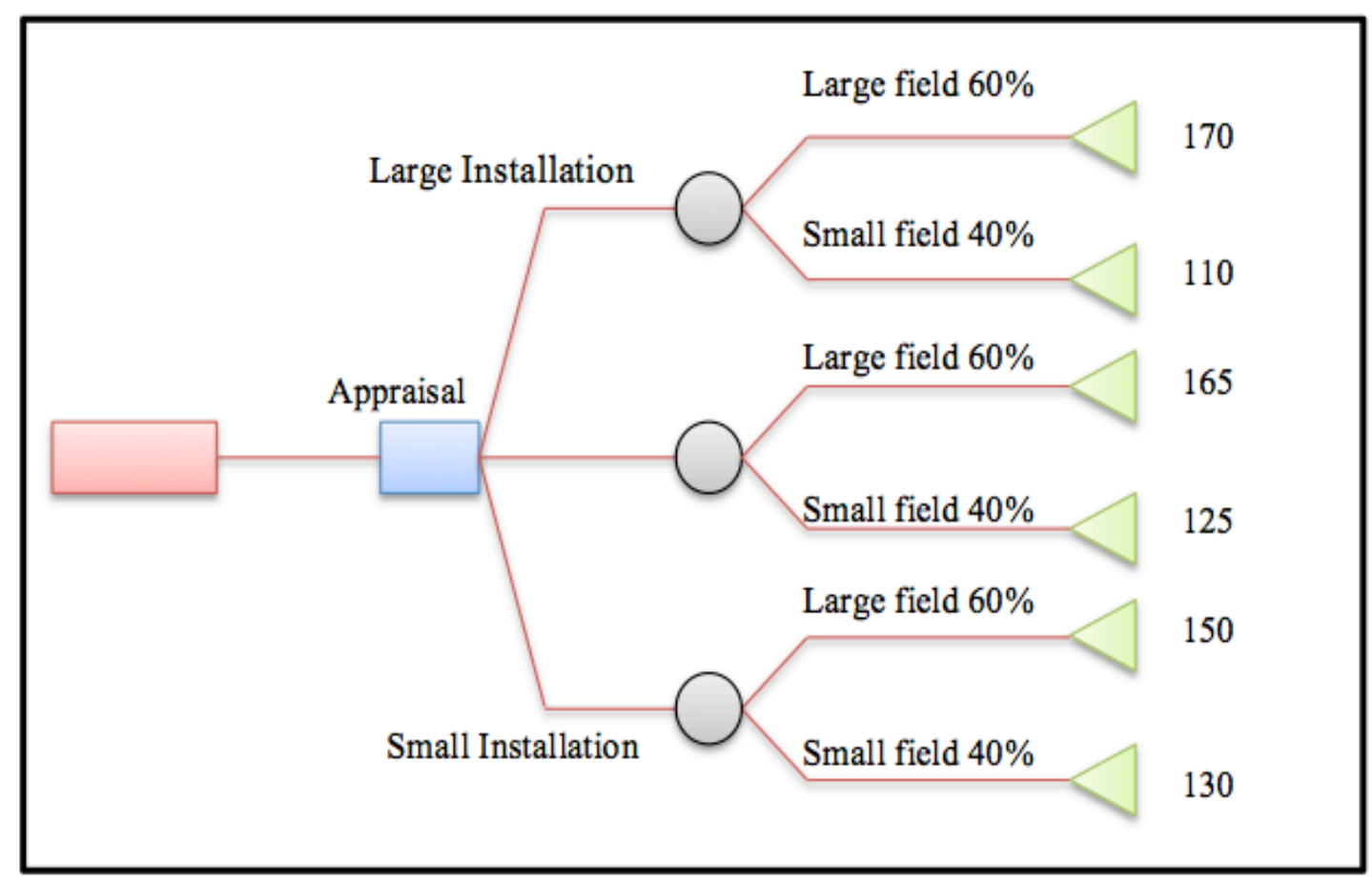

Figure 21: DTA Implementation in Oil Industry

In order for the decision maker to make a decision they have to calculate the profit for each scenario.

$$
\begin{aligned}
& (170 * 0.6)+(110 * 0.4)=146 \\
& (165 * 0.6)+(125 * 0.4)=149 \\
& (150 * 0.6)+(130 * 0.4)=142
\end{aligned}
$$

Based on the calculation, the best decision would require additional reserve's information and implement seismic test before choosing the size of the platform. Furthermore, decision tree analysis can be combined with other decision techniques to analyze many investment projects particularly when uncertainty is incorporated in the decision at discrete points [191]. In reality, each tool has strengths and weaknesses 
[193][190] and the following is the highlighting advantage and disadvantage of using decision tree analysis.

\subsubsection{Strengths of Using Decision Tree Analysis (DTA)}

1. Decision tree can state out the problem clearly and it is easy to modify a decision tree as new information becomes available. Set up a decision tree to compare how changing input values affect various decision alternatives. Standard decision tree notation is easy to adopt [194].

2. It can be fit into project management tools. For example, the decision tree method can help evaluate project schedules [195] and decision trees can handle both nominal and numerical attributes and is considered as a nonparametric method [196].

3. Decision trees are capable of handling datasets that may have errors and missing values [194].

\subsubsection{Limitations of Decision Tree Analysis (DTA)}

1. Big and complex decision trees require professional users and experts to solve it. Computing probabilities of different possible branches, determining the best split of each node, and selecting optimal combining weights to prune algorithms contained in the decision tree are complicated tasks that require much expertise and experience.

2. Decision trees, while providing easy to view illustrations, can also be unwieldy. Even data that is perfectly divided into classes and uses only simple threshold 
tests may require a large decision tree. Large trees are not intelligible, and pose presentation difficulties.

3. The complexity in creating large decision trees mandates people involved in preparing decision trees having advanced knowledge in quantitative and statistical analysis. This raises the expenditure and cost.

4. Another limitation of the decision tree method is that when evaluating a project with this approach, subjective probabilities and a risk-adjusted discount rate are usually applied. Although it may capture both time and risk preference of the investor, it is not appropriate when many options are present in the investment evaluation [191].

5. Naturally, decision makers prefer less complex decision trees, since they may be considered more comprehensible. Furthermore, according to Breiman (1984) the tree complexity has a crucial effect on its accuracy [194].

6. Irrelevant attributes may affect the construction of a decision tree adversely and a sub-tree can be replicated several times.

7. It is true that decision trees can handle missing values but this also has a disadvantage. Handling the missing data requires a lot of computation which is a drawback by means of computational time.

8. One of the important limitation of using decision tree analysis in $O \& G$ industry is that DTA method mainly estimates EV. Its criterion assumes that the decisionmaker is only interested in monetary gain [197]. However, when a company is deciding how best to decommission an offshore production facility, for example, 
they will want to consider other factors such as corporate image and environmental concerns. All these attributes, like the monetary returns, would have some degree of risk and uncertainty associated with them [190].

\subsubsection{Monte Carlo Simulations}

Monte Carlo approach was introduced by Metropolis and Ulam in 1949 [198]. It is a numerical experimentation technique to obtain the statistics for the output variables of a system model given the statistics for the input variables. The method is considered as one of the powerful tools in risk analysis, and evaluating all kinds of uncertainties [198][199]. Monte-Carlo simulation method is also called Random simulation or Random sampling technology. In recent decades, with the development of computer technology, this method has been developing rapidly and widely used. At present, Monte-Carlo simulation has been applied to physics, medicine, materials science, agriculture, transportation, management science, social science and many other areas [199]. In the field of the project management Monte Carlo simulation is used primarily in project risk management to estimate the risks associated with the time and the cost of the project [200][201]. The use of Monte Carlo simulation allows not only to find the most likely time or budget of the project, but also to compute their probability of occurrence of any value specified [202]. A summary of the steps used in performing a Monte Carlo simulation are shown in the following pattern [202]:

1. Define an input domain.

2. Generate input variables randomly from the input domain. 
3. Perform a deterministic computation on the input variables.

4. Gather the results.

The awareness of using Monte Carlo simulation in O\&G industry has increased in the past few years. Decision maker in O\&G industry rely on Monte Carlo simulation to generate estimates of prospect reserves as well as the probability of the projects [190]. The equation below shows how the Monte Carlo simulation could calculate the NPV for a simplified oil project with a life of $n$ years, and using a discount rate $i$ [192].

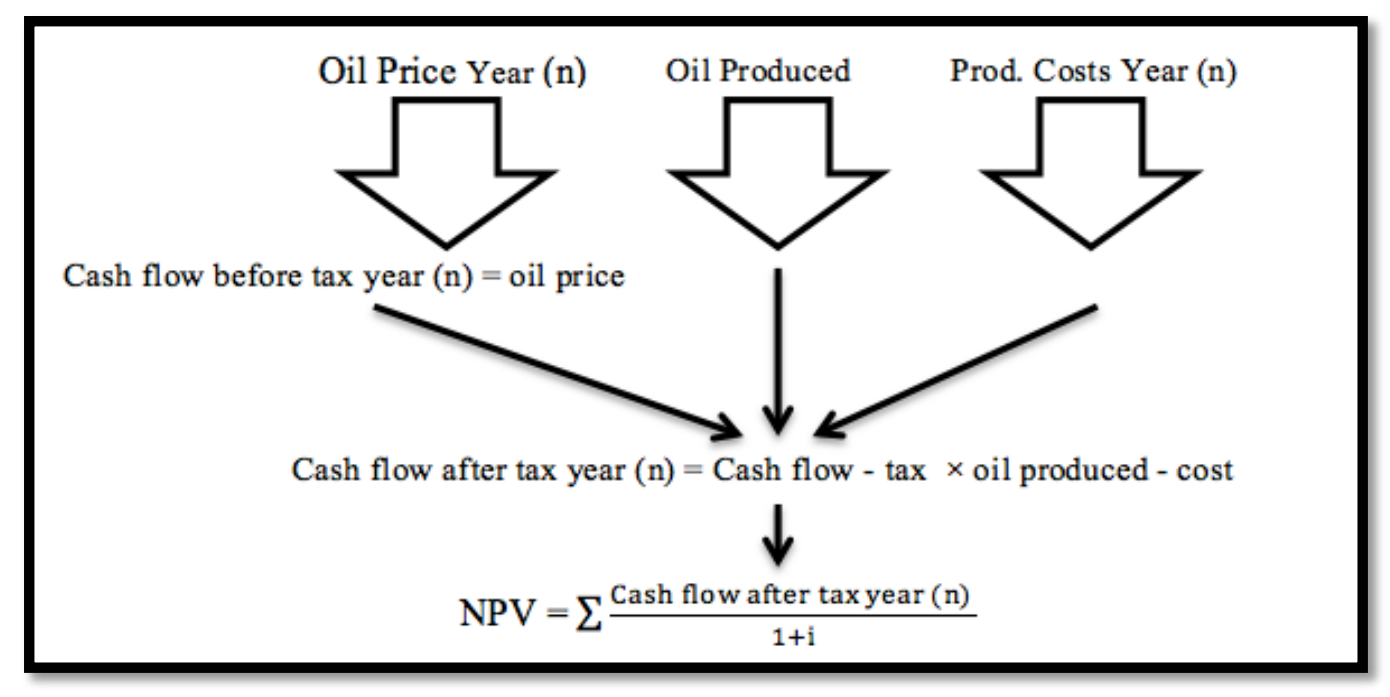

Figure 22: Monte Carlo Equation to Calculate the NPV for a Simplified Oil Project

\subsubsection{Strengths of Using Monte Carlo Simulations}

1. Monte Carlo Simulations allows the analyst to describe risk and uncertainty as a range and distribution of possible values for any unknown factor [190].

2. Monte Carlo Simulations allows the analyst to identify factors that have the most significant effect on the resulting values of profit and it can fit with other 
approaches such as sensitivity analysis to understand the impact of these factors further [190].

\subsubsection{Limitation of Using Monte Carlo Simulations}

1. One of biggest limitation of using Monte Carlo simulations in oil industry is that a Monte Carlo simulation is not able to assess factors that affect the oil industry such as oil price, political factors and environmental factors and it is mainly used to calculate the NPV and the profitability of the project [190].

2. Appling Monte Carlo simulations to solve decision making problems is quite complicated and requires a large amount of data for analysis and many factors for consideration. Moreover, the decision maker should be familiar with it in order to solve the problem.

3. Appling Monte Carlo simulation requires professional users and experts to solve it and analyze the results.

\subsection{Why the HDM Approach is Implemented in this Research}

Decision-making could be based on an economic analysis that involves the assessment of revenues and costs, potentially materializing in the future as a result of investments made at the current time. However, decision-making in the oil and gas projects need to be evaluated from extensive points of view since they are influenced by technical, environmental, financial, economical, geopolitical and other perspectives. The investment decision in the oil industry has to be quick and continuous based on the available information [186]. Using the hierarchical decision model (HDM) approach to 
make decisions on oil industry has many advantages, and the following is a summary of these benefits.

1. Other methods are mainly focused on economic aspects such as NPV and return on investment. However, the HDM provides a comprehensive evaluation to all factors that impact oil projects such as technical, environmental, financial, economical, and geopolitical.

2. The HDM is a great method to handle different scenarios, and it can be conducted with other tools, such as sensitivity analysis, to provide a clear picture of the problem for decision makers.

3. Decision making in the oil industry is associated with a higher level of complexity and requires large amounts of information and many qualified people who have significant experience to provide their evaluation in the decision making process. Using a HDM in oil industry requires qualified people from all levels that can increase the interaction between top level decision makers with that of technicians and engineers from different departments and divisions.

4. Using the HDM, oil companies can make quick and continuous decisions based on the evaluation results provided by their experts and engineers.

5. In general, the HDM is a great tool to conduct the academic researcher's standpoint of real in-field practices by involving experts in this process. Moreover, the HDM is a great way to translate qualitative data into quantitative information that will make it much easier for decision makers to analyze the problem and define solutions. 


\section{CHAPTER 6: MODEL DEVELOPMENT AND PANELS FORMAT}

This section introduces the initial model of the research as well as the definition of each component of the model. Moreover, this chapter presents the required experiences, expertise and area of interest for each panel.

\subsection{Initial Model}

The decision model is based on the comprehensive literature review that was described in the previous sections as well as based on experts' feedbacks and recommendations through the third independent study. Five perspectives have been identified in order to asses and measure the offshore oil projects to improve the investment decision. These perspectives are financial, technical, politics, environmental and safety. Under each perspective there are multiple criteria that are linked to each other with complex processes and unique challenges. An assessment of these challenges associated with offshore oil projects lead to reduced risk and an increased probability of success. Prospects in offshore petroleum projects encounter several challenges such as, safety performance, production performance, geologic and subsurface reservoir uncertainty, government stability, oil spills. Figure 23 illustrates the research model. 


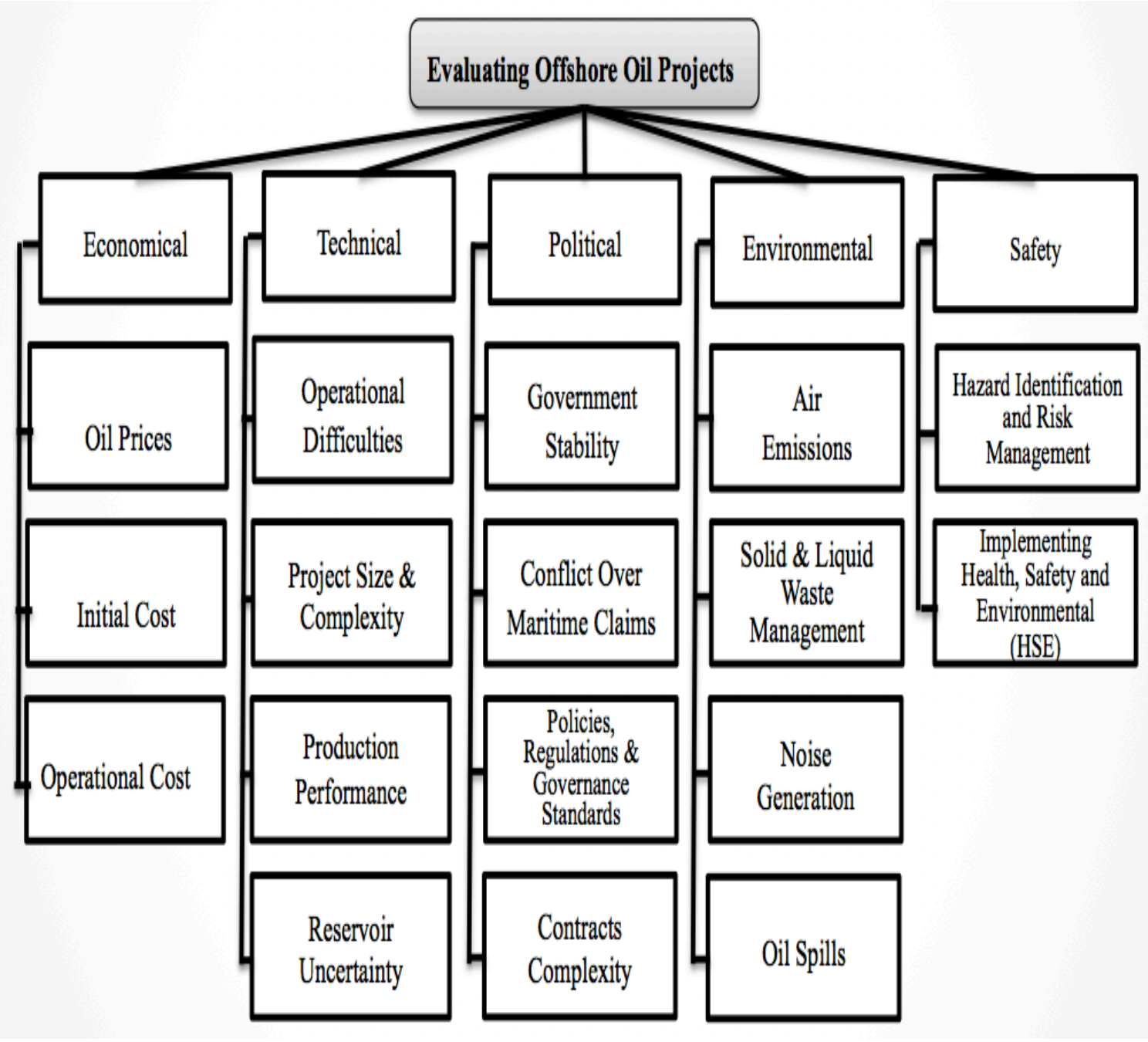

Figure 23: Initial Research Model

\subsection{Model Levels and Definition}

The initial model contents four different levels as following model mission, perspectives level, criteria level and desirability carve. 


\subsubsection{Level (1) Model Mission}

The mission level states the objective of this research, which is evaluating offshore oil projects.

\subsubsection{Level (2) Perspectives}

\begin{tabular}{|c|c|c|c|}
\hline & & Definition & References \\
\hline 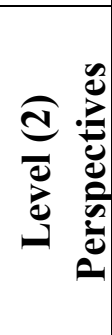 & Economical & $\begin{array}{l}\text { The economic evaluation underlying the } \\
\text { investment decision is based on the } \\
\text { entity's reasonable forecast of future } \\
\text { conditions, including costs and prices, } \\
\text { which will exist during the life of the } \\
\text { project. }\end{array}$ & $\begin{array}{l}{[10][29][30][} \\
4][31][32] \\
{[33]}\end{array}$ \\
\hline \multirow{3}{*}{ 党 } & Oil Price: & $\begin{array}{l}\text { The price of a barrel of oil is one of the } \\
\text { most important variables in determining } \\
\text { company's capital investment strategy. A } \\
\text { change in oil price will affect the whole } \\
\text { project. The prices will be different from } \\
\text { one project to another based on production } \\
\text { starting time, characteristics and quality of } \\
\text { the oil. There are about } 160 \text { crude oils that } \\
\text { are traded internationally. They vary in } \\
\text { terms of their characteristics \& quality. }\end{array}$ & {$[10][29]$} \\
\hline & Initial Cost: & $\begin{array}{l}\text { Offshore projects cost a huge amount of } \\
\text { money and initial cost is a major challenge } \\
\text { to start-up these kinds of projects. }\end{array}$ & {$[30][4]$} \\
\hline & $\begin{array}{l}\text { Operational } \\
\text { Cost: }\end{array}$ & $\begin{array}{l}\text { Operating expenses is the key to maintain } \\
\text { production and stay in business. } \\
\text { Operational cost include staff expenditure, } \\
\text { subsea, pollution control, water injection, } \\
\text { maintenance, insurance, transport charges, } \\
\text { miscellaneous etc. }\end{array}$ & {$[31][32][33]$} \\
\hline
\end{tabular}

Table 11: Definition of Economical Perspective and Criteria 


\begin{tabular}{|c|c|c|c|}
\hline \multirow[b]{2}{*}{ 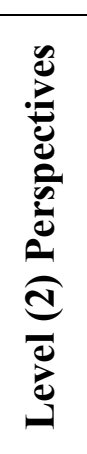 } & & Definition & References \\
\hline & Technical & $\begin{array}{l}\text { Technical implications are one of } \\
\text { challenging factors that are faced by project } \\
\text { managers and decision makers in offshore } \\
\text { hydrocarbon projects. These include } \\
\text { operational difficulties, large size \& } \\
\text { multiple scopes, production and reservoir } \\
\text { performance etc. }\end{array}$ & $\begin{array}{l}{[34][35][36]} \\
{[37][38][39][} \\
40][41][4][10 \\
][42] \\
{[43][30][14][} \\
44]\end{array}$ \\
\hline \multirow{4}{*}{ 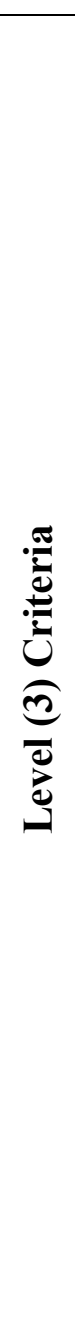 } & $\begin{array}{l}\text { Operational } \\
\text { Difficulties }\end{array}$ & $\begin{array}{l}\text { Offshore petroleum projects face different } \\
\text { types of operational difficulties such as, } \\
\text { complex working equipment, harsh weather } \\
\text { conditions, limited access to safety points, } \\
\text { hydrocarbon releases, fire, high degrees of } \\
\text { temperature and pressure, fatigue, etc. }\end{array}$ & $\begin{array}{l}{[34][35][36][} \\
37][38][39][4 \\
0][41]\end{array}$ \\
\hline & $\begin{array}{l}\text { Size \& } \\
\text { Complexity }\end{array}$ & $\begin{array}{l}\text { Offshore projects have a larger number of } \\
\text { sub-scopes, such as well, subsea system, } \\
\text { production system, transportation system, } \\
\text { etc. These individual project sub-scopes are } \\
\text { also quite large with costs in the hundreds } \\
\text { of millions of dollars. }\end{array}$ & {$[4][10]$} \\
\hline & $\begin{array}{l}\text { Production } \\
\text { Performance }\end{array}$ & $\begin{array}{l}\text { If a project fails to produce the planned } \\
\text { production, it should be considered a failure } \\
\text { because the production volume of the oil } \\
\text { and gas is one of the key factors to } \\
\text { determine a project's profitability. }\end{array}$ & {$[4][42]$} \\
\hline & $\begin{array}{l}\text { Reservoir } \\
\text { Uncertainty }\end{array}$ & $\begin{array}{l}\text { Even though, geological and geophysical } \\
\text { clues can be reassuring, but drilling is the } \\
\text { only way to confirm if an oil or gas field } \\
\text { actually exists in that location. The geologic } \\
\text { and seismic uncertainty can cause the } \\
\text { company to lose money and waste time and } \\
\text { resources. }\end{array}$ & $\begin{array}{l}{[43][30][14][} \\
44]\end{array}$ \\
\hline
\end{tabular}

Table 12: Definition of Technical Perspective and Criteria 


\begin{tabular}{|c|c|c|c|}
\hline & & Definition & References \\
\hline 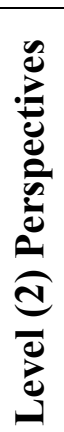 & Political & $\begin{array}{l}\text { Politics is a central concern for the O\&G } \\
\text { sector and can be viewed as a source of both } \\
\text { risk and opportunity. It is no coincidence that } \\
\text { one of the top risks facing oil offshore project, } \\
\text { as identified by most recent risk studies, was } \\
\text { geopolitics. }\end{array}$ & $\begin{array}{l}{[45][46]} \\
{[47][49][50]} \\
{[2]} \\
{[51][52][42]} \\
{[14][11]}\end{array}$ \\
\hline \multirow{4}{*}{ (ֶ) } & $\begin{array}{l}\text { Government } \\
\text { Stability }\end{array}$ & $\begin{array}{l}\text { Oil and Gas companies tend to prefer } \\
\text { countries with stable political systems and a } \\
\text { history of granting and enforcing long-term } \\
\text { leases. }\end{array}$ & {$[45][47]$} \\
\hline & $\begin{array}{l}\text { Conflict Over } \\
\text { Maritime } \\
\text { Claims }\end{array}$ & $\begin{array}{l}\text { The conflict over maritime most likely occurs } \\
\text { when the high production performance has } \\
\text { been achieved which means that a lot of } \\
\text { money and effort have already been put on the } \\
\text { project, so any cancellation or delay can lead } \\
\text { to a disaster. }\end{array}$ & $\begin{array}{l}{[48][49][50]} \\
{[2]}\end{array}$ \\
\hline & $\begin{array}{l}\text { Policies, } \\
\text { Regulations } \\
\& \\
\text { Governance } \\
\text { Standards }\end{array}$ & $\begin{array}{l}\text { The success of a petroleum project is greatly } \\
\text { influenced by political and regulation } \\
\text { uncertainty, such as changing taxes, public } \\
\text { service announcement terms, workplace } \\
\text { health, safety and environmental security, } \\
\text { government stability in the developing } \\
\text { countries, etc. }\end{array}$ & {$[51][52][42]$} \\
\hline & $\begin{array}{l}\text { Contracts } \\
\text { Complexity }\end{array}$ & $\begin{array}{l}\text { O\&G companies are required to have a license } \\
\text { to explore for hydrocarbons. Also, due to the } \\
\text { larger number of sub-scopes, such as well, } \\
\text { subsea system, production system, } \\
\text { transportation system, etc. O\&G companies } \\
\text { are required to implement and manage } \\
\text { multiple contractors. These kind of individual } \\
\text { contractors increase the cost and risk. }\end{array}$ & {$[14][11]$} \\
\hline
\end{tabular}

Table 13: Definition of Political Perspective and Criteria 


\begin{tabular}{|c|c|c|c|}
\hline & & Definition & References \\
\hline 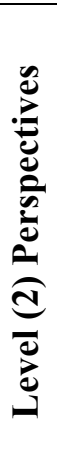 & Environmental & $\begin{array}{l}\text { Environmental impacts of oil and gas operations } \\
\text { may influence species, populations, assemblages, } \\
\text { or ecosystems by modifying a variety of } \\
\text { ecological parameters. Potential environmental } \\
\text { issues associated with offshore oil and gas } \\
\text { development projects include the following: Air } \\
\text { emissions, Wastewater discharges, Solid and } \\
\text { liquid waste management, Noise generation and } \\
\text { Spills. }\end{array}$ & $\begin{array}{l}{[53][54][55][5} \\
6][57][58][59][ \\
60][32][61][62 \\
][63][64][65][6 \\
6][67][68][25][ \\
69][70][71][72 \\
][73][74]\end{array}$ \\
\hline \multirow{4}{*}{ (ֶ) } & Air Emissions & $\begin{array}{l}\text { The main sources of air emissions resulting from } \\
\text { offshore activities include: combustion sources } \\
\text { from power and heat generation, and the use of } \\
\text { compressors, pumps, and reciprocating engines } \\
\text { on offshore facilities including support and } \\
\text { supply vessels and helicopters; emissions } \\
\text { resulting from flaring and venting of } \\
\text { hydrocarbons; and fugitive emissions. }\end{array}$ & $\begin{array}{l}{[53][54][55][5} \\
6][57][58] \\
{[59][60][32]}\end{array}$ \\
\hline & $\begin{array}{l}\text { Solid \& Liquid } \\
\text { Waste } \\
\text { Management }\end{array}$ & $\begin{array}{l}\text { Typical non-hazardous and hazardous wastes } \\
\text { routinely generated at offshore facilities include } \\
\text { general office and packaging wastes, waste oils, } \\
\text { oil contaminated rags, hydraulic fluids, used } \\
\text { batteries, empty paint cans, waste chemicals and } \\
\text { used chemical containers, used filters, } \\
\text { fluorescent tubes, scrap metals, and medical } \\
\text { waste. }\end{array}$ & $\begin{array}{l}{[61][62]} \\
{[63][64][60]}\end{array}$ \\
\hline & $\begin{array}{l}\text { Noise } \\
\text { Generation }\end{array}$ & $\begin{array}{l}\text { O\&G offshore activities generating marine noise } \\
\text { include seismic operations, drilling and } \\
\text { production activities, offshore and near shore } \\
\text { structural installation and construction activities, } \\
\text { and marine traffic. }\end{array}$ & $\begin{array}{l}{[65][66][67]} \\
{[56][68][25]} \\
{[60][69][70]}\end{array}$ \\
\hline & Oil Spills & $\begin{array}{l}\text { Spills from offshore facilities can occur due to } \\
\text { leaks, equipment failure, accidents, or human } \\
\text { error. Abilities to respond to oil spills are } \\
\text { extremely limited, posing significant challenges } \\
\text { for implementing pollution prevention } \\
\text { techniques. }\end{array}$ & $\begin{array}{l}{[71][72][73]} \\
{[74]}\end{array}$ \\
\hline
\end{tabular}

Table 14: Definition of Environmental Perspective and Criteria 


\begin{tabular}{|c|c|c|c|}
\hline & & Definition & References \\
\hline 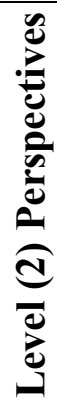 & Safety & $\begin{array}{l}\text { Offshore petroleum projects function in } \\
\text { unsafe environments and constantly deal } \\
\text { with risky products. Due to the nature of the } \\
\text { work environment and the properties of the } \\
\text { products, offshore O\&G projects pose more } \\
\text { serious safety threats to the workers than } \\
\text { their counterparts in other industries. }\end{array}$ & $\begin{array}{l}{[75][76][77][} \\
4] \\
{[78][79][80]} \\
{[81][82][83]} \\
{[9][84][85]}\end{array}$ \\
\hline \multirow{2}{*}{ 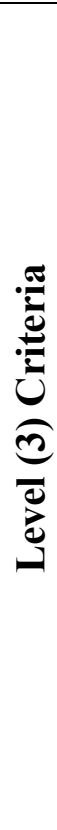 } & $\begin{array}{l}\text { Hazard } \\
\text { Identification } \\
\text { \& Risk } \\
\text { Management }\end{array}$ & $\begin{array}{l}\text { Hazard identification is an essential step } \\
\text { before project implementation and during the } \\
\text { project lifecycle phases. Issues potentially } \\
\text { impacting safety and environmental } \\
\text { stewardship are promptly identified, fully } \\
\text { evaluated, and promptly addressed or } \\
\text { corrected commensurate with their } \\
\text { significance. }\end{array}$ & $\begin{array}{l}{[75][76][4]} \\
{[77][78][79]} \\
{[80][81][82]}\end{array}$ \\
\hline & $\begin{array}{l}\text { Implementing } \\
\text { Health, Safety } \\
\text { and } \\
\text { Environmenta } \\
1 \text { (HSE) }\end{array}$ & $\begin{array}{l}\text { Early evaluation of implementing health, } \\
\text { safety and environmental (HSE) principles is } \\
\text { essential to the success of the project. HSE } \\
\text { principles contain the performance levels and } \\
\text { measures that are generally considered to be } \\
\text { achievable in new facilities by existing } \\
\text { technologies at reasonable costs. }\end{array}$ & $\begin{array}{l}{[83][84][85][} \\
86]\end{array}$ \\
\hline
\end{tabular}

Table 15: Definition of Safety Perspective and Criteria

\subsection{Experts' Specialized}

Finding the right expert is one of the baggiest challenges in this research. It is very important to classify the experts and what their areas of interest are so that they can fit in with the panel requirements before we select them. The basic criteria for choosing and inviting experts to participate in the study were: Expertise in the field, contributions to the field, absence of conflicts of interest, willingness to participate, and availability to 
participate. The methods used in selecting the experts were social network analysis and professional connections, both complemented by snowball sampling. In reference to the discussion of the experts' characteristic in section 4.6 this research implements experts metrics identification to ensure that expert biases were under control and not impairing an objective interpretation of the results. The table below shows the required experiences and area of interest for each panel.

\begin{tabular}{|c|l|l|}
\hline $\begin{array}{c}\text { Panel } \\
\text { No. }\end{array}$ & \multicolumn{1}{|c|}{ Panel Focus } & Required Expertise \\
\hline Panel 1 & $\begin{array}{l}\text { To validate the literature based hierarchical } \\
\text { decision model. }\end{array}$ & $\begin{array}{l}\text { Project Managers } \\
\text { Finance Specialists } \\
\text { Project Design } \\
\text { Policy Managers } \\
\text { Environmental } \\
\text { Engineers } \\
\text { Technical Specialists }\end{array}$ \\
\hline Panel 2 & $\begin{array}{l}\text { To quantify the perspective level and its } \\
\text { contribution to the decision level. }\end{array}$ & $\begin{array}{l}\text { Project Managers } \\
\text { Project Design }\end{array}$ \\
\hline Panel 3 & $\begin{array}{l}\text { To quantify the economical perspective of the } \\
\text { model. }\end{array}$ & $\begin{array}{l}\text { Project Managers } \\
\text { Finance Specialists }\end{array}$ \\
\hline Panel 4 & $\begin{array}{l}\text { To quantify the technical perspective of the } \\
\text { model. }\end{array}$ & $\begin{array}{l}\text { Project Managers } \\
\text { Technical Specialists }\end{array}$ \\
\hline Panel 5 & $\begin{array}{l}\text { To quantify the political perspective of the } \\
\text { model. }\end{array}$ & $\begin{array}{l}\text { Project Managers } \\
\text { Policy Managers }\end{array}$ \\
\hline Panel 6 & $\begin{array}{l}\text { To quantify the Environmental \& Safety } \\
\text { perspective of the model. }\end{array}$ & $\begin{array}{l}\text { Project Managers } \\
\text { Safety Managers }\end{array}$ \\
\hline Panel 7 & To validate and quantify the desirability curve. & $\begin{array}{l}\text { Project Managers } \\
\text { Finance Specialists } \\
\text { Project Design } \\
\text { Policy Managers } \\
\text { Environmental } \\
\text { Engineers }\end{array}$ \\
\hline
\end{tabular}




\begin{tabular}{|l|l|l|} 
& & Technical Specialists \\
\hline & & Project Managers \\
& & Finance Specialists \\
Panel & To validate and evaluate the application case and & Project Design \\
& Posults & Policy Managers \\
& & Environmental \\
& & Engineers \\
& & Technical Specialists \\
\hline
\end{tabular}

Table 16: Required Experiences Each Panel

\subsection{Expert Panels Format}

A total of 43 Experts responded to the invitation and participated in the research expert panels. Appendix A includes a sample of the invitation letter sent to experts. The 43 experts were identified based on their specializations and qualifications that were described in the pervious section. Table 17 illustrates a list of the experts along with their backgrounds, job titles and their countries.

\begin{tabular}{|c|l|l|l|l|l|l|l|l|l|l|}
\hline NO. & Current Position & \multicolumn{1}{|c|}{ Country } & P1 & P2 & P3 & P4 & P5 & P6 & P7 & P8 \\
\hline Expert 1 & $\begin{array}{l}\text { O\&G Offshore } \\
\text { Project Manager }\end{array}$ & Ghana & $\mathrm{X}$ & & & & & & & \\
\hline Expert 2 & $\begin{array}{l}\text { O\&G Offshore } \\
\text { Project Manager }\end{array}$ & Italy & $\mathrm{X}$ & & & & & & & \\
\hline Expert 3 & $\begin{array}{l}\text { O\&G Offshore } \\
\text { Project Manager }\end{array}$ & Ghana & $\mathrm{X}$ & & & & & & & \\
\hline Expert 4 & $\begin{array}{l}\text { O\&G Offshore } \\
\text { Project Manager }\end{array}$ & Ghana & $\mathrm{X}$ & & & & & & & \\
\hline Expert 5 & $\begin{array}{l}\text { O\&G Offshore } \\
\text { Project Manager }\end{array}$ & Portugal & $\mathrm{X}$ & & & & & & & \\
\hline Expert 6 & $\begin{array}{l}\text { O\&G Offshore } \\
\text { Project Manager }\end{array}$ & Italy & $\mathrm{X}$ & & & & & & & \\
\hline Expert 7 & Senior Manager & Malaysia & $\mathrm{X}$ & & & & & & & \\
\hline Expert 8 & $\begin{array}{l}\text { O\&G Offshore } \\
\text { Project Manager }\end{array}$ & $\begin{array}{l}\text { Houston, } \\
\text { Texas }\end{array}$ & $\mathrm{X}$ & & & & & & & \\
\hline
\end{tabular}




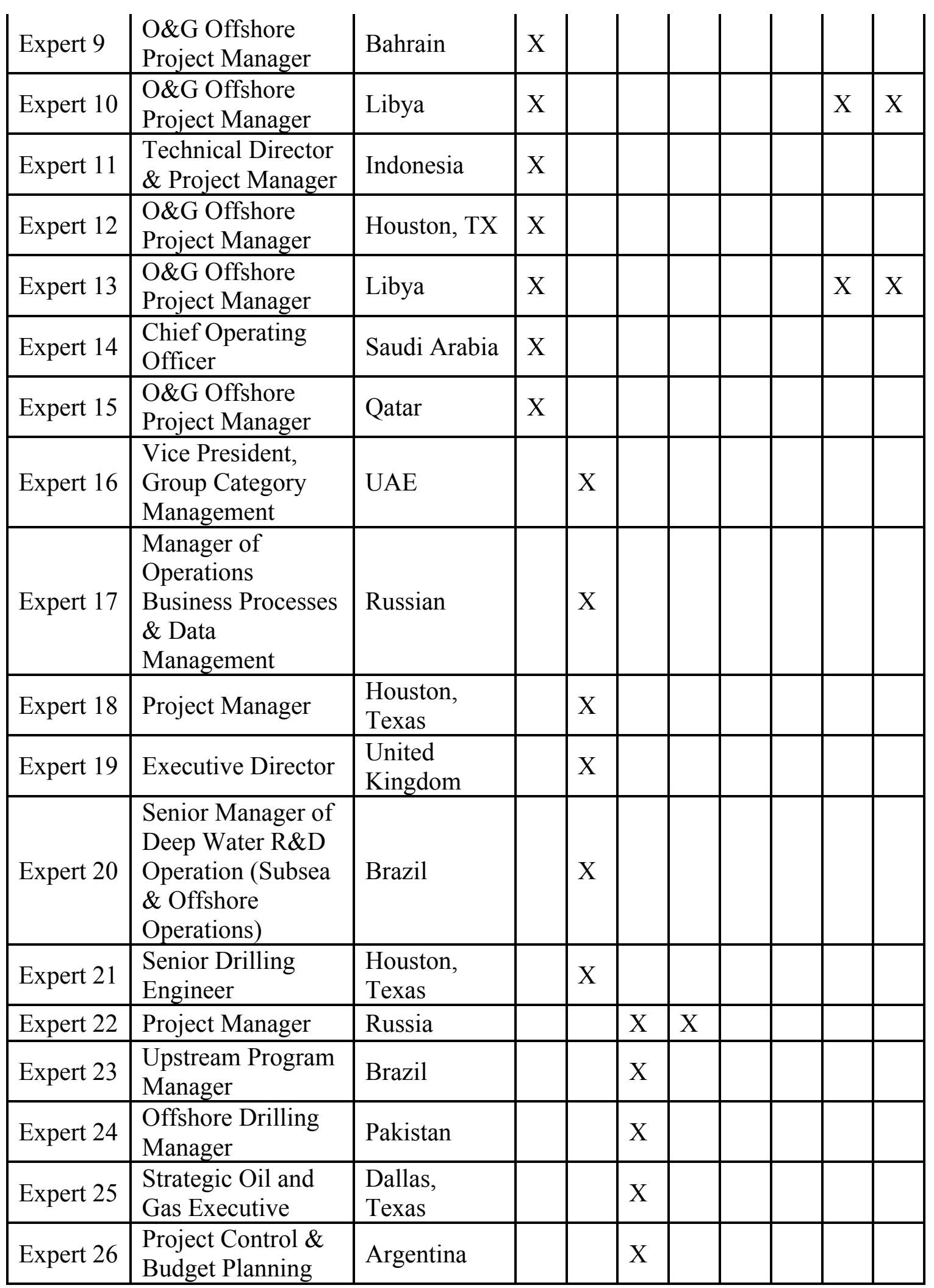




\begin{tabular}{|c|c|c|c|c|c|c|c|c|}
\hline Expert 27 & Project Manager & Brazil & $X$ & & & & & \\
\hline Expert 28 & $\begin{array}{l}\text { Senior Controller/ } \\
\text { Accounting } \\
\text { Manager }\end{array}$ & Italy & $\mathrm{X}$ & & & & & \\
\hline Expert 29 & Drilling Engineer & Russia & & $\mathrm{X}$ & & & & \\
\hline Expert 30 & $\begin{array}{l}\text { Quality Manager, } \\
\text { Site Manager }\end{array}$ & Germany & & $X$ & & & & \\
\hline Expert 31 & $\begin{array}{l}\text { Senior Project } \\
\text { Manager }\end{array}$ & India & & $X$ & & & & \\
\hline Expert 32 & $\begin{array}{l}\text { Product } \\
\text { Development and } \\
\text { Project Manager }\end{array}$ & Saudi Arabia & & $X$ & & & & \\
\hline Expert 33 & $\begin{array}{l}\text { Chief Well } \\
\text { Engineer }\end{array}$ & USA & & & $X$ & & & \\
\hline Expert 34 & $\begin{array}{l}\text { Project Drilling } \\
\text { Manager }\end{array}$ & Spain & & & $\mathrm{X}$ & & & \\
\hline Expert 35 & $\begin{array}{l}\text { Operations } \\
\text { Manager }\end{array}$ & D.R. Congo & & & $X$ & & & \\
\hline Expert 36 & $\begin{array}{l}\text { Global Markets } \\
\text { Manager }\end{array}$ & Oman & & & $\mathrm{X}$ & & & \\
\hline Expert 37 & $\begin{array}{l}\text { Project Data } \\
\text { Engineer }\end{array}$ & $\begin{array}{l}\text { United } \\
\text { Kingdom }\end{array}$ & & & $X$ & & & \\
\hline Expert 38 & $\begin{array}{l}\text { Senior Staff } \\
\text { Process Safety } \\
\text { Engineer } \\
\end{array}$ & Saudi Arabia & & & & $\mathrm{X}$ & & \\
\hline Expert 39 & $\begin{array}{l}\text { Drilling Ops \& Rig } \\
\text { Manager }\end{array}$ & Russia & & & & $\mathrm{X}$ & & \\
\hline Expert 40 & Drilling Manage & UAE & & & & $\mathrm{X}$ & & \\
\hline Expert 41 & $\begin{array}{l}\text { Chef Department } \\
\text { Environmental } \\
\text { Group }\end{array}$ & France & & & & $X$ & & \\
\hline Expert 42 & QHSE Engineer & Brazil & & & & $\mathrm{X}$ & & \\
\hline Expert 43 & $\begin{array}{l}\text { Production } \\
\text { Manager }\end{array}$ & Libya & & & & & $X$ & $X$ \\
\hline
\end{tabular}

Table 17: Panels Distribution

- Panel (1): was formed to validate the model. 
- Panel (2) was formed to quantify the perspective level and its contribution to the decision level.

- Panel (3) was formed to quantify the economical criteria.

- Panel (4) was formed to quantify the technical criteria.

- Panel (5) was formed to quantify the political criteria.

- Panel (6) was formed to quantify the environmental \& safety criteria.

- Panel (7) was formed to validate and quantify the desirability curves.

- Panel (8) was formed to validate and evaluate the case application and results.

\subsection{Data Collection}

Experts were invited using email and linkedin.com. Appendix A includes a sample of the invitation. In addition, email and linkedin.com were used to send the details for participating in the model validation and the model quantification. Appendix B and C include samples of the communications with experts. Qualtrics surveys and one-on-one interviews were used to elicit expert's judgment and feedback for both the validation and quantification steps of the research model. Furthermore, results from quantification were re-entered by the researcher into HDM tool for further analysis. 


\section{CHAPTER 7: MODEL VALIDATION, QUANTIFICATION AND DESIRABILTY CURVES DETERMINATION}

This chapter introduces the steps that were applied to validate the model. In addition, this chapter presents the results of quantification phase and how the desirability curves were determined.

\subsection{Model Validation}

As it has been mentioned in chapter three the main purpose of the validation phase is to answer the following questions:

1- Does the model capture the necessary elements needed to satisfy the research goal?

2- Does the model valid to apply?

The initial model was validated by the experts based on the steps that were described in the validation processes chart below. Two rounds of validation took place using a Qualtrics survey (see Appendix B for the survey format). In the first round, experts evaluated the factors identified by the research as the most critical factors affecting the investment decision in offshore oil project. Experts also were given a chance to suggest other factors based on their experience. In the second round experts validated the factors that were added to the model based on the first round experts' feedback. 


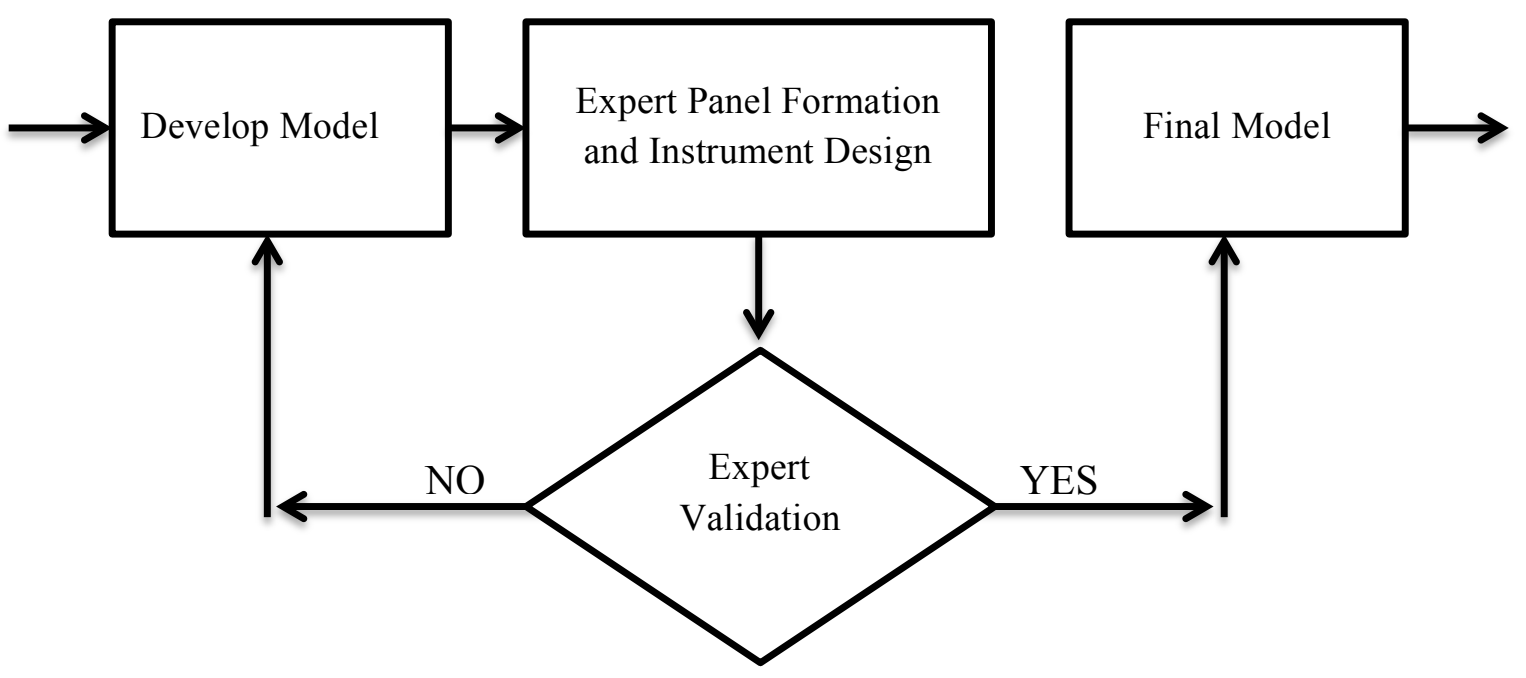

Figure 24: Validation Processes Chart

To validate the items successfully, at lest three-quarters of the panelists $[75 \%$ acceptance rate] should indicate that the captured factor is essential [101][109]. Fifteen experts participated in validation phase from ten different organizations and eleven countries. Expert panel P1 was formed to validate the literature based hierarchical decision model. The experts were selected based on their expertise in the offshore oil field.

\begin{tabular}{|l|l|l|}
\hline \multicolumn{1}{|c|}{ NO. } & \multicolumn{1}{|c|}{ Current Position } & \multicolumn{1}{c|}{ Country } \\
\hline Expert 1 & O\&G Offshore Project Manager & Ghana \\
\hline Expert 2 & O\&G Offshore Project Manager & Italy \\
\hline Expert 3 & O\&G Offshore Project Manager & Ghana \\
\hline Expert 4 & O\&G Offshore Project Manager & Ghana \\
\hline Expert 5 & O\&G Offshore Project Manager & Portugal \\
\hline Expert 6 & O\&G Offshore Project Manager & Italy \\
\hline Expert 7 & Senior Manager & Malaysia \\
\hline Expert 8 & O\&G Offshore Project Manager & Houston, Texas \\
\hline
\end{tabular}




\begin{tabular}{|l|l|l|} 
Expert 9 & O\&G Offshore Project Manager & Bahrain \\
\hline Expert 10 & O\&G Offshore Project Manager & Libya \\
\hline Expert 11 & Technical Director \& Project Manager & Indonesia \\
\hline Expert 12 & O\&G Offshore Project Manager & Houston, TX \\
\hline Expert 13 & O\&G Offshore Project Manager & Libya \\
\hline Expert 14 & Chief Operating Officer & Saudi Arabia \\
\hline Expert 15 & O\&G Offshore Project Manager & Qatar \\
\hline
\end{tabular}

Table 18: List of Experts in Validation Panel

\subsubsection{Perspectives Validation}

Fifteen experts were participated to validate the perspectives level. The panelists indicated that all the perspectives items were essential. However, most of the experts agree that environmental and safety should be captured under one perspective.

\section{Perspectives Validation}

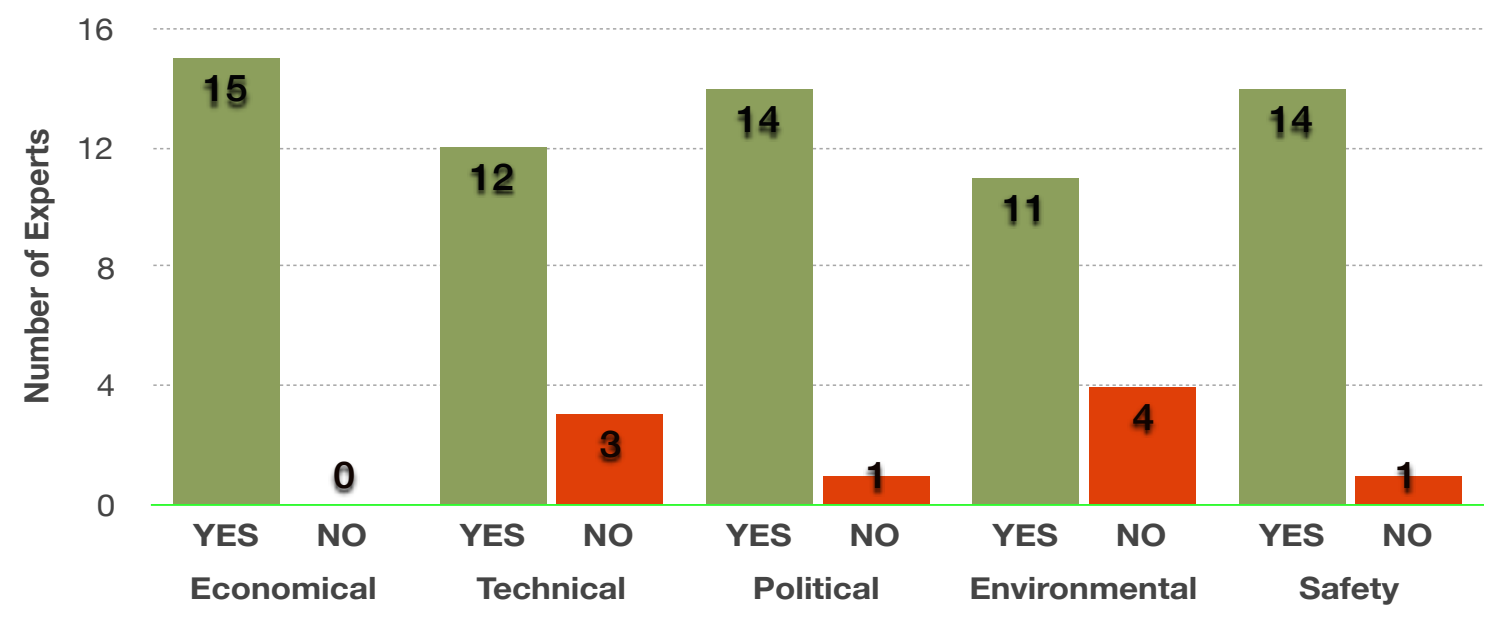

Figure 25: Perspectives Validation Results 


\subsubsection{Economical Criteria Validation}

Fifteen experts were participated to validate the economical factors. The panelists indicated that all of the economical items were essential. Moreover, experts were suggested that return on investment should be added to the economical criteria.

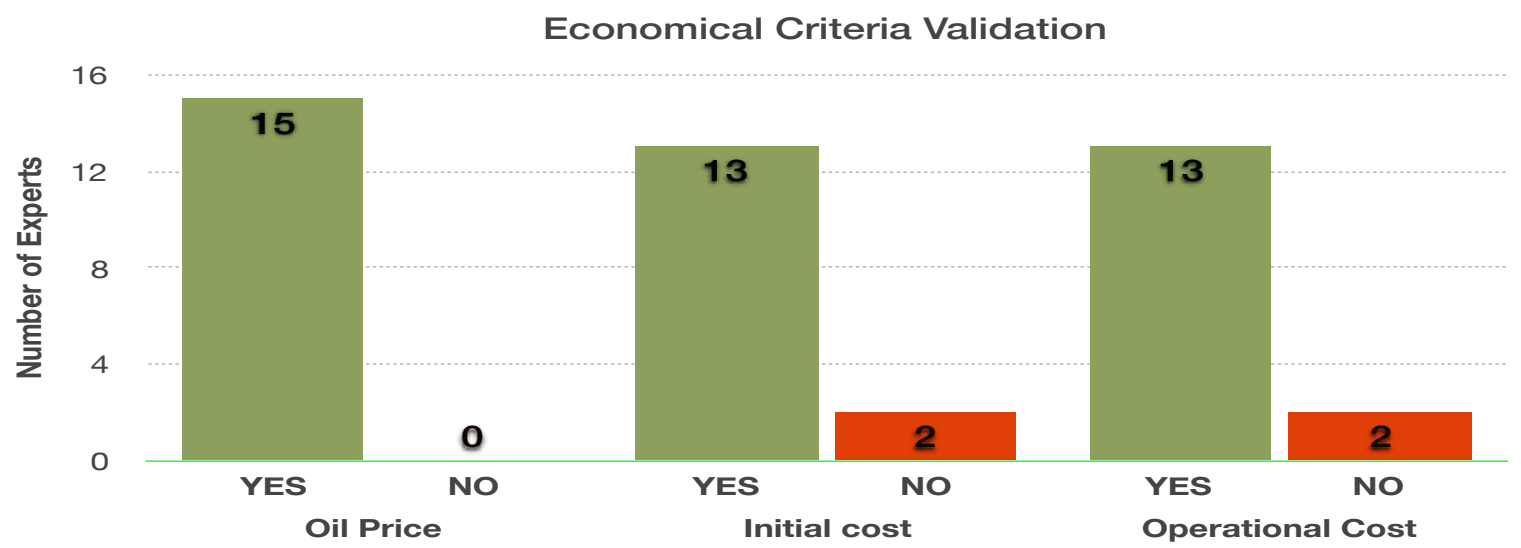

Figure 26: Economical Validation Results

\subsubsection{Technical Criteria Validation}

Fifteen experts were participated to validate the technical factors. The panelists indicated that all of the technical items were essential.

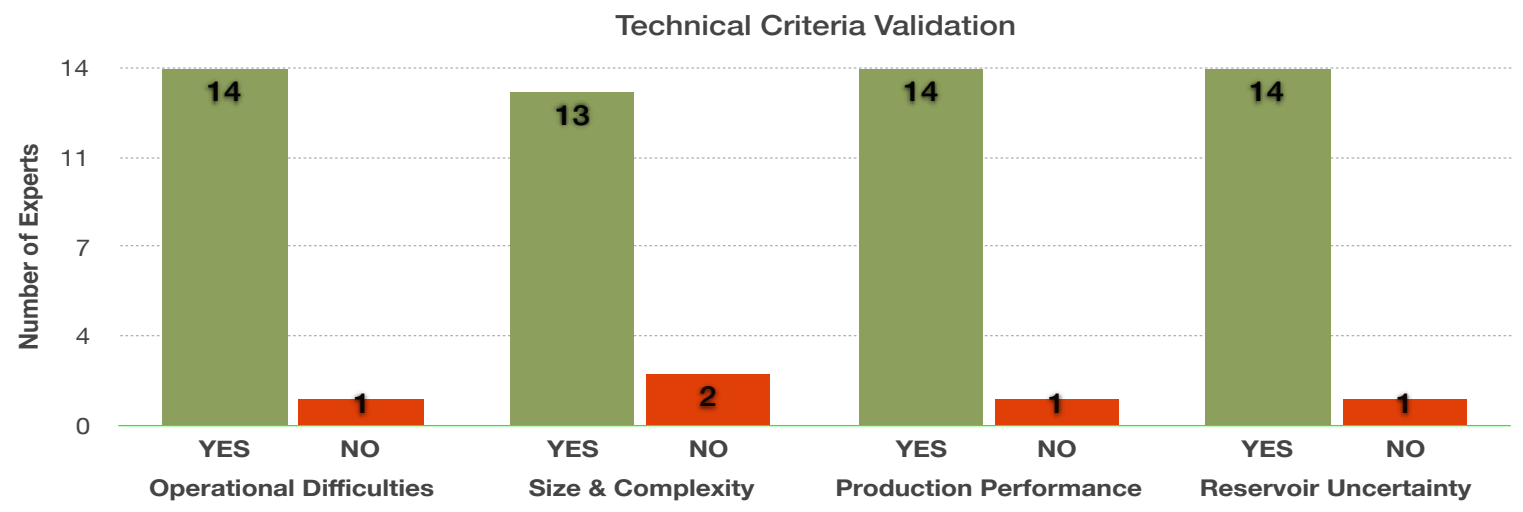

Figure 27: Technical Validation Results 


\subsubsection{Political Criteria Validation}

Fifteen experts were participated to validate the political factors. The panelists indicated that all of the political items were essential.

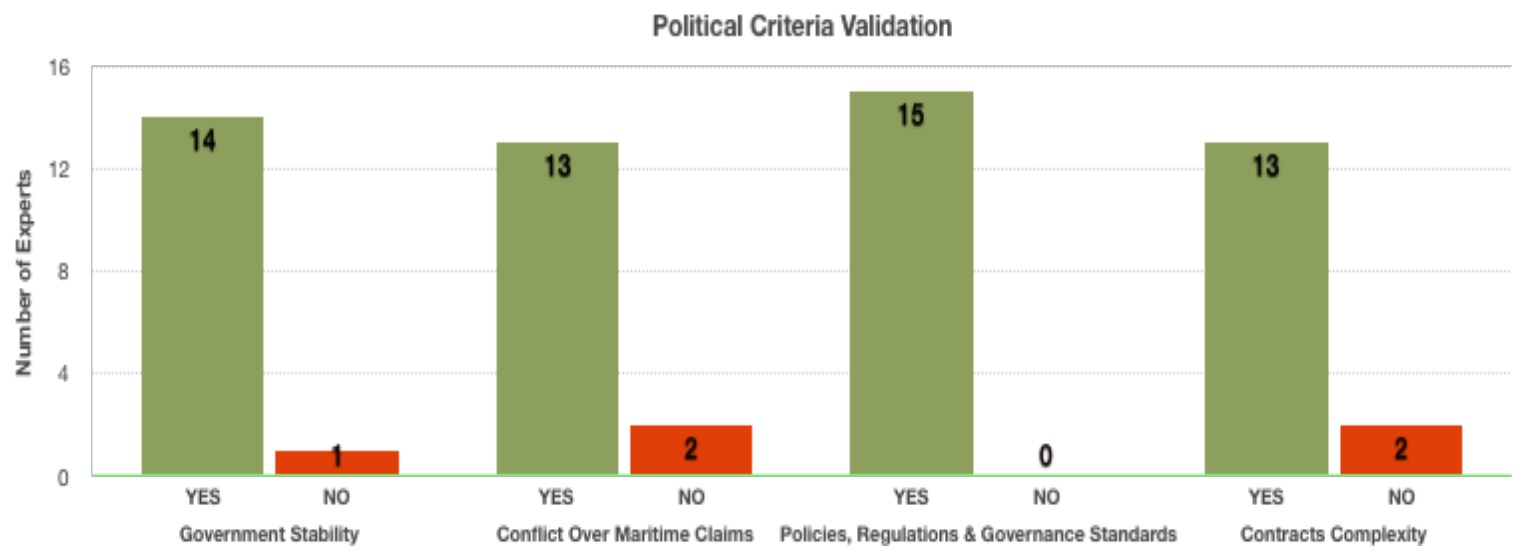

Figure 28: Political Validation Results

\subsubsection{Environmental Criteria Validation}

Fifteen experts were participated to validate the environmental factors. The panelists indicated that two of the environmental items were essential and two were rejected. Moreover, experts recommended that environmental factors related to the safety perspective.

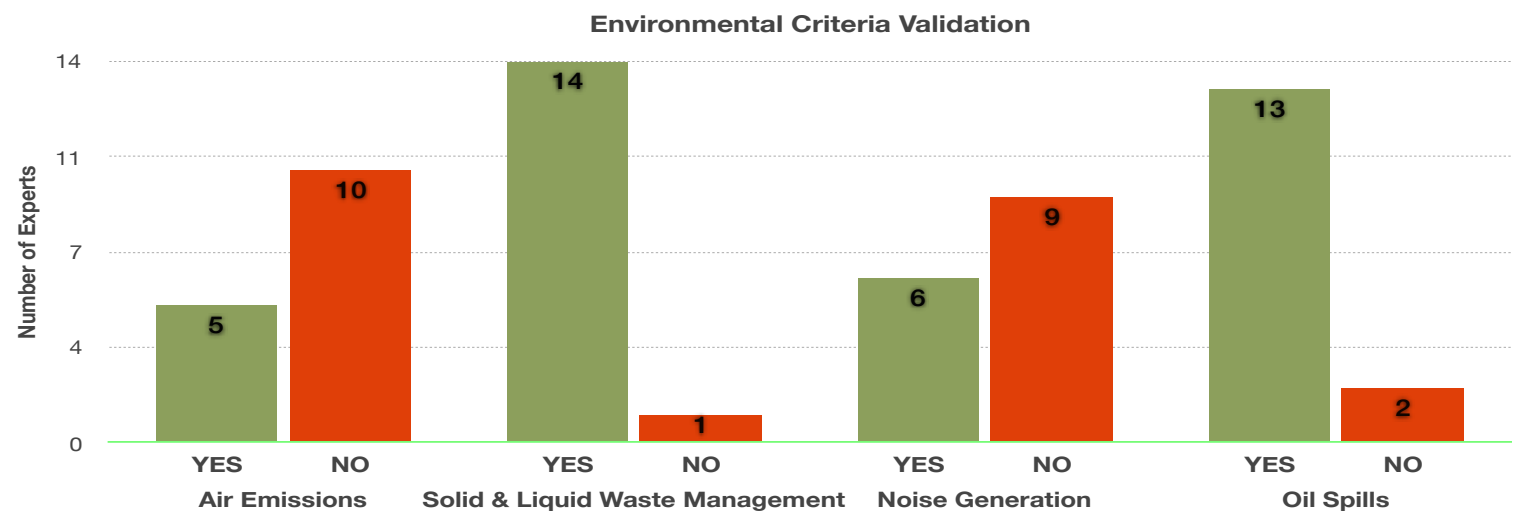

Figure 29: Environmental Validation Results 


\subsubsection{Safety Criteria Validation}

Fifteen experts were participated to validate the safety factors. The panelists indicated that all of the safety items were essential. Moreover, experts were suggested that stringent of the local HSE standards and environmental risk management integration should be added to the economical criteria.

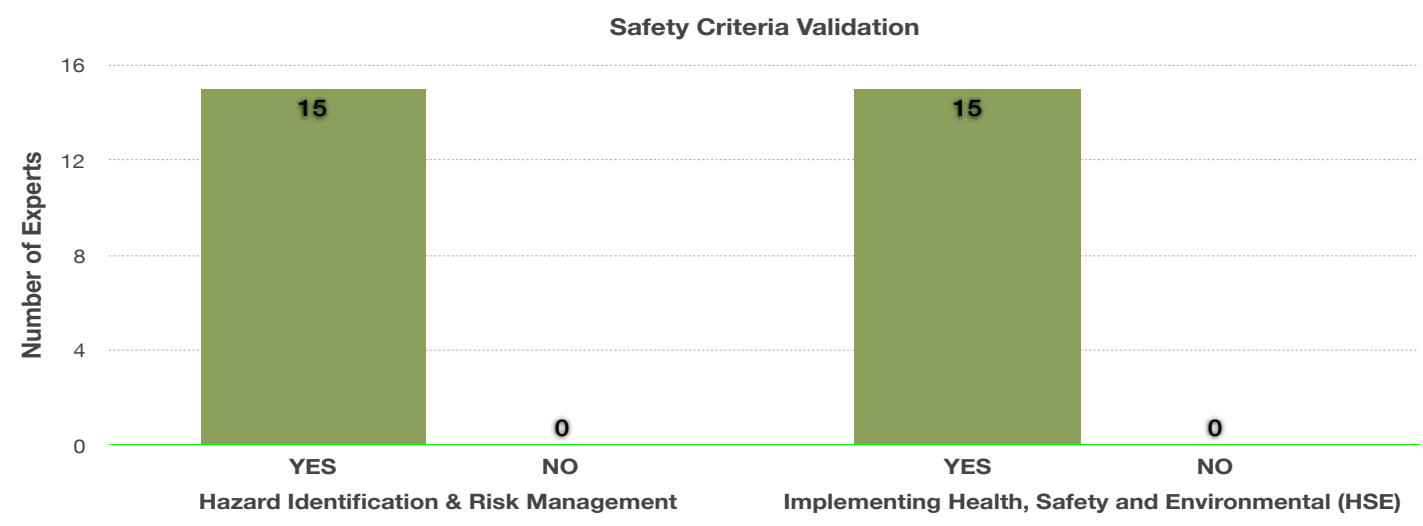

Figure 30: Safety Validation Results

\subsection{Second Round of the Validation Phase}

Based on the experts feedback form the first round three more factors were added to the model and validated return on investment (ROI), stringent of the local HSE standards and environmental risk management Integration. Fifteen experts were participated in the second round to validate the changes and the new factors. The panelists indicated that all of the new items were essential. 


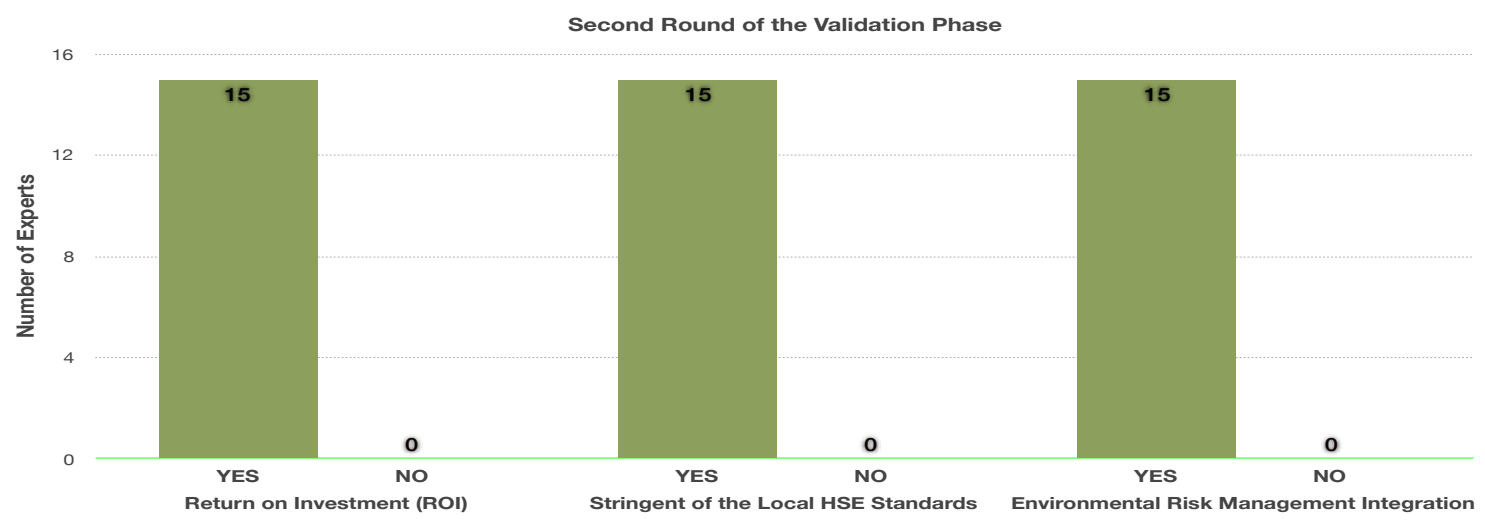

Figure 31: Second Round Validation Results

\subsubsection{Return on investment (ROI)}

A higher ROI number does not always mean a better investment option. For example, two investments have the same ROI of $50 \%$. However, the first investment is completed in three years, while the second investment needs five years to produce the same yield. The same ROI for both investments blurred the bigger picture, but when the factor of time was added, the investor easily sees the better option. The investor needs to compare two instruments under the same time period and same circumstances [204]. In this research annualized ROI was implemented in order to evaluate different offshore oil projects under the same time period and same circumstances. The annualized ROI calculated as following:

Annualized ROI $=\left[(\text { Ending Value } / \text { Beginning Value })^{\wedge}(1 /\right.$ Number of Years $\left.)\right]-1$ (19)

Where: Number of years $=($ Ending date - Starting Date $) / 365$

\subsection{Final Model}

The figure below shows the validated hierarchical decision model that will be used to evaluate offshore oil projects. 


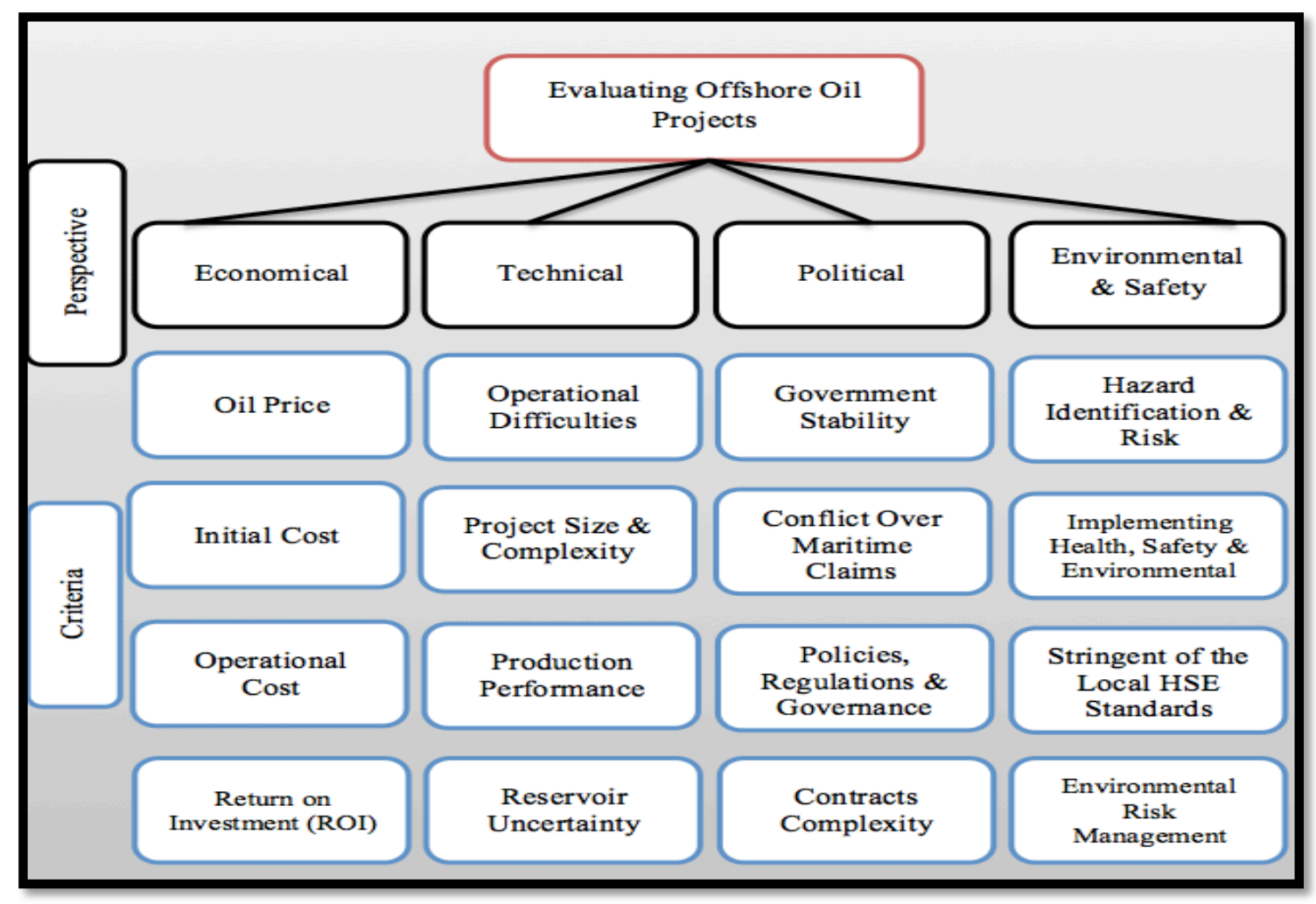

Figure 32: Final Model

\subsection{Research Quantification}

Twenty-seven experts were agreed to participate in the quantification phase in order to quantify the research model and score each factors based on its relative importance to the mission level. In this phase five panels have been formatted including perspectives quantification, economical quantification, technical quantification, political quantification and environmental \& safety quantification. As it was explained in previse chapter, experts' judgments were captured through pair-wise comparisons utilizing the constantsum method. Each comparison is made by distributing 100 points between the pair of items being compared. Data is collected through an online survey tool and the analysis is 
done using the HDM software, which also calculated the individual logical inconsistencies and the group disagreements (see Appendix E for the HDM software analysis). In order to quantify the decision for each element, HDM uses pairwise comparison technique. The following equation shows the number of pairwise comparisons [96].

$$
N=\frac{n(n-1)}{2} \quad \text { for, } \quad \mathrm{n}>0
$$

Where:

$\mathrm{N}$ : number of pair-wise comparisons.

$n$ : number of elements.

By applying this equation, we can find the number of pairwise comparisons that have been made by the experts for each panel. The following explanation illustrates how many pairwise comparisons the participants went through for each panel.

- Perspective Level: The experts were asked to compare the contribution of the four perspectives to the overall research objective of offshore oil projects evaluation. Based to the equation the experts completed six comparisons to determine the level output.

Number of comparisons $=[(4 * 3)] / 2=6$

- Economical: The experts were asked to assess the relative contribution of the four success attributes to the Economical perspective. Based to the equation the experts completed six comparisons to determine the level output.

Number of comparisons $=[(4 * 3)] / 2=6$ 
- Technical Level: The experts were asked to assess the relative contribution of the four success attributes to the technical perspective. Based to the equation the experts completed six comparisons to determine the level output.

Number of comparisons $=[(4 * 3)] / 2=6$

- Political Level: The experts were asked to assess the relative contribution of the four success attributes to the political perspective. Based to the equation the experts completed six comparisons to determine the level output.

Number of comparisons $=[(4 * 3)] / 2=6$

- Environmental \& Safety: The experts were asked to assess the relative contribution of the four success attributes to the environmental perspective. Based to the equation the experts completed six comparisons to determine the level output. Number of comparisons $=[(4 * 3)] / 2=6$

\begin{tabular}{|cc|}
\hline Panel & Panel Focus \\
\hline P2 & Perspective Level Quantification \\
\hline P3 & Economical Quantification \\
\hline P4 & Technical Quantification \\
\hline P5 & Political Quantification \\
\hline P6 & Environmental \& Safety Quantification \\
\hline
\end{tabular}

Table 19: Quantification Expert Panels Breakdown

\subsubsection{Perspectives Quantification}

Panel 2 consisted of 6 participants. They were asked to compare the contribution of the four perspectives to the overall research objective of evaluating offshore oil projects. The experts completed six comparisons to determine the output shown in table 21 . 


\begin{tabular}{|l|l|l|}
\hline \multicolumn{1}{|c|}{ NO. } & \multicolumn{1}{|c|}{ Current Position } & \multicolumn{1}{c|}{ Country } \\
\hline Expert 16 & Vice President, Group Category Management & $\begin{array}{l}\text { United Arab } \\
\text { Emirates }\end{array}$ \\
\hline Expert 17 & $\begin{array}{l}\text { Manager of Operations Business Processes \& } \\
\text { Data Management }\end{array}$ & Russia \\
\hline Expert 18 & Project Manager & Houston, Texas \\
\hline Expert 19 & Executive Director & United Kingdom \\
\hline Expert 20 & $\begin{array}{l}\text { Senior Manager of Deep Water R\&D } \\
\text { Operation (Subsea \& Offshore Operations) }\end{array}$ & Brazil \\
\hline Expert 21 & Senior Drilling Engineer & Houston, Texas \\
\hline
\end{tabular}

Table 20: Expert in Panel 2

\begin{tabular}{|l|c|c|c|c|c|}
\hline & Economical & Technical & Political & $\begin{array}{c}\text { Environmental } \\
\text { \& Safety }\end{array}$ & Inconsistency \\
\hline Expert 16 & 0.36 & 0.12 & 0.25 & 0.27 & 0.02 \\
\hline Expert 17 & 0.35 & 0.11 & 0.26 & 0.28 & 0.04 \\
\hline Expert 18 & 0.3 & 0.13 & 0.31 & 0.27 & 0 \\
\hline Expert 19 & 0.38 & 0.09 & 0.17 & 0.35 & 0.04 \\
\hline Expert 20 & 0.28 & 0.22 & 0.2 & 0.31 & 0.03 \\
\hline Expert 21 & 0.27 & 0.18 & 0.26 & 0.29 & 0.07 \\
\hline Mean & 0.32 & 0.14 & 0.24 & 0.3 & \\
\hline Minimum & 0.27 & 0.09 & 0.17 & 0.27 & \\
\hline Maximum & 0.38 & 0.22 & 0.31 & 0.35 & \\
\hline $\begin{array}{l}\text { Std. } \\
\text { Deviation }\end{array}$ & 0.04 & 0.04 & 0.05 & 0.03 & \\
\hline Disagreement & & & & \\
\hline
\end{tabular}

Table 21: Perspectives Quantification Results 
Perspectives
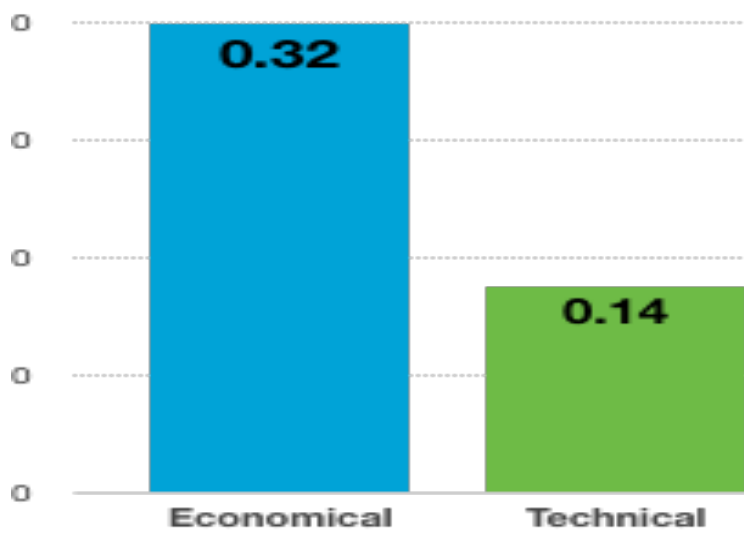

Technical

Political Environmental \& Safety

Figure 33: Perspectives Quantification

The inconsistency within each expert is acceptable (all $<0.10$ ). Based on this panel's results, the economical perspective is assessed as the most important factor with $(0.32)$ score followed by environmental \& safety perspective with (0.30) score.

\subsubsection{Economical Quantification}

Panel P3 consisted of 7 participants. They were asked to assess the relative contribution of the four success attributes to the economics perspective. The experts completed six comparisons to determine the output shown in table 23.

\begin{tabular}{|l|l|l|}
\hline NO. & \multicolumn{1}{|c|}{ Current Position } & \multicolumn{1}{c|}{ Country } \\
\hline Expert 22 & Project Manager & Russia \\
\hline Expert 23 & Upstream Program Manager & Brazil \\
\hline Expert 24 & Offshore Drilling Manager & Pakistan \\
\hline Expert 25 & Strategic Oil and Gas Executive & Dallas, Texas \\
\hline Expert 26 & Project Control \& Budget Planning & Argentina \\
\hline Expert 27 & Project Manager & Brazil \\
\hline Expert 28 & Senior Controller/ Accounting Manager & Italy \\
\hline
\end{tabular}

Table 22: Experts in Panel 3 


\begin{tabular}{|l|c|c|c|c|c|}
\hline & $\begin{array}{c}\text { Oil } \\
\text { Prices }\end{array}$ & $\begin{array}{c}\text { Initial } \\
\text { Cost }\end{array}$ & $\begin{array}{c}\text { Operational } \\
\text { Cost }\end{array}$ & $\begin{array}{c}\text { Return on } \\
\text { Investment }\end{array}$ & Inconsistency \\
\hline Expert 22 & 0.4 & 0.15 & 0.16 & 0.29 & 0.03 \\
\hline Expert 23 & 0.41 & 0.13 & 0.17 & 0.28 & 0.01 \\
\hline Expert 24 & 0.48 & 0.14 & 0.16 & 0.22 & 0.01 \\
\hline Expert 25 & 0.37 & 0.12 & 0.07 & 0.43 & 0.01 \\
\hline Expert 26 & 0.25 & 0.24 & 0.21 & 0.31 & 0.02 \\
\hline Expert 27 & 0.28 & 0.17 & 0.14 & 0.4 & 0.08 \\
\hline Expert 28 & 0.25 & 0.26 & 0.18 & 0.31 & 0 \\
\hline Mean & 0.35 & 0.17 & 0.16 & 0.32 & 0.22 \\
\hline Minimum & 0.25 & 0.12 & 0.07 & 0.43 & \\
\hline Maximum & 0.48 & 0.26 & 0.21 & 0.07 & \\
\hline $\begin{array}{l}\text { Std. } \\
\text { Deviation }\end{array}$ & 0.08 & 0.05 & 0.04 & 06 \\
\hline Disagreement
\end{tabular}

Table 23: Economical Criteria Quantification Results

\section{Economical Perspective}

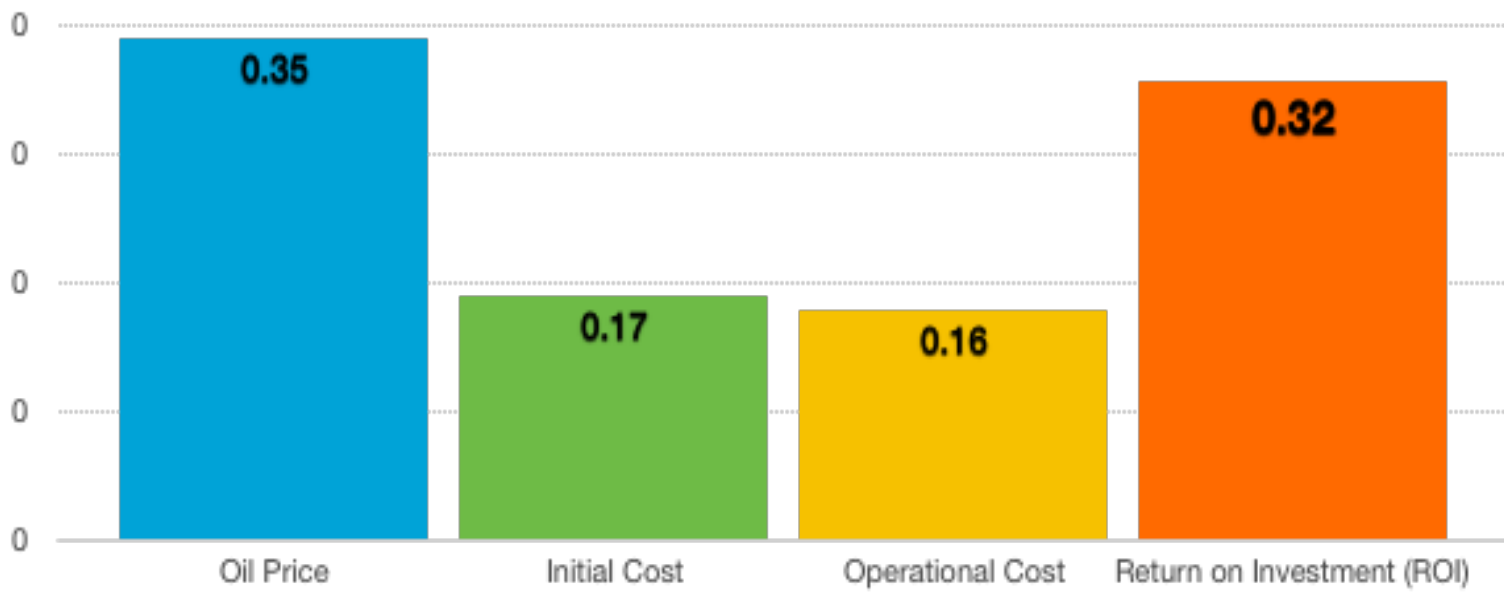

Figure 34: Economical Quantification

The inconsistency within each expert is acceptable (all $<0.10$ ). Based on this panel, oil price criterion is assessed as the most important factor with a score of $(0.35)$. 


\subsubsection{Technical Quantification}

Panel P4 consisted of 5 participants. They were asked to assess the relative contribution of the four success attributes to the technical perspective. The experts completed six comparisons to determine the output shown in table 25 .

\begin{tabular}{|l|l|l|}
\hline NO. & \multicolumn{1}{|c|}{ Current Position } & \multicolumn{1}{c|}{ Country } \\
\hline Expert 29 & Drilling Engineer & Russia \\
\hline $\begin{array}{l}\text { Expert } \\
22 *\end{array}$ & Project Manager & Russia \\
\hline Expert 30 & Quality Manager, Site Manager & Germany \\
\hline Expert 31 & Senior Project Manager & India \\
\hline Expert 32 & Product Development and Project Manager & Saudi Arabia \\
\hline
\end{tabular}

Table 24: Experts in Panel 4

\begin{tabular}{|l|c|c|c|c|c|}
\hline Technical & $\begin{array}{c}\text { Operational } \\
\text { Difficulties }\end{array}$ & $\begin{array}{c}\text { Project } \\
\text { Size \& } \\
\text { Complexity }\end{array}$ & $\begin{array}{c}\text { Production } \\
\text { Performance }\end{array}$ & $\begin{array}{c}\text { Reservoir } \\
\text { Uncertainty }\end{array}$ & Inconsistency \\
\hline Expert 29 & 0.12 & 0.24 & 0.43 & 0.22 & 0.04 \\
\hline Expert 22* & 0.07 & 0.11 & 0.32 & 0.51 & 0.08 \\
\hline Expert 30 & 0.1 & 0.1 & 0.36 & 0.45 & 0 \\
\hline Expert 31 & 0.26 & 0.29 & 0.27 & 0.18 & 0 \\
\hline Expert 32 & 0.18 & 0.25 & 0.31 & 0.26 & 0.04 \\
\hline Mean & 0.15 & 0.2 & 0.34 & 0.31 & \\
\hline Minimum & 0.07 & 0.1 & 0.27 & 0.18 & \\
\hline Maximum & 0.26 & 0.29 & 0.43 & 0.51 & 0.084 \\
\hline Std. Deviation & 0.07 & 0.08 & 0.05 & 0.13 & \\
\hline Disagreement & \multicolumn{7}{|l}{} \\
\hline
\end{tabular}

Table 25: Technical Criteria Quantification Results 


\section{Technical Perspectives}

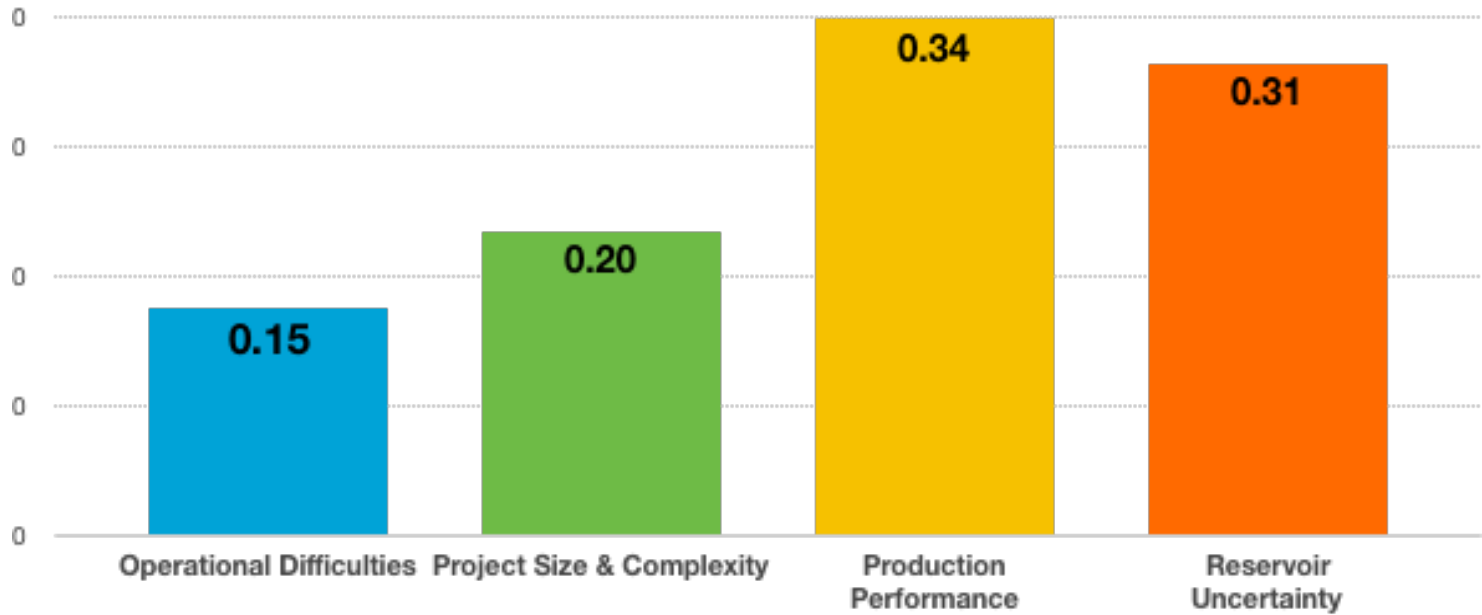

Figure 35: Technical Quantification

The inconsistency within each expert is acceptable (all $<0.10)$. Based on this panel, production performance criteria is assessed as the most important factor with a score of (0.34).

\subsubsection{Political Quantification}

Panel P5 consisted of 5 participants. They were asked to assess the relative contribution of the four success attributes to the political perspective. The experts completed six comparisons to determine the output shown in table 27.

\begin{tabular}{|l|l|l|}
\hline NO. & \multicolumn{1}{|c|}{ Current Position } & \multicolumn{1}{c|}{ Country } \\
\hline Expert 33 & Chief Well Engineer & USA \\
\hline Expert 34 & Project Drilling Manager & Spain \\
\hline Expert 35 & Operations Manager & Democratic Republic of the Congo \\
\hline Expert 36 & Global Markets Manager & Oman \\
\hline Expert 37 & Project Data Engineer & United Kingdom \\
\hline
\end{tabular}

Table 26: Experts in Panel 5 


\begin{tabular}{|l|c|c|c|c|c|}
\hline & $\begin{array}{c}\text { Government } \\
\text { Stability }\end{array}$ & $\begin{array}{c}\text { Conflict } \\
\text { Over } \\
\text { Maritime } \\
\text { Claims }\end{array}$ & $\begin{array}{c}\text { Policies, } \\
\text { Regulations \& } \\
\text { Governance } \\
\text { Standards }\end{array}$ & $\begin{array}{c}\text { Contracts } \\
\text { Complexity }\end{array}$ & Inconsistency \\
\hline Expert 33 & 0.48 & 0.07 & 0.31 & 0.14 & 0.05 \\
\hline Expert 34 & 0.4 & 0.18 & 0.24 & 0.18 & 0.03 \\
\hline Expert 35 & 0.16 & 0.07 & 0.38 & 0.39 & 0.07 \\
\hline Expert 36 & 0.19 & 0.19 & 0.22 & 0.4 & 0.05 \\
\hline Expert 37 & 0.35 & 0.16 & 0.27 & 0.22 & 0 \\
\hline Mean & 0.32 & 0.13 & 0.28 & 0.27 & \\
\hline Minimum & 0.16 & 0.07 & 0.22 & 0.14 & \\
\hline Maximum & 0.48 & 0.19 & 0.38 & 0.4 & \\
\hline $\begin{array}{l}\text { Std. } \\
\text { Deviation }\end{array}$ & 0.12 & 0.05 & 0.06 & 0.11 & \\
\hline Disagreement & & & & 0.085 \\
\hline
\end{tabular}

Table 27: Political Criteria Quantification Results

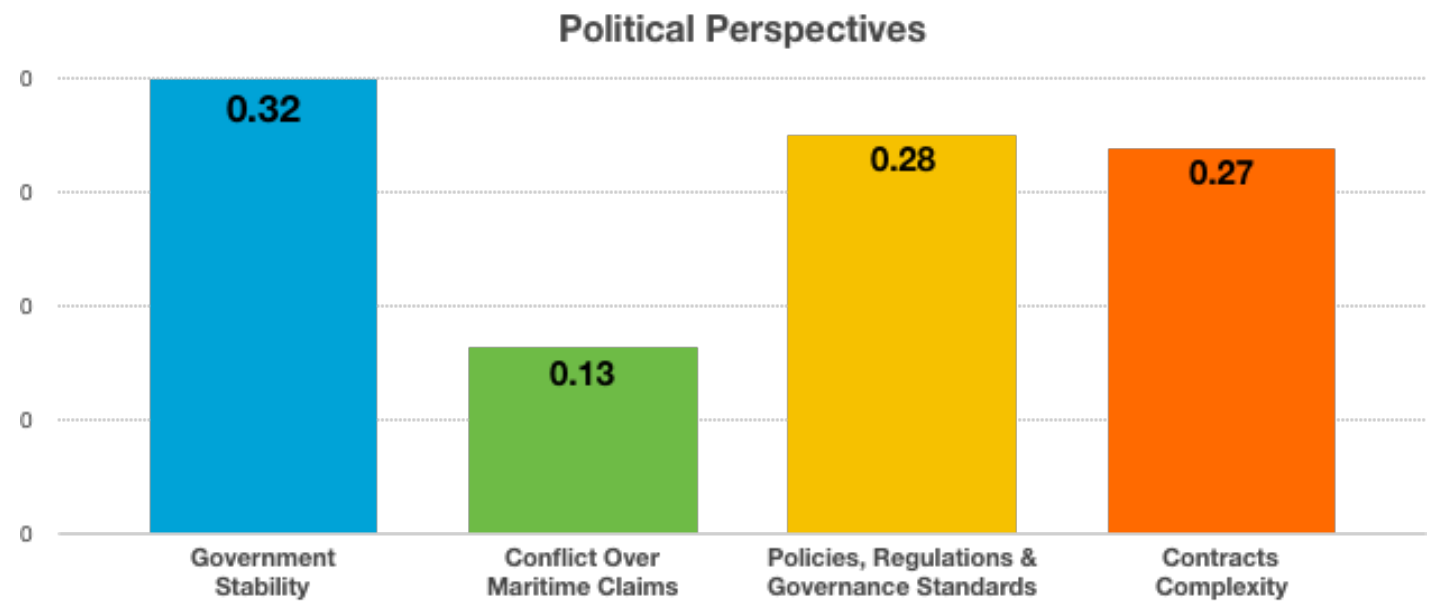

Figure 36: Political Quantification

The inconsistency within each expert is acceptable (all $<0.10)$. Based on this panel, government stability criteria is assessed as the most important factor with a score of (0.32). 


\subsubsection{Environmental \& Safety Quantification}

Panel P6 consisted of 5 participants. They were asked to assess the relative contribution of the four success attributes to the environmental \& safety perspective. The experts completed six comparisons to determine the output shown in table 29 .

\begin{tabular}{|l|l|l|}
\hline NO. & \multicolumn{1}{|c|}{ Current Position } & \multicolumn{1}{c|}{ Country } \\
\hline Expert 38 & Senior Staff Process Safety Engineer & Saudi Arabia \\
\hline Expert 39 & Drilling Ops \& Rig Manager & Russia \\
\hline Expert 40 & Drilling Manage & United Arab Emirates \\
\hline Expert 41 & Chef Department Environmental Group & France \\
\hline Expert 42 & QHSE Engineer & Brazil \\
\hline
\end{tabular}

Table 28: Experts in Panel 6

\begin{tabular}{|l|c|c|c|c|c|}
\hline & $\begin{array}{c}\text { Hazard } \\
\text { Identification } \\
\text { and Risk } \\
\text { Management }\end{array}$ & $\begin{array}{c}\text { Implementing } \\
\text { Health, Safety } \\
\text { and } \\
\text { Environmental }\end{array}$ & $\begin{array}{c}\text { Stringent of } \\
\text { the Local } \\
\text { HSE } \\
\text { Standards }\end{array}$ & $\begin{array}{c}\text { Environmental } \\
\text { Risk } \\
\text { Management } \\
\text { Integration }\end{array}$ & Inconsistency \\
\hline Expert 38 & 0.39 & 0.18 & 0.27 & 0.16 & 0 \\
\hline Expert 39 & 0.24 & 0.22 & 0.35 & 0.19 & 0 \\
\hline Expert 40 & 0.27 & 0.18 & 0.33 & 0.22 & 0.03 \\
\hline Expert 41 & 0.46 & 0.23 & 0.16 & 0.15 & 0.05 \\
\hline Expert 42 & 0.35 & 0.22 & 0.27 & 0.16 & 0.04 \\
\hline Mean & 0.34 & 0.21 & 0.27 & 0.18 & \\
\hline Minimum & 0.24 & 0.18 & 0.16 & 0.15 & \\
\hline Maximum & 0.46 & 0.23 & 0.35 & 0.22 & \\
\hline $\begin{array}{l}\text { Std. } \\
\text { Deviation }\end{array}$ & 0.08 & 0.02 & 0.07 & 0.03 & \\
\hline Disagreement & \multicolumn{5}{l|}{} \\
\hline
\end{tabular}

Table 29: Environmental \& Safety Criteria Quantification Results 


\section{Environmental \& Safety Perspectives}

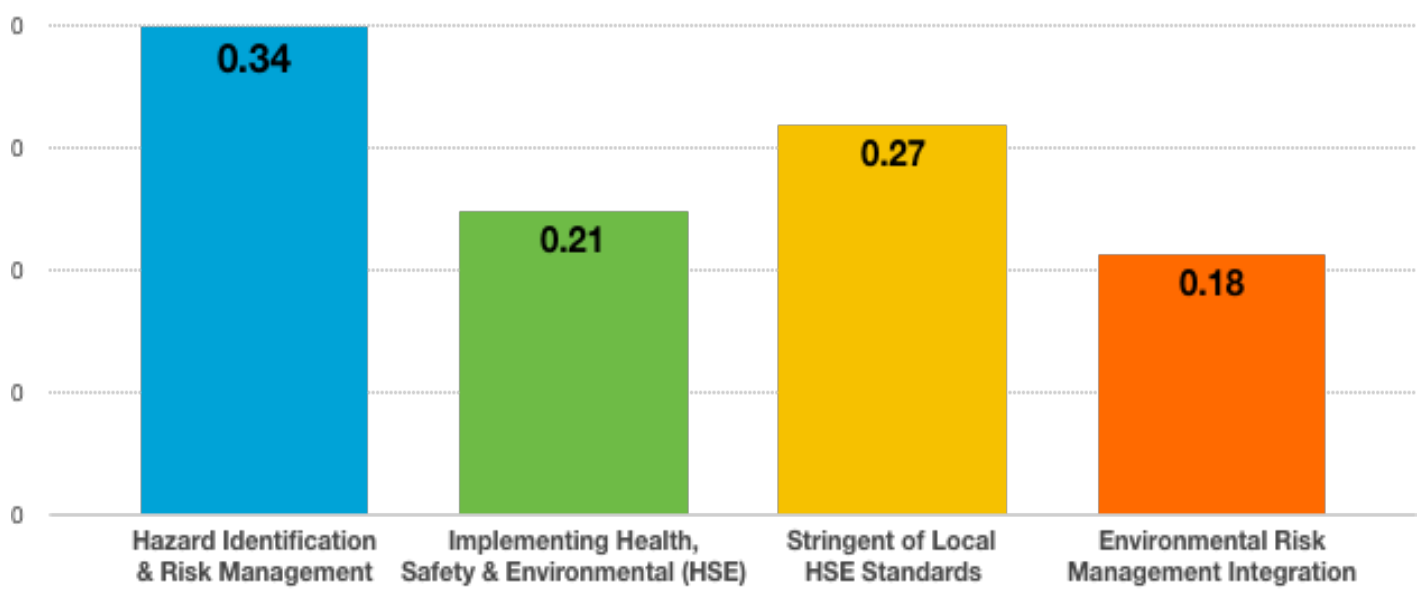

Figure 37: Environmental \& Safety Quantification

The inconsistency within each expert is acceptable (all $<0.10$ ). Based on this panel, Hazard identification \& risk management criteria is assessed as the most important factor with a score of (0.34).

\subsection{Final Model Weights}

The output of experts' judgment quantification has been summarized in Table 30 and Figure 38. The table includes local and global importance values for each factor. The most important perspective is economic with a score of 0.32 and the corresponding most important success attribute is oil price 0.35 . The experts scored environmental and safety as the second most important perspective with a value of 0.3 and indicated that it is affected by the hazard identification and risk management criterion that has a value of 0.34. Nevertheless, return on investment, production performance, and government stability have high impacts on offshore oil project overall evaluation based on experts' judgment quantification. 


\begin{tabular}{|c|c|c|c|c|}
\hline Perspectives & Value & Criteria & $\begin{array}{l}\text { Local } \\
\text { Value }\end{array}$ & $\begin{array}{l}\text { Global } \\
\text { Value }\end{array}$ \\
\hline \multirow{4}{*}{ Economical } & \multirow{4}{*}{0.32} & Petroleum Prices & 0.35 & 0.12 \\
\hline & & Initial Cost & 0.17 & 0.05 \\
\hline & & Operational Cost & 0.16 & 0.05 \\
\hline & & Return on Investment (ROI) & 0.32 & 0.10 \\
\hline \multirow{4}{*}{ Technical } & \multirow{4}{*}{0.14} & Operational Difficulties & 0.15 & 0.02 \\
\hline & & Project Size \& Complexity & 0.2 & 0.03 \\
\hline & & Production Performance & 0.34 & 0.05 \\
\hline & & Reservoir Uncertainty & 0.31 & 0.04 \\
\hline \multirow{4}{*}{ Political } & \multirow{4}{*}{0.24} & Government Stability & 0.32 & 0.08 \\
\hline & & Conflict Over Maritime Claims & 0.13 & 0.03 \\
\hline & & $\begin{array}{l}\text { Policies, Regulations \& Governance } \\
\text { Standards }\end{array}$ & 0.28 & 0.07 \\
\hline & & Contracts Complexity & 0.27 & 0.06 \\
\hline \multirow{4}{*}{$\begin{array}{l}\text { Environment } \\
\text { al \& Safety }\end{array}$} & \multirow{4}{*}{0.3} & $\begin{array}{l}\text { Hazard Identification and Risk } \\
\text { Management }\end{array}$ & 0.34 & 0.10 \\
\hline & & $\begin{array}{l}\text { Implementing Health, Safety and } \\
\text { Environmental (HSE) }\end{array}$ & 0.21 & 0.06 \\
\hline & & Stringent of the Local HSE Standards & 0.27 & 0.09 \\
\hline & & $\begin{array}{l}\text { Environmental Risk Management } \\
\text { Integration }\end{array}$ & 0.18 & 0.05 \\
\hline
\end{tabular}

Table 30: Experts' Judgment Quantification Output

The following graph shows the final global weights that represent the contribution of each criterion to the mission through the perspectives. 


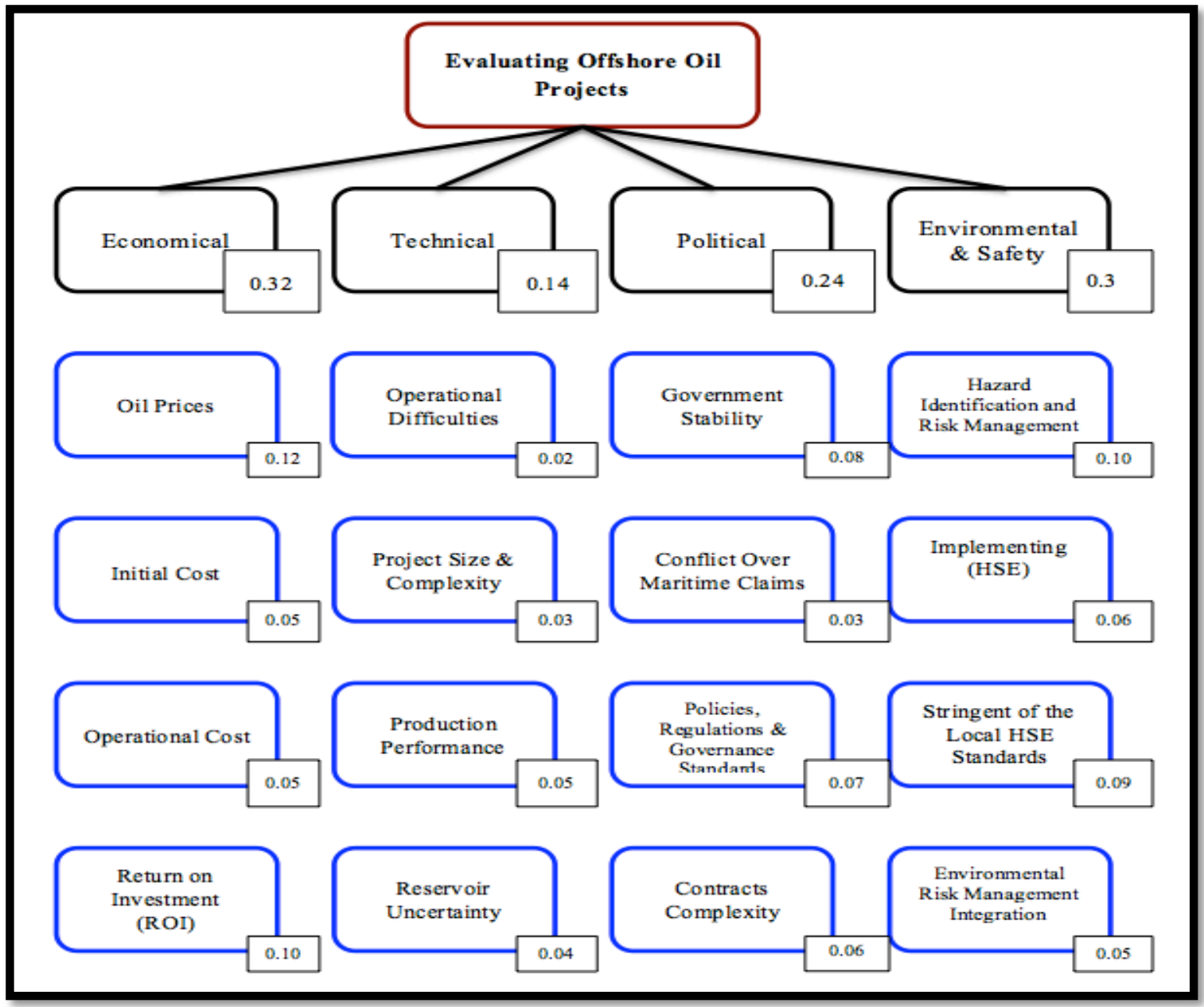

Figure 38: Final Model Weights

\subsection{Model Inconsistency Results}

Inconsistency is one of the critical factors that could affect the results of the model and it should be calculated and controlled in order to achieve reliable outcomes. Acceptable inconsistency has a value of 0.1 or less, according to Kocaoglu. Experts' judgment was analyzed mathematically for inconsistency (more details about 
inconsistency analysis can be found in Sections 4.9). Based on the HDM results, inconsistency value among the experts is described as the following:

- The highest inconsistency value among the experts in P2 (Perspective Panel) was 0.07. The highest inconsistency value among the experts in P3 (Economical Panel) was 0.08 .

- The highest inconsistency value among the experts in P4 (Technical Panel) was 0.08 .

- The highest inconsistency value among the experts in P5 (Political Panel) was 0.07 .

- The highest inconsistency value among the experts in P6 (Environmental \& Safety Panel) was 0.05 .

Therefore, the inconsistency within each expert is acceptable (all $<0.10)$.

\subsection{Model Disagreement Results}

Disagreements amongst experts can show different quantifications and different perspectives to the same analysis. There is group disagreement if the disagreement exceeds a value of 0.10 and a value of 0 would imply complete agreement among the experts [106]. Experts have different backgrounds and experiences that most likely will increase the level of disagreements amongst them. However, Acceptable disagreement has a value of 0.1 or less, according to Kocaoglu. Experts' judgment was analyzed mathematically for disagreement (more details about disagreement analysis can be found 
in Sections 4.10). Based on HDM disagreements value among the experts is described as the following:

- Disagreements value among the experts in P2 (Perspective Panel) was 0.038.

- Disagreements value among the experts in P3 (Economical Panel) was 0.06.

- Disagreements value among the experts in P4 (Technical Panel) was 0.084.

- Disagreements value among the experts in P5 (Political Panel) was 0.085.

- Disagreements value among the experts in P6 (Environmental \& Safety Panel) was 0.048 .

Therefore, the disagreement among the experts is acceptable $($ all $<0.10)$.

\subsection{Desirability Curves}

Panel 7 was formatted to validate and quantify the desirability curves (see section 6.4). Following previous research [97][98], the average value of experts' judgments was considered as the final value for the curves creation. The following chart shows each expert's judgments along with the mean values and the curves for each factor. The main benefit of using desirability functions is to provide a standard metrics that decision makers can rely on to make quick and constant decisions without having to go back and consult with the experts or replicate the model and apply it again. Additionally, the desirability metric as a powerful tool that can be conducted with the HDM has been implemented widely in several studies [109][95]. 


\subsubsection{Economical Perspective Desirability Value}

The results of the desirability metrics quantifications of the economical factors show in tables $31-38$.

\begin{tabular}{|c|c|c|}
\hline Factors & Desirability Units & Desirability Scores \\
\hline \multirow{5}{*}{ Oil Prices } & Oil Price $\leq \$ 10$ & \multirow{5}{*}{$\begin{array}{l}\text { From } 0 \text { to } 100 \text { experts were asked to score and } \\
\text { rank oil price desirability unit based on their } \\
\text { experiences. } \\
\text { Notice: In July } 2008 \text { crude oil reached a record } \\
\text { peak of US } \$ 147.27 \text {. In } 2015 \text { crude oil price was } \\
\text { between } \$ 48.56 \text { - } 33.04 \text { at that time } 67 \text { US oil and } \\
\text { natural gas companies filed for bankruptcy. }\end{array}$} \\
\hline & Oil Price $=\$ 40$ & \\
\hline & Oil Price $=\$ 60$ & \\
\hline & Oil Price $=\$ 120$ & \\
\hline & Oil Price $\geq \$ 150$ & \\
\hline
\end{tabular}

Table 31: Oil Price Desirability Units

\begin{tabular}{|l|c|}
\hline \multicolumn{1}{|l|}{ Oil Price } \\
\hline \multicolumn{1}{|c|}{ Description } & Desirability \\
\hline Oil Price $\leq \$ 10$ & 0 \\
Oil Price $=\$ 40$ & 28 \\
Oil Price $=\$ 60$ & 53 \\
Oil Price $=\$ 120$ & 92 \\
Oil Price $\geq \$ 150$ & 100 \\
\cline { 2 - 2 } &
\end{tabular}

Table 32: Oil Price Desirability Value

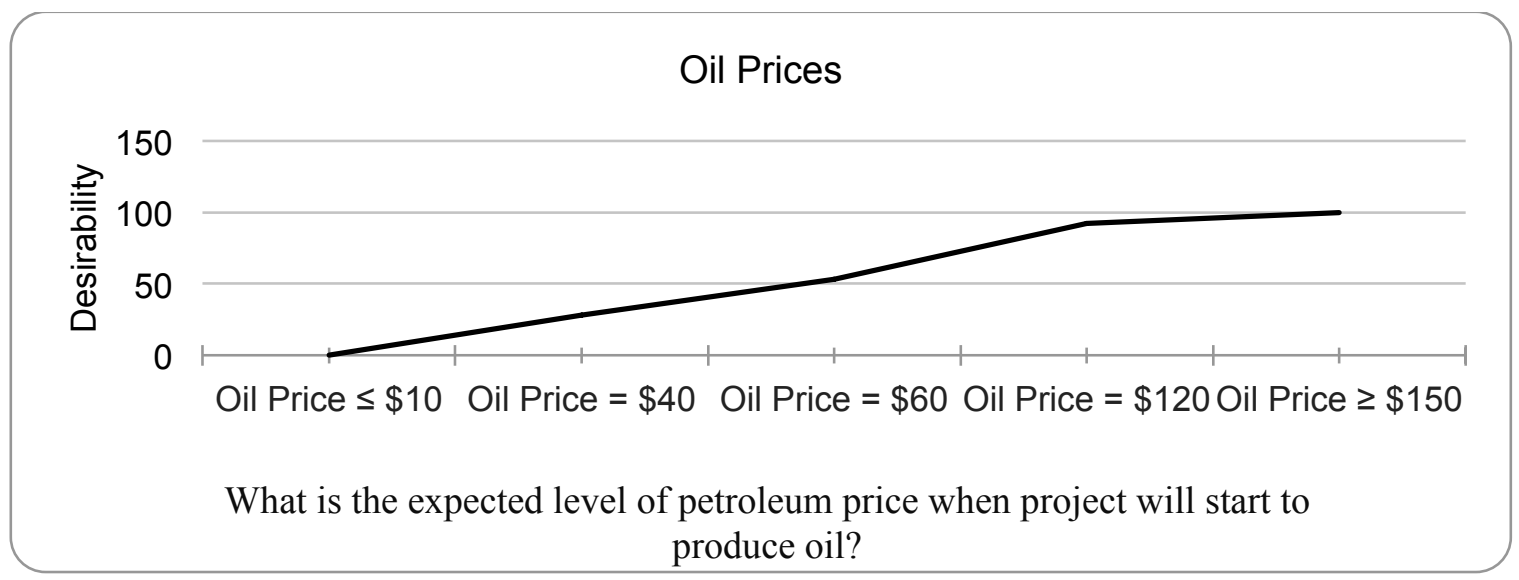

Figure 39: Oil Price Desirability Value

113 


\begin{tabular}{|c|c|c|}
\hline Factors & Desirability Units & Desirability Scores \\
\hline \multirow{5}{*}{$\begin{array}{l}\text { Initial } \\
\text { Cost }\end{array}$} & Initial Cost $\leq 500$ million & \multirow{5}{*}{$\begin{array}{l}\text { From } 0 \text { to } 100 \text { experts were asked } \\
\text { to score and rank initial cost } \\
\text { desirability unit based on their } \\
\text { experiences. }\end{array}$} \\
\hline & Initial Cost $=1$ Billion & \\
\hline & Initial Cost $=10$ Billion & \\
\hline & Initial Cost $=50$ Billion & \\
\hline & Initial Cost $\geq 95$ Billion & \\
\hline
\end{tabular}

Table 33: Initial Cost Desirability Units

\begin{tabular}{|l|c|}
\hline \multicolumn{1}{|c|}{ Initial Cost } \\
\hline \multicolumn{1}{|c|}{ Description } & Desirability \\
\hline Initial Cost $\leq 500$ million & 100 \\
Initial Cost $=$ 1 Billion & 70 \\
Initial Cost $=$ 10 Billion & 43 \\
Initial Cost $=50$ Billion & 20 \\
Initial Cost $\geq 95$ Billion & 0 \\
\cline { 2 - 2 }
\end{tabular}

Table 34: Initial Cost Desirability Value

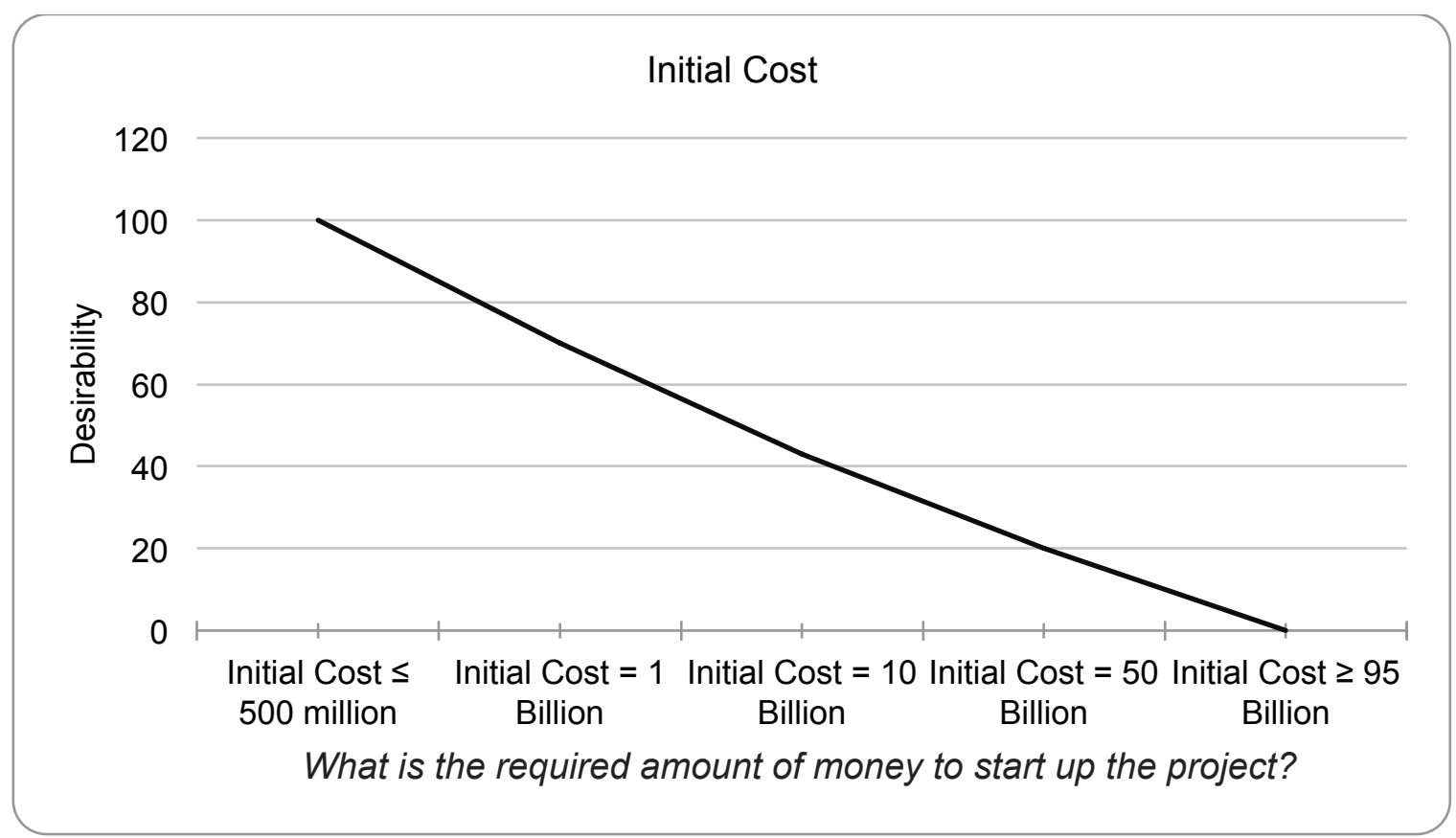

Figure 40: Initial Cost Desirability Value 


\begin{tabular}{|l|l|l|}
\hline Factors & Desirability Units & Desirability Scores \\
\hline \multirow{4}{*}{$\begin{array}{l}\text { Operational } \\
\text { Cost }\end{array}$} & $\begin{array}{l}\text { Low estimated cost of operating } \\
\text { expenses }\end{array}$ & $\begin{array}{l}\text { From } 0 \text { to } 100 \text { experts were asked } \\
\text { to score and rank operational cost } \\
\text { desirability unit based on their } \\
\text { experiences. } \\
\text { operating expenses }\end{array}$ \\
\cline { 2 - 2 } & $\begin{array}{l}\text { High estimated cost of operating } \\
\text { expenses }\end{array}$ & \\
\cline { 2 - 2 } & $\begin{array}{l}\text { Extremely high estimated cost of } \\
\text { operating expenses }\end{array}$ & \\
\hline
\end{tabular}

Table 35: Operational Cost Desirability Units

\begin{tabular}{|l|c|}
\hline \multicolumn{2}{|c|}{ Operational Cost } \\
\hline \multicolumn{1}{|c|}{ Description } & Desirability \\
\hline Low estimated cost of operating expenses & 100 \\
Average estimated cost of operating expenses & 80 \\
High estimated cost of operating expenses & 30 \\
Extremely high estimated cost of operating expenses & 0 \\
\cline { 2 - 2 } &
\end{tabular}

Table 36: Operational Cost Desirability Value

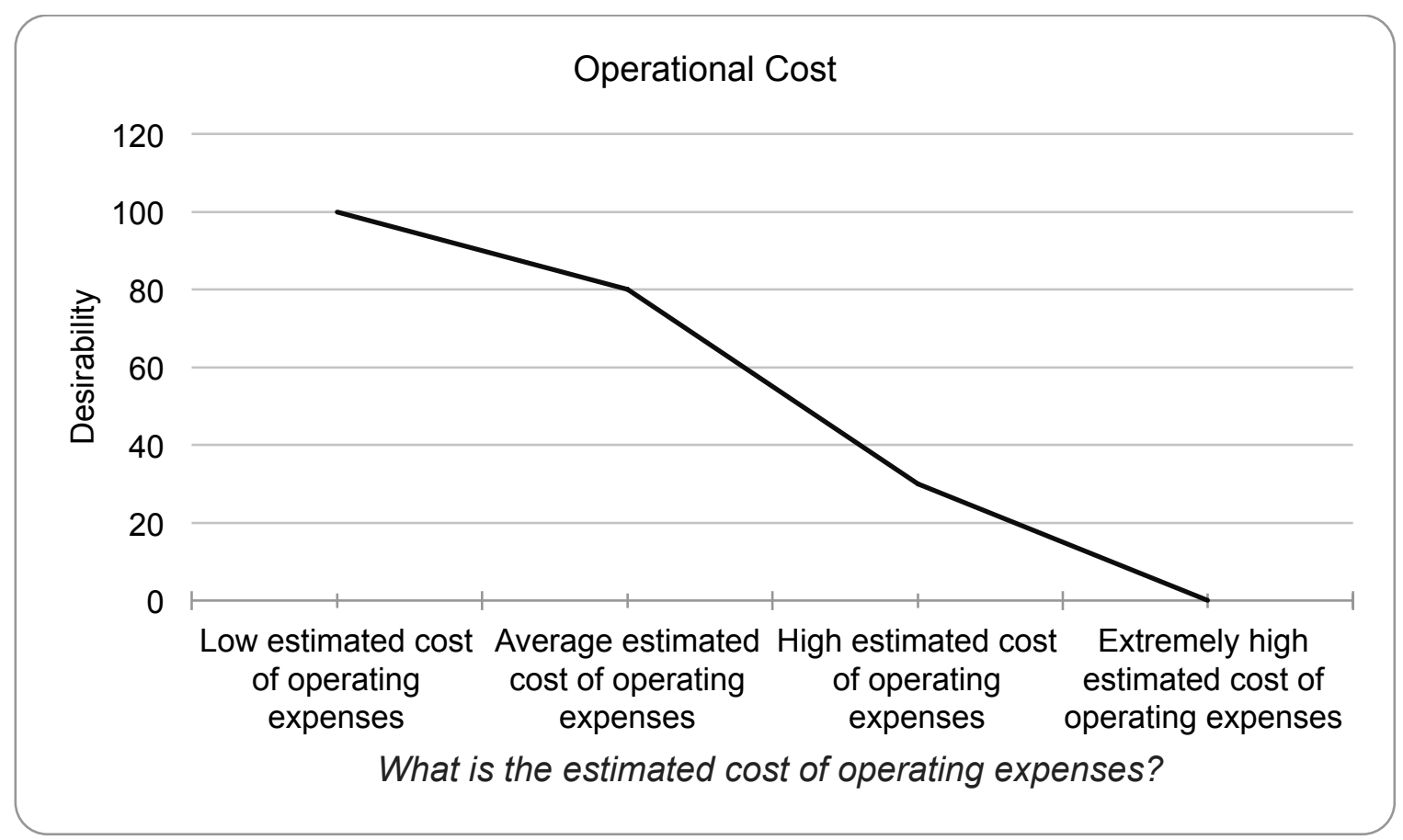

Figure 41: Operational Cost Desirability Value 


\begin{tabular}{|l|l|l|}
\hline Factors & Desirability Units & Desirability Scores \\
\hline \multirow{4}{*}{$\begin{array}{l}\text { Return on } \\
\text { Investment } \\
\text { (ROI) }\end{array}$} & Negative or less than zero & From 0 to 100 experts were asked to \\
\cline { 2 - 2 } & ROI between $10-50$ percent & score and rank return on investment \\
\cline { 2 - 2 } & ROI between $50-70$ percent & desirability unit based on their \\
\cline { 2 - 2 } & ROI between $70-90$ percent & experiences. \\
\cline { 2 - 2 } & ROI equal or exceed 100 percent & \\
\hline
\end{tabular}

Table 37: Return on Investment Desirability Units

\begin{tabular}{|l|c|}
\hline \multicolumn{1}{|c|}{ Return on Investment (ROI) } \\
\hline \multicolumn{1}{|c|}{ Description } & Desirability \\
\hline Negative or less than zero & 0 \\
ROI between $10-50$ percent & 50 \\
ROI between 50 - 70 percent & 70 \\
\cline { 2 - 2 } ROI between 70 - 90 percent & 92 \\
\cline { 2 - 2 } ROI equal or exceed 100 percent & 100 \\
\cline { 2 - 3 }
\end{tabular}

Table 38: Return on Investment Desirability Value

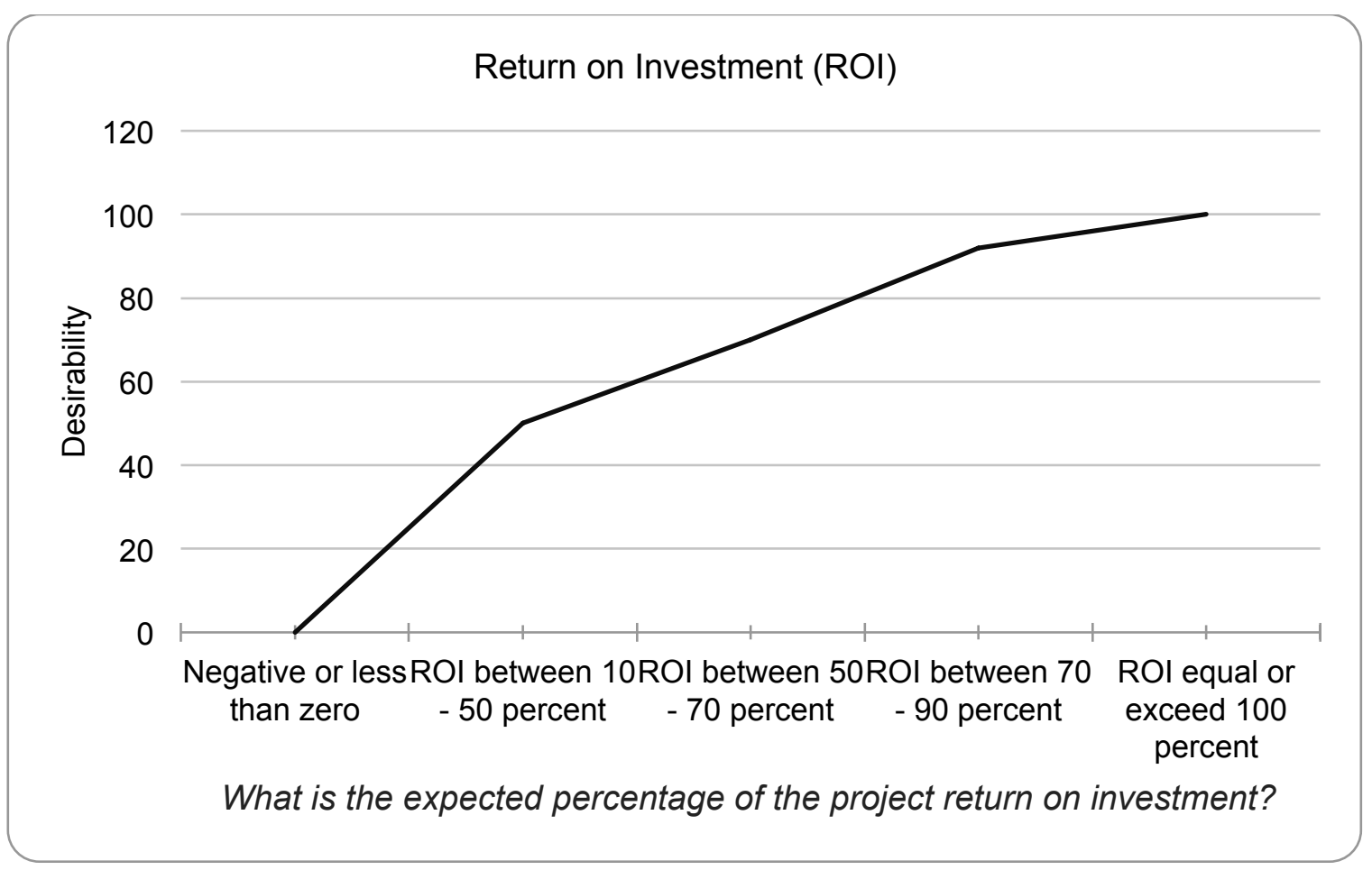

Figure 42: Return on Investment Desirability Value 


\subsubsection{Technical Perspective Desirability Value}

The results of the desirability metrics quantifications of the technical factors show in Tables $39-46$.

\begin{tabular}{|c|c|c|}
\hline Factors & Desirability Units & Desirability Scores \\
\hline \multirow{4}{*}{$\begin{array}{l}\text { Operational } \\
\text { Difficulties }\end{array}$} & $\begin{array}{l}\text { Project expected to face low level of } \\
\text { operational difficulties }\end{array}$ & \multirow{4}{*}{$\begin{array}{l}\text { From } 0 \text { to } 100 \text { experts were } \\
\text { asked to score and rank } \\
\text { operational difficulties } \\
\text { desirability unit based on } \\
\text { their experiences. }\end{array}$} \\
\hline & $\begin{array}{l}\text { Project expected to face medium level } \\
\text { of operational difficulties }\end{array}$ & \\
\hline & $\begin{array}{l}\text { Project expected to face high level of } \\
\text { operational difficulties }\end{array}$ & \\
\hline & $\begin{array}{l}\text { Project expected to face extremely high } \\
\text { level of operational difficulties }\end{array}$ & \\
\hline
\end{tabular}

Table 39: Operational Difficulties Desirability Units

\section{Operational Difficulties}

\begin{tabular}{|l|c|}
\hline \multicolumn{1}{|c|}{ Description } & Desirability \\
\hline Project expected to face low level of operational difficulties & 100 \\
Project expected to face medium level of operational difficulties & 74 \\
\cline { 2 - 2 } Project expected to face high level of operational difficulties & 23 \\
Project expected to face extremely high level of operational difficulties & 0 \\
\hline
\end{tabular}

Table 40: Operational Difficulties Desirability Value

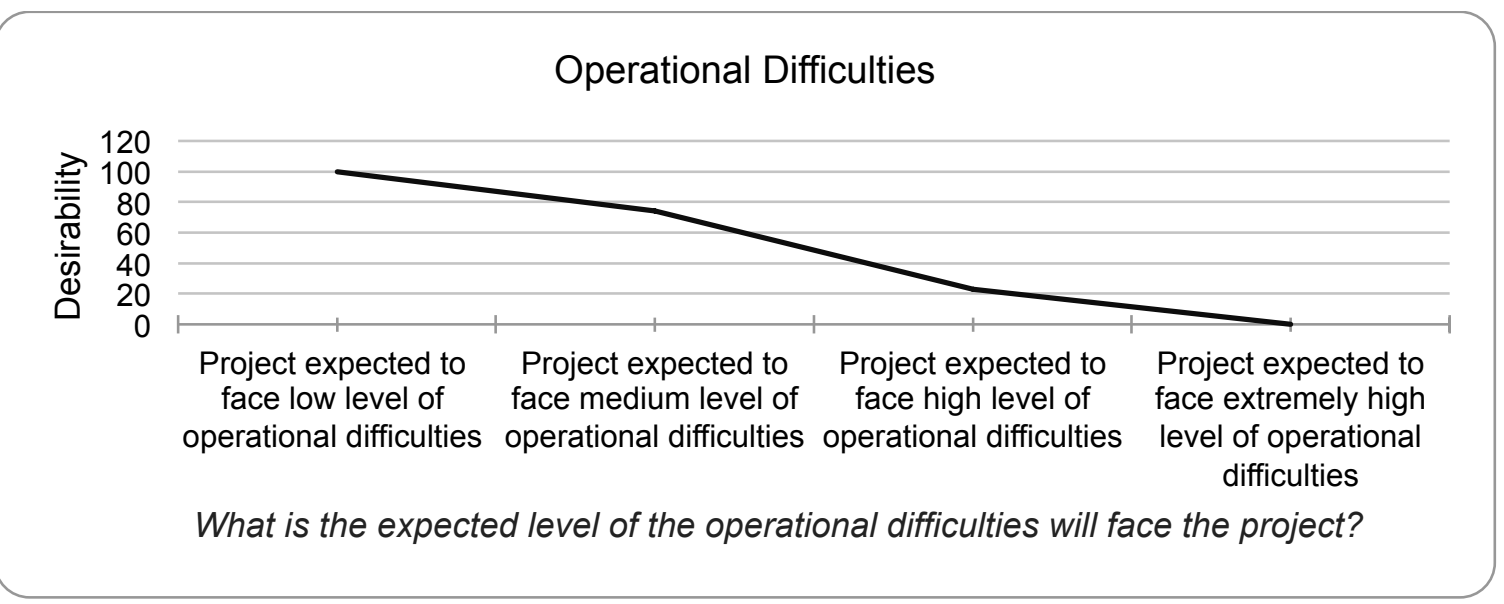

Figure 43: Operational Difficulties Desirability Value 


\begin{tabular}{|c|c|c|}
\hline Factors & Desirability Units & Desirability Scores \\
\hline \multirow{4}{*}{$\begin{array}{l}\text { Project Size } \\
\& \\
\text { Complexity }\end{array}$} & No complexity & \multirow{4}{*}{$\begin{array}{l}\text { From } 0 \text { to } 100 \text { experts were asked } \\
\text { to score and rank project size } \& \\
\text { complexity desirability unit based } \\
\text { on their experiences. }\end{array}$} \\
\hline & Average complexity & \\
\hline & High complexity & \\
\hline & Extremely high complexity & \\
\hline
\end{tabular}

Table 41: Project Size \& Complexity Desirability Units

\begin{tabular}{|l|l|}
\hline Project Size \& Complexity \\
\hline Description & Desirability \\
\hline No complexity & 100 \\
\cline { 2 - 2 } Average complexity & 67 \\
\cline { 2 - 2 } High complexity & 27 \\
\cline { 2 - 2 } Extremely high complexity & 0 \\
\hline
\end{tabular}

Table 42: Project Size \& Complexity Desirability Value

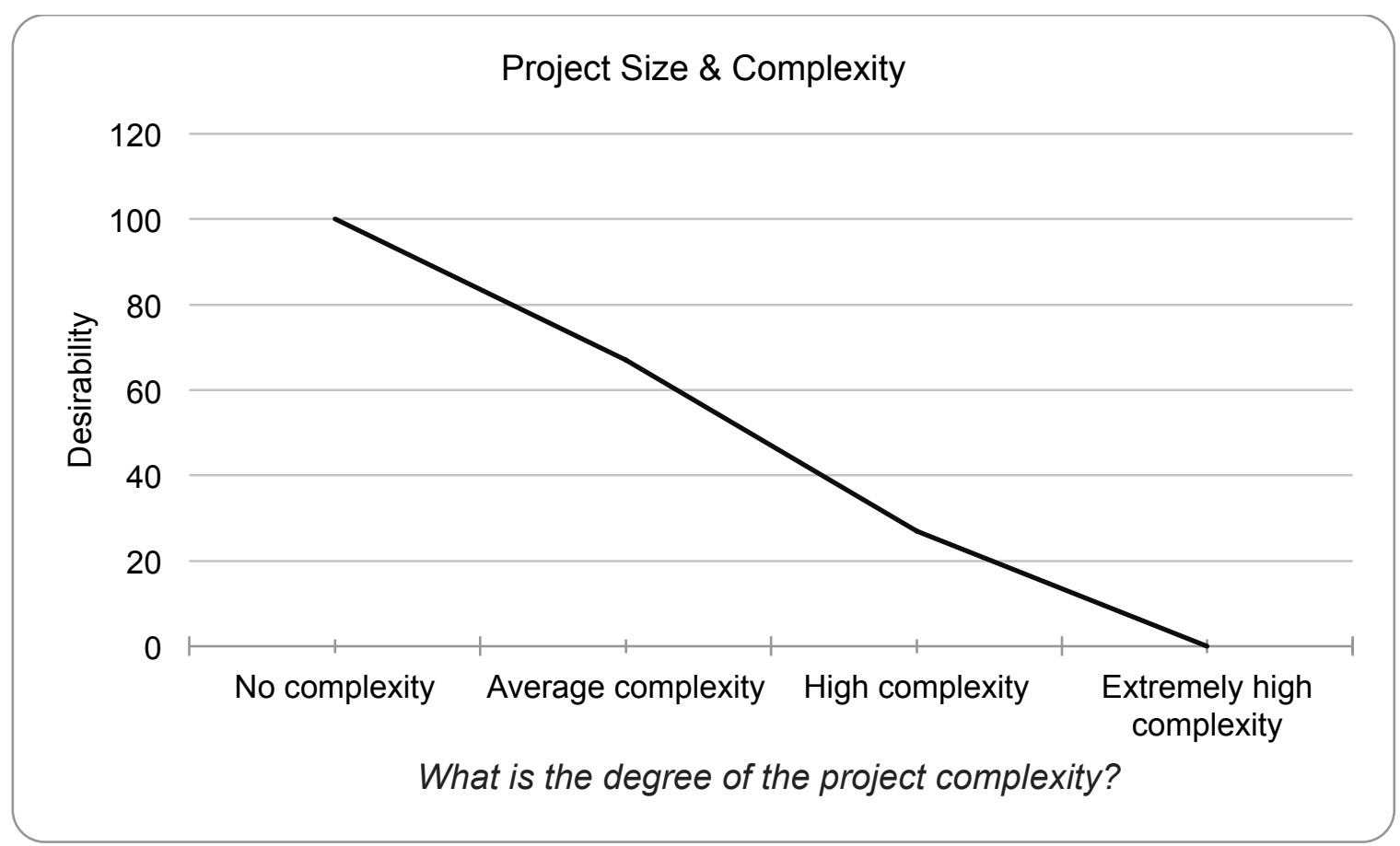

Figure 44: Project Size \& Complexity Desirability Value 


\begin{tabular}{|c|c|c|}
\hline Factors & Desirability Units & Desirability Scores \\
\hline \multirow{4}{*}{$\begin{array}{l}\text { Production } \\
\text { Performance }\end{array}$} & Low Production Performance & \multirow{4}{*}{$\begin{array}{l}\text { From } 0 \text { to } 100 \text { experts were } \\
\text { asked to score and rank } \\
\text { production performance } \\
\text { desirability unit based on } \\
\text { their experiences. }\end{array}$} \\
\hline & Average Production Performance & \\
\hline & High Production Performance & \\
\hline & Extremely high Production Performance & \\
\hline
\end{tabular}

Table 43: Production Performance Desirability Units

\begin{tabular}{|l|c|}
\hline Production Performance \\
\hline Description & Desirability \\
\hline Low Production Performance & 0 \\
Average Production Performance & 43 \\
High Production Performance & 83 \\
\cline { 2 - 2 } Extremely high Production Performance & 100 \\
\cline { 2 - 2 }
\end{tabular}

Table 44: Production Performance Desirability Value

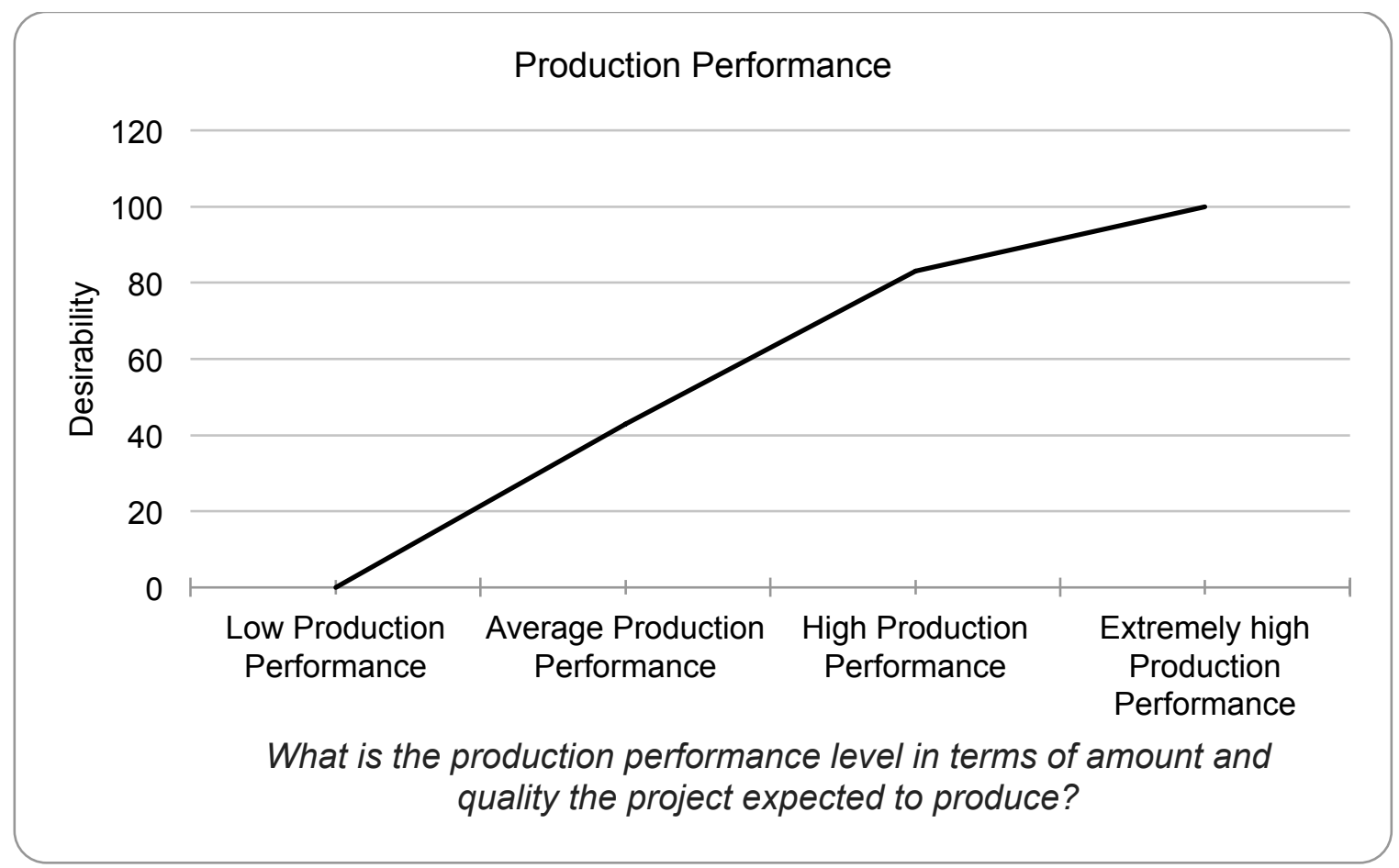

Figure 45: Production Performance Desirability Value 


\begin{tabular}{|c|c|c|}
\hline Factors & Desirability Units & Desirability Scores \\
\hline \multirow{4}{*}{$\begin{array}{l}\text { Subsurface \& } \\
\text { Reservoir }\end{array}$} & $\begin{array}{l}\text { Project has a high certainty of reservoir } \\
\text { volume }\end{array}$ & \multirow{4}{*}{$\begin{array}{l}\text { From } 0 \text { to } 100 \text { experts } \\
\text { were asked to score } \\
\text { and rank subsurface \& } \\
\text { reservoir desirability } \\
\text { unit based on their } \\
\text { experiences. }\end{array}$} \\
\hline & $\begin{array}{l}\text { Project has a low uncertainty of reservoir } \\
\text { volume }\end{array}$ & \\
\hline & $\begin{array}{l}\text { Project has a average uncertainty of reservoir } \\
\text { volume }\end{array}$ & \\
\hline & $\begin{array}{l}\text { Project has a high uncertainty of reservoir } \\
\text { volume }\end{array}$ & \\
\hline
\end{tabular}

Table 45: Subsurface \& Reservoir Desirability Units

\begin{tabular}{|l|l|}
\hline Subsurface \& Reservoir & Desirability \\
\hline Description & 100 \\
\hline Project has a high certainty of reservoir volume & 77 \\
\cline { 2 - 2 } Project has a low uncertainty of reservoir volume & 33 \\
\cline { 2 - 2 } Project has a average uncertainty of reservoir volume & 0 \\
Project has a high uncertainty of reservoir volume &
\end{tabular}

Table 46: Subsurface \& Reservoir Desirability Value

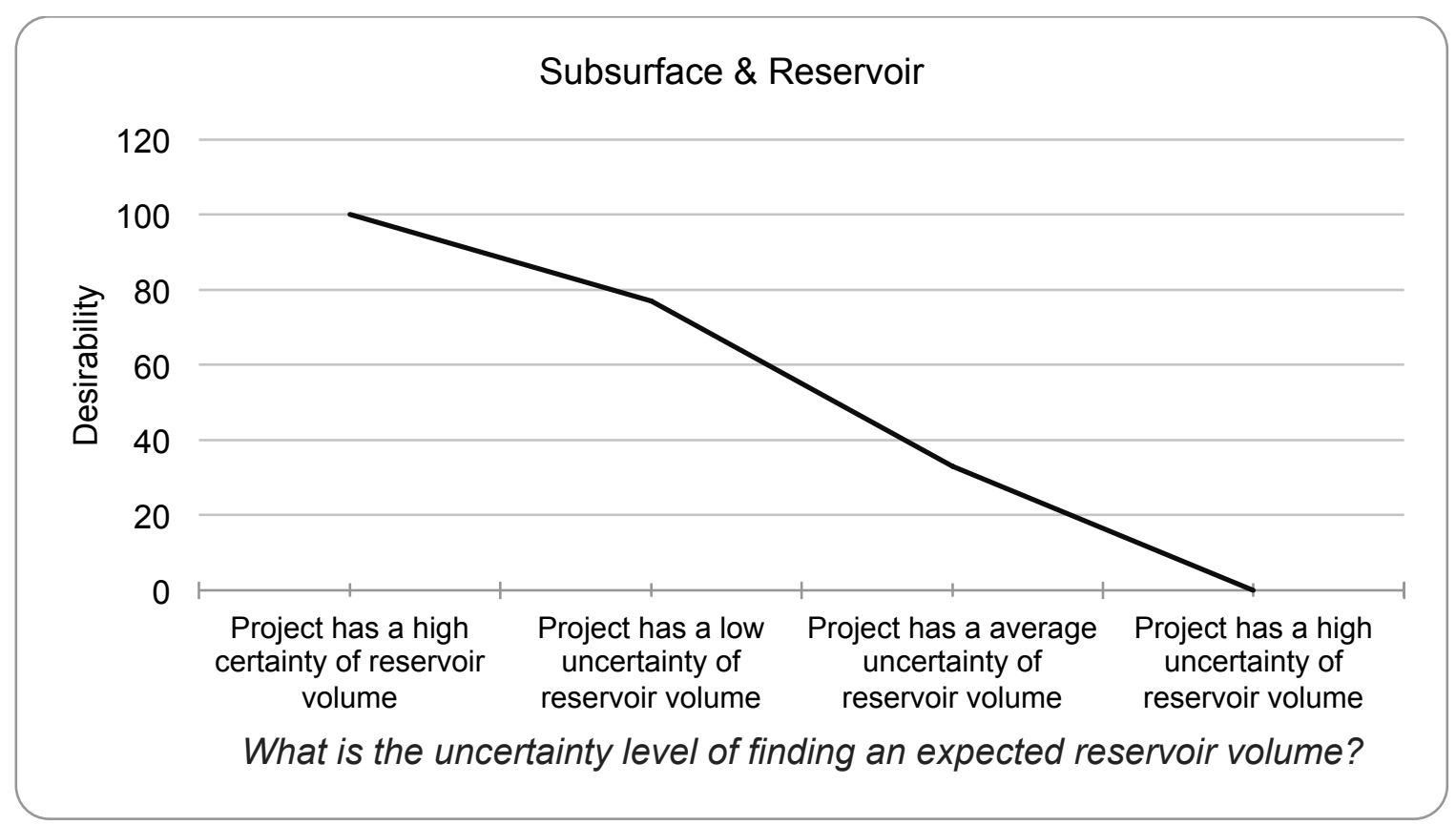

Figure 46: Subsurface $\&$ Reservoir Desirability Value 


\subsubsection{Political Perspective Desirability Value}

The results of the desirability metrics quantifications of the political factors show in

Tables $47-54$

\begin{tabular}{|c|c|c|}
\hline Factors & Desirability Units & Desirability Scores \\
\hline \multirow{4}{*}{$\begin{array}{l}\text { Government } \\
\text { Stability }\end{array}$} & Unstable country & \multirow{4}{*}{$\begin{array}{l}\text { From } 0 \text { to } 100 \text { experts were asked } \\
\text { to score and rank government } \\
\text { stability desirability unit based on } \\
\text { their experiences. }\end{array}$} \\
\hline & High risk of instability & \\
\hline & Some risk of instability & \\
\hline & Stable country & \\
\hline
\end{tabular}

Table 47: Government Stability Desirability Units

\begin{tabular}{|l|c|}
\hline Government Stability \\
\hline Description & Desirability \\
\hline Unstable country & 0 \\
High risk of instability & 15 \\
\cline { 2 - 2 } Some risk of instability & 47 \\
\cline { 2 - 2 } Stable country & 100 \\
\cline { 2 - 2 } &
\end{tabular}

Table 48: Government Stability Desirability Value

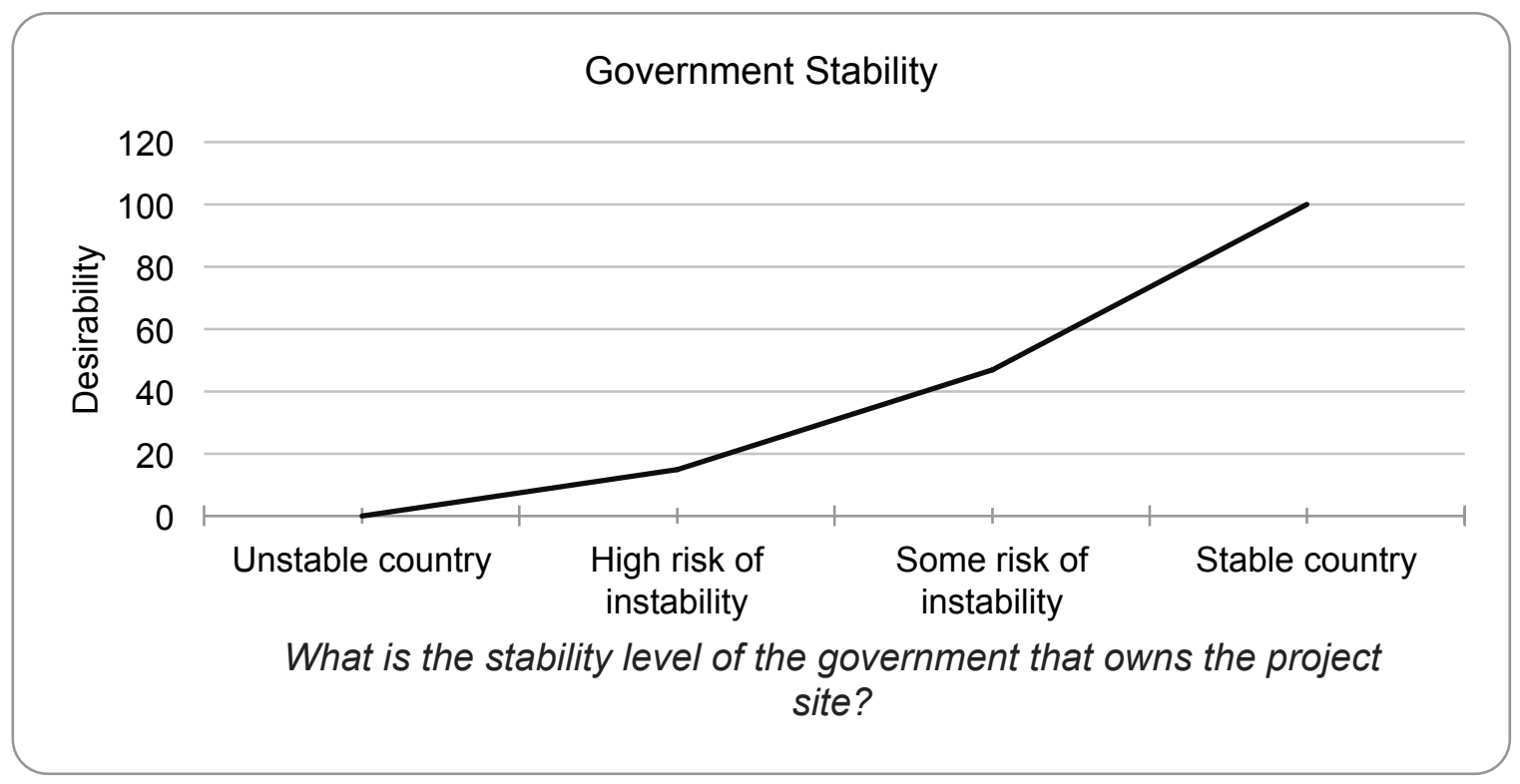

Figure 47: Government Stability Desirability Value 


\begin{tabular}{|c|c|c|}
\hline Factors & Desirability Units & Desirability Scores \\
\hline \multirow{4}{*}{$\begin{array}{l}\text { Conflict } \\
\text { Over } \\
\text { Maritime } \\
\text { Claims }\end{array}$} & No conflict over maritime & \multirow{4}{*}{$\begin{array}{l}\text { From } 0 \text { to } 100 \text { experts were } \\
\text { asked to score and rank } \\
\text { conflict over maritime } \\
\text { claims desirability unit } \\
\text { based on their experiences. }\end{array}$} \\
\hline & $\begin{array}{l}\text { Low probability of conflict over } \\
\text { maritime }\end{array}$ & \\
\hline & $\begin{array}{l}\text { High probability of conflict over } \\
\text { maritime }\end{array}$ & \\
\hline & Conflicted Area & \\
\hline
\end{tabular}

Table 49: Conflict Over Maritime Claims Desirability Units

\begin{tabular}{|l|c|}
\hline Conflict Over Maritime Claims \\
\hline Description & Desirability \\
\hline No conflict over maritime & 100 \\
Low probability of conflict over maritime & 70 \\
High probability of conflict over maritime & 23 \\
\cline { 2 - 2 } Conflicted Area & 0 \\
\cline { 2 - 2 }
\end{tabular}

Table 50: Conflict Over Maritime Claims Desirability Value

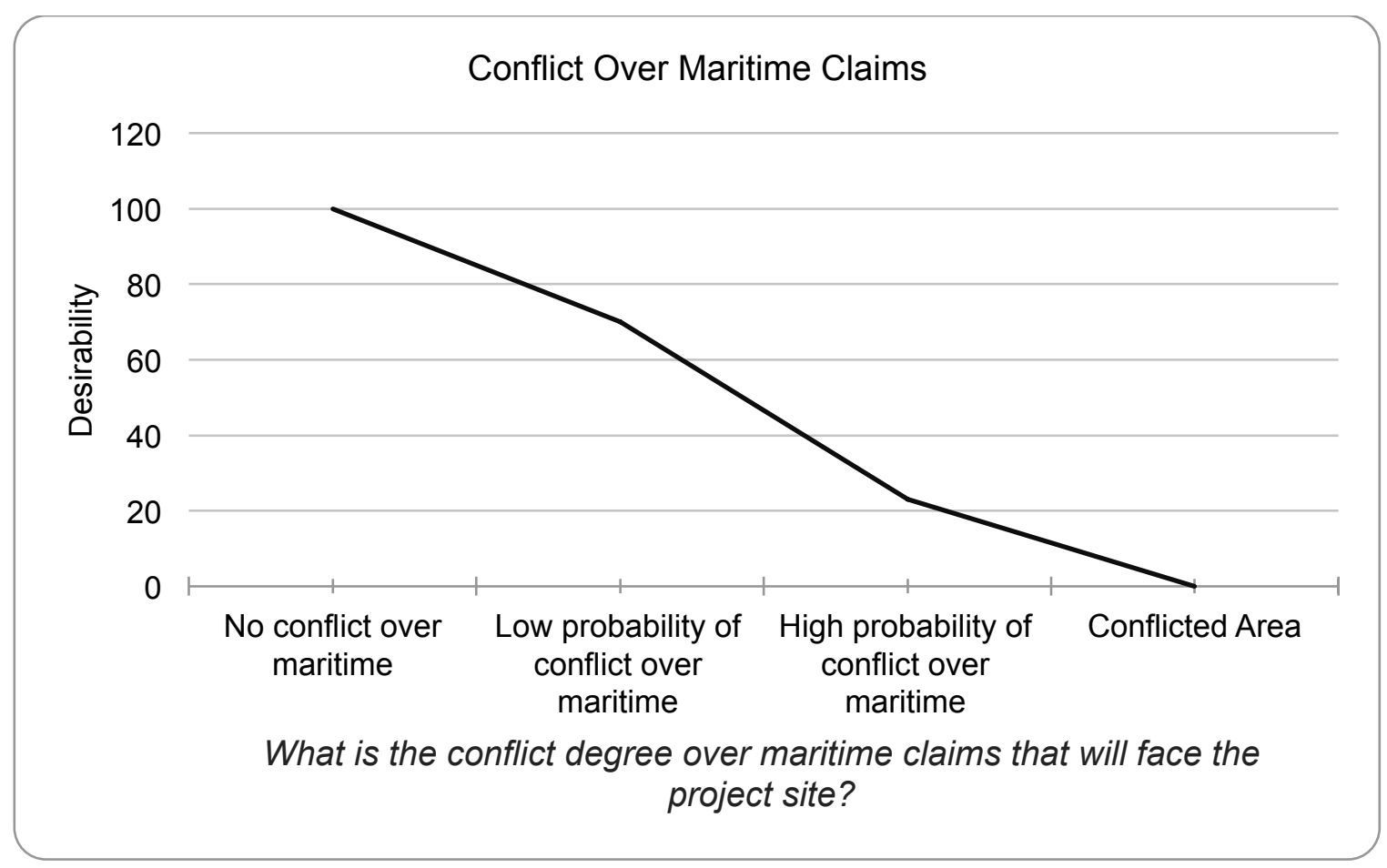

Figure 48: Conflict Over Maritime Claims Desirability Value 


\begin{tabular}{|c|c|c|}
\hline Factors & Desirability Units & Desirability Scores \\
\hline \multirow{4}{*}{$\begin{array}{l}\text { Policies, } \\
\text { Regulations } \\
\& \\
\text { Governance } \\
\text { Standards }\end{array}$} & $\begin{array}{l}\text { Low level of policies, regulations and } \\
\text { governance standards }\end{array}$ & \multirow{4}{*}{$\begin{array}{l}\text { From } 0 \text { to } 100 \text { experts } \\
\text { were asked to score } \\
\text { and rank policies, } \\
\text { regulations \& } \\
\text { governance standards } \\
\text { desirability unit based } \\
\text { on their experiences. }\end{array}$} \\
\hline & $\begin{array}{l}\text { Average level of policies, regulations and } \\
\text { governance standards }\end{array}$ & \\
\hline & $\begin{array}{l}\text { High level of policies, regulations and } \\
\text { governance standards }\end{array}$ & \\
\hline & $\begin{array}{l}\text { Extremely high level of policies, regulations } \\
\text { and governance standards }\end{array}$ & \\
\hline
\end{tabular}

Table 51: Policies, Regulations \& Governance Standards Desirability Units

\begin{tabular}{|l|c|}
\hline Policies, Regulations \& Governance Standards \\
\hline Description & Desirability \\
\hline Low level of policies, regulations and governance standards & 100 \\
\cline { 2 - 2 } Average level of policies, regulations and governance standards & 73 \\
\cline { 2 - 2 } High level of policies, regulations and governance standards & 30 \\
\cline { 2 - 2 } Extremely high level of policies, regulations and governance standards & 0 \\
\hline
\end{tabular}

Table 52: Policies, Regulations \& Governance Standards Desirability Value

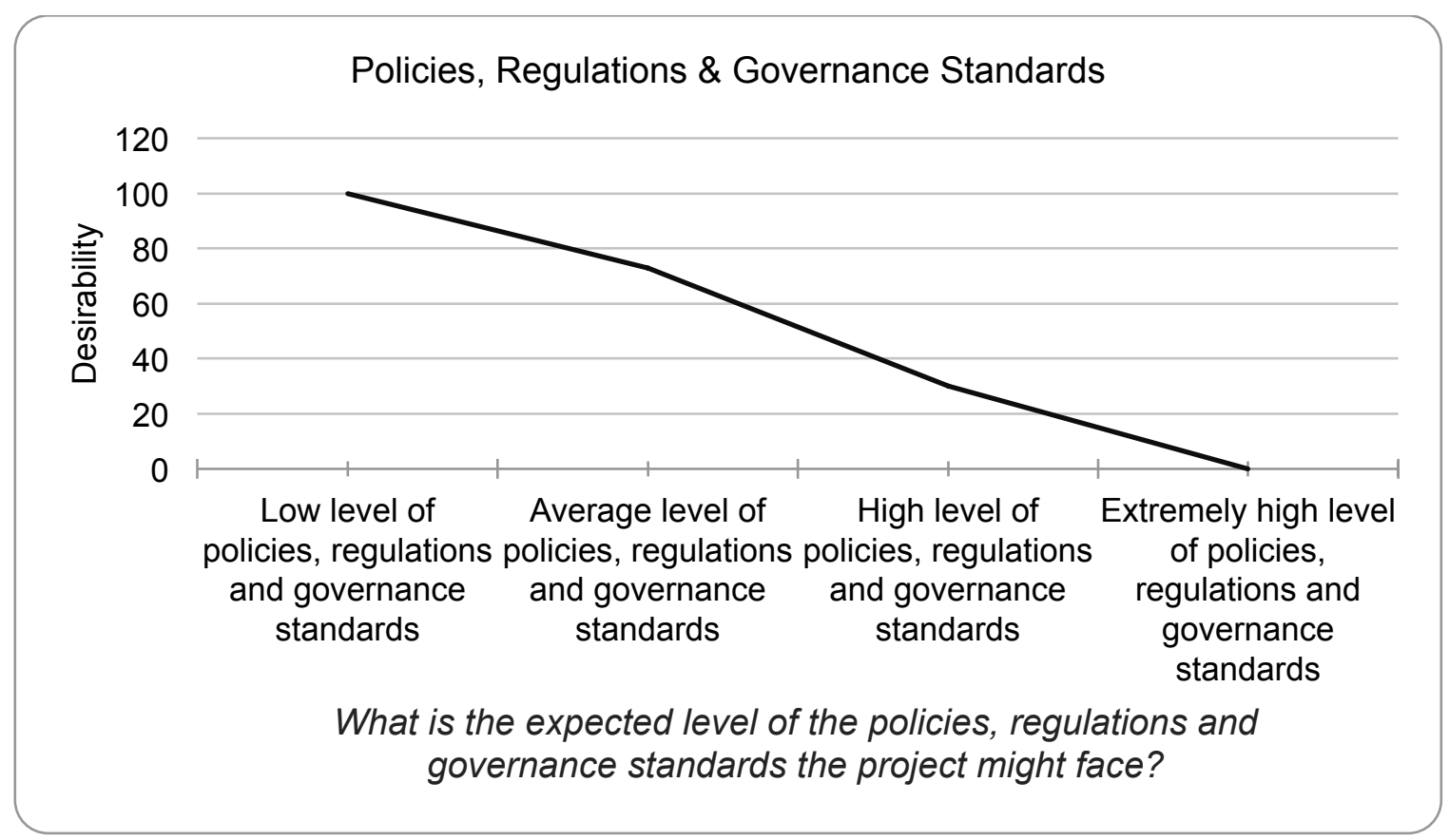

Figure 49: Policies, Regulations \& Governance Standards Desirability Value 


\begin{tabular}{|c|c|c|}
\hline Factors & Desirability Units & Desirability Scores \\
\hline \multirow{4}{*}{$\begin{array}{l}\text { Contracts } \\
\text { Complexity }\end{array}$} & Simple & \multirow{4}{*}{$\begin{array}{l}\text { From } 0 \text { to } 100 \text { experts were asked to } \\
\text { score and rank contracts complexity } \\
\text { desirability unit based on their } \\
\text { experiences. }\end{array}$} \\
\hline & Reasonable & \\
\hline & Complex & \\
\hline & Very Complex & \\
\hline
\end{tabular}

Table 53: Contracts Complexity Standards Desirability Units

\begin{tabular}{|l|c|}
\hline Contracts Complexity \\
\hline Description & Desirability \\
\hline Simple & 100 \\
\cline { 2 - 2 } Reasonable & 73 \\
\cline { 2 - 2 } Complex & 27 \\
Very Complex & 0 \\
\cline { 2 - 2 }
\end{tabular}

Table 54: Contracts Complexity Standards Desirability Value

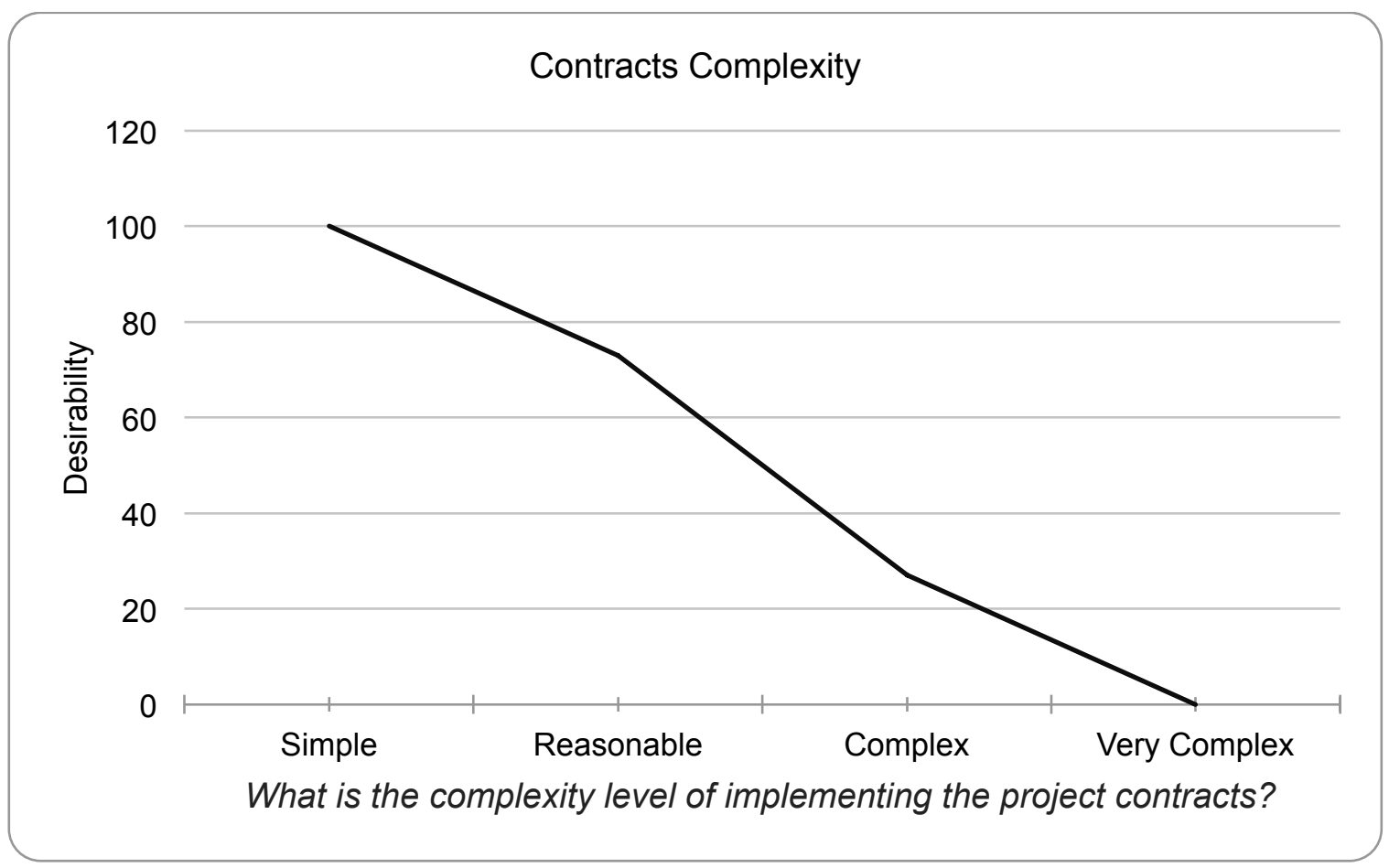

Figure 50: Contracts Complexity Standards Desirability Value 


\subsubsection{Environmental \& Safety Perspective Desirability Value}

The results of the desirability metrics quantifications of the environmental \& safety factors show in Tables $55-62$.

\begin{tabular}{|c|c|c|}
\hline Factors & Desirability Units & Desirability Scores \\
\hline \multirow{4}{*}{$\begin{array}{l}\text { Hazard } \\
\text { Identification } \\
\text { \& Risk } \\
\text { Management }\end{array}$} & Low-level of safety risk & \multirow{4}{*}{$\begin{array}{l}\text { From } 0 \text { to } 100 \text { experts were } \\
\text { asked to score and rank hazard } \\
\text { identification } \& \text { risk } \\
\text { management desirability unit } \\
\text { based on their experiences. }\end{array}$} \\
\hline & Average level of safety risk & \\
\hline & High-level of safety risk & \\
\hline & Extremely high-level of safety risk & \\
\hline
\end{tabular}

Table 55: Hazard Identification \& Risk Management Desirability Units

\begin{tabular}{|l|l|}
\hline Hazard Identification \& Risk Management \\
\hline Description & Desirability \\
\hline Low-level of safety risk & 100 \\
Average level of safety risk & 63 \\
\cline { 2 - 2 } High-level of safety risk & 17 \\
\cline { 2 - 2 } Extremely high-level of safety risk & 0 \\
\hline
\end{tabular}

Table 56: Hazard Identification \& Risk Management Desirability Value

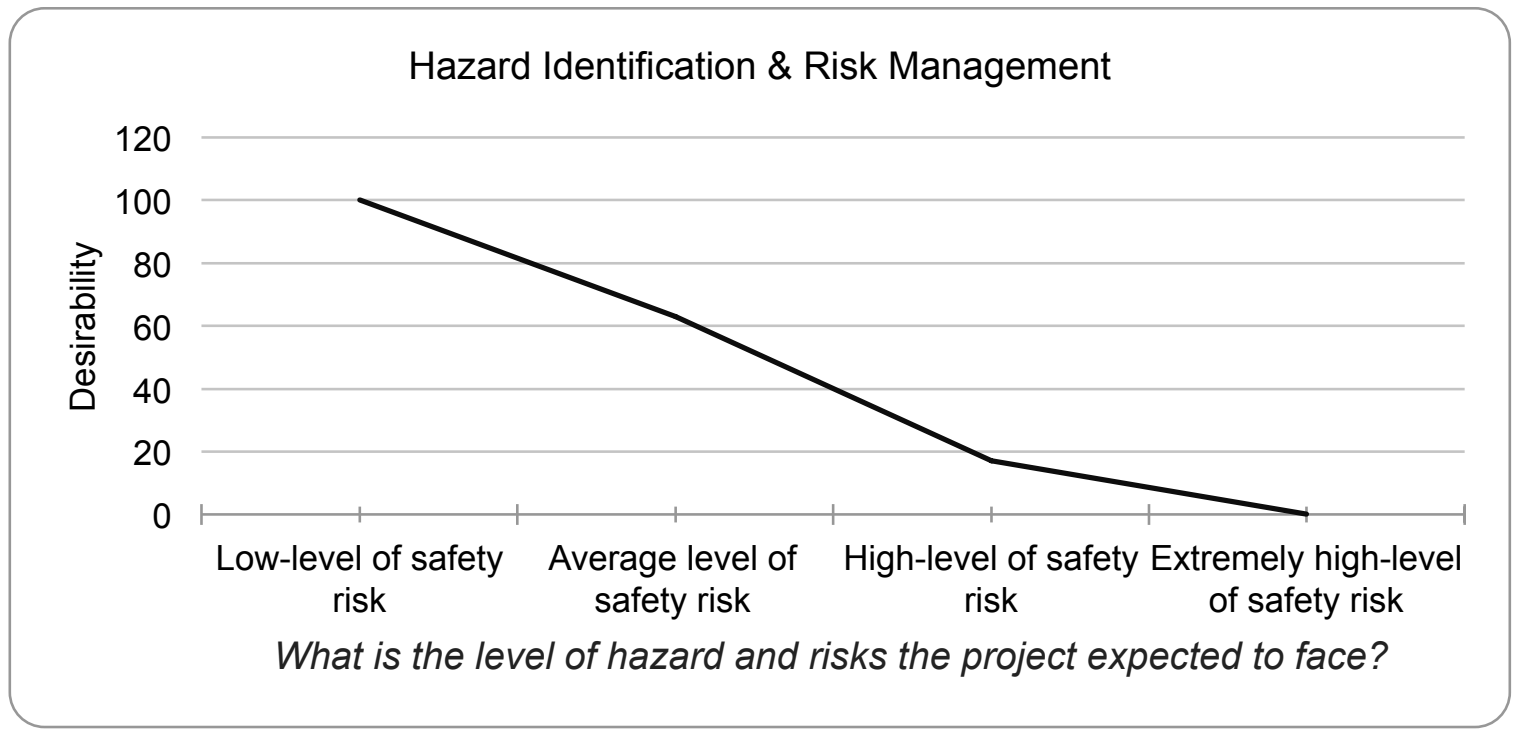

Figure 51: Hazard Identification \& Risk Management Desirability Value 


\begin{tabular}{|l|l|l|}
\hline Factors & Desirability Units & Desirability Scores \\
\hline Implementing & HSE easy to implement & From 0 to 100 experts were asked \\
Health, Safety & to score and rank Implementing \\
\cline { 2 - 2 } $\begin{array}{l}\text { and } \\
\text { Environmental }\end{array}$ & HSE reasonable to implement & Health, Safety and Environmental \\
\cline { 2 - 2 } (HSE) & HSE complex to implement & HSE very complex to implement desirability unit based on \\
\cline { 2 - 3 } & & their experiences. \\
\hline
\end{tabular}

Table 57: Implementing HSE Desirability Units

\begin{tabular}{|l|c|}
\hline Implementing Health, Safety and Environmental (HSE) \\
\hline Description & Desirability \\
\hline HSE easy to implement & 100 \\
HSE reasonable to implement & 73 \\
HSE complex to implement & 30 \\
\cline { 2 - 2 } HSE very complex to implement & 0 \\
\hline
\end{tabular}

Table 58: Implementing HSE Desirability Value

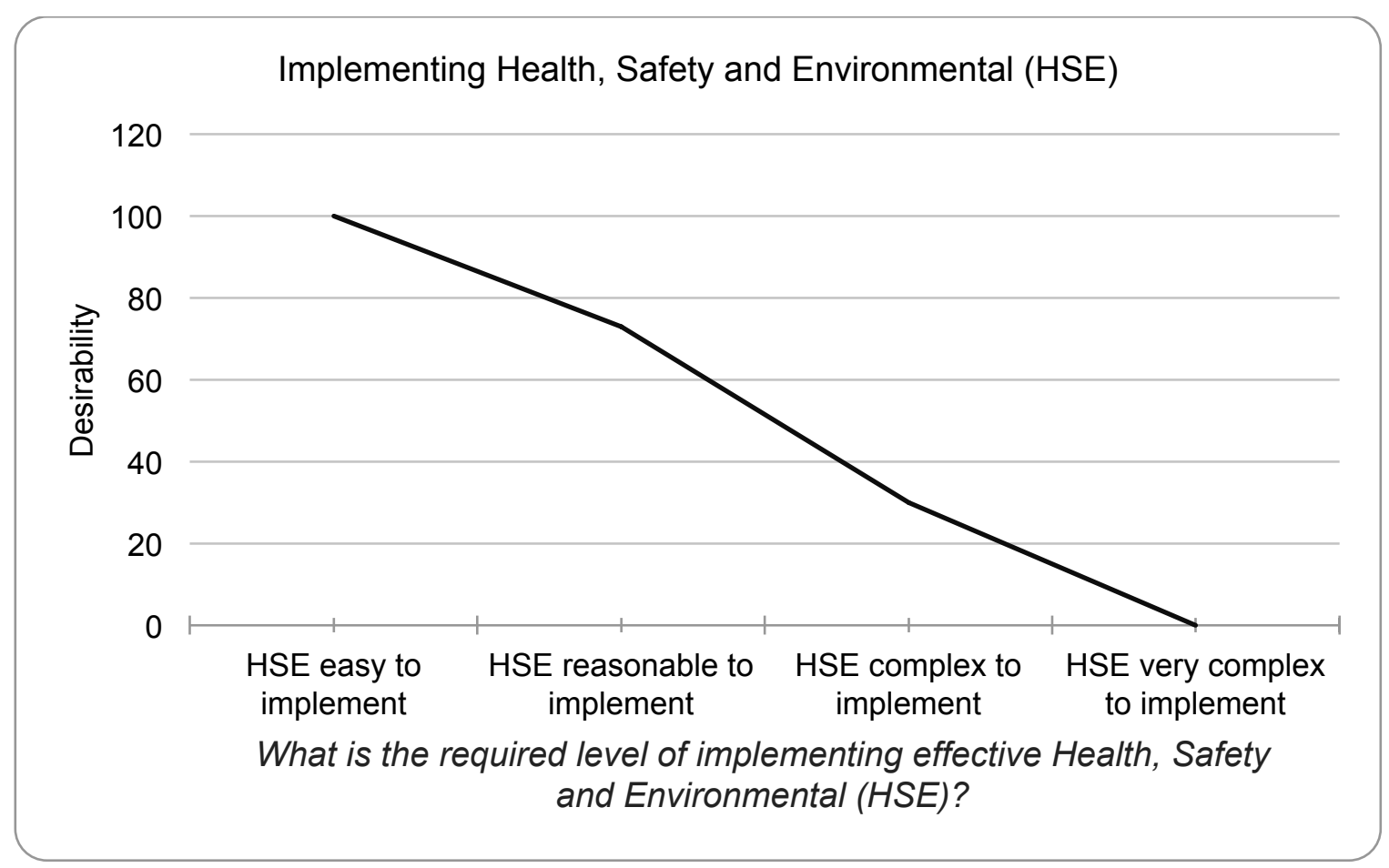

Figure 52: Implementing HSE Desirability Value 


\begin{tabular}{|c|c|c|}
\hline Factors & Desirability Units & Desirability Scores \\
\hline \multirow{4}{*}{$\begin{array}{l}\text { Stringent of the } \\
\text { Local Health } \\
\text { and Safety } \\
\text { Standards }\end{array}$} & $\begin{array}{l}\text { Low stringent of local Health and Safety } \\
\text { Standards }\end{array}$ & \multirow{4}{*}{$\begin{array}{l}\text { From } 0 \text { to } 100 \text { experts } \\
\text { were asked to score } \\
\text { and rank stringent of } \\
\text { local Health and } \\
\text { Safety Standards } \\
\text { desirability unit based } \\
\text { on their experiences. }\end{array}$} \\
\hline & $\begin{array}{l}\text { Average stringent of local Health and } \\
\text { Safety Standards }\end{array}$ & \\
\hline & $\begin{array}{l}\text { High stringent of local Health and Safety } \\
\text { Standards }\end{array}$ & \\
\hline & $\begin{array}{l}\text { Extremely high stringent of local Health } \\
\text { and Safety Standards }\end{array}$ & \\
\hline
\end{tabular}

Table 59: Stringent of the Local HSS Desirability Units

\begin{tabular}{|l|c|}
\hline Stringent of the Local Health, Safety and Environmental (HSE) Standards \\
\hline Description & Desirability \\
\hline Low stringent of local Health and Safety Standards & 100 \\
\cline { 2 - 2 } Average stringent of local Health and Safety Standards & 70 \\
High stringent of local Health and Safety Standards & 23 \\
\cline { 2 - 2 } Extremely high stringent of local Health and Safety Standards & 0 \\
\hline
\end{tabular}

Table 60: Stringent of the Local HSS Desirability Value

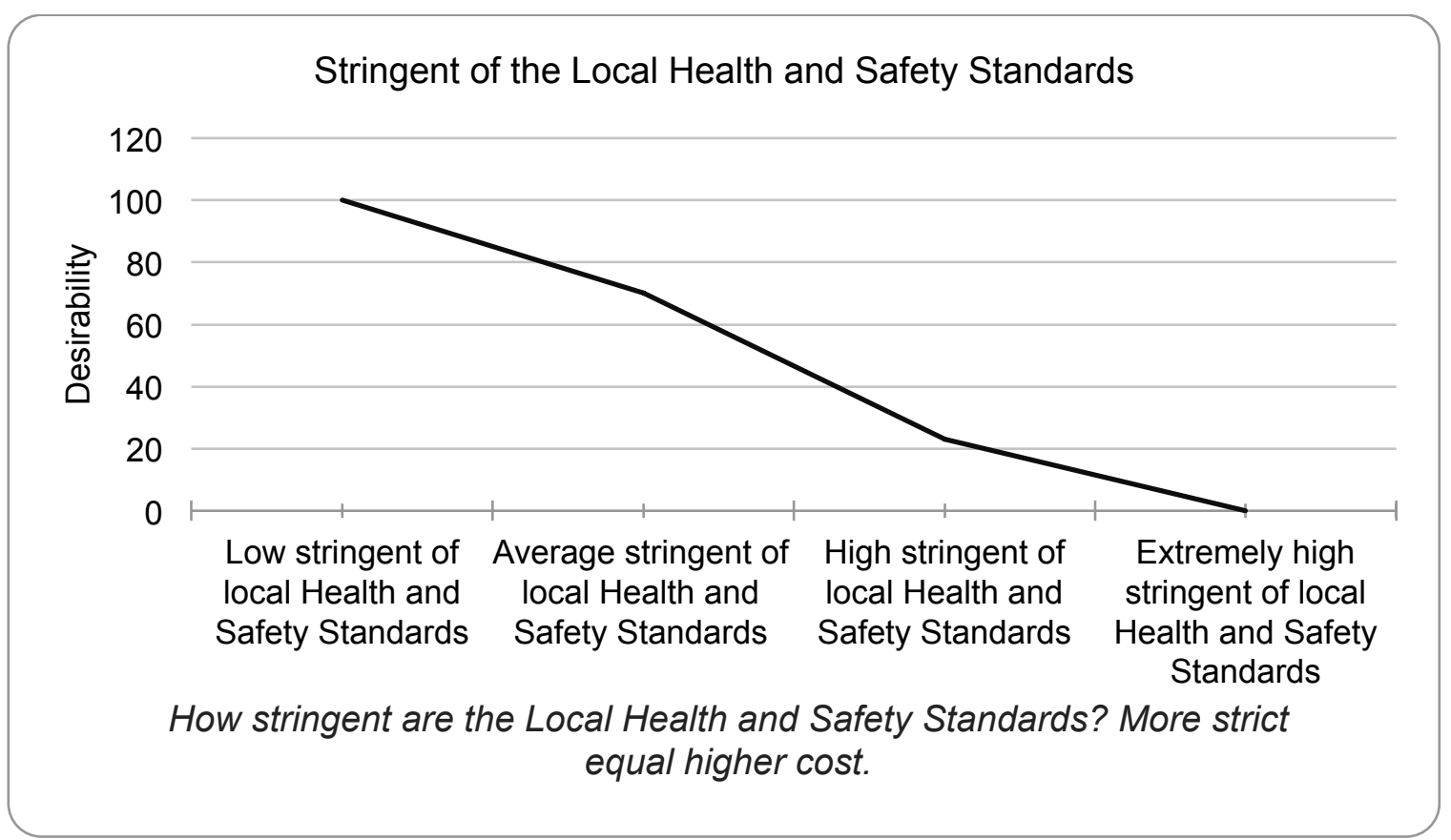

Figure 53: Stringent of the Local HSS Desirability Value 


\begin{tabular}{|l|l|l|}
\hline Factors & Desirability Units & Desirability Scores \\
\hline \multirow{4}{*}{$\begin{array}{l}\text { Environmental } \\
\text { Risk }\end{array}$} & $\begin{array}{l}\text { Low level of regulation on environmental } \\
\text { Management }\end{array}$ & $\begin{array}{l}\text { From } 0 \text { to } 100 \text { experts } \\
\text { threats is required }\end{array}$ \\
\cline { 2 - 2 } Integration & $\begin{array}{l}\text { Average level of regulation on } \\
\text { environmental threats is required }\end{array}$ & $\begin{array}{l}\text { and rank } \\
\text { environmental risk } \\
\text { management } \\
\text { integration desirability } \\
\text { unit based on their } \\
\text { experiences. }\end{array}$ \\
\cline { 2 - 3 } & $\begin{array}{l}\text { High level of regulation on environmental } \\
\text { threats is required }\end{array}$ & $\begin{array}{l}\text { Extremely high level of regulation on } \\
\text { environmental threats is required }\end{array}$ \\
\cline { 2 - 3 } & & \\
\hline
\end{tabular}

Table 61: Environmental Risk Management Integration Desirability Units

\section{Environmental Risk Management Integration}

\begin{tabular}{|l|c|}
\hline Description & Desirability \\
\hline Low level of regulation on environmental threats is required & 100 \\
\cline { 2 - 2 } Average level of regulation on environmental threats is required & 73 \\
\cline { 2 - 2 } High level of regulation on environmental threats is required & 20 \\
\cline { 2 - 2 } Extremely high level of regulation on environmental threats is required & 0 \\
\hline
\end{tabular}

Table 62: Environmental Risk Management Integration Desirability Value

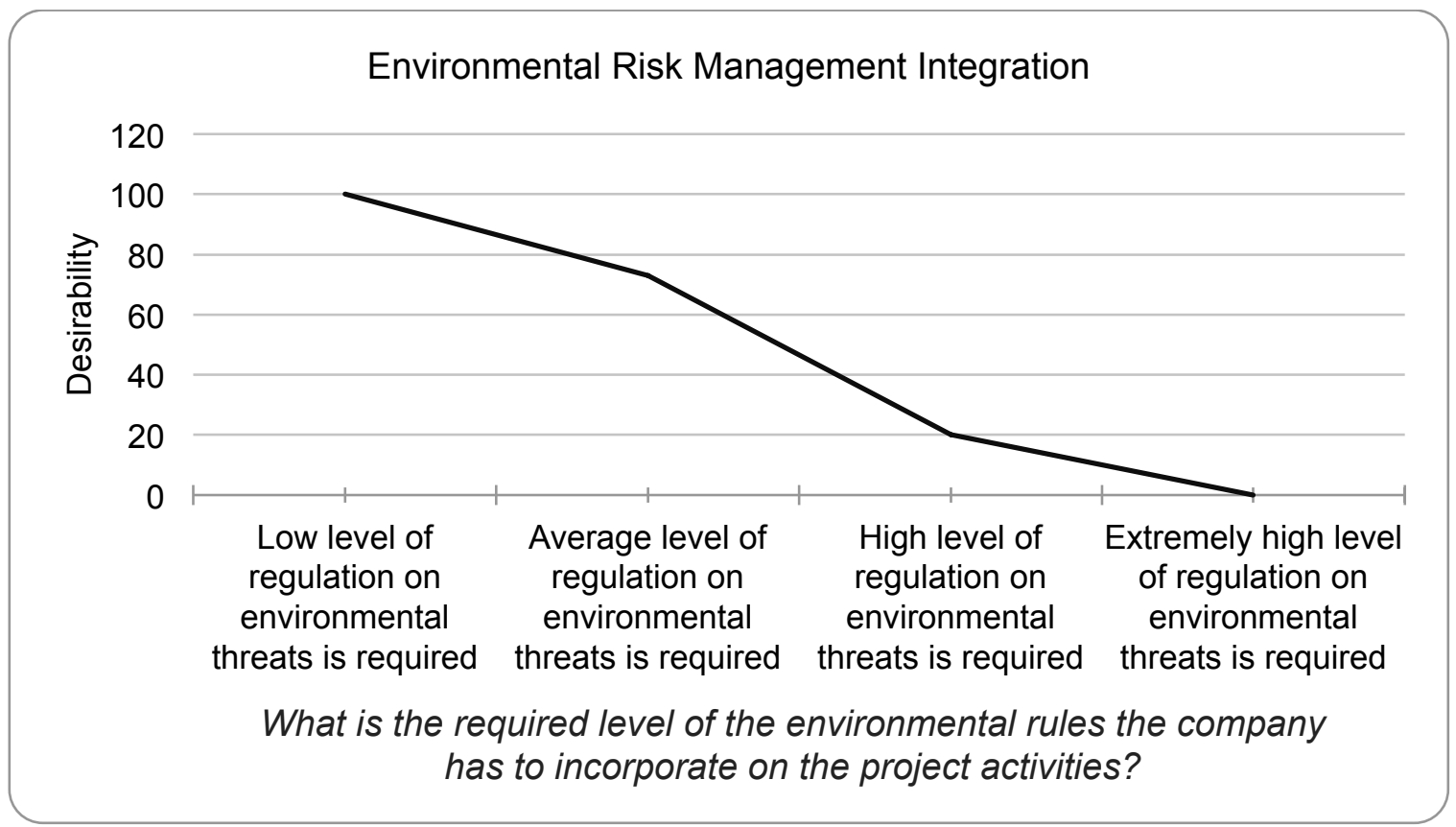

Figure 54: Environmental Risk Management Integration Desirability Value 
The table below summarizes unit of measurements that helps decision makers to assign value to each of the factors on the value curve.

\begin{tabular}{|c|c|c|}
\hline Perspective & Factors & Unit of Measurements \\
\hline \multirow[t]{4}{*}{ Economical } & Oil Prices & $\begin{array}{l}\text { What is the expected level of oil price } \\
\text { when project will start to produce oil? }\end{array}$ \\
\hline & Initial Cost & $\begin{array}{l}\text { What is the required amount of money to } \\
\text { start up the project? }\end{array}$ \\
\hline & Operational Cost & $\begin{array}{l}\text { What is the estimated cost of operating } \\
\text { expenses? }\end{array}$ \\
\hline & $\begin{array}{l}\text { Return on Investment } \\
\text { (ROI) }\end{array}$ & $\begin{array}{l}\text { What is the expected percentage of the } \\
\text { project return on investment? }\end{array}$ \\
\hline \multirow[t]{4}{*}{ Technical } & Operational Difficulties & $\begin{array}{l}\text { What is the expected level of operational } \\
\text { difficulties that the project will face? }\end{array}$ \\
\hline & $\begin{array}{l}\text { Project Size \& } \\
\text { Complexity }\end{array}$ & What is the degree of project complexity? \\
\hline & Production Performance & $\begin{array}{l}\text { What is the production performance level } \\
\text { in terms of amount and quality that the } \\
\text { project is expected to produce? }\end{array}$ \\
\hline & $\begin{array}{l}\text { Subsurface \& Reservoir } \\
\text { Uncertainty }\end{array}$ & $\begin{array}{l}\text { What is the uncertainty level of finding an } \\
\text { expected reservoir volume? }\end{array}$ \\
\hline \multirow[t]{4}{*}{ Political } & Government Stability & $\begin{array}{l}\text { What is the stability level of the } \\
\text { government that owns the project site? }\end{array}$ \\
\hline & $\begin{array}{l}\text { Conflict Over Maritime } \\
\text { Claims }\end{array}$ & $\begin{array}{l}\text { What is the conflict degree over maritime } \\
\text { claims that will face the project site? }\end{array}$ \\
\hline & $\begin{array}{l}\text { Policies, Regulations \& } \\
\text { Governance Standards }\end{array}$ & $\begin{array}{l}\text { What is the expected level of the policies, } \\
\text { regulations and governance standards the } \\
\text { project might face? }\end{array}$ \\
\hline & Contracts Complexity & $\begin{array}{l}\text { What is the complexity level of } \\
\text { implementing the project contracts? }\end{array}$ \\
\hline \multirow[t]{3}{*}{$\begin{array}{l}\text { Safety \& } \\
\text { Environmental }\end{array}$} & $\begin{array}{l}\text { Hazard Identification \& } \\
\text { Risk Management }\end{array}$ & $\begin{array}{l}\text { What is the level of hazard and risks the } \\
\text { project is expected to face? }\end{array}$ \\
\hline & $\begin{array}{l}\text { Implementing Health, } \\
\text { Safety and } \\
\text { Environmental (HSE) }\end{array}$ & $\begin{array}{l}\text { What is the required level of } \\
\text { implementing effective Health, Safety and } \\
\text { Environmental (HSE)? }\end{array}$ \\
\hline & Stringent of the Local & How stringent are the local Health, Safety \\
\hline
\end{tabular}




\begin{tabular}{|l|l|l|}
\hline & $\begin{array}{l}\text { Health, Safety and } \\
\text { Environmental (HSE) } \\
\text { Standards }\end{array}$ & $\begin{array}{l}\text { and Environmental (HSE) Standards? } \\
\text { More strict equal higher cost. }\end{array}$ \\
\cline { 2 - 3 } $\begin{array}{l}\text { Environmental Risk } \\
\text { Management } \\
\text { Integration }\end{array}$ & $\begin{array}{l}\text { What is the required level of the } \\
\text { environmental rules the company has to } \\
\text { incorporate on the project activities? }\end{array}$ \\
\hline
\end{tabular}

Table 63: Unit of Measurements Value On Desirability Curve 


\section{CHAPTER 8: RESEARCH APPLICATION}

Applying a case application can be considered a robust research method that allows the exploration and understanding of complex issues particularly when a holistic, indepth investigation is required [205]. Through case application methods, a researcher is able to go beyond the quantitative statistical results and understand the behavioral conditions through the actor's perspective. By including both quantitative and qualitative data, a case application helps explain both the process and outcome of a phenomenon through complete observation, reconstruction and analysis of the cases under investigation [206] [207]. The table below explains the advantages of implementing the case application.

\begin{tabular}{|c|c|c|}
\hline No & Advantages of Case Application & References \\
\hline 1. & Potential to achieve high conceptual validity. & {$[208][209][$} \\
\hline 2. & Strong procedures for fostering new hypotheses. & $210][211]$ \\
\hline 3. & $\begin{array}{l}\text { Case studies allow for both quantitative and qualitative } \\
\text { analyses of the data. }\end{array}$ & \\
\hline 4. & $\begin{array}{l}\text { Usefulness for closely examining the hypothesized role of } \\
\text { causal mechanisms in the context of individual cases. }\end{array}$ & \\
\hline 5 . & The detailed qualitative accounts often produced in case & \\
\hline & studies not only help to explore or describe the data in real- & \\
\hline & life environment, but also help to explain the complexities of & \\
\hline & $\begin{array}{l}\text { real-life situations, which may not be captured through } \\
\text { experimental or survey research. }\end{array}$ & \\
\hline 6. & Capacity for addressing causal complexity. & \\
\hline
\end{tabular}

Table 64: Advantages and Disadvantages of Case Studies Method

Eni and Mellitah Oil \& Gas is considered as a case application subject for this research and the main objective of implementing this case application is to test the model 
and demonstrate the idea of this research. Specifically, three offshore oil projects that are located in North Africa and operated by Eni and Mellitah Oil \& Gas are implemented as a case application. Baraka offshore oil project is located in Tunisia and the project operated by Eni Oil \& Gas. DP3 and DP4 offshore projects are located in Libya and both projects operated by Eni and Mellitah Oil \& Gas. Nevertheless, North Africa is considered as one of the essential players in the global oil and gas industry. Appling such a case study to one of the biggest O\&G companies in that area will enhance and supplement the results of this research.

\subsection{Tunisian Oil industry}

Tunisia's oil and gas resources are very small by international standards and especially as compared with those of its neighbors. Its proven oil reserves of 0.42 billion barrels (bnbls) and gas reserves of 0.06 trillion cubic meters. Oil production in Tunisia has been steadily declining after reaching a peak of 120,000 barrels per day (bls/d) in the early 1980 s. In 2017 , it reached $42,000 \mathrm{bls} / \mathrm{d}$, according to the international energy statistics of the U.S. Energy Information Administration (EIA). Despite the small resource base, the oil and gas sector plays an important role in the economy. Over the last twenty years, it has represented between 3 percent and 7 percent of GDP, and between 8 percent and 18 percent of exports [212].

\subsection{Libyan Oil Industry}

According to official energy statistics from the US government (EIA), Libya holds the largest oil reserves in Africa, about 41.5 billion barrels as of January 2007; and the 
8th largest in the world. However, Libya still remains highly unexplored, as current agreements with oil companies only cover 25 percent of Libya. About 90 percent of Libya's oil is sold to Western Europe. Libya has more oil than its aging equipment can process, and after the recent lifting of the sanctions, the country has resumed the purchase of parts and equipment to upgrade its refining and producing capacities.

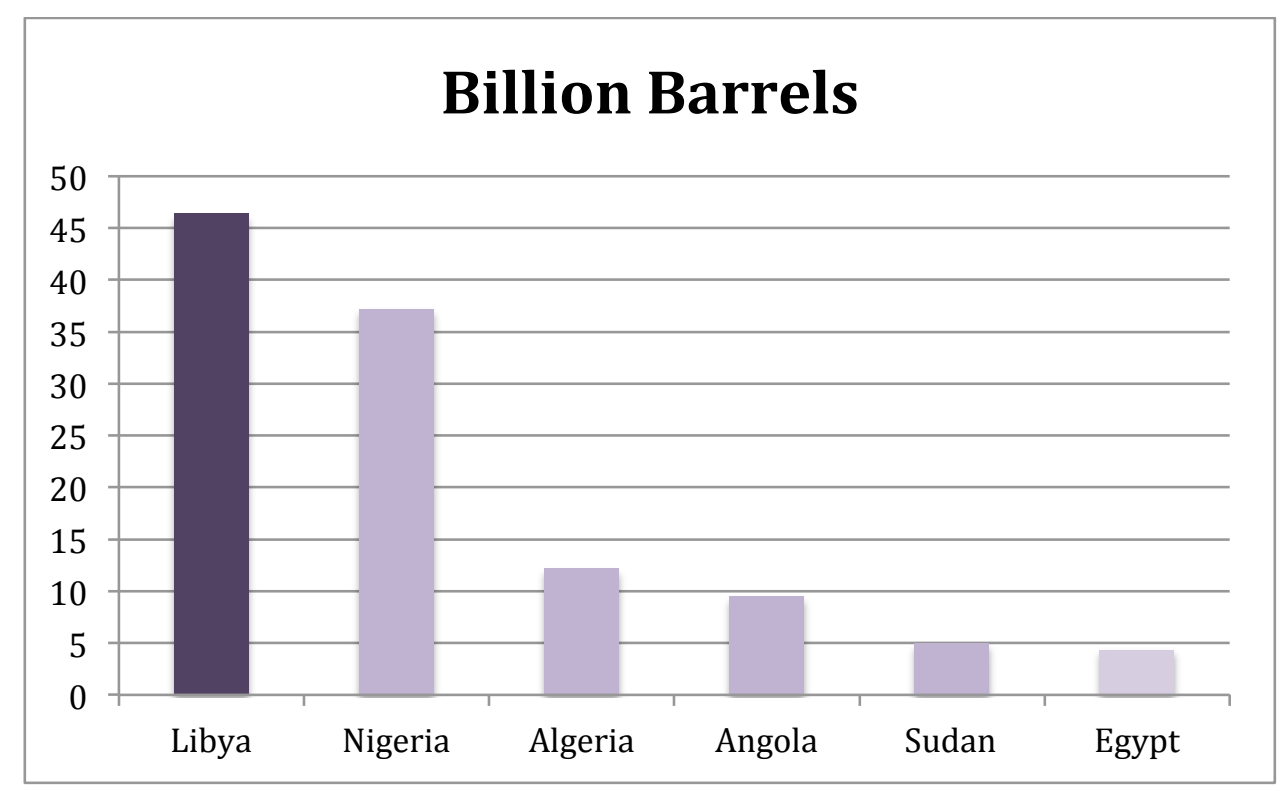

Figure 55: Top African Nation Oil Reserves (Billion Barrels)

The country's economy is almost dependent on hydrocarbon production, with crude oil and natural gas representing about 96 percent of all government revenue [213]. The oil and gas facilities are scattered all over the country, on-shore and off-shore, in which water demands for quality and quantity are very high. These facilities include oil and gas fields, pipelines and terminal ports of oil and gas shipping, refineries, gas processing plants and chemical complexes [217]. Libyan oil classified as a "sweet" crude, which means that it has a low percentage of impurities a very desirable attribute [213]. 
Nevertheless, Libyan oil industry is driven by its foreign policy and interaction with the international community. According to Mills' reports in 2008, Libyan oil production dropped from a peak of 3.4 million barrels per day in 1970 to 1.0 million barrels per day in 1987 due to sanctions and political turmoil. In 2002 and 2006 the oil production reached to 1.4 and 1.8 million barrels per day respectively [214].

\subsection{Eni and Mellitah Oil \& Gas}

The company was established on $21 / 04 / 2008$ in accordance to an agreement concluded between the National Oil Corp. and Eni North Africa on 16/10/2007. Mellitah Oil \& Gas B.V Libyan Branch owned a set of large Gas/Oil processing plants that were worth more than 6 billion U.S. dollars in total investment. The Company manages several onshore and offshore fields spread across the country. Mellitah Oil \& Gas ranks as the biggest oil Company in Libya by producing 600,000 equivalent oil barrel/day Crude Oil, Natural Gas, Condensed Gas: Propane, Butane and Nafta in addition to a daily production of 450 tons of Sulphur [215]. Early on 2018 the company has begun production from the second phase of the Bahr Essalam offshore gas field, which is the largest gas field in Libya. Two further wells will begin production within a week under the Eni-NOC joint venture and further seven wells will come on-stream by the end of 2018. The second phase of the Bahr Essalam project will increase the company production potential by 400 million cubic feet of standard gas per day (MMSCFD) to a total output from the field of 1,100 MMSCFD [216]. Moreover, the company made a new discovery of gas and condensates offshore. According to the company, the discovery is closely located to 
previously developed fields, $15 \mathrm{~km}$ southwest of the Bouri field and $5 \mathrm{~km}$ north of the Bahr Essalam field. The discovered well has the capacity to produce in excess of 7,000 barrels of oil equivalent per day (Boepd) and represents Eni's further discoveries in Libyan offshore Area D, following earlier discoveries in 2015 [217].

\subsection{Offshore Oil Projects}

Baraka Project: Baraka is an offshore oil platform located in Tunisia at the Gulf of Hammamet side. The project operates at depth of $90 \mathrm{~m}$. The field operated by ENI Oil Company with $\$ 650$ million of total estimate cost to produce 34,000 bpd. [218].

DP3 Project: DP3 platform is apart of the Bouri offshore field. The Bouri Offshore Field is part of Block NC-41, which is located 120 kilometers $(75 \mathrm{mi})$ north of the Libyan coast in the Mediterranean Sea. Consisting of 38 wells, the field was developed using two platforms, a central processing platform (DP4) and a satellite platform (DP3) to produce 150,000bopd of crude oil for export [219].

DP4 Project: DP4 platform is apart of the Bouri offshore field as well. The Bouri oil reservoir is considered to be the biggest of its kind in the Mediterranean region. The DP4 platform is permanently moored at a single point to a Floating Storage and Offloading (FSO) tanker with a storage capacity of approximately 1.5 million barrels $(240,000 \mathrm{~m} 3)$ $[220][221]$. 


\section{CHAPTER 9: ANALYSIS OF CASE AND SENSITIVITY ANALYSIS}

The model developed in this research was applied to identify overall evaluation scores of the each project that was described in the previous section. A discussion with the experts in panel 8 has been conducted in order to assign a value curve score for each project. The discussion with the experts took place by means of phone interviews and emails. The computation of the final evaluation score is done by the application of the equation 14 that was presented in chapter 4 . The following tables show final evaluation scores for each project.

\subsection{Project (1): Baraka}

\begin{tabular}{|c|c|c|c|c|c|}
\hline \multicolumn{6}{|c|}{ Project 1: Baraka } \\
\hline Perspectives & Criteria & $\begin{array}{l}\text { Global } \\
\text { Value }\end{array}$ & $\begin{array}{l}\text { Value } \\
\text { Curve }\end{array}$ & $\begin{array}{l}\text { Final } \\
\text { Score }\end{array}$ & $\begin{array}{l}\text { Perspectives } \\
\text { Sum }\end{array}$ \\
\hline \multirow{4}{*}{ Economical } & Oil Price & 0.12 & 50 & 6 & \multirow{4}{*}{23.4} \\
\hline & Initial Cost & 0.05 & 88 & 4.4 & \\
\hline & Operational Cost & 0.05 & 80 & 4 & \\
\hline & Return on Investment (ROI) & 0.1 & 90 & 9 & \\
\hline \multirow{4}{*}{ Technical } & Operational Difficulties & 0.02 & 75 & 1.5 & \multirow{4}{*}{6.4} \\
\hline & \begin{tabular}{|l|} 
Project Size \& Complexity \\
\end{tabular} & 0.03 & 65 & 1.95 & \\
\hline & Production Performance & 0.05 & 35 & 1.75 & \\
\hline & $\begin{array}{l}\text { Subsurface \& Reservoir } \\
\text { Uncertainty }\end{array}$ & 0.04 & 30 & 1.2 & \\
\hline \multirow{4}{*}{ Political } & \begin{tabular}{|l} 
Government Stability \\
\end{tabular} & 0.08 & 47 & 3.76 & \multirow{4}{*}{16.93} \\
\hline & Conflict Over Maritime Claims & 0.03 & 100 & 3 & \\
\hline & $\begin{array}{l}\text { Policies, Regulations \& } \\
\text { Governance Standards }\end{array}$ & 0.07 & 75 & 5.25 & \\
\hline & \begin{tabular}{|l|} 
Contracts Complexity \\
\end{tabular} & 0.06 & 82 & 4.92 & \\
\hline \multirow{3}{*}{$\begin{array}{l}\text { Safety \& } \\
\text { Environmental }\end{array}$} & $\begin{array}{l}\text { Hazard Identification \& Risk } \\
\text { Management }\end{array}$ & 0.1 & 50 & 5 & \multirow{3}{*}{17.55} \\
\hline & $\begin{array}{l}\text { Implementing Health, Safety and } \\
\text { Environmental (HSE) }\end{array}$ & 0.06 & 55 & 3.3 & \\
\hline & $\begin{array}{l}\text { Stringent of the Local Health, } \\
\text { Safety and Environmental (HSE) } \\
\text { Standards }\end{array}$ & 0.09 & 75 & 6.75 & \\
\hline
\end{tabular}




\begin{tabular}{|l|l|l|l|l|l|} 
& $\begin{array}{l}\text { Environmental Risk } \\
\text { Management Integration }\end{array}$ & 0.05 & 50 & 2.5 & \\
\hline Project Total Score
\end{tabular}

Table 65: Evaluation Scores for Project 1

\subsection{Project (2): Bouri - DP3}

\begin{tabular}{|c|c|c|c|c|c|}
\hline \multicolumn{6}{|c|}{ Project 2: Bouri - DP3 } \\
\hline Perspectives & Criteria & $\begin{array}{l}\text { Global } \\
\text { Value }\end{array}$ & $\begin{array}{l}\text { Value } \\
\text { Curve }\end{array}$ & $\begin{array}{l}\text { Final } \\
\text { Score }\end{array}$ & $\begin{array}{l}\text { Perspectives } \\
\text { Sum }\end{array}$ \\
\hline \multirow{4}{*}{ Economical } & Oil Price & 0.12 & 53 & 6.36 & \multirow{4}{*}{23.11} \\
\hline & Initial Cost & 0.05 & 70 & 3.5 & \\
\hline & Operational Cost & 0.05 & 65 & 3.25 & \\
\hline & Return on Investment (ROI) & 0.1 & 100 & 10 & \\
\hline \multirow{4}{*}{ Technical } & Operational Difficulties & 0.02 & 80 & 1.6 & \multirow{4}{*}{11.5} \\
\hline & Project Size \& Complexity & 0.03 & 35 & 1.05 & \\
\hline & Production Performance & 0.05 & 97 & 4.85 & \\
\hline & $\begin{array}{l}\text { Subsurface \& Reservoir } \\
\text { Uncertainty }\end{array}$ & 0.04 & 100 & 4 & \\
\hline \multirow{4}{*}{ Political } & Government Stability & 0.08 & 15 & 1.2 & \multirow{4}{*}{14.88} \\
\hline & Conflict Over Maritime Claims & 0.03 & 100 & 3 & \\
\hline & $\begin{array}{l}\text { Policies, Regulations \& } \\
\text { Governance Standards }\end{array}$ & 0.07 & 90 & 6.3 & \\
\hline & Contracts Complexity & 0.06 & 73 & 4.38 & \\
\hline \multirow{4}{*}{$\begin{array}{l}\text { Safety \& } \\
\text { Environmental }\end{array}$} & $\begin{array}{l}\text { Hazard Identification \& Risk } \\
\text { Management }\end{array}$ & 0.1 & 40 & 4 & \multirow{4}{*}{18.35} \\
\hline & $\begin{array}{l}\text { Implementing Health, Safety and } \\
\text { Environmental (HSE) }\end{array}$ & 0.06 & 30 & 1.8 & \\
\hline & $\begin{array}{l}\text { Stringent of the Local Health, } \\
\text { Safety and Environmental (HSE) } \\
\text { Standards }\end{array}$ & 0.09 & 95 & 8.55 & \\
\hline & $\begin{array}{l}\text { Environmental Risk } \\
\text { Management Integration }\end{array}$ & 0.05 & 80 & 4 & \\
\hline \multicolumn{5}{|c|}{ Project Total Score } & 67.84 \\
\hline
\end{tabular}

Table 66: Evaluation Scores for Project 2 


\subsection{Project (2): Bouri - DP4}

\begin{tabular}{|c|c|c|c|c|c|}
\hline \multicolumn{6}{|c|}{ Project 3: Bouri - DP4 } \\
\hline Perspectives & Criteria & $\begin{array}{l}\text { Global } \\
\text { Value }\end{array}$ & $\begin{array}{l}\text { Value } \\
\text { Curve }\end{array}$ & $\begin{array}{l}\text { Final } \\
\text { Score }\end{array}$ & $\begin{array}{c}\text { Perspectives } \\
\text { Sum }\end{array}$ \\
\hline \multirow{4}{*}{ Economical } & Oil Price & 0.12 & 58 & 6.96 & \multirow{4}{*}{24.71} \\
\hline & Initial Cost & 0.05 & 75 & 3.75 & \\
\hline & Operational Cost & 0.05 & 80 & 4 & \\
\hline & Return on Investment (ROI) & 0.1 & 100 & 10 & \\
\hline \multirow{4}{*}{ Technical } & Operational Difficulties & 0.02 & 85 & 1.7 & \multirow{4}{*}{11.75} \\
\hline & Project Size \& Complexity & 0.03 & 35 & 1.05 & \\
\hline & Production Performance & 0.05 & 100 & 5 & \\
\hline & $\begin{array}{l}\text { Subsurface \& Reservoir } \\
\text { Uncertainty }\end{array}$ & 0.04 & 100 & 4 & \\
\hline \multirow{4}{*}{ Political } & Government Stability & 0.08 & 15 & 1.2 & \multirow{4}{*}{15.3} \\
\hline & Conflict Over Maritime Claims & 0.03 & 100 & 3 & \\
\hline & $\begin{array}{l}\text { Policies, Regulations \& } \\
\text { Governance Standards }\end{array}$ & 0.07 & 90 & 6.3 & \\
\hline & Contracts Complexity & 0.06 & 80 & 4.8 & \\
\hline \multirow{4}{*}{$\begin{array}{l}\text { Safety \& } \\
\text { Environmental }\end{array}$} & $\begin{array}{l}\text { Hazard Identification \& Risk } \\
\text { Management }\end{array}$ & 0.1 & 45 & 4.5 & \multirow{4}{*}{19.1} \\
\hline & $\begin{array}{l}\text { Implementing Health, Safety and } \\
\text { Environmental (HSE) }\end{array}$ & 0.06 & 30 & 1.8 & \\
\hline & $\begin{array}{l}\text { Stringent of the Local Health, } \\
\text { Safety and Environmental (HSE) } \\
\text { Standards }\end{array}$ & 0.09 & 95 & 8.55 & \\
\hline & $\begin{array}{l}\text { Environmental Risk } \\
\text { Management Integration }\end{array}$ & 0.05 & 85 & 4.25 & \\
\hline \multicolumn{5}{|c|}{ Project Total Score } & 70.86 \\
\hline
\end{tabular}

Table 67: Evaluation Scores for Project 3

\subsection{Discussion of Case Application}

The importance weights of the sixteen factors were obtained from the model, then experts in panel 7 assigned values for each factor using the desirability curves. In order to get the weighted score for each attribute, each value was obtained by the desirability curves multiplied by its important weight. Lastly, the weighted scores were added to get an overall project score. The analysis results show that the DP4 project has higher evaluation scores than other projects. The total evaluation score of the DP4 project is 
(70.86) out of 100 while the total evaluation score of projects Baraka and DP3 are (64.28) and (67.84) respectively. See graph number 56. However, if we compare the total score of each perspective, we can notice that the political perspective of the Baraka project is (16.93) which is a better score than the DP3 and DP4 projects. Graph 57 illustrates the evaluation value of each perspective for the three projects.

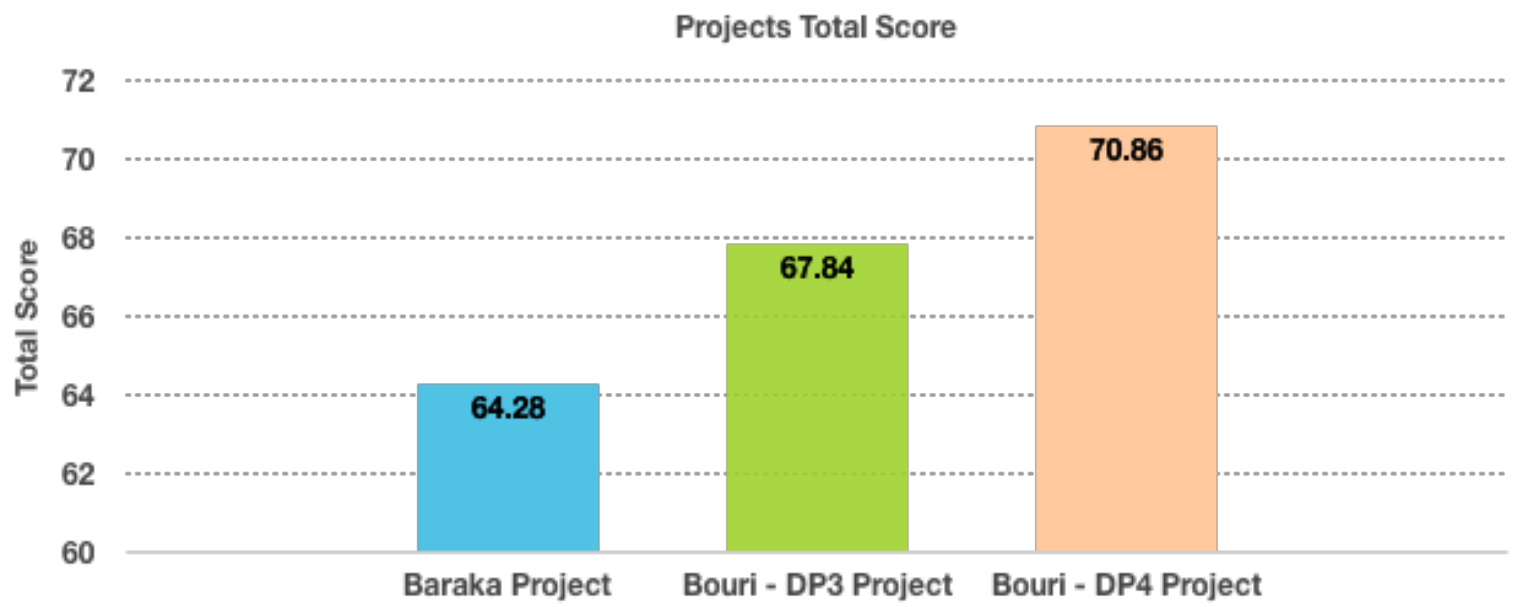

Figure 56: Projects Evaluation Results

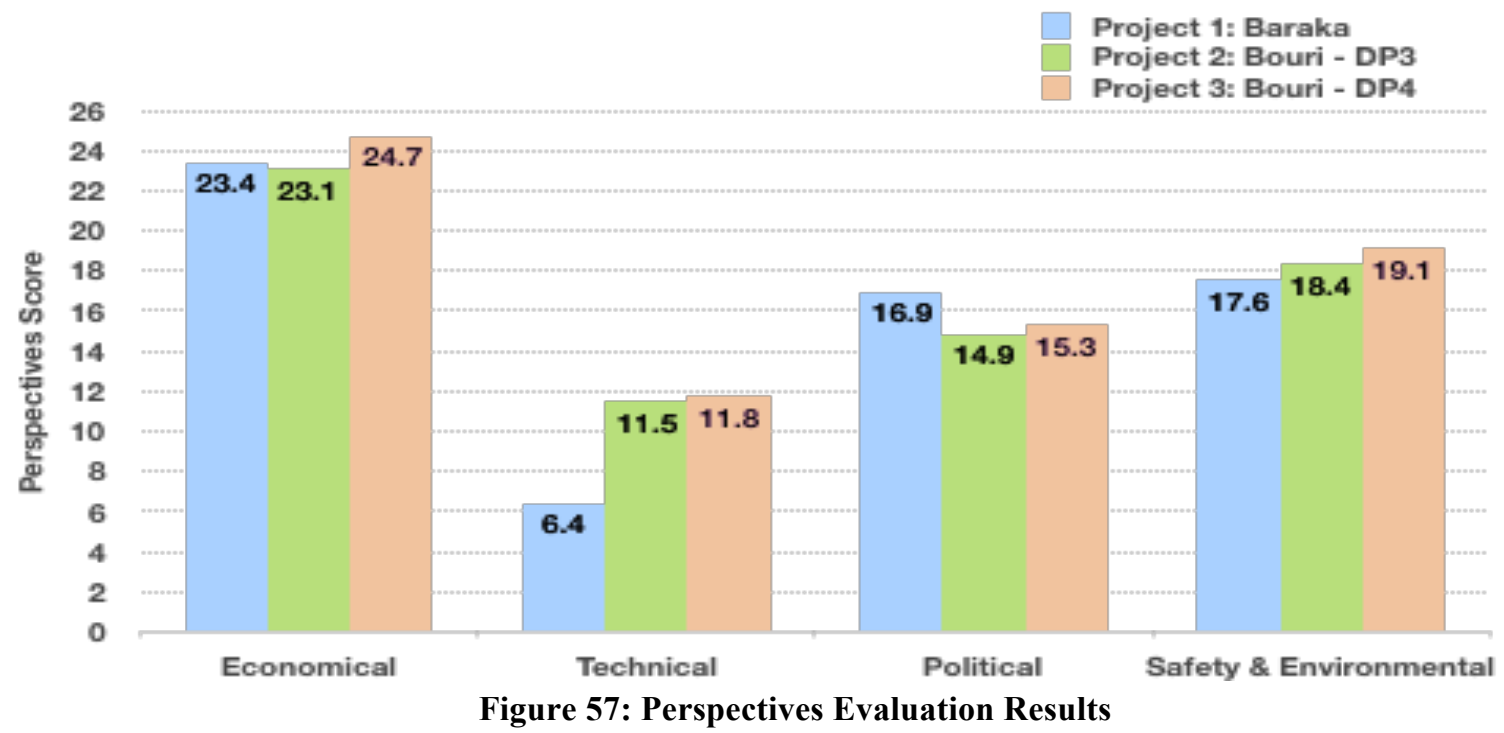


By taking a closer look at the results, we can notice that the comparison score of the technical perspective of the three projects was expected since projects 2 and 3 have more production and contain higher reservoir volume. In the political side, it is not a surprise that project 1 gained more scores than other projects. Projects 2 and 3 were mainly affected by the Libyan government stability; however, the Tunisian government was considered more stable. Alternately, the economical perspective shows unexpected results. Even though project 1 has less oil production, it has higher economic sectors than project 2 . The project 1 higher economical scores mainly were driven by low operational cost and initial cost.

\subsection{Strengths and Weaknesses}

In order to get a clear evaluation, strengths and weaknesses of each project have been emphasized. On one hand, the political perspective ranked high in Project 1 as it was affected by the stability of the country that hosted the site. On the other hand, production performance and subsurface and reservoir uncertainty attributes were weaknesses of Project 1. Unlike Project 1, Project 2 and 3 showed strengths and high scores in both factors, including production performance and reservoir. However, the two projects express the same weaknesses, which is government stability. The following tables summarize strengths and weaknesses of each project. 


\section{Project 1:}

\begin{tabular}{|l|l|l|c|c|c|}
\hline \multicolumn{1}{|c|}{ Project 1 } & Perspectives & \multicolumn{1}{|c|}{ Criteria } & $\begin{array}{c}\text { Global } \\
\text { Value }\end{array}$ & $\begin{array}{c}\text { Value } \\
\text { Curve }\end{array}$ & $\begin{array}{c}\text { Final } \\
\text { Score }\end{array}$ \\
\hline Strengths & Political & Government Stability & 0.08 & 47 & 3.76 \\
\hline Weaknesses & Technical & Production Performance & 0.05 & 35 & 1.75 \\
& Subsurface \& Reservoir Uncertainty & 0.04 & 30 & 1.2 \\
\hline
\end{tabular}

Table 68: Strengths and Weaknesses of Project 1

\section{Project 2:}

\begin{tabular}{|l|l|l|c|c|c|}
\hline Project 2 & Perspectives & \multicolumn{1}{|c|}{ Criteria } & $\begin{array}{c}\text { Global } \\
\text { Value }\end{array}$ & $\begin{array}{c}\text { Value } \\
\text { Curve }\end{array}$ & $\begin{array}{c}\text { Final } \\
\text { Score }\end{array}$ \\
\hline Strengths & Technical & $\begin{array}{l}\text { Production Performance } \\
\text { Subsurface \& Reservoir Uncertainty }\end{array}$ & $\begin{array}{c}0.05 \\
0.04\end{array}$ & $\begin{array}{c}97 \\
100\end{array}$ & $\begin{array}{c}4.85 \\
4\end{array}$ \\
\hline Weaknesses & Political & Government Stability & 0.08 & 15 & 1.2 \\
\hline
\end{tabular}

Table 69: Strengths and Weaknesses of Project 2

\section{Project 3:}

\begin{tabular}{|l|l|l|c|c|c|}
\hline \multicolumn{1}{|c|}{ Project 3 } & Perspectives & \multicolumn{1}{|c|}{ Criteria } & $\begin{array}{c}\text { Global } \\
\text { Value }\end{array}$ & $\begin{array}{c}\text { Value } \\
\text { Curve }\end{array}$ & $\begin{array}{c}\text { Final } \\
\text { Score }\end{array}$ \\
\hline \multirow{2}{*}{ Strengths } & \multirow{2}{*}{ Technical } & Production Performance & 0.05 & 100 & 5 \\
& & Subsurface \& Reservoir Uncertainty & 0.04 & 100 & 4 \\
\hline Weaknesses & Political & Government Stability & 0.08 & 15 & 1.2 \\
\hline
\end{tabular}

Table 70: Strengths and Weaknesses of Project 3

\subsection{Scenario Analysis}

Scenario analysis is conducted to test the robustness of the model. In order to analyze the impacts of potential changes in the values at any level of the model, scenario analysis approach has been used to test the robustness of the model. This analysis aims to measure 
how the model's final output will react to changes in the relevance of criteria. Multiple scenarios were created to capture the result of the analyses. Each scenario alters the relevance of perspectives by boosting one of the perspectives and the same process will be repeated for the four perspectives. For instance, economical perspective boosted to be 0.97 , while the remaining perspective's values will be 0.01 for each as it shows in table 71 .

\begin{tabular}{|l|cccc|}
\hline \multicolumn{1}{|c|}{ Perspectives } & Economical & Technical & Political & $\begin{array}{c}\text { Safety \& } \\
\text { Environmental }\end{array}$ \\
\hline First Scenario & 0.97 & 0.01 & 0.01 & 0.01 \\
$\begin{array}{l}\text { Second } \\
\text { Scenario }\end{array}$ & 0.01 & 0.97 & 0.01 & 0.01 \\
Third Scenario & 0.01 & 0.01 & 0.97 & 0.01 \\
Fourth Scenario & 0.01 & 0.01 & 0.01 & 0.97 \\
\hline
\end{tabular}

Table 71: Sensitivity Analysis Scenarios

In the first scenario economical perspective was boosted to the maximum value and it has been considering the most important factor. The result shows that the overall Project 1 score was increased from 64.28 to 73.58 . Table 72 demonstrations the changes in the overall score for Project 1 and the changes in perspective scores.

\begin{tabular}{|c|c|c|c|c|c|c|}
\hline \multicolumn{7}{|c|}{ First Scenario Economical Perspective Boosted to 0.97} \\
\hline \multicolumn{2}{|l|}{ Perspectives } & \multirow[b]{2}{*}{ Criteria } & \multirow{2}{*}{$\begin{array}{l}\text { Local } \\
\text { Value }\end{array}$} & \multirow{2}{*}{$\begin{array}{l}\text { Global } \\
\text { Value }\end{array}$} & \multicolumn{2}{|c|}{ Project1 } \\
\hline Name & Score & & & & $\begin{array}{l}\text { Value } \\
\text { Curve }\end{array}$ & $\begin{array}{l}\text { Final } \\
\text { Score }\end{array}$ \\
\hline \multirow{4}{*}{ Economical } & \multirow{4}{*}{0.97} & Oil Price & 0.35 & 0.3395 & 50 & 16.98 \\
\hline & & Initial Cost & 0.17 & 0.1649 & 88 & 14.51 \\
\hline & & Operational Cost & 0.16 & 0.1552 & 80 & 12.42 \\
\hline & & Return on Investment (ROI) & 0.32 & 0.3104 & 90 & 27.94 \\
\hline \multirow{2}{*}{ Technical } & \multirow{2}{*}{0.01} & Operational Difficulties & 0.15 & 0.0015 & 75 & 0.11 \\
\hline & & Project Size \& Complexity & 0.2 & 0.0020 & 65 & 0.13 \\
\hline
\end{tabular}




\begin{tabular}{|c|c|c|c|c|c|c|}
\hline & & Production Performance & 0.34 & 0.0034 & 35 & 0.12 \\
\hline & & $\begin{array}{l}\text { Subsurface \& Reservoir } \\
\text { Uncertainty }\end{array}$ & 0.31 & 0.0031 & 30 & 0.09 \\
\hline \multirow{4}{*}{ Political } & \multirow{4}{*}{0.01} & Government Stability & 0.32 & 0.0032 & 47 & 0.15 \\
\hline & & Conflict Over Maritime Claims & 0.13 & 0.0013 & 100 & 0.13 \\
\hline & & $\begin{array}{l}\text { Policies, Regulations \& } \\
\text { Governance Standards }\end{array}$ & 0.28 & 0.0028 & 75 & 0.21 \\
\hline & & Contracts Complexity & 0.27 & 0.0027 & 82 & 0.22 \\
\hline \multirow{4}{*}{$\begin{array}{l}\text { Safety \& } \\
\text { Environmental }\end{array}$} & \multirow{4}{*}{0.01} & $\begin{array}{l}\text { Hazard Identification \& Risk } \\
\text { Management }\end{array}$ & 0.34 & 0.0034 & 50 & 0.17 \\
\hline & & $\begin{array}{l}\text { Implementing Health, Safety } \\
\text { and Environmental (HSE) }\end{array}$ & 0.21 & 0.0021 & 55 & 0.12 \\
\hline & & $\begin{array}{l}\text { Stringent of the Local Health, } \\
\text { Safety and Environmental } \\
\text { (HSE) Standards }\end{array}$ & 0.27 & 0.0027 & 75 & 0.20 \\
\hline & & $\begin{array}{l}\text { Environmental Risk } \\
\text { Management Integration }\end{array}$ & 0.18 & 0.0018 & 50 & 0.09 \\
\hline \multicolumn{5}{|c|}{ Project Total Score } & & 73.58 \\
\hline
\end{tabular}

Table 72: First Scenario Result Project 1

Overall score of Project 2 increased favorably from 67.84 to 72.72 . Table 73 demonstrates changes in the overall score for Project 2 and the changes in perspectives scores as well.

\begin{tabular}{|c|c|c|c|c|c|c|}
\hline \multicolumn{7}{|c|}{ First Scenario Economical Perspective Boosted to 0.97} \\
\hline \multicolumn{2}{|l|}{ Perspectives } & \multirow[b]{2}{*}{ Criteria } & \multirow{2}{*}{$\begin{array}{l}\text { Local } \\
\text { Value }\end{array}$} & \multirow{2}{*}{$\begin{array}{l}\text { Global } \\
\text { Value }\end{array}$} & \multicolumn{2}{|c|}{ Project 2} \\
\hline Name & Score & & & & $\begin{array}{l}\text { Value } \\
\text { Curve }\end{array}$ & $\begin{array}{l}\text { Final } \\
\text { Score }\end{array}$ \\
\hline \multirow{4}{*}{ Economical } & \multirow{4}{*}{0.97} & Oil Price & 0.35 & 0.3395 & 53 & 17.99 \\
\hline & & Initial Cost & 0.17 & 0.1649 & 70 & 11.54 \\
\hline & & Operational Cost & 0.16 & 0.1552 & 65 & 10.09 \\
\hline & & Return on Investment (ROI) & 0.32 & 0.3104 & 100 & 31.04 \\
\hline \multirow{4}{*}{ Technical } & \multirow{4}{*}{0.01} & Operational Difficulties & 0.15 & 0.0015 & 80 & 0.12 \\
\hline & & Project Size \& Complexity & 0.2 & 0.0020 & 35 & 0.07 \\
\hline & & Production Performance & 0.34 & 0.0034 & 97 & 0.33 \\
\hline & & $\begin{array}{l}\text { Subsurface \& Reservoir } \\
\text { Uncertainty }\end{array}$ & 0.31 & 0.0031 & 100 & 0.31 \\
\hline
\end{tabular}




\begin{tabular}{|l|l|l|c|c|c|c|}
\hline \multirow{5}{*}{ Political } & \multirow{5}{*}{0.01} & 0.32 & 0.0032 & 15 & 0.05 \\
\cline { 3 - 7 } & & Government Stability & 0.13 & 0.0013 & 100 & 0.13 \\
\cline { 3 - 7 } & & $\begin{array}{l}\text { Ponflict Over Maritime Claims } \\
\text { Governance Standards }\end{array}$ & 0.28 & 0.0028 & 90 & 0.25 \\
\cline { 3 - 7 } & Contracts Complexity & 0.27 & 0.0027 & 73 & 0.20 \\
\hline \multirow{3}{*}{$\begin{array}{l}\text { Safety \& } \\
\text { Environmental }\end{array}$} & $\begin{array}{l}\text { Hazard Identification \& Risk } \\
\text { Management }\end{array}$ & 0.34 & 0.0034 & 40 & 0.14 \\
\cline { 3 - 7 } & $\begin{array}{l}\text { Implementing Health, Safety and } \\
\text { Environmental (HSE) }\end{array}$ & 0.21 & 0.0021 & 30 & 0.06 \\
\cline { 3 - 7 } & $\begin{array}{l}\text { Stringent of the Local Health, } \\
\text { Safety and Environmental (HSE) } \\
\text { Standards }\end{array}$ & 0.27 & 0.0027 & 95 & 0.26 \\
\cline { 3 - 8 } & $\begin{array}{l}\text { Environmental Risk } \\
\text { Management Integration }\end{array}$ & 0.18 & 0.0018 & 80 & 0.14 \\
\hline
\end{tabular}

\section{Table 73: First Scenario Result Project 2}

Overall score of Project 3 increased favorably from 70.86 to 77.63 . Table 74 demonstrates changes in the overall score for Project 3 and the changes in perspectives scores as well.

\begin{tabular}{|c|c|c|c|c|c|c|}
\hline \multicolumn{7}{|c|}{ First Scenario Economical Perspective Boosted to 0.97} \\
\hline \multicolumn{2}{|l|}{ Perspectives } & \multirow[b]{2}{*}{ Criteria } & \multirow{2}{*}{$\begin{array}{l}\text { Local } \\
\text { Value }\end{array}$} & \multirow{2}{*}{$\begin{array}{l}\text { Global } \\
\text { Value }\end{array}$} & \multicolumn{2}{|c|}{ Project 3} \\
\hline Name & Score & & & & $\begin{array}{l}\text { Value } \\
\text { Curve }\end{array}$ & $\begin{array}{l}\text { Final } \\
\text { Score }\end{array}$ \\
\hline \multirow{4}{*}{ Economical } & \multirow{4}{*}{0.97} & Oil Price & 0.35 & 0.3395 & 58 & 19.69 \\
\hline & & Initial Cost & 0.17 & 0.1649 & 75 & 12.37 \\
\hline & & Operational Cost & 0.16 & 0.1552 & 80 & 12.42 \\
\hline & & Return on Investment (ROI) & 0.32 & 0.3104 & 100 & 31.04 \\
\hline \multirow{4}{*}{ Technical } & \multirow{4}{*}{0.01} & Operational Difficulties & 0.15 & 0.0015 & 85 & 0.13 \\
\hline & & Project Size \& Complexity & 0.2 & 0.0020 & 35 & 0.07 \\
\hline & & Production Performance & 0.34 & 0.0034 & 100 & 0.34 \\
\hline & & $\begin{array}{l}\text { Subsurface \& Reservoir } \\
\text { Uncertainty }\end{array}$ & 0.31 & 0.0031 & 100 & 0.31 \\
\hline \multirow[b]{2}{*}{ Political } & \multirow[b]{2}{*}{0.01} & Government Stability & 0.32 & 0.0032 & 15 & 0.05 \\
\hline & & $\begin{array}{l}\text { Conflict Over Maritime } \\
\text { Claims }\end{array}$ & 0.13 & 0.0013 & 100 & 0.13 \\
\hline
\end{tabular}




\begin{tabular}{|l|l|l|c|c|c|c|} 
& & $\begin{array}{l}\text { Policies, Regulations \& } \\
\text { Governance Standards }\end{array}$ & 0.28 & 0.0028 & 90 & 0.25 \\
\cline { 3 - 7 } & & Contracts Complexity & 0.27 & 0.0027 & 80 & 0.22 \\
\hline \multirow{5}{*}{$\begin{array}{l}\text { Safety \& } \\
\text { Environmental }\end{array}$} & \multirow{2}{*}{0.01} & $\begin{array}{l}\text { Hazard Identification \& Risk } \\
\text { Management }\end{array}$ & 0.34 & 0.0034 & 45 & 0.15 \\
\cline { 3 - 7 } & $\begin{array}{l}\text { Implementing Health, Safety } \\
\text { and Environmental (HSE) }\end{array}$ & 0.21 & 0.0021 & 30 & 0.06 \\
\cline { 3 - 7 } & $\begin{array}{l}\text { Stringent of the Local Health, } \\
\text { Safety and Environmental } \\
\text { (HSE) Standards }\end{array}$ & 0.27 & 0.0027 & 95 & 0.26 \\
\cline { 2 - 7 } & $\begin{array}{l}\text { Environmental Risk } \\
\text { Management Integration }\end{array}$ & 0.18 & 0.0018 & 85 & 0.15 \\
\hline \multicolumn{2}{|l|}{ Project Total Score } \\
\hline
\end{tabular}

Table 74: First Scenario Result Project 3

The increase in economic value positively impacted the overall scores on all three projects. Table 75 summarizes the changes of projects scores and the changes in ranks of each project. The results showed that there was a rank change in first scenarios. However, those are extreme scenarios, and in practice most likely any change would be much less extreme, thus the model is reliable enough.

\begin{tabular}{|c|c|c|c|}
\hline \multicolumn{5}{|c|}{ First Scenario Economical Perspective Boosted to 0.97 } \\
\hline Project Name & Project 1: Baraka & Project 2: Bouri - DP3 & Project 3: Bouri - DP4 \\
\hline Original Scores & 64.28 & 67.84 & 70.86 \\
\hline Scenario Scores & 73.58 & 72.72 & 77.63 \\
\hline Value Changes & 9.30 & 4.88 & 6.77 \\
\hline Original Ranks & 3 & 2 & 1 \\
\hline Scenario Ranks & 2 & 3 & 1 \\
\hline
\end{tabular}

Table 75: Summarizes First Scenario Changes of Scores

In the second scenario, technical perspective was boosted to the maximum value and it is considered as the most significant factor. The result shows that the overall Project 1 score was impacted negatively and decreased from 64.28 to 46.12 since a technical 
perspective was the critical area in Project 1 evaluation. Table 76 demonstrations changing of Project 1 overall score and changing in perspective scores.

\begin{tabular}{|c|c|c|c|c|c|c|}
\hline \multicolumn{7}{|c|}{ Second Scenario Technical Perspective Boosted to 0.97} \\
\hline \multicolumn{2}{|l|}{ Perspectives } & \multirow[b]{2}{*}{ Criteria } & \multirow{2}{*}{$\begin{array}{l}\text { Local } \\
\text { Value }\end{array}$} & \multirow{2}{*}{$\begin{array}{l}\text { Global } \\
\text { Value }\end{array}$} & \multicolumn{2}{|c|}{ Project 1} \\
\hline Name & Score & & & & $\begin{array}{l}\text { Value } \\
\text { Curve }\end{array}$ & $\begin{array}{l}\text { Final } \\
\text { Score }\end{array}$ \\
\hline \multirow{4}{*}{ Economical } & \multirow{4}{*}{0.01} & Oil Price & 0.35 & 0.0035 & 50 & 0.18 \\
\hline & & Initial Cost & 0.17 & 0.0017 & 88 & 0.15 \\
\hline & & Operational Cost & 0.16 & 0.0016 & 80 & 0.13 \\
\hline & & Return on Investment (ROI) & 0.32 & 0.0032 & 90 & 0.29 \\
\hline \multirow{4}{*}{ Technical } & \multirow{4}{*}{0.97} & Operational Difficulties & 0.15 & 0.1455 & 75 & 10.91 \\
\hline & & Project Size \& Complexity & 0.2 & 0.1940 & 65 & 12.61 \\
\hline & & Production Performance & 0.34 & 0.3298 & 35 & 11.54 \\
\hline & & $\begin{array}{l}\text { Subsurface \& Reservoir } \\
\text { Uncertainty }\end{array}$ & 0.31 & 0.3007 & 30 & 9.02 \\
\hline \multirow{4}{*}{ Political } & \multirow{4}{*}{0.01} & Government Stability & 0.32 & 0.0032 & 47 & 0.15 \\
\hline & & $\begin{array}{l}\text { Conflict Over Maritime } \\
\text { Claims }\end{array}$ & 0.13 & 0.0013 & 100 & 0.13 \\
\hline & & $\begin{array}{l}\text { Policies, Regulations \& } \\
\text { Governance Standards }\end{array}$ & 0.28 & 0.0028 & 75 & 0.21 \\
\hline & & Contracts Complexity & 0.27 & 0.0027 & 82 & 0.22 \\
\hline \multirow{4}{*}{$\begin{array}{l}\text { Safety \& } \\
\text { Environmental }\end{array}$} & \multirow{4}{*}{0.01} & $\begin{array}{l}\text { Hazard Identification \& Risk } \\
\text { Management }\end{array}$ & 0.34 & 0.0034 & 50 & 0.17 \\
\hline & & $\begin{array}{l}\text { Implementing Health, Safety } \\
\text { and Environmental (HSE) }\end{array}$ & 0.21 & 0.0021 & 55 & 0.12 \\
\hline & & $\begin{array}{l}\text { Stringent of the Local Health, } \\
\text { Safety and Environmental } \\
\text { (HSE) Standards }\end{array}$ & 0.27 & 0.0027 & 75 & 0.20 \\
\hline & & $\begin{array}{l}\text { Environmental Risk } \\
\text { Management Integration }\end{array}$ & 0.18 & 0.0018 & 50 & 0.09 \\
\hline \multicolumn{5}{|c|}{ Project Total Score } & & 46.12 \\
\hline
\end{tabular}

Table 76: Second Scenario Result Project 1 
When the technical perspective was boosted to the maximum value, the overall score of Project 2 was increased favorably by 14.61 points. Table 77 demonstrations changing of Project 2 overall score and changes in perspective scores as well.

\begin{tabular}{|c|c|c|c|c|c|c|}
\hline \multicolumn{7}{|c|}{ Second Scenario Technical Perspective Boosted to 0.97} \\
\hline \multicolumn{2}{|l|}{ Perspectives } & \multirow[b]{2}{*}{ Criteria } & \multirow{2}{*}{$\begin{array}{l}\text { Local } \\
\text { Value }\end{array}$} & \multirow{2}{*}{$\begin{array}{l}\text { Global } \\
\text { Value }\end{array}$} & \multicolumn{2}{|c|}{ Project 2} \\
\hline Name & Score & & & & $\begin{array}{l}\text { Value } \\
\text { Curve }\end{array}$ & $\begin{array}{l}\text { Final } \\
\text { Score }\end{array}$ \\
\hline \multirow{4}{*}{ Economical } & \multirow{4}{*}{0.01} & Oil Price & 0.35 & 0.0035 & 53 & 0.19 \\
\hline & & Initial Cost & 0.17 & 0.0017 & 70 & 0.12 \\
\hline & & Operational Cost & 0.16 & 0.0016 & 65 & 0.10 \\
\hline & & Return on Investment (ROI) & 0.32 & 0.0032 & 100 & 0.32 \\
\hline \multirow{4}{*}{ Technical } & \multirow{4}{*}{0.97} & Operational Difficulties & 0.15 & 0.1455 & 80 & 11.64 \\
\hline & & Project Size \& Complexity & 0.2 & 0.1940 & 35 & 6.79 \\
\hline & & Production Performance & 0.34 & 0.3298 & 97 & 31.99 \\
\hline & & $\begin{array}{l}\text { Subsurface \& Reservoir } \\
\text { Uncertainty }\end{array}$ & 0.31 & 0.3007 & 100 & 30.07 \\
\hline \multirow{4}{*}{ Political } & \multirow{4}{*}{0.01} & Government Stability & 0.32 & 0.0032 & 15 & 0.05 \\
\hline & & Conflict Over Maritime Claims & 0.13 & 0.0013 & 100 & 0.13 \\
\hline & & $\begin{array}{l}\text { Policies, Regulations \& } \\
\text { Governance Standards }\end{array}$ & 0.28 & 0.0028 & 90 & 0.25 \\
\hline & & Contracts Complexity & 0.27 & 0.0027 & 73 & 0.20 \\
\hline \multirow{4}{*}{$\begin{array}{l}\text { Safety \& } \\
\text { Environmental }\end{array}$} & \multirow{4}{*}{0.01} & $\begin{array}{l}\text { Hazard Identification \& Risk } \\
\text { Management }\end{array}$ & 0.34 & 0.0034 & 40 & 0.14 \\
\hline & & $\begin{array}{l}\text { Implementing Health, Safety } \\
\text { and Environmental (HSE) }\end{array}$ & 0.21 & 0.0021 & 30 & 0.06 \\
\hline & & $\begin{array}{l}\text { Stringent of the Local Health, } \\
\text { Safety and Environmental } \\
\text { (HSE) Standards }\end{array}$ & 0.27 & 0.0027 & 95 & 0.26 \\
\hline & & $\begin{array}{l}\text { Environmental Risk } \\
\text { Management Integration }\end{array}$ & 0.18 & 0.0018 & 80 & 0.14 \\
\hline \multicolumn{5}{|c|}{ Project Total Score } & & 82.45 \\
\hline
\end{tabular}

Table 77: Second Scenario Result Project 2 
Overall score of Project 3 was increased positively by 13.40 points. Table 78 demonstrates changes of Project 3 overall score and changes in perspectives scores as well.

\begin{tabular}{|c|c|c|c|c|c|c|}
\hline \multicolumn{7}{|c|}{ Second Scenario Technical Perspective Boosted to 0.97} \\
\hline \multicolumn{2}{|l|}{ Perspectives } & \multirow[b]{2}{*}{ Criteria } & \multirow{2}{*}{$\begin{array}{l}\text { Local } \\
\text { Value }\end{array}$} & \multirow[b]{2}{*}{$\begin{array}{l}\text { Global } \\
\text { Value }\end{array}$} & \multicolumn{2}{|c|}{ Project 3} \\
\hline Name & Score & & & & $\begin{array}{l}\text { Value } \\
\text { Curve }\end{array}$ & $\begin{array}{l}\text { Final } \\
\text { Score }\end{array}$ \\
\hline \multirow{4}{*}{ Economical } & \multirow{4}{*}{0.01} & Oil Price & 0.35 & 0.0035 & 58 & 0.20 \\
\hline & & Initial Cost & 0.17 & 0.0017 & 75 & 0.13 \\
\hline & & Operational Cost & 0.16 & 0.0016 & 80 & 0.13 \\
\hline & & Return on Investment (ROI) & 0.32 & 0.0032 & 100 & 0.32 \\
\hline \multirow{4}{*}{ Technical } & \multirow{4}{*}{0.97} & Operational Difficulties & 0.15 & 0.1455 & 85 & 12.37 \\
\hline & & Project Size \& Complexity & 0.2 & 0.1940 & 35 & 6.79 \\
\hline & & Production Performance & 0.34 & 0.3298 & 100 & 32.98 \\
\hline & & $\begin{array}{l}\text { Subsurface \& Reservoir } \\
\text { Uncertainty }\end{array}$ & 0.31 & 0.3007 & 100 & 30.07 \\
\hline \multirow{4}{*}{ Political } & \multirow{4}{*}{0.01} & Government Stability & 0.32 & 0.0032 & 15 & 0.05 \\
\hline & & Conflict Over Maritime Claims & 0.13 & 0.0013 & 100 & 0.13 \\
\hline & & $\begin{array}{l}\text { Policies, Regulations \& } \\
\text { Governance Standards }\end{array}$ & 0.28 & 0.0028 & 90 & 0.25 \\
\hline & & Contracts Complexity & 0.27 & 0.0027 & 80 & 0.22 \\
\hline \multirow{4}{*}{$\begin{array}{l}\text { Safety \& } \\
\text { Environmental }\end{array}$} & \multirow{4}{*}{0.01} & $\begin{array}{l}\text { Hazard Identification \& Risk } \\
\text { Management }\end{array}$ & 0.34 & 0.0034 & 45 & 0.15 \\
\hline & & $\begin{array}{l}\text { Implementing Health, Safety and } \\
\text { Environmental (HSE) }\end{array}$ & 0.21 & 0.0021 & 30 & 0.06 \\
\hline & & $\begin{array}{l}\text { Stringent of the Local Health, } \\
\text { Safety and Environmental } \\
\text { Standards }\end{array}$ & 0.27 & 0.0027 & 95 & 0.26 \\
\hline & & $\begin{array}{l}\text { Environmental Risk } \\
\text { Management Integration }\end{array}$ & 0.18 & 0.0018 & 85 & 0.15 \\
\hline \multicolumn{5}{|c|}{ Project Total Score } & & 84.26 \\
\hline
\end{tabular}

Table 78: Second Scenario Result Project 3

The positive changes on the technical value impacted each project differently. Table 79 summarizes the changes on project scores due to this boost. The results showed that there wasn't a rank change in second scenarios, thus the model is reliable enough. 


\begin{tabular}{|l|c|c|c|}
\hline \multicolumn{5}{|l|}{ Second Scenario Technical Perspective Boosted to 0.97 } \\
\hline Project Name & Project 1: Baraka & Project 2: Bouri - DP3 & Project 3: Bouri - DP4 \\
\hline Original Scores & 64.28 & 67.84 & 70.86 \\
\hline Scenario Scores & 46.12 & 82.45 & 84.26 \\
\hline Value Changes & -18.16 & 14.61 & 13.40 \\
\hline Original Ranks & 3 & 2 & 1 \\
\hline Scenario Ranks & 3 & 2 & 1 \\
\hline
\end{tabular}

Table 79: Summarizes Second Scenario Changes of Scores

In the third scenario, the political perspective was boosted to the maximum value and it is considered as the most important factor. The result shows that the overall Project 1 scores have been affected positively and increased by 6.54 points. Table 80 demonstrations changes to Project 1 overall scores and changes in perspective scores as well.

\begin{tabular}{|c|c|c|c|c|c|c|}
\hline \multicolumn{7}{|c|}{ Third Scenario Political Perspective Boosted to 0.97} \\
\hline \multicolumn{2}{|l|}{ Perspectives } & \multirow[b]{2}{*}{ Criteria } & \multirow[b]{2}{*}{$\begin{array}{l}\text { Local } \\
\text { Values }\end{array}$} & \multirow[b]{2}{*}{$\begin{array}{l}\text { Global } \\
\text { Values }\end{array}$} & \multicolumn{2}{|c|}{ Project 1} \\
\hline Name & Score & & & & $\begin{array}{l}\text { Value } \\
\text { Curve }\end{array}$ & \begin{tabular}{|l|} 
Final \\
Score
\end{tabular} \\
\hline \multirow{4}{*}{ Economical } & \multirow{4}{*}{0.01} & Oil Price & 0.35 & 0.0035 & 50 & 0.18 \\
\hline & & Initial Cost & 0.17 & 0.0017 & 88 & 0.15 \\
\hline & & Operational Cost & 0.16 & 0.0016 & 80 & 0.13 \\
\hline & & Return on Investment (ROI) & 0.32 & 0.0032 & 90 & 0.29 \\
\hline \multirow{4}{*}{ Technical } & \multirow{4}{*}{0.01} & Operational Difficulties & 0.15 & 0.0015 & 75 & 0.11 \\
\hline & & Project Size \& Complexity & 0.2 & 0.0020 & 65 & 0.13 \\
\hline & & Production Performance & 0.34 & 0.0034 & 35 & 0.12 \\
\hline & & $\begin{array}{l}\text { Subsurface \& Reservoir } \\
\text { Uncertainty }\end{array}$ & 0.31 & 0.0031 & 30 & 0.09 \\
\hline \multirow{4}{*}{ Political } & \multirow{4}{*}{0.97} & Government Stability & 0.32 & 0.3104 & 47 & 14.59 \\
\hline & & $\begin{array}{l}\text { Conflict Over Maritime } \\
\text { Claims }\end{array}$ & 0.13 & 0.1261 & 100 & 12.61 \\
\hline & & $\begin{array}{l}\text { Policies, Regulations \& } \\
\text { Governance Standards }\end{array}$ & 0.28 & 0.2716 & 75 & 20.37 \\
\hline & & Contracts Complexity & 0.27 & 0.2619 & 82 & 21.48 \\
\hline \multirow{2}{*}{$\begin{array}{l}\text { Safety \& } \\
\text { Environmental }\end{array}$} & \multirow{2}{*}{0.01} & $\begin{array}{l}\text { Hazard Identification \& Risk } \\
\text { Management }\end{array}$ & 0.34 & 0.0034 & 50 & 0.17 \\
\hline & & $\begin{array}{l}\text { Implementing Health, Safety } \\
\text { and Environmental (HSE) }\end{array}$ & 0.21 & 0.0021 & 55 & 0.12 \\
\hline
\end{tabular}




\begin{tabular}{|l|l|l|l|l|l|} 
& $\begin{array}{l}\text { Stringent of the Local Health, } \\
\text { Safety and Environmental } \\
\text { (HSE) Standards }\end{array}$ & 0.27 & 0.0027 & 75 & 0.20 \\
\cline { 2 - 6 } & $\begin{array}{l}\text { Environmental Risk } \\
\text { Management Integration }\end{array}$ & 0.18 & 0.0018 & 50 & 0.09 \\
\hline
\end{tabular}

Table 80: Third Scenario Result Project 1

Moreover, the third scenario's results show that the overall Project 2 and Project 3 scores were affected negatively. Both projects are considering the political perspective as critical a part. Table 81 demonstrates changes of the overall score and the perspective score of Project 2.

\begin{tabular}{|c|c|c|c|c|c|c|}
\hline \multicolumn{7}{|c|}{ Third Scenario Political Perspective Boosted to 0.97} \\
\hline \multicolumn{2}{|l|}{ Perspectives } & \multirow[b]{2}{*}{ Criteria } & \multirow{2}{*}{$\begin{array}{l}\text { Local } \\
\text { Values }\end{array}$} & \multirow{2}{*}{$\begin{array}{l}\text { Global } \\
\text { Values }\end{array}$} & \multicolumn{2}{|c|}{ Project 2} \\
\hline Name & Score & & & & $\begin{array}{l}\text { Value } \\
\text { Curve }\end{array}$ & $\begin{array}{l}\text { Final } \\
\text { Score }\end{array}$ \\
\hline \multirow{4}{*}{ Economical } & \multirow{4}{*}{0.01} & Oil Price & 0.35 & 0.0035 & 53 & 0.19 \\
\hline & & Initial Cost & 0.17 & 0.0017 & 70 & 0.12 \\
\hline & & Operational Cost & 0.16 & 0.0016 & 65 & 0.10 \\
\hline & & Return on Investment (ROI) & 0.32 & 0.0032 & 100 & 0.32 \\
\hline \multirow{4}{*}{ Technical } & \multirow{4}{*}{0.01} & Operational Difficulties & 0.15 & 0.0015 & 80 & 0.12 \\
\hline & & Project Size \& Complexity & 0.2 & 0.0020 & 35 & 0.07 \\
\hline & & Production Performance & 0.34 & 0.0034 & 97 & 0.33 \\
\hline & & $\begin{array}{l}\text { Subsurface \& Reservoir } \\
\text { Uncertainty }\end{array}$ & 0.31 & 0.0031 & 100 & 0.31 \\
\hline \multirow{4}{*}{ Political } & \multirow{4}{*}{0.97} & Government Stability & 0.32 & 0.3104 & 15 & 4.66 \\
\hline & & $\begin{array}{l}\text { Conflict Over Maritime } \\
\text { Claims }\end{array}$ & 0.13 & 0.1261 & 100 & 12.61 \\
\hline & & $\begin{array}{l}\text { Policies, Regulations \& } \\
\text { Governance Standards }\end{array}$ & 0.28 & 0.2716 & 90 & 24.44 \\
\hline & & Contracts Complexity & 0.27 & 0.2619 & 73 & 19.12 \\
\hline \multirow{3}{*}{$\begin{array}{l}\text { Safety \& } \\
\text { Environmental }\end{array}$} & \multirow{3}{*}{0.01} & $\begin{array}{l}\text { Hazard Identification \& Risk } \\
\text { Management }\end{array}$ & 0.34 & 0.0034 & 40 & 0.14 \\
\hline & & $\begin{array}{l}\text { Implementing Health, Safety } \\
\text { and Environmental (HSE) }\end{array}$ & 0.21 & 0.0021 & 30 & 0.06 \\
\hline & & Stringent of the Local Health, & 0.27 & 0.0027 & 95 & 0.26 \\
\hline
\end{tabular}




\begin{tabular}{|l|l|l|l|l|l|} 
& $\begin{array}{l}\text { Safety and Environmental } \\
\text { (HSE) Standards }\end{array}$ & & & & \\
\cline { 2 - 6 } & $\begin{array}{l}\text { Environmental Risk } \\
\text { Management Integration }\end{array}$ & 0.18 & 0.0018 & 80 & 0.14 \\
\hline Project Total Score
\end{tabular}

Table 81: Third Scenario Result Project 2

Project 3 scores been dropped by almost 6 point as summarized in table 82 .

\begin{tabular}{|c|c|c|c|c|c|c|}
\hline \multicolumn{7}{|c|}{ Third Scenario Political Perspective Boosted to 0.97} \\
\hline \multicolumn{2}{|l|}{ Perspectives } & \multirow[b]{2}{*}{ Criteria } & \multirow{2}{*}{$\begin{array}{l}\text { Local } \\
\text { Values }\end{array}$} & \multirow{2}{*}{$\begin{array}{l}\text { Global } \\
\text { Values }\end{array}$} & \multicolumn{2}{|c|}{ Project 3} \\
\hline Name & Score & & & & $\begin{array}{l}\text { Value } \\
\text { Curve }\end{array}$ & $\begin{array}{l}\text { Final } \\
\text { Score }\end{array}$ \\
\hline \multirow{4}{*}{ Economical } & \multirow{4}{*}{0.01} & Oil Price & 0.35 & 0.0035 & 58 & 0.20 \\
\hline & & Initial Cost & 0.17 & 0.0017 & 75 & 0.13 \\
\hline & & Operational Cost & 0.16 & 0.0016 & 80 & 0.13 \\
\hline & & Return on Investment (ROI) & 0.32 & 0.0032 & 100 & 0.32 \\
\hline \multirow{4}{*}{ Technical } & \multirow{4}{*}{0.01} & Operational Difficulties & 0.15 & 0.0015 & 85 & 0.13 \\
\hline & & Project Size \& Complexity & 0.2 & 0.0020 & 35 & 0.07 \\
\hline & & Production Performance & 0.34 & 0.0034 & 100 & 0.34 \\
\hline & & $\begin{array}{l}\text { Subsurface \& Reservoir } \\
\text { Uncertainty }\end{array}$ & 0.31 & 0.0031 & 100 & 0.31 \\
\hline \multirow{4}{*}{ Political } & \multirow{4}{*}{0.97} & Government Stability & 0.32 & 0.3104 & 15 & 4.66 \\
\hline & & $\begin{array}{l}\text { Conflict Over Maritime } \\
\text { Claims }\end{array}$ & 0.13 & 0.1261 & 100 & 12.61 \\
\hline & & $\begin{array}{l}\text { Policies, Regulations \& } \\
\text { Governance Standards }\end{array}$ & 0.28 & 0.2716 & 90 & 24.44 \\
\hline & & Contracts Complexity & 0.27 & 0.2619 & 80 & 20.95 \\
\hline \multirow{4}{*}{$\begin{array}{l}\text { Safety \& } \\
\text { Environmental }\end{array}$} & \multirow{4}{*}{0.01} & $\begin{array}{l}\text { Hazard Identification \& Risk } \\
\text { Management }\end{array}$ & 0.34 & 0.0034 & 45 & 0.15 \\
\hline & & $\begin{array}{l}\text { Implementing Health, Safety } \\
\text { and Environmental (HSE) }\end{array}$ & 0.21 & 0.0021 & 30 & 0.06 \\
\hline & & $\begin{array}{l}\text { Stringent of the Local Health, } \\
\text { Safety and Environmental } \\
\text { (HSE) Standards }\end{array}$ & 0.27 & 0.0027 & 95 & 0.26 \\
\hline & & $\begin{array}{l}\text { Environmental Risk } \\
\text { Management Integration }\end{array}$ & 0.18 & 0.0018 & 85 & 0.15 \\
\hline \multicolumn{5}{|c|}{ Project Total Score } & & 64.91 \\
\hline
\end{tabular}

Table 82: Third Scenario Result Project 3 
An increase in the political value affected each project differently. Table 83 summarizes the changes on project scores and their rankings. The results showed that there was a rank change in third scenarios. However, those are extreme scenarios, and in practice most likely any change would be much less extreme, thus the model is reliable enough.

\begin{tabular}{|l|c|c|c|}
\hline \multicolumn{5}{|l|}{ Third Scenario Political Perspective Boosted to 0.97 } \\
\hline Project Name & Project 1: Baraka & Project 2: Bouri - DP3 & Project 3: Bouri - DP4 \\
\hline Original Scores & 64.28 & 67.84 & 70.86 \\
\hline Scenario Scores & 70.82 & 62.99 & 64.91 \\
\hline Value Changes & 6.54 & -4.85 & -5.95 \\
\hline Original Ranks & 3 & 2 & 1 \\
\hline Scenario Ranks & 1 & 3 & 2 \\
\hline
\end{tabular}

Table 83: Summarizes Third Scenario Changes of Scores

In the forth scenario, safety \& environmental perspective was boosted to the maximum value and it has been considered as the key factor. The result shows that the overall Project 1 scores have been affected negatively and dropped by 6.31 points. Table 84 demonstrations changes to Project 1 overall scores and changes in perspective scores.

\begin{tabular}{|c|c|c|c|c|c|c|}
\hline \multicolumn{7}{|c|}{ Forth Scenario Safety \& Environmental Perspective Boosted to 0.97} \\
\hline \multicolumn{2}{|l|}{ Perspectives } & \multirow[b]{2}{*}{ Criteria } & \multirow{2}{*}{$\begin{array}{l}\text { Local } \\
\text { Value }\end{array}$} & \multirow{2}{*}{$\begin{array}{l}\text { Global } \\
\text { Value }\end{array}$} & \multicolumn{2}{|c|}{ Project 1} \\
\hline Name & Score & & & & $\begin{array}{l}\text { Value } \\
\text { Curve }\end{array}$ & $\begin{array}{l}\text { Final } \\
\text { Score }\end{array}$ \\
\hline \multirow{4}{*}{ Economical } & \multirow{4}{*}{0.01} & Oil Price & 0.35 & 0.0035 & 50 & 0.18 \\
\hline & & Initial Cost & 0.17 & 0.0017 & 88 & 0.15 \\
\hline & & Operational Cost & 0.16 & 0.0016 & 80 & 0.13 \\
\hline & & Return on Investment (ROI) & 0.32 & 0.0032 & 90 & 0.29 \\
\hline \multirow{4}{*}{ Technical } & \multirow{4}{*}{0.01} & Operational Difficulties & 0.15 & 0.0015 & 75 & 0.11 \\
\hline & & Project Size \& Complexity & 0.2 & 0.0020 & 65 & 0.13 \\
\hline & & Production Performance & 0.34 & 0.0034 & 35 & 0.12 \\
\hline & & $\begin{array}{l}\text { Subsurface \& Reservoir } \\
\text { Uncertainty }\end{array}$ & 0.31 & 0.0031 & 30 & 0.09 \\
\hline
\end{tabular}




\begin{tabular}{|c|c|c|c|c|c|c|}
\hline \multirow{4}{*}{ Political } & \multirow{4}{*}{0.01} & Government Stability & 0.32 & 0.0032 & 47 & 0.15 \\
\hline & & Conflict Over Maritime Claims & 0.13 & 0.0013 & 100 & 0.13 \\
\hline & & $\begin{array}{l}\text { Policies, Regulations \& } \\
\text { Governance Standards }\end{array}$ & 0.28 & 0.0028 & 75 & 0.21 \\
\hline & & Contracts Complexity & 0.27 & 0.0027 & 82 & 0.22 \\
\hline \multirow{4}{*}{$\begin{array}{l}\text { Safety \& } \\
\text { Environmental }\end{array}$} & \multirow{4}{*}{0.97} & $\begin{array}{l}\text { Hazard Identification \& Risk } \\
\text { Management }\end{array}$ & 0.34 & 0.3298 & 50 & 16.49 \\
\hline & & $\begin{array}{l}\text { Implementing Health, Safety } \\
\text { and Environmental (HSE) }\end{array}$ & 0.21 & 0.2037 & 55 & 11.20 \\
\hline & & $\begin{array}{l}\text { Stringent of the Local Health, } \\
\text { Safety and Environmental } \\
\text { (HSE) Standards }\end{array}$ & 0.27 & 0.2619 & 75 & 19.64 \\
\hline & & $\begin{array}{l}\text { Environmental Risk } \\
\text { Management Integration }\end{array}$ & 0.18 & 0.1746 & 50 & 8.73 \\
\hline \multicolumn{5}{|c|}{ Project Total Score } & \multicolumn{2}{|r|}{57.97} \\
\hline
\end{tabular}

Table 84: Forth Scenario Result Project 1

When the safety \& environmental perspective was boosted to the maximum value, the overall scores of Project 2 been dropped by 7.50 points. Table 85 demonstrates changes to Project 2 overall score and changes in perspectives scores as well.

\begin{tabular}{|c|c|c|c|c|c|c|}
\hline \multicolumn{7}{|c|}{ Forth Scenario Safety \& Environmental Perspective Boosted to 0.97} \\
\hline \multicolumn{2}{|l|}{ Perspectives } & \multirow[b]{2}{*}{ Criteria } & \multirow{2}{*}{$\begin{array}{l}\text { Local } \\
\text { Value }\end{array}$} & \multirow{2}{*}{$\begin{array}{l}\text { Global } \\
\text { Value }\end{array}$} & \multicolumn{2}{|c|}{ Project 2} \\
\hline Name & Score & & & & $\begin{array}{l}\text { Value } \\
\text { Curve }\end{array}$ & $\begin{array}{l}\text { Final } \\
\text { Score }\end{array}$ \\
\hline \multirow{4}{*}{ Economical } & \multirow{4}{*}{0.01} & Oil Price & 0.35 & 0.0035 & 53 & 0.19 \\
\hline & & Initial Cost & 0.17 & 0.0017 & 70 & 0.12 \\
\hline & & Operational Cost & 0.16 & 0.0016 & 65 & 0.10 \\
\hline & & Return on Investment (ROI) & 0.32 & 0.0032 & 100 & 0.32 \\
\hline \multirow{4}{*}{ Technical } & \multirow{4}{*}{0.01} & Operational Difficulties & 0.15 & 0.0015 & 80 & 0.12 \\
\hline & & Project Size \& Complexity & 0.2 & 0.0020 & 35 & 0.07 \\
\hline & & Production Performance & 0.34 & 0.0034 & 97 & 0.33 \\
\hline & & $\begin{array}{l}\text { Subsurface \& Reservoir } \\
\text { Uncertainty }\end{array}$ & 0.31 & 0.0031 & 100 & 0.31 \\
\hline \multirow{3}{*}{ Political } & \multirow{3}{*}{0.01} & Government Stability & 0.32 & 0.0032 & 15 & 0.05 \\
\hline & & Conflict Over Maritime Claims & 0.13 & 0.0013 & 100 & 0.13 \\
\hline & & Policies, Regulations \& & 0.28 & 0.0028 & 90 & 0.25 \\
\hline
\end{tabular}




\begin{tabular}{|l|l|l|c|c|c|c|}
\cline { 3 - 6 } & & Governance Standards & & & & \\
\cline { 3 - 6 } & & Contracts Complexity & 0.27 & 0.0027 & 73 & 0.20 \\
\hline $\begin{array}{l}\text { Safety \& } \\
\text { Environmental }\end{array}$ & 0.97 & $\begin{array}{l}\text { Hazard Identification \& Risk } \\
\text { Management }\end{array}$ & 0.34 & 0.3298 & 40 & 13.19 \\
\cline { 3 - 6 } & $\begin{array}{l}\text { Implementing Health, Safety } \\
\text { and Environmental (HSE) }\end{array}$ & 0.21 & 0.2037 & 30 & 6.11 \\
\cline { 4 - 7 } & $\begin{array}{l}\text { Stringent of the Local Health, } \\
\text { Safety and Environmental } \\
\text { (HSE) Standards }\end{array}$ & 0.27 & 0.2619 & 95 & 24.88 \\
\hline & $\begin{array}{l}\text { Environmental Risk } \\
\text { Management Integration }\end{array}$ & 0.18 & 0.1746 & 80 & 13.97 \\
\hline
\end{tabular}

Table 85: Forth Scenario Result Project 2

The overall scores of Project 3 dropped by 7.91 points. Table 86 demonstrates changes to

Project 3 overall score and changes in perspectives scores as well.

\begin{tabular}{|c|c|c|c|c|c|c|}
\hline \multicolumn{7}{|c|}{ Forth Scenario Safety \& Environmental Perspective Boosted to 0.97} \\
\hline \multicolumn{2}{|l|}{ Perspectives } & \multirow[b]{2}{*}{ Criteria } & \multirow{2}{*}{$\begin{array}{l}\text { Local } \\
\text { Value }\end{array}$} & \multirow{2}{*}{$\begin{array}{l}\text { Global } \\
\text { Value }\end{array}$} & \multicolumn{2}{|c|}{ Project 3} \\
\hline Name & Score & & & & $\begin{array}{l}\text { Value } \\
\text { Curve }\end{array}$ & $\begin{array}{l}\text { Final } \\
\text { Score }\end{array}$ \\
\hline \multirow{4}{*}{ Economical } & \multirow{4}{*}{0.01} & Oil Price & 0.35 & 0.0035 & 58 & 0.20 \\
\hline & & Initial Cost & 0.17 & 0.0017 & 75 & 0.13 \\
\hline & & Operational Cost & 0.16 & 0.0016 & 80 & 0.13 \\
\hline & & Return on Investment (ROI) & 0.32 & 0.0032 & 100 & 0.32 \\
\hline \multirow{4}{*}{ Technical } & \multirow{4}{*}{0.01} & Operational Difficulties & 0.15 & 0.0015 & 85 & 0.13 \\
\hline & & Project Size \& Complexity & 0.2 & 0.0020 & 35 & 0.07 \\
\hline & & Production Performance & 0.34 & 0.0034 & 100 & 0.34 \\
\hline & & $\begin{array}{l}\text { Subsurface \& Reservoir } \\
\text { Uncertainty }\end{array}$ & 0.31 & 0.0031 & 100 & 0.31 \\
\hline \multirow{4}{*}{ Political } & \multirow{4}{*}{0.01} & Government Stability & 0.32 & 0.0032 & 15 & 0.05 \\
\hline & & Conflict Over Maritime Claims & 0.13 & 0.0013 & 100 & 0.13 \\
\hline & & $\begin{array}{l}\text { Policies, Regulations \& } \\
\text { Governance Standards }\end{array}$ & 0.28 & 0.0028 & 90 & 0.25 \\
\hline & & Contracts Complexity & 0.27 & 0.0027 & 80 & 0.22 \\
\hline \multirow{2}{*}{$\begin{array}{l}\text { Safety \& } \\
\text { Environmental }\end{array}$} & \multirow[t]{2}{*}{0.97} & $\begin{array}{l}\text { Hazard Identification \& Risk } \\
\text { Management }\end{array}$ & 0.34 & 0.3298 & 45 & 14.84 \\
\hline & & Implementing Health, Safety & 0.21 & 0.2037 & 30 & 6.11 \\
\hline
\end{tabular}




\begin{tabular}{|l|l|l|l|c|c|c|}
\hline \multirow{1}{*}{} & and Environmental (HSE) & & & & \\
\cline { 2 - 6 } & $\begin{array}{l}\text { Stringent of the Local Health, } \\
\text { Safety and Environmental } \\
\text { (HSE) Standards }\end{array}$ & 0.27 & 0.2619 & 95 & 24.88 \\
\hline & $\begin{array}{l}\text { Environmental Risk } \\
\text { Management Integration }\end{array}$ & 0.18 & 0.1746 & 85 & 14.84 \\
\hline Project Total Score
\end{tabular}

Table 86: Forth Scenario Result Project 3

Increasing the safety \& environmental value influenced each project differently. Table 87 summarizes the change on projects scores. The results showed that there wasn't a rank change in forth scenarios, thus the model is reliable enough.

\begin{tabular}{|l|c|c|c|}
\hline \multicolumn{5}{|l|}{ Forth Scenario Safety \& Environmental Perspective Boosted to 0.97 } \\
\hline Project Name & Project 1: Baraka & Project 2: Bouri - DP3 & Project 3: Bouri - DP4 \\
\hline Original Scores & 64.28 & 67.84 & 70.86 \\
\hline Scenario Scores & 57.97 & 60.34 & 62.95 \\
\hline Value Changes & -6.31 & -7.50 & -7.91 \\
\hline Original Ranks & 3 & 2 & 1 \\
\hline Scenario Ranks & 3 & 2 & 1 \\
\hline
\end{tabular}

Table 87: Summarizes Forth Scenario Changes of Scores 


\section{CHAPTER 10: RESEARCH VALIDITY}

As it has been mentioned in the previous chapter, the main purpose of the validation phase is to answer the following questions:

- Does the model capture the necessary elements needed to satisfy the research goal?

- Does the model valid to apply?

Following previous PhD dissertations [105][117][120][121], the research validity has been guaranteed to answer these questions. However, the validity of the research should be tested by adopting three measures applied at different phases of the research: construct validity, content validity and criteria-related validity.

\subsection{Construct validity}

Construct validity refers to the degree to which a research approach complies with its underlying theories and to determine if the preliminary model construct is suitable for measuring the desired outcome. The decision model was developed based on the comprehensive literature review that was described in the previous sections as well as based on experts' feedbacks and recommendations through the third independent study. Construct validity of the initial model was tested by faculty and a group of ETM doctoral students, who have significant amount of research experience in both the energy field and hierarchical decision modeling. 


\subsection{Content validity}

Content validity refers to the degree to which a measure represents a given domain of interest. Content validity has been tested during the model development phase. After the preliminary model was constructed based on the literature, Subject matter experts who are familiar with decision models were asked to provide their feedback using the content of the model. Expert panel P1 was formed to validate the literature based hierarchical decision model. The experts were selected based on their expertise in the offshore oil field. Two rounds of validation took place using a Qualtrics survey. In the first round, experts evaluated the factors identified by the research as the most critical factors affecting the investment decision in offshore oil project. Experts also were given a chance to suggest other factors based on their experience. In the second round, experts validated the factors that were added to the model based on the first round expert's feedback.

Moreover, five panels have been formatted including perspectives quantification, economical quantification, technical quantification, political quantification and environmental \& safety quantification in order to quantify the research model and score each factor based on its relative importance to the mission level. As it was explained in fourth chapter, expert's judgments were captured through pair-wise comparisons utilizing the constant-sum method. Each comparison is made by distributing 100 points between the pair of items being compared. Data is collected through an online survey tool and the analysis is done using the HDM software, which also calculated the individual logical inconsistencies and the group disagreements. 


\section{3 Criterion-related validity}

Criterion-related validity refers to the degree of effectiveness of a model in predicting real-life phenomenon. Criterion-related validity is implemented after the analysis is completed. The quantified model has been tested against a case study and subject matter experts determined if the results were acceptable. Also, these experts were asked to verify if the model could be generalized to other areas than the case study application. Three different offshore oil projects were conducted through the model as a case study. Expert panel P8 was formed to allocate scores to each project against the value curve. In addition, the model results were presented to these experts and they were asked if the assessment framework was appropriate enough for evaluating offshore oil projects. The experts confirmed that the model could be a helpful method to aid and even possible enhance the investment decision. This model also indicated the potential to be applied to various offshore oil projects. 


\section{CHAPTER 11: DISCUSSION}

This chapter brings forward a discussion of the research results that includes model validation and qualification, and an implemented case study.

\subsection{Practical Application: General}

The gap analysis in chapter 4 illustrated that a comprehensive approach and advanced tools are required to evaluate offshore oil projects that can have a significant impact before any investment decisions are made. The research model has been validated by expert panels that have a broad understanding and experience of managing offshore oil projects. The expert panels confirmed that the structure and model content were appropriate for evaluating offshore oil projects. Moreover, the research quantification that includes assigning weights for the perspective level and success attributes were assessed by expert panels that hold a breadth of management experience in oil projects. Thus, the research model is considered quite versatile and can be readily applied to any offshore oil project.

Based on the experts' judgments, the quantification phase of the model generated outstanding results. The economical perspective was assessed as the most important factor with $32 \%$ of relative weight followed by the environmental and safety perspective with $30 \%$ of relative weight. The political perspective was evaluated as the third factor with $24 \%$ of relative weight, followed by the technical perspective with $14 \%$ of relative weight. 


\subsection{Practical Application: Economical Perspective}

Under the economical perspective, there are multiple criteria that are linked to each other with complex processes and unique challenges that include oil price, initial cost, operational cost and return on investment (ROI). An assessment of these challenges associated with oil offshore projects leads to reduced risk and an increased probability of success. Based on experts' judgments, oil price criterion was assessed as the most important factor with $35 \%$ relative weight. Oil prices change from one project to another depending on the type and quality of the oil that the project will produce. Another factor that affected the economical perspective is the return on investment. The experts assigned $32 \%$ of relative weight to the return on investment factor. In addition, the initial cost factor was assigned as the third most important factor with $17 \%$ of relative weight. However, operational cost was assigned as the least important economical factor with $16 \%$ of relative weight. Decision makers, before they make their investment decision, should get a clear picture of project economical factors such as oil prices, initial cost, operational cost, and ROI.

\subsection{Practical Application: Technical Perspective}

Under the technical perspective, experts validated four factors: operational difficulties, project size and complexity, production performance, and reservoir uncertainty. The experts assigned production performance as the most important technical factor with $34 \%$ of relative weight. The second ranked technical factor was reservoir uncertainty with $31 \%$ of relative weight. In addition, project size and 
complexity was ranked as the third most vital technical factor with $20 \%$ of relative weight. The least important technical factor was reasoned to be operational difficulties with $15 \%$ of relative weight. The opinions of the experts aligned with the results of the study where the production performance factor has a significantly higher impact on project profitability and success.

\subsection{Practical Application: Political Perspective}

Under the political perspective, experts endorsed four factors that play essential roles in offshore oil evaluation. These included government stability, conflict over maritime claims, contracts complexity, and policies, regulations, and governance standards. The experts indicated that government stability was the most significant political factor with a contribution weight of $32 \%$ among other political factors. Offshore oil projects have long life cycle time and government stability can play a vital role in the success of these types of projects. The second main political factor was policies, regulations, and governance standards, with $28 \%$ of relative weight. On the other hand, the contracts complexity factor was considered the third most important factor with $27 \%$ of relative weight. Finally, all the experts agreed that even though conflict over maritime claims is a key factor that should be evaluated before the investment decision takes place, conflict over maritime claims is not a critical factor to all offshore oil projects. The experts indicated that conflict over maritime claims ranked as a fourth political factor with only $13 \%$ of relative weight. 


\subsection{Practical Application: Environmental \& Safety Perspective}

Under the environmental and safety perspective, experts validated four factors: hazard identification and risk management, implementing health, safety and environmental (HSE), stringent local HSE standards, and environmental risk management integration. The experts indicated that hazard identification and risk management was the most important environmental and safety factor with a contribution weight of $34 \%$ among other environmental \& safety factors. The second most important environmental and safety factor was stringent local HSE standards with a relative weight of $27 \%$. Based on their opinion, the rise in a project's costs can be directly driven by tougher HSE standards. Ultimately, the implementing health, safety and environmental (HSE) factor was assigned as the third most important factor with $21 \%$ of relative weight. The environmental risk management integration ranked fourth with $18 \%$ of relative weight.

\subsection{Model Generalization}

The oil business sector can be classified into two types of projects, onshore and offshore oil projects. As it was mentioned in the previous sections, the research model is generalizable and can be readily applied to any offshore oil project around the world. Theoretically, most of the perspectives and criteria used in this study can be applied to evaluate onshore oil projects. However, changes of factor's weight should be considered in this evaluation since the influence of various criteria on investment decisions will be much different. For example, on the environmental and safety factor, the offshore oil 
projects operate in more hazardous environments where the risk factors are much higher compared to onshore oil projects. Therefore, the relative weight of the environmental and safety factor would be different in onshore and offshore projects. Conclusively, indeed the same model can be used to evaluate a wide variety of oil projects, whether it be onshore or offshore, as long as the correct criteria weights are assigned to the study with respect to their corresponding situations. 


\section{CHAPTER 12: CONCLUSIONS}

The final chapter of this research summarizes the research by documenting the conclusions, demonstrating how the gaps were addressed, and how this research contributes to improve offshore oil project evaluation before and after the investment decision takes place. The analysis of the data identified potential limitations, the various assumptions that were made, and a few particulars that represent constraints or model limitations. A discussion is included to suggest how the present limitations can create opportunities for future research.

\subsection{Conclusions and Contributions}

Evaluating and selecting the right project in the offshore oil sector is characterized by a high volatile price setting market, increasing pressure to minimize cost structures, political concerns, and safety and environmental risks. The combinations of these characteristics provide a motivation for development of new tools for allocating capital and improving the quality of overall decisions in the exploration and production decisions. Making important decisions in the oil industry requires an incorporation of major uncertainties, long time horizons, multiple alternatives, and complex value issues in the decision model [222]. As it was described in chapters 2 and 3, the academic literature shows that a comprehensive approach to evaluate the offshore oil projects and improve the investment decision is lacking. Improving offshore oil capital project efficiency is critically needed. Relying on financial assessments alone will not solve the rising problems later on. A comprehensive approach is needed to measure project 
outcomes and identify gaps for future improvements [94]. Nevertheless, the main contribution of the proposed research is to fulfill the research gap and provide a framework that can be used for assessing and evaluating offshore oil projects to improve the investment decision. This study provides a comprehensive approach including most of the factors impacting the investment decision of offshore oil projects and assessing their weights of impact as well as those associated with desirability matrices and sensitivity analyses to estimate multiple scenarios.

By implementing the research model decision makers will not only be able to evaluate the four important perspectives (economical, technical, political, and environmental and safety) that affect the offshore oil projects, but also they will be able to obtain the contribution weights of the sixteen factors under these perspectives to the overall project evaluation. The contribution result of the research model is to provide a specific weighted score for each offshore oil proposals project. First of all, the hierarchical decision model provides a specific important weight to the sixteen factors that affect the offshore project investment decision. Then the research provides a desirability curves standard that decision makers can use to rank and assign scores for each of sixteen attributes in order to evaluate multiple projects. The desirability functions offer a standard metrics that decision makers can rely on to make quick and constant decision without having to go back and consult with the experts or replicate the model and apply it again. After obtaining the importance weights of the sixteen factors from the model and factors scores from the desirability curves, decision makers would be able to get the weighted score for each attribute - each score multiplied by its important weight. 
Lastly, the weighted scores would be added to get an overall project score. The investment decision in offshore oil projects is associated with high risk and is directly affected by different factors. The research model helps decision makers to achieve better evaluation of offshore oil projects and improve their investment decision. The model addresses the gaps identified as part of the literature review. The main contribution of this study is summarizing as following:

1. The first multi perspective hierarchical model that highlighted the importance weights of different factors for evaluating offshore oil projects for the industry use.

2. Scores and desirability curves indicate improvement paths and potential solutions.

3. The model can be used to evaluate multiple offshore oil projects in the region.

Table 88 summarizes the gaps and the contributions this research addresses.

\begin{tabular}{|l|l|}
\hline \multicolumn{1}{|c|}{ Research Gaps } & \multicolumn{1}{c|}{ Contributions } \\
\hline $\begin{array}{l}\text { There is not a specific study, which is } \\
\text { aimed to identify the most internal } \\
\text { and external factors that impact the } \\
\text { offshore oil project. }\end{array}$ & $\begin{array}{l}\text { This research identifies the major challenging } \\
\text { factors and assesses their impact on offshore } \\
\text { oil projects. }\end{array}$ \\
\hline $\begin{array}{l}\text { There is a lack of a comprehensive } \\
\text { approach to evaluate offshore oil } \\
\text { projects before and after the } \\
\text { investment decision takes place. }\end{array}$ & $\begin{array}{l}\text { This study provides a comprehensive } \\
\text { approach including the factors that most } \\
\text { impact investment decisions in offshore oil } \\
\text { projects and assessing their weights of } \\
\text { impacts as well as those associated with } \\
\text { desirability matrices and sensitivity analyses } \\
\text { to estimate multiple scenarios. }\end{array}$ \\
\hline
\end{tabular}

Table 88: Summarizes the Gaps and the Contributions 
Table 89 summarizes the research questions and how the research addressed these questions.

\begin{tabular}{|l|l|}
\hline \multicolumn{1}{|c|}{ Research Questions } & \multicolumn{1}{c|}{ Addressing the Questions } \\
\hline $\begin{array}{l}\text { Which attributes are most important for } \\
\text { evaluating offshore oil project? }\end{array}$ & $\begin{array}{l}\text { Model validation and quantification } \\
\text { address this question. For more details see } \\
\text { chapter 7. }\end{array}$ \\
\hline $\begin{array}{l}\text { Is the assessment framework appropriate } \\
\text { for assessing offshore oil projects? }\end{array}$ & $\begin{array}{l}\text { Research application and the case study } \\
\text { analysis address this question. For more } \\
\text { details see chapter 8 and chapter 9. }\end{array}$ \\
\hline $\begin{array}{l}\text { To what extent the developed model } \\
\text { results could help project managers and } \\
\text { decision makers to evaluate offshore oil } \\
\text { projects? }\end{array}$ & $\begin{array}{l}\text { Panel 8 was formed to validate the model } \\
\text { and the case study results. In this step the } \\
\text { model results were presented to experts } \\
\text { and they were asked if the assessment } \\
\text { framework is appropriate enough for } \\
\text { evaluating oil offshore projects. The } \\
\text { experts confirmed that the model would } \\
\text { be a helpful method to enhance the } \\
\text { investment decision and it could be } \\
\text { applied to different offshore oil projects } \\
\text { around the world. For more details see } \\
\text { chapter 10. }\end{array}$ \\
\hline
\end{tabular}

Table 89: Summarizes Research Questions and How Were Addressed

\subsection{Limitations}

This study provides a comprehensive approach that take account of the factors that impact the decision making process for the establishment of offshore oil projects, assessing their weights of impact as well as those associated with desirability matrices and sensitivity analyses to estimate multiple scenarios. Thus, it's very important to mention that the main goal of this model is to enhance and often aid the decision making process during the early phases of project selection. However, decision makers must 
perform the necessary due diligence and engage other tools to assess important factors that are not represented in this research model such as net present value, discount rate, and other factors. Moreover, certain factors that have been demonstrated by the model need further assessment by the decision makers before assigning their scores on a desirability curve. For instance, when assessing the government stability factor, decision makers should take into consideration that the concept of government stability is not only a governing body's ability of granting and enforcing long term leases, but also comes with unfavorable aspects such as their effectiveness in execution, their ability to control corruption, political stability, and maintain regulatory quality.

Great care was taken to identify the best panels in order to provide their judgment quantification. Nevertheless, different users may obtain different results when using the same method. People have different experiences and background. The preferred information associated with experts on the evaluation criteria varies from person to person. Meanwhile, different relative criteria weights have a significant effect on the selection of the most appropriate alternatives. The ranking results are very sensitive to the changes in attribute weights. The presence of different attribute weights may result in different ranking orders. While the scenario analysis attempted to mitigate these biases, there is still the potential for some impact.

The proposed model aimed to assess most factors impacting offshore oil projects to support an investment decision. For this purpose, a case application was conducted with the research to test the robustness of the model. Due to the competitiveness of the oil sector, companies tend to withhold any information related to an investment proposals 
project. However, the future proposals investments of offshore oil projects led by this study referenced ongoing offshore oil projects as a case application. This step will not affect the result since the same steps should be completed to evaluate any future investment project.

\subsection{Future Work}

The limitations described in the previous section offer opportunities to develop the model further. In particular, considering more factors that might impact the success of offshore oil projects, such as natural disasters and economic recessions, as well as refreshing the model periodically, will maintain its relevance. As described in the limitation section, the complexity of certain factors needs further analysis by the decision makers before they assign their scores on a desirability curve that offers opportunities to expand the implementation of these factors. More specifically, the economical and political factors that have highest affected weights on offshore oil projects based on the experts' evaluation needs further analysis. Finding resources that can provide information related to the future proposals investments of offshore oil projects, and using the research model to evaluate these projects, would likely identify additional opportunities. Another opportunity for future work is to extend the application of the model to other oil projects. Conducting the research model with onshore oil projects requires some modifications to relative weights to ensure accurate results. 


\section{REFERENCES}

[1] National Petroleum Council (NPC), "Offshore oil and gas supply," presented at the National Petroleum Council, Washington, DC, 2011.

[2] E. Nyman, "Offshore oil development and maritime conflict in the 20th century: A statistical analysis of international trends," Energy Res. Soc. Sci., vol. 6, pp. 1-7, Mar. 2015.

[3] Maribus, Exzellenzcluster Ozean der Zukunft, and International Ocean Institute, Eds., "Marine resources - opportunities and risks," Hamburg 2014.

[4] Z. Rui et al., "Development of industry performance metrics for offshore oil and gas project," J. Nat. Gas Sci. Eng., vol. 39, pp. 44-53, Mar. 2017.

[5] Y. Tan, Y. Song, X. Liu, X. Wang, and J. C. P. Cheng, "A BIM-based framework for lift planning in topsides disassembly of offshore oil and gas platforms," Autom. Constr., vol. 79, pp. 19-30, Jul. 2017.

[6] S. T. Orszulik, Ed., "Environmental technology in the oil industry," 2. ed. Dordrecht: Springer, 2008.

[7] A. Shukla and H. Karki, "Application of robotics in offshore oil and gas industryA review Part II,” Robot. Auton. Syst., vol. 75, pp. 508-524, Jan. 2016.

[8] R. Sandrea and I. Sandrea, "Deepwater crude oil output: How large will the uptick be?," Oil Gas J 108, pp. 48-48, 2010.

[9] J. Ferentinos, "Global offshore oil and gas outlook," 2013.

[10] P. M. Doherty and D. Systemes, "The Economics, Execution and Management of Complex Offshore Projects," Offshore Technology Conference, pp. 1-11, May 2011.

[11] EYGM Limited, "Spotlight on oil and gas megaprojects." 2014.

[12] E. W. Merrow, "Oil and Gas Industry Megaprojects: Our Recent Track Record," Oil Gas Facil., vol. 1, no. 02, pp. 38-42, Apr. 2012.

[13] IEA, 2011. IEA World Energy Outlook. IEA, Paris.

[14] Z. Rui, F. Peng, K. Ling, H. Chang, G. Chen, and X. Zhou, "Investigation into the performance of oil and gas projects," J. Nat. Gas Sci. Eng., vol. 38, pp. 12-20, Feb. 2017.

[15] M. Holmager and M. Redda, "Offshore Center Danmark Offshore Book." Jul2010.

[16] EY, "Spotlight on Oil and Gas Megaprojects," Ernst Yong UK, 2014.

[17] The Statistics Portal, 2015.

[18] Knoema, "Oil Production and Operating Costs," 2014.

[19] Z. Rui et al., "Development of industry performance metrics for offshore oil and gas project," J. Nat. Gas Sci. Eng., vol. 39, pp. 44-53, Mar. 2017. 
[20] FMC Technologies: Tour d' FMC - a confluence of cycles, Macquarie Research, 12 June 2013, via Thompson One.

[21] Cooper smith E, Dean G, Mc Vean J, Storaune E. "Making decisions in the oil and gas industry". Oilfield Rev 2000;12(4): 2001.

[22] Bailey W, Couët B, Lamb F, Simpson G, Rose P. Taking a calculated risk. Oilfield Rev 2000;12 (3): 20-35.

[23] L. Castillo and C. A. Dorao, "Decision-making in the oil and gas projects based on game theory: Conceptual process design," Energy Convers. Manag. vol. 66, pp. 48-55, Feb. 2013.

[24] S. Kudratova, X. Huang, and X. Zhou, "Sustainable project selection: Optimal project selection considering sustainability under reinvestment strategy," J. Clean. Prod., vol. 203, pp. 469-481, Dec. 2018.

[25] D. Fantazzini, "The oil price crash in 2014/15: Was there a (negative) financial bubble?," Energy Policy, vol. 96, pp. 383-396, Sep. 2016.

[26] M. Holmager, M. Redda, and J. C. Design, Offshore Book: An introduction to the offshore industry. Offshore Center Danmark, 2010.

[27] P. K. Verma and A. K. Srinivasan, "Operating Cost Optimisation: Importance \& Approach," presented at the 7 th International Conferenve \& Exposition on Petroleum Geophysics, 2008, vol. 7, pp. 1-7.

[28] Trends in U.S. Oil and Natural Gas Upstream Costs. U.S. Energy Information Administration, Mar-2016.

[29] Operational excellence in oil and gas: Cost containment strategies for the oil and gas industry. 2018.

[30] A. Albert, O. M. Aamo, J. M. Godhavn, and A. Pavlov, "Suppressing Pressure Oscillations in Offshore Drilling: Control Design and Experimental Results," IEEE Trans. Control Syst. Technol., vol. 23, no. 2, pp. 813-819, Mar. 2015.

[31] M. J. Kaiser, B. Snyder, and A. G. Pulsipher, "Offshore Drilling Industry and Rig Construction Market in the Gulf of Mexico," Cooperative Agreement Coastal Marine Institute Louisiana State University, BOEM 2013-0112, Mar. 2013.

[32] H. Mao, Z. Qiu, B. Xie, Z. Wang, Z. Shen, and W. Hou, "Development and Application of Ultra-High Temperature Drilling Fluids in Offshore Oilfield Around Bohai Sea Bay Basin, China," 2016.

[33] D. Rich, B. Rogers, W. Dyson, K. Olson, J. Smart, and D. Tiffin, "GoM deepwater completions - the devil is in the details," presented at the offshore technology conference, Houston, USA, 2010.

[34] J. E. Skogdalen and J. E. Vinnem, "Quantitative risk analysis of oil and gas drilling, using Deepwater Horizon as case study," Reliab. Eng. Syst. Saf., vol. 100, pp. 58-66, Apr. 2012. 
[35] A. Selot, "Short-Term Supply Chain Management in Upstream Natural Gas Systems," 2009.

[36] J. Brown, "Fueling the Oil and Gas Supply Chain," Jul. 2014.

[37] C. Herrera, "Outsourcing Logistics in the oil and gas Industry," May 2012.

[38] N. Nandurdikar and L. Wallace, "Failure to Produce: an Investigation of Deficiencies in Production Attainment," in SPE ATCE, Colorado, USA, 2011.

[39] Advancing Systems and Technologies to Produce Cleaner Fuels in Offshore Safety and Spill Prevention, QuadrennialTechnologyReview2015, 2015.

[40] Z. Rui et al., "A quantitative oil and gas reservoir evaluation system for development," J. Nat. Gas Sci. Eng., vol. 42, pp. 31-39, Jun. 2017.

[41] M. El Baz, "E\&P Risk Analysis: Expecting the Unexpected." 2018.

[42] M. Akerele, "Challenges in the oil and gas sector overview and outlook." 2015.

[43] J. Ellis, "Law of the sea convention, Essential Concepts of Global Environmental Governance," 2014, vol. 113.

[44] United Nations General Assembly, "Convention of the Law of the Sea," 1982.

[45] S. Gulas, M. Downton, K. D’Souza, K. Hayden, and T. R. Walker, "Declining Arctic Ocean oil and gas developments: Opportunities to improve governance and environmental pollution control," Mar. Policy, vol. 75, pp. 53-61, Jan. 2017.

[46] Navigating geopolitics in oil and gas: Business solutions for a complex world, 2014.

[47] P. Clancy, "Offshore Petroleum Politics: A Changing Frontier in a Global System," Policy Soc., vol. 26, no. 1, pp. 113-134, Jan. 2007.

[48] D. Fant, "An Analysis and Evaluation of Rules and Procedures Governing OCS Operations," presented at the American Bar Association, Washington, DC, 1990.

[49] D. A. Holdway, "The acute and chronic effects of wastes associated with offshore oil and gas production on temperate and tropical marine ecological processes," Mar. Pollut. Bull., vol. 44, no. 3, pp. 185-203, Mar. 2002.

[50] G. Huppes, M. D. Davidson, J. Kuyper, L. van Oers, H. A. Udo de Haes, and G. Warringa, "Eco-efficient environmental policy in oil and gas production in The Netherlands," Ecol. Econ., vol. 61, no. 1, pp. 43-51, Feb. 2007.

[51] J. P. Ducrotoy and M. Elliott, "The science and management of the North Sea and the Baltic Sea: Natural history, present threats and future challenges," Mar. Pollut. Bull., vol. 57, no. 1-5, pp. 8-21, Jan. 2008.

[52] A. Barker and C. Jones, "A critique of the performance of EIA within the offshore oil and gas sector," Environ. Impact Assess. Rev., vol. 43, pp. 31-39, Nov. 2013.

[53] E. Salter and J. Ford, "Holistic Environmental Assessment and Offshore Oil Field Exploration and Production," Mar. Pollut. Bull., vol. 42, no. 1, pp. 45-58, Jan. 2001. 
[54] F. K. Wiese, W. . Montevecchi, G. . Davoren, F. Huettmann, A. . Diamond, and J. Linke, "Seabirds at Risk around Offshore Oil Platforms in the North-west Atlantic,” Mar. Pollut. Bull., vol. 42, no. 12, pp. 1285-1290, Dec. 2001.

[55] Environmental guidance document: waste management in exploration and production operations. 1997.

[56] Environmental, Health, and Safety Guidelines for Offshore Oil and Gas Development. 2007.

[57] F. Douvere, "The importance of marine spatial planning in advancing ecosystembased sea use management," Mar. Policy, vol. 32, no. 5, pp. 762-771, Sep. 2008.

[58] S. Kidd, A. Plater, and C. Frid, "The ecosystem approach to marine planning and management," presented at the Earthscan, London, 2011.

[59] B. S. Halpern, K. A. Selkoe, F. Micheli, and C. V. Kappel, "Evaluating and Ranking the Vulnerability of Global Marine Ecosystems to Anthropogenic Threats," Conserv. Biol., vol. 21, no. 5, pp. 1301-1315, Oct. 2007.

[60] M. Ruckelshaus, T. Klinger, N. Knowlton, and D. P. DeMASTER, "Marine Ecosystem-based Management in Practice: Scientific and Governance Challenges," BioScience, vol. 58, no. 1, p. 53, 2008.

[61] T. Geehan, A. Gilmour, and Q. Guo, "The Cutting Edge in Drilling Waste Management," 2007.

[62] Z. Ayele, A. Barabadi, and J. Barabady, "Drilling Waste Handling and Management in the High North," presented at the IEEE International Conference on Industrial Engineering and Engineering Management, Bangkok, Thailand, 2013, pp. 673-678.

[63] Y. Z. Ayele, A. Barabadi, and E. L. Droguett, "Risk-Based Cost-Effectiveness Analysis of Waste Handling Practices in the Arctic Drilling Operation," J. Offshore Mech. Arct. Eng., vol. 138, no. 3, p. 031301, Apr. 2016.

[64] S. B. Henderson, S. J. W. Grigson, P. Johnson, and B. D. Roddie, "Potential Impact of Production Chemicals on the Toxicity of Produced Water Discharges from North Sea Oil Platforms," Mar. Pollut. Bull., vol. 38, no. 12, pp. 1141-1151, Dec. 1999.

[65] D. Lincoln, "Sense and Nonsense-The Environmental Impacts of Exploration on Marine Organisms Offshore Cape Breton." Cape Breton Island, Nova Scotia, Sierra Club Canada, 2002.

[66] Overview and Characteristics of Some Occupational Exposures and Health Risks on Offshore Oil and Gas Installations, Ann. Occup. Hyg., Mar. 2003.

[67] W. Amos, "Development of Canadian Arctic Offshore Oil and Gas Drilling: Lessons from the Gulf of Mexico: CANADIAN ARCTIC OFFSHORE OIL AND 
GAS DRILLING," Rev. Eur. Community Int. Environ. Law, vol. 20, no. 1, pp. 3946, Apr. 2011.

[68] C. Fidler and B. Noble, "Advancing strategic environmental assessment in the offshore oil and gas sector: Lessons from Norway, Canada, and the United Kingdom,” Environ. Impact Assess. Rev., vol. 34, pp. 12-21, Apr. 2012.

[69] M. Knol and P. Arbo, "Oil spill response in the Arctic: Norwegian experiences and future perspectives," Mar. Policy, vol. 50, pp. 171-177, Dec. 2014.

[70] Environmental performance in the E\&P industry - 2010 data. OGP, 2011.

[71] S. Rathnayaka, F. Khan, and P. Amyotte, "Accident modeling approach for safety assessment in an LNG processing facility," J. Loss Prev. Process Ind., vol. 25, no. 2, pp. 414-423, Mar. 2012.

[72] M. Henrion, B. Bernstein, and S. Swamy, "A multi-attribute decision analysis for decommissioning offshore oil and gas platforms: Decision Tool for Decommissioning Offshore Oil Platforms," Integr. Environ. Assess. Manag., vol. 11, no. 4, pp. 594-609, Oct. 2015.

[73] NUS, "Centre for International Law, National University of Singapore, Prospects for Large Scale Artificial Reefs in South East Asian Tropical Seas." 2013.

[74] S. Rid and K. Retzer, "Understanding Oil and Gas Extraction Worker Fatalities through the Fatalities in Oil and Gas Extraction Database," in SPE Health, Safety, Security, Environment, \& Social Responsibility Conference - North America, New Orleans, Louisiana, USA, 2017.

[75] Bureau of Safety and Environmental Enforcement, Department of Interior, 20-Dec2012.

[76] “Offshore Technology, The World's Worst Offshore Oil Rig Disasters, http://www. offshore-technology.com/features/feature-the-worlds-deadliestoffshore oil-rigdisasters-4149812/, (2014) (Accessed on 2017.05).

[77] I.G. Wallace, The assessment of evacuation, escape and rescue provisions on offshore installations, Institution of Chemical Engineers Symposium Series, Vol. 130 Hemsphere Publishing Corporation, 1993, p. 713."

[78] G. Mould, Assessing systems for offshore emergency evacuation, J. Oper. Res. Soc. (2001) 401-408.

[79] J. C. P. Cheng, Y. Tan, Y. Song, Z. Mei, V. J. L. Gan, and X. Wang, "Developing an evacuation evaluation model for offshore oil and gas platforms using BIM and agent-based model," Autom. Constr., vol. 89, pp. 214-224, May 2018.

[80] K. Retzer and R. Hill, "Fatalities in the U.S. Oil \& Gas Extraction Industry," Fireline, pp. 1-6, 2016.

[81] Environmental, Health, and Safety Guidelines offshore Oil and gas Development. World Bank Group, 05-Jun-2015. 
[82] Integrate Health, Safety and Environment into Engineering Project. IHI E\&C International Corp, Apr-2013.

[83] M. Bucelli, G. Landucci, S. Haugen, N. Paltrinieri, and V. Cozzani, “Assessment of safety barriers for the prevention of cascading events in oil and gas offshore installations operating in harsh environment," Ocean Eng., vol. 158, pp. 171-185, Jun. 2018.

[84] Z. Rui, F. Peng, K. Ling, H. Chang, G. Chen, and X. Zhou, "Investigation into the performance of oil and gas projects," J. Nat. Gas Sci. Eng., vol. 38, pp. 12-20, Feb. 2017.

[85] B. J. Kolltveit and K. Grønhaug, "The importance of the early phase: the case of construction and building projects," Int. J. Proj. Manag., vol. 22, no. 7, pp. 545551, Oct. 2004.

[86] R. Meyers, "Cost overruns, delays may hinder future Australian LNG projects." Fuel Fix, 2014.

[87] Another \$2b cost blowout for Gorgon LNG. 2013.

[88] N. Torres, "Development cost overruns hit Norway offshore projects." Petro Global News, 2014.

[89] The Oxford Institute for Energy Studies, "The Prospects and Challenges for Arctic Oil Development." 2014.

[90] Oil and Gas Reality Check 2015 A look at the top issues facing the oil and gas sector. Deloitte, 2015.

[91] M. Augusto, S. Suslick, and s. Pinto, "Impact of offshore drilling rigs availability in the optimal investment timing on high-deep water projects in the Santos Basin," Int. J. Oil Gas Coal Technol., vol. 15, no. 3, p. 217, 2017.

[92] T. Copeland and V. Antikarov, "Real Options - A Practitioner's Guide." 2001.

[93] Gabriel Costa LimaSaul B. Suslick, "Investment decision in oil and gas projects using real option and risk tolerance models" International Journal of Oil Gas and Coal Technology, December 2007.

[94] Y. Lopes; A. Almeida, "A multicriteria decision model for selecting a portfolio of oil and gas exploration projects". Pesqui. Oper. vol.33 no.3 Rio de Janeiro Sept. Nov 08, 2013.

[95] T. U. Daim, Ed., Hierarchical Decision Modeling. Cham: Springer International Publishing, 2016. .

[96] M. G. Morgan, "Use (and abuse) of expert elicitation in support of decision making for public policy," Natl Acad Sci U S, vol. 111, no. 20, pp. 7176-84, 2014.

[97] J. Estep, 'Development of a Technology Transfer Score for Evaluating Research Proposals: Case Study of Demand Response Technologies in the Pacific 
Northwest,' Doctor of Philosophy in Technology Management, Portland State University, 2017.

[98] E. Gibson, "A Measurement System for Science and Engineering Research Center Performance Evaluation," Jan. 2016.

[99] R. Abotah, 'Evaluation of Energy Policy Instruments for the Adoption of Renewable Energy: Case of Wind Energy in the Pacific Northwest U.S,' Ph.D., Portland State University, United States -- Oregon, 2015.

[100] S. Munkongsujarit et al., "Decision model for a place to live at PSU: The case of international graduate students," PICMET 09 - 2009 Portland Int. Conf. Manag. Eng. Technol., pp. 513-534, Aug. 2009.

[101] J. Lavoie, "A Scoring Model to Assess Organizations' Technology Transfer Capabilities: the Case of a Power Utility in the Northwest USA", May 2019.

[102] R. A. Taha, B. C. Choi, P. Chuengparsitporn, A. Cutar, Q. Gu, and K. Phan, "Application of Hierarchical Decision Modeling for Selection of Laptop," PICMET 07 - 2007 Portland Int. Conf. Manag. Eng. Technol., pp. 1160-1175, Aug. 2007.

[103] P. Gerdsri and D. F. Kocaoglu, "HDM for Developing N ational Emerging Technology Strategy and Policy Supporting Sustainable Economy : A Case S tudy of N anotechnology for Thailand's Agriculture," no. c, pp. 27-31, 2008.

[104] J. Thompson, B. Barnwell, T. Calderwood, A. Kumar, and S. Vang, "Decision Model for Portland Metro Bike Commuters," 2011.

[105] N. Sheikh, "Assessment of Solar Photovoltaic Technologies Using Multiple Perspectives and Hierarchical Decision Modeling," Jan. 2000.

[106] B. Wang, D. F. Kocaoglu, T. U. Daim, and J. Yang, "A decision model for energy resource selection in China," Energy Policy, vol. 38, no. 11, pp. 7130-7141, Nov. 2010.

[107] L. Hogaboam, B. Ragel, and T. Daim, 'Development of a Hierarchical Decision Model (HDM) for health technology assessment (HTA) to design and implement a new patient care database for low back pain,' presented at the PICMET '14, Portland. OR, 2014, pp. 3511-3517.

[108] T. Turan, M. Amer, P. Tibbot, M. Almasri, F. A. Fayez, and S. Graham, 'Use of Hierarchal Decision Modeling (HDM) for selection of graduate school for master of science degree program in engineering,' 2009, pp. 535-549.

[109] H. Barham, "Development of a Readiness Assessment Model for Evaluating Big Data Projects: Case Study of Smart City in Oregon, USA" 2019.

[110] P. Tynjala, "Towards expert knowledge? A comparison between a constructivist and a traditional learning environment in the university," Elsevier Sci. Ltd, vol. 31, pp. 357-442, 1999. 
[111] Expert Definition in the Cambridge English Dictionary,' Cambridge Dictionary. [Online]. Available: http://dictionary.cambridge.org/us/dictionary/english/expert. [Accessed: 08- Sep-2017].

[112] A. Ericsson, M. Prietula, and E. Cokely, "The Making of an Expert." Harvard Business Review, 2007.

[113] H. L. Dreyfus and S. E. Dreyfus, "Peripheral Vision: Expertise in Real World Contexts," Organ. Stud., vol. 26, no. 5, pp. 779-792, May 2005.

[114] Definition of PANEL,' Merriam-Webster Dictionary. [Online]. Available: https://www.merriam-webster.com/dictionary/panel. [Accessed: 08-Sep- 2017].

[115] Department of Sustainability and Environment, "Book 3 the engagement toolkit." State of Victoria, Department of Sustainability and Environment, 2005.

[116] Regulations For Expert Advisory Panels And Committees, 2007.

[117] L. Chan, "Developing a Strategic Policy Choice Framework for Technological Innovation: Case of Chinese Pharmaceuticals," Jan. 2000.

[118] European Commission, "Expert Panels." 2017.

[119] T. A. Tran, 'Strategic Evaluation of University Knowledge and Technology Transfer Effectiveness,' Portland State University, 2013.

[120] P. Gerdsri and D. Kocaoglu, "A systematic approach to developing national technology policy and strategy for emerging technologies: A case study of nanotechnology for Thailand's agriculture industry," 2009, pp. 447-461.

[121] I. Iskin, "An Assessment Model for Energy Efficiency Program Planning in Electric Utilities: Case of the Pacific of Northwest U.S.A.," Jan. 2000.

[122] D. F. Kocaoglu, 'A participative approach to program evaluation,' IEEE Trans. Eng. Manag., vol. EM-30, no. 3, pp. 112-118, 1983.

[123] M. Abbas, "Consistency Analysis for Judgment Quantification in Hierarchical Decision Model," Jan. 2000.

[124] K. Phan, "Innovation Measurement: A Decision Framework to Determine Innovativeness of a Company," Jan. 2000.

[125] Santos CC, Pereira CA, Bernardes J. Agreement studies in obstetrics and gynaecology: inappropriateness, controversies and consequences. Br J Obstet Gynaecol 2005;112:667e9.

[126] H. A. Alanazi, T. Daim, and D. F. Kocaoglu, 'Identify the best alternatives to help the diffusion of teleconsultation by using the Hierarchical Decision Model (HDM), ' presented at the Portl. Int. Conf. Manag. Eng. Technol, Portland. OR, 2015, pp. 422-432.

[127] Muller R, Buttner P. A critical discussion of intraclass correlation co- efficients. Stat Med 1994;13:2465e76. 
[128] Burdock E, Fleiss JL, Hardesty AS. A new view of interobserver agreement. Person Psychol 1963;16:373e84.

[129] Shrout. P.E. and Fleiss. J.L., 'Intraclass Correlation: Uses In Assessing Rater Reliability,' Psychological Bulletin, vol. 86, pp. 420-428, 1979.

[130] T. K. Koo and M. Y. Li, "A Guideline of Selecting and Reporting Intraclass Correlation Coefficients for Reliability Research,” J. Chiropr. Med., vol. 15, no. 2, pp. 155-163, Jun. 2016.

[131] C. Costa-Santos, J. Bernardes, D. Ayres-de-Campos, A. Costa, and C. Costa, "The limits of agreement and the intraclass correlation coefficient may be inconsistent in the interpretation of agreement," J. Clin. Epidemiol., vol. 64, no. 3, pp. 264-269, Mar. 2011.

[132] H. Chen and D. F. Kocaoglu, "A sensitivity analysis algorithm for hierarchical decision models,” Eur. J. Oper. Res., vol. 185, no. 1, pp. 266-288, Feb. 2008.

[133] Bartko JJ. The intraclass correlation coefficient as a measure of reli- ability. Psychol Rep 1966;19:3e11.

[134] De Vet H. Observer reliability and agreement. In: Armitage P, Colton T, editors. Encyclopedia of biostatistics. 1st edition. Chichester, UK: Wiley; 1999. p. $3123 \mathrm{e} 7$.

[135] M. Yurdakul and Y. Tansel İÇ, "Application of correlation test to criteria selection for multi criteria decision making (MCDM) models," Int. J. Adv. Manuf. Technol., vol. 40, no. 3-4, pp. 403-412, Jan. 2009.

[136] P. Wang, Z. Zhu, and Y. Wang, "A novel hybrid MCDM model combining the SAW, TOPSIS and GRA methods based on experimental design," Inf. Sci., vol. 345, pp. 27-45, Jun. 2016.

[137] R. Simanaviciene and L. Ustinovichius, "Sensitivity Analysis for Multiple Criteria Decision Making Methods: TOPSIS and SAW," Procedia - Soc. Behav. Sci., vol. 2, no. 6, pp. 7743-7744, 2010.

[138] P. Ji, H. Zhang, and J. Wang, "Selecting an outsourcing provider based on the combined MABAC-ELECTRE method using single-valued neutrosophic linguistic sets,” Comput. Ind. Eng., vol. 120, pp. 429-441, Jun. 2018.

[139] S. Mufazzal and S. M. Muzakkir, "A new multi-criterion decision making (MCDM) method based on proximity indexed value for minimizing rank reversals," Comput. Ind. Eng., vol. 119, pp. 427-438, May 2018.

[140] M. R. Asadabadi, "The stratified multi-criteria decision-making method," Knowl.Based Syst., vol. 162, pp. 115-123, Dec. 2018.

[141] G. De Tré, R. De Mol, and A. Bronselaer, "Handling veracity in multi-criteria decision-making: A multi-dimensional approach," Inf. Sci., vol. 460-461, pp. 541554, Sep. 2018. 
[142] Gore, C., Murray, K., \& Richardson, B. (1992). Strategic decision-making. USA: CassellPress.

[143] J. Si, L. Marjanovic-Halburd, F. Nasiri, and S. Bell, "Assessment of buildingintegrated green technologies: A review and case study on applications of MultiCriteria Decision Making (MCDM) method," Sustain. Cities Soc., vol. 27, pp. 106-115, Nov. 2016.

[144] H. Badri Ahmadi, S. H. Hashemi Petrudi, and X. Wang, "Integrating sustainability into supplier selection with analytical hierarchy process and improved grey relational analysis: a case of telecom industry," Int. J. Adv. Manuf. Technol., vol. 90, no. 9-12, pp. 2413-2427, Jun. 2017.

[145] F. Liu, Q. Yu, W. Pedrycz, and W.-G. Zhang, "A group decision making model based on an inconsistency index of interval multiplicative reciprocal matrices," Knowl.-Based Syst., vol. 145, pp. 67-76, Apr. 2018.

[146] Z. Xu and H. Liao, "Intuitionistic Fuzzy Analytic Hierarchy Process," IEEE Trans. Fuzzy Syst., vol. 22, no. 4, pp. 749-761, Aug. 2014.

[147] Saaty TL. The analytic hierarchy process. New York: McGraw-Hill; 1980.

[148] Erensal YC, O zcan T, Demircan ML. Determining key capabilities in technology management using fuzzy analytic hierarchy process: a case study of Turkey. Inf Sci 2006;176:2755-70.

[149] T. Ertay, D. Ruan, and U. Tuzkaya, "Integrating data envelopment analysis and analytic hierarchy for the facility layout design in manufacturing systems," Inf. Sci., vol. 176, no. 3, pp. 237-262, Feb. 2006.

[150] Kahraman C, Ruan D, Dog an I. Fuzzy group decision-making for facility location selection. Inf Sci 2003;157:135-53.

[151] Kulak O, Kahraman C. Fuzzy multi-attribute selection among transportation companies using axiomatic design and analytic hierarchy process. Inf Sci 2005; 170:191-210.

[152] X. Liang, X. Sun, G. Shu, K. Sun, X. Wang, and X. Wang, "Using the analytic network process (ANP) to determine method of waste energy recovery from engine,” Energy Convers. Manag., vol. 66, pp. 304-311, Feb. 2013.

[153] T. L. Saaty, Decision making with dependence and feedback: the analytic network process: the organization and prioritization of complexity, 1st ed. Pittsburgh, PA: RWS Publications, 1996.

[154] S.-H. Chung, A. H. I. Lee, and W. L. Pearn, "Analytic network process (ANP) approach for product mix planning in semiconductor fabricator," Int. J. Prod. Econ., vol. 96, no. 1, pp. 15-36, Apr. 2005. 
[155] L. M. Meade and J. Sarkis, "Analyzing organizational project alternatives for agile manufacturing processes: An analytical network approach,” Int. J. Prod. Res., vol. 37, no. 2, pp. 241-261, Feb. 1999.

[156] H. Liao, X. Mi, Z. Xu, J. Xu, and F. Herrera, "Intuitionistic Fuzzy Analytic Network Process," IEEE Trans. Fuzzy Syst., vol. 26, no. 5, pp. 2578-2590, Oct. 2018.

[157] J. Qin, X. Liu, and W. Pedrycz, “An extended TODIM multi-criteria group decision making method for green supplier selection in interval type-2 fuzzy environment,” Eur. J. Oper. Res., vol. 258, no. 2, pp. 626-638, Apr. 2017.

[158] A. P. F. Lopes, M. M. Muñoz, and P. Alarcón-Urbistondo, "Regional tourism competitiveness using the PROMETHEE approach,” Ann. Tour. Res., vol. 73, pp. 1-13, Nov. 2018.

[159] M. A. Boujelben, "A unicriterion analysis based on the PROMETHEE principles for multicriteria ordered clustering," Omega, vol. 69, pp. 126-140, Jun. 2017.

[160] S. Opricovic, Multicriteria optimization of civil engineering systems, Fac. Civ.Eng. Belgrade 2 (1998) 5-21.

[161] M. Gul, E. Celik, N. Aydin, A. Taskin Gumus, and A. F. Guneri, "A state of the art literature review of VIKOR and its fuzzy extensions on applications," Appl. Soft Comput., vol. 46, pp. 60-89, Sep. 2016.

[162] S. Opricovic and G.-H. Tzeng, "Compromise solution by MCDM methods: A comparative analysis of VIKOR and TOPSIS,” Eur. J. Oper. Res., vol. 156, no. 2, pp. 445-455, Jul. 2004.

[163] H. Liao, Z. Xu, and X.-J. Zeng, "Hesitant Fuzzy Linguistic VIKOR Method and Its Application in Qualitative Multiple Criteria Decision Making," IEEE Trans. Fuzzy Syst., vol. 23, no. 5, pp. 1343-1355, Oct. 2015.

[164] Z. Ren, Z. Xu, and H. Wang, "Dual hesitant fuzzy VIKOR method for multicriteria group decision making based on fuzzy measure and new comparison method," Inf. Sci., vol. 388-389, pp. 1-16, May 2017.

[165] S. Wan, G. Xu, and J. Dong, "Supplier selection using ANP and ELECTRE II in interval 2-tuple linguistic environment," Inf. Sci., vol. 385-386, pp. 19-38, Apr. 2017.

[166] Roy B. : 'The outranking approach and the foundations of ELECTRE methods', Theory and Decision, 31, 1991, 49-73.

[167] C. Giannoulis and A. Ishizaka, "A Web-based decision support system with ELECTRE III for a personalised ranking of British universities," Decis. Support Syst., vol. 48, no. 3, pp. 488-497, Feb. 2010. 
[168] S. Ulubeyli and A. Kazaz, “A MULTIPLE CRITERIA DECISION-MAKING APPROACH TO THE SELECTION OF CONCRETE PUMPS," J. Civ. Eng. Manag., vol. 15, no. 4, pp. 369-376, Dec. 2009.

[169] M. M. Marzouk, "ELECTRE III model for value engineering applications," Autom. Constr., vol. 20, no. 5, pp. 596-600, Aug. 2011.

[170] S. A. S. A. Mary and G. Suganya, "Multi-Criteria Decision Making Using ELECTRE,” Circuits Syst., vol. 07, no. 06, pp. 1008-1020, 2016.

[171] J. M. Sánchez-Lozano, M. S. García-Cascales, and M. T. Lamata, "Comparative TOPSIS-ELECTRE TRI methods for optimal sites for photovoltaic solar farms. Case study in Spain,” J. Clean. Prod., vol. 127, pp. 387-398, Jul. 2016.

[172] J. Rezaei, "Best-worst multi-criteria decision-making method," Omega, vol. 53, pp. 49-57, Jun. 2015.

[173] N. Salimi and J. Rezaei, "Evaluating firms' R\&D performance using best worst method," Eval. Program Plann., vol. 66, pp. 147-155, Feb. 2018.

[174] J. Rezaei, "Best-worst multi-criteria decision-making method: Some properties and a linear model," Omega, vol. 64, pp. 126-130, Oct. 2016.

[175] C.Y. Wang and S.-M. Chen, "Multiple attribute decision making based on intervalvalued intuitionistic fuzzy sets, linear programming methodology, and the extended TOPSIS method," Inf. Sci., vol. 397-398, pp. 155-167, Aug. 2017.

[176] C.L. Hwang and K. Yoon, Multiple Attribute Decision Making, vol. 186. Berlin, Heidelberg: Springer Berlin Heidelberg, 1981.

[177] M. Yazdani, P. Chatterjee, E. K. Zavadskas, and S. Hashemkhani Zolfani, "Integrated QFD-MCDM framework for green supplier selection," J. Clean. Prod., vol. 142, pp. 3728-3740, Jan. 2017.

[178] Gabus, A., Fontela, E., 1973. Perceptions of the World Problematique: Communication Procedure, Communicating with those Bearing Collective Responsibility, DEMATEL Report No. 1. Battelle Geneva Research Center, Geneva, Switzerland.

[179] Fontela, E., Gabus, A., 1976. The DEMATEL Observer, DEMATEL 1976 Report. Battelle Geneva Research Center, Switzerland, Geneva.

[180] J. Ren, A. Manzardo, S. Toniolo, and A. Scipioni, "Sustainability of hydrogen supply chain. Part I: Identification of critical criteria and cause-effect analysis for enhancing the sustainability using DEMATEL," Int. J. Hydrog. Energy, vol. 38, no. 33, pp. 14159-14171, Nov. 2013.

[181] C.-W. Hsu, T.-C. Kuo, S.-H. Chen, and A. H. Hu, "Using DEMATEL to develop a carbon management model of supplier selection in green supply chain management," J. Clean. Prod., vol. 56, pp. 164-172, Oct. 2013. 
[182] J. Shieh, H. Wu, and K. Huang, "A DEMATEL Method in Identifying Key Success Factors of Hospital Service Quality," Knowl-Based Syst., vol. 23, no. 3, pp. $277-$ 282, Apr. 2010.

[183] L. Cui, H. K. Chan, Y. Zhou, J. Dai, and J. J. Lim, "Exploring critical factors of green business failure based on Grey-Decision Making Trial and Evaluation Laboratory (DEMATEL),” J. Bus. Res., Mar. 2018.

[184] J. Brown, 'Fueling the Oil and Gas Supply Chain,' Jul. 2014.

[285] Bailey W, Couët B, Lamb F, Simpson G, Rose P. Taking a calculated risk. Oilfield Rev 2000;12(3):20-35.

[186] L. Castillo and C. A. Dorao, "Decision-making in the oil and gas projects based on game theory: Conceptual process design," Energy Convers. Manag., vol. 66, pp. 48-55, Feb. 2013.

[187] J.R. Quinlan, Induction of decision trees, Machine Learning (1986).

[188] J. Han, M. Kamber, Data mining concepts and techniques, Elsevier Inc., San Francisco, 2006.

[189] Z. Yu, F. Haghighat, B. C. M. Fung, and H. Yoshino, "A decision tree method for building energy demand modeling,” Energy Build., vol. 42, no. 10, pp. 1637-1646, Oct. 2010.

[190] F. Macmillan, "Risk, Uncertainty and Investment Decision- Making in the Upstream Oil and Gas Industry," University of Aberdeen, 2000.

[191] I. Owusu-Ansah, "Financial decision making about found oil and gas in Ghana: Real Options vs. Traditional Methods," Michigan Technological University, 2008.

[192] A. Galli, M. Armstrong, and B. Jehl, "Comparing Three Methods for Evaluating Oil Projects: Option Pricing, Decision Trees, and Monte Carlo Simulations," 1999. [193] Lefley, F., and Morgan, M., 1999, The NPV Profile: a creative way of looking at NPV, Management Accounting, June, volume 77, issue 6, p39.

[194] C. Petri, "Decision Trees.” 2010.

[195] J. Gehrke, V. Ganti, R. Ramakrishnan, W.Y. Loh, BOAT-optimistic decision tree construction, in: International Conference on Management of Data (SICMOD), ACM, 1999, pp. 169-180.

[196] X. Wang, X. Liu, W. Pedrycz, and L. Zhang, "Fuzzy rule based decision trees," Pattern Recognit., vol. 48, no. 1, pp. 50-59, Jan. 2015.

[197] Goodwin, P., and Wright G., 1991, Decision analysis for management judgement, John Wiley\&Sons Limited, Chichester, England.

[198] J.W.Hayse.Using Monte Carlo analysis in ecological risk assessments, United States Environmental Protection Agency,2000,October.

[199] W. Yang and C. Tian, "Monte-Carlo simulation of information system project performance," Syst. Eng. Procedia, vol. 3, pp. 340-345, 2012. 
[200] Kerzner H., Project Management. A systems approach to planning, scheduling, and controlling - 9th ed., John Wiley and Sons, 2006.

[201] PMI, The Practice Standard for Project Risk Management, Project Management Institute 2009.

[202] P. Wyrozębski and A. Wyrozębska, "Benefits of Monte Carlo simulation as the extension to the Programe Evaluation and Review Technique," 2013.

[203] B. Yildiz, "Assessment of Policy Alternatives for Mitigation of Barriers to EV Adoption," Portland State University, Portland, Oregon, 2018.

[204] Corporate Finance Institute (CFI), 2016 https://corporatefinanceinstitute.com/resources/knowledge/finance/return-oninvestment-roi-formula/

[205] G. S and K. A, "Teaching ICT to teacher candidates using PBL: A qualitative and quantitative evaluation," in Educational Technology \& Society, 2006, vol. 9 (2), pp. 96-106.

[206] Tellis and Winston, "Introduction to Case Study. The Qualitative Report," presented at the 2, 1997, vol. 3.

[207] Z. Zainal, "Case study as a research method," Jurnal Kemanusiaan, vol. 9, Jun. 2007.

[208] C. Meyer, “A Case in Case Study Methodology,” Sage Publ., vol. 13, no. 4, pp. 329-352, Nov. 2001.

[209] A. Starman, "The case study as a type of qualitative research," J. Contemp. Educ. Stud., pp. 28-43, 2013.

[210] Yin, R.K., (1984). Case Study Research: Design and Methods. Beverly Hills, Calif: Sage Publications. .

[211] Z. Zainal, "Case study as a research method," J. Kemanus. Bil9, Jun. 2007.

[212] Natural Resource Governance Institute, "Assessing Tunisia's Upstream Petroleum Fiscal Regime", September 2019.

[213] A. M. Etelawi, K. A. Blatner, and J. McCluskey, "Crude Oil and the Libyan Economy,” Int. J. Econ. Finance, vol. 9, no. 4, p. 95, Mar. 2017.

[214] S. Al-Hengari, M. El-Bousiffi, and W. El-Moudir, "Libyan Petroleum Institute experience in evaluation ofdesalination plants in the Libyan oil sector," Desalination, vol. 206, no. 1-3, pp. 633-652, Feb. 2007.

[215] Mellitah Company, "Mellitah Oil \& Gas Company Profile." 2018.

[216] Riproduzione Riservata, "Eni, Libyan national oil corporation start output from offshore gas field." BUSINESS, 2018.

[217] M. Tiryakioğlu, "Eni discovers new gas field offshore Libya." AA Energy, 2017.

[218] Oxford Business Group, "The Report Tunisia' 2010.

[219] Offshore Energy, "Libya: Bouri Offshore Field Back in Production", 2011. 
[220] Offshore Technology, "Bouri Field, Mediterranean Sea", 2017.

[221] A.Msallem, A.Nasef, B.Bazzoni, and P.Marcassoli, "Assessment of the Underwater Works and Anode Removal on the Cathodic Protection Status of an Offshore Platform Through FEM Modelling", Offshore Mediterranean Conference and Exhibition in Ravenna, Italy, March 29, 2019.

[222] S.B. Suslick and D.J. Schiozer, "Risk Analysis Applied to Petroleum Exploration and Production an Overview" Journal of Petroleum Science and Engineering, vol 44,n.2, pp1-9, 2004. 


\title{
APPENDIX A: LETTERS OF INVITATION TO EXPERTS
}

Invitation Letter/Email

Re: Invitation to be an expert in Abdulhakim Giadedi's PhD research

Dear Mr./Ms.:

My name is Abdulhakim Giadedi, $\mathrm{PhD}$ Candidate in Engineering and Technology Management Department (ETM) at Portland State University (PSU). I am conducting my dissertation research entitled "Offshore Oil Projects Evaluation".

As part of my research, I am conducting a survey to help me validate and quantify my research model. I have identified you as an expert in the field. Your knowledge, background, experience, and expertise will be very helpful for my research.

If you agree to participate in this research, I will send you web-based data collection instruments for you to provide your response. The research instruments will take about $5 \sim 10$ minutes to complete.

I will be honored if you could accept my invitation and join the expert panel. I would also appreciate greatly if you could suggest other experts who have expertise or experiences in Offshore Oil Projects.

I look forward to receiving your reply!

Best Regards,

Consent:

Your participation in this study indicates that you have read the information provided (or the information was read to you) on this link:

https://drive.google.com/file/d/1hKD1k0uwjiYs6rP72vsN_m9yTNmfaW18/view?usp=sh aring

\author{
Abdulhakim Giadedi \\ PhD Candidate \\ Engineering and Technology Management Department (ETM) \\ Portland State University (PSU)
}




\section{APPENDIX B: Qualtrics Surveys to Validate The Model}

\section{Oil and Gas Offshore Projects Evaluation}

The purpose of this research is to provide a comprehensive framework that can be used for assessing and evaluating $O \& G$ offshore projects to select the right project.

The preliminary Hierarchical Decision Model (HDM) for evaluating $O \& G$ offshore projects shown below for your reference:

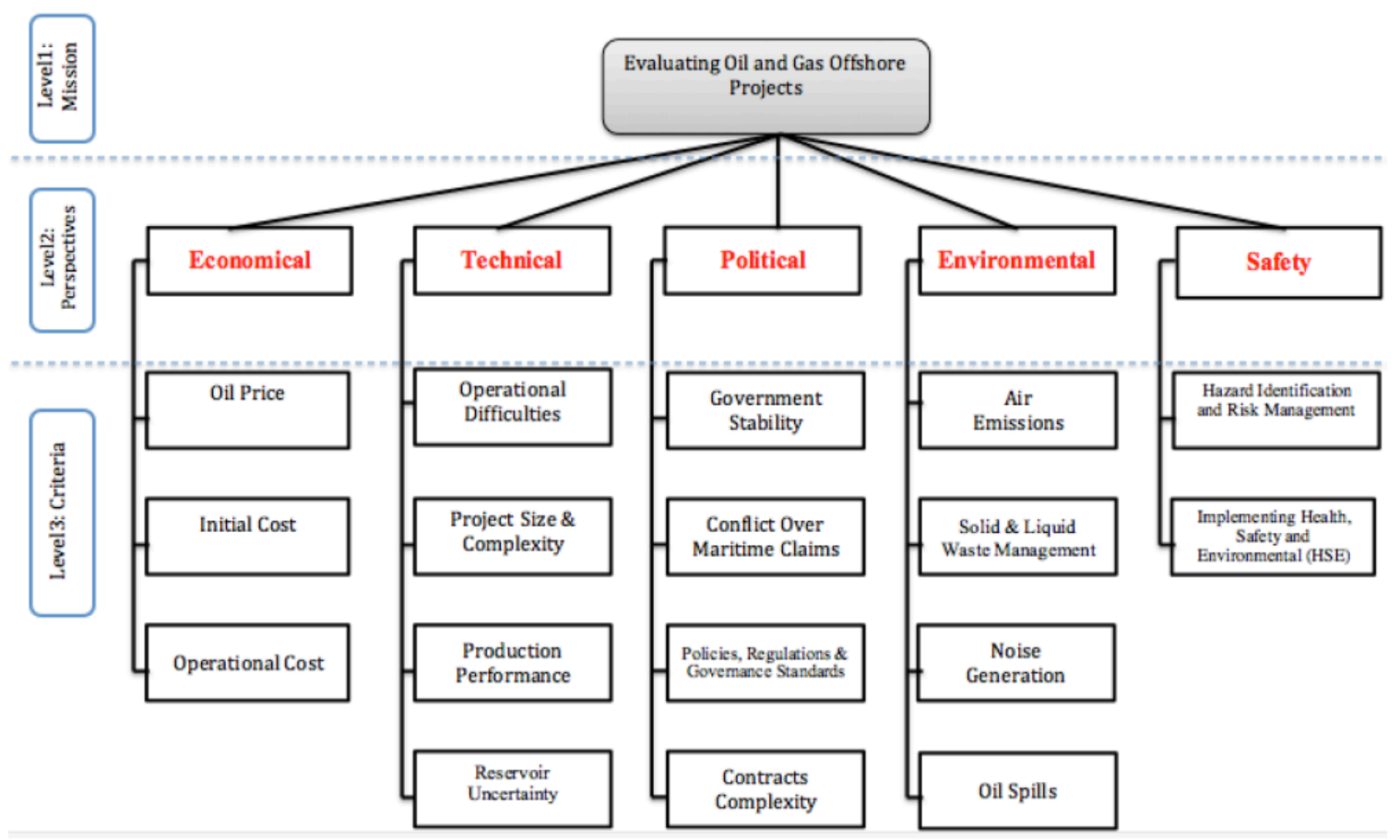

- Please click "Yes" if you think that the specific perspective or the specific criteria contributes to the Oil and Gas offshore projects evaluation.

- Please click "No" if you think that the specific perspective or the specific criteria does not contribute to the Oil and Gas offshore projects evaluation.

- If there are other perspectives, please add them in the space provided.

- If you have any comments, please add them in the space provided. 


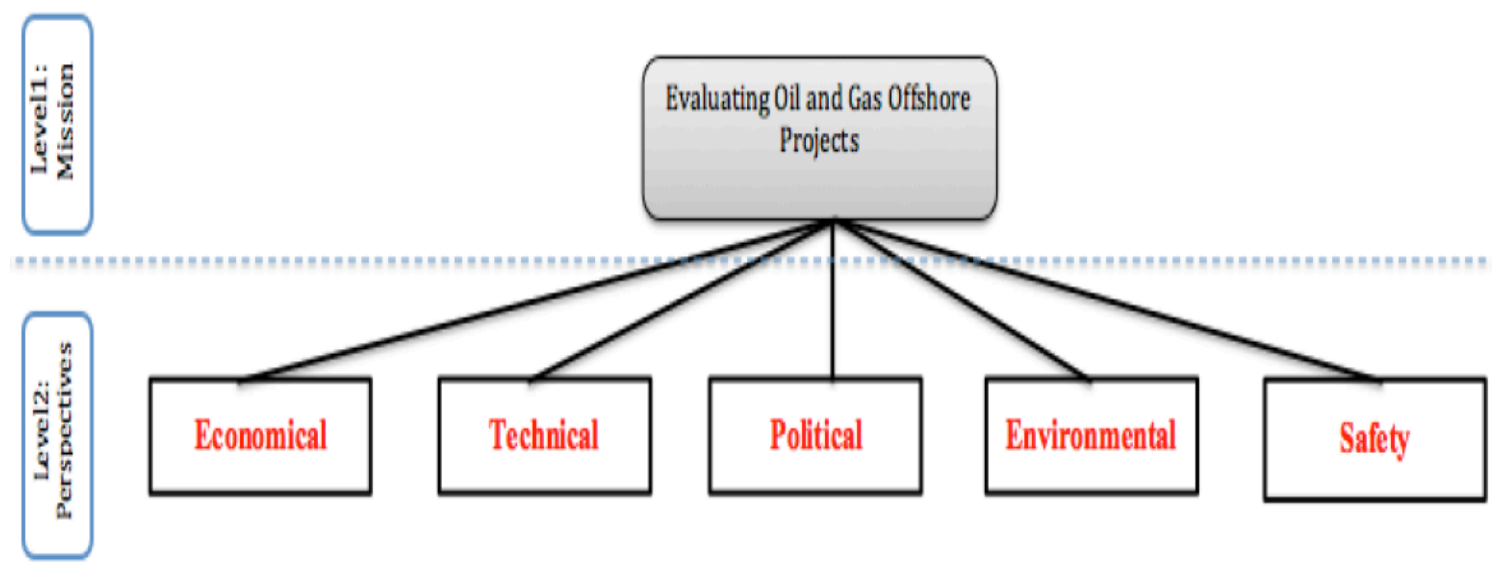

Please identify the perspectives that contribute to the O\& $G$ offshore projects evaluation:

\begin{tabular}{lcc}
\hline & YES & No \\
\hline Economical & 0 & 0 \\
Technical & 0 & 0 \\
Political & 0 & 0 \\
Environmental & 0 & \\
Safety & & \\
& & \\
\hline If you think that there are other additional perspectives needed to be added, please add them below: & \\
\hline
\end{tabular}

Other comments: 
Please validate the criteria associated with Economical perspective:

\begin{tabular}{lcc} 
& YES & No \\
\hline Oil Price: & 0 & $\bigcirc$ \\
Initial Cost: & 0 & $\bigcirc$ \\
Operational Cost: & 0 & 0
\end{tabular}

If there are other criteria needed to be added, please add them below:

If you have any comments, please add them below:

Hlease validate the criterla assoclated with lechnical perspectlve:

YES No

Operational Difficulties:

Size \& Complexity:

Production Performance:

Reservoir Uncertainty:

If there are other criteria needed to be added, please add them below:

If you have any comments, please add them below: 
Please validate the criteria associated with Political perspective:

\begin{tabular}{lcc} 
& YES & No \\
\hline Government Stability: & $\bigcirc$ & 0 \\
Conflict Over Maritime Claims: & & \\
Policies, Regulations \& & 0 \\
Governance Standards: & & \\
Contracts Complexity: & &
\end{tabular}

If there are other criteria needed to be added, please add them below:

If you have any comments, please add them below:

Please validate the criteria associated with Environmental perspective:

\begin{tabular}{lcc}
\hline & YES & No \\
\hline Air Emissions: & & \\
Solid \& Liquid Waste & 0 & $\bigcirc$ \\
Management: & & \\
Noise Generation: & $\bigcirc$ &
\end{tabular}

If there are other criteria needed to be added, please add them below:

If you have any comments, please add them below:

Please validate the criteria associated with Safety perspective:

YES 
Hazard Identification \& Risk

Management:

Implementing Health, Saiety and

Environmental (HSE):

If there are other criteria needed to be added, please add them below:

If you have any comments, please add them below: 
APPENDIX C: QUALTRICS SURVEYS TO QUANTIFY THE MODEL

Abdulhakim Giadedi's Ph.D. Research Model

\section{A Hierarchical Decision Model to Evaluating Oil and Gas Offshore Projects}

Specific Objectives of the Research:

1. To identify the major challenging perspectives as well as associated sub-criteria impacting O\&G offshore projects.

2. To evaluate and score these factors and highlight their weight of impact on offshore O\&G projects.

3. To provide a comprehensive framework that can be used for assessing and evaluating O\&G offshore projects to select the right project.

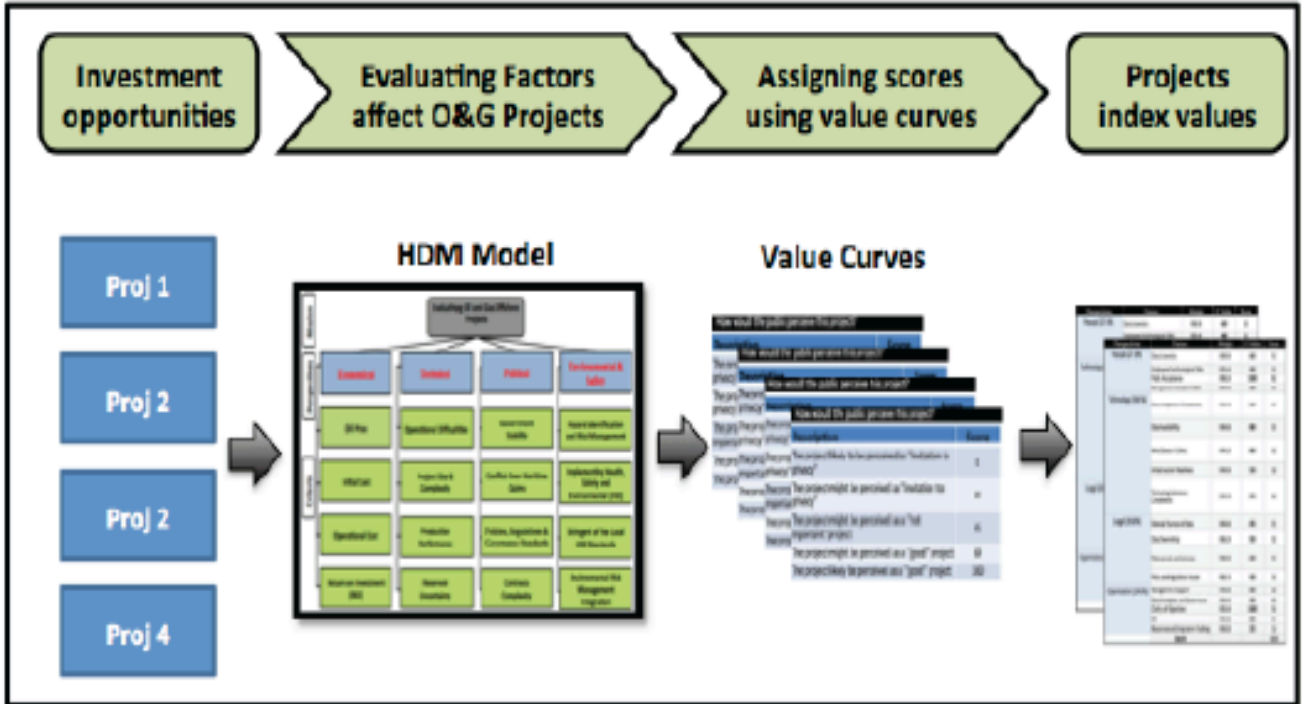

Please click on the next button $(\rightarrow)$ on the right bottom of the screen to start the survey. 
First Name

Last Name

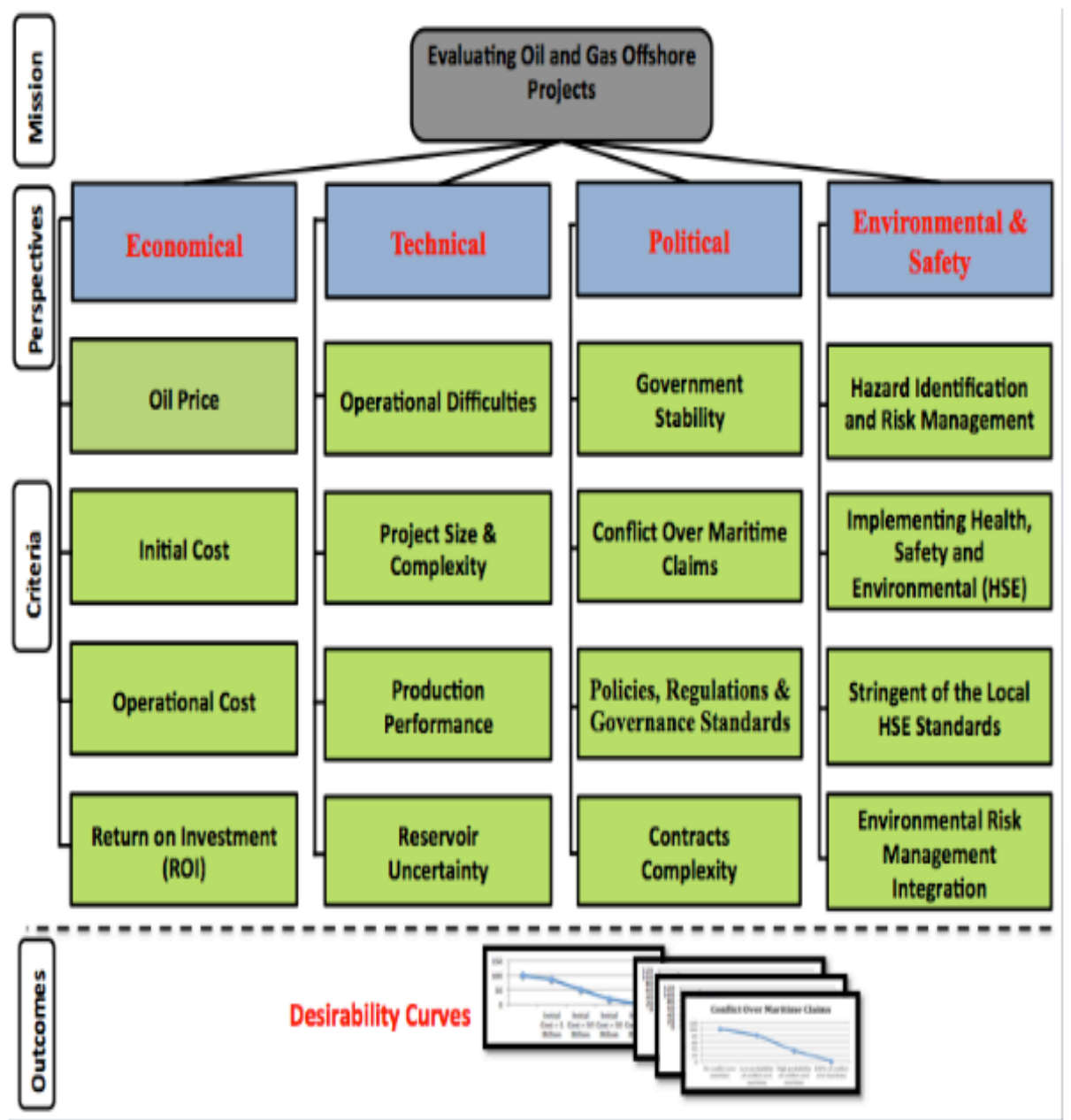

Please click on the next button $(\rightarrow>)$ on the right bottom of the screen 
You will quantify the importance of each perspective through pairwise comparisons. Please read the instructions below:

Items will be compared against each other, in pairs. Assign the points according to your opinion. The assignment of points should reflect the importance of each item. Example: if A is 3x more important than B, A should receive 75 points and B should receive 25 points. Note that for each pairwise comparison, the total of points assigned must be 100 . Please try to be logically consistent in your choices, i.e., if A is better than B, and B is better than C, A must be better than C.

Note: Please refer to the above table for summary about each factor

Please judge the importance of the following factors dividing 100 points between them. Drag the bars below assigning more points to the one you deem more important.

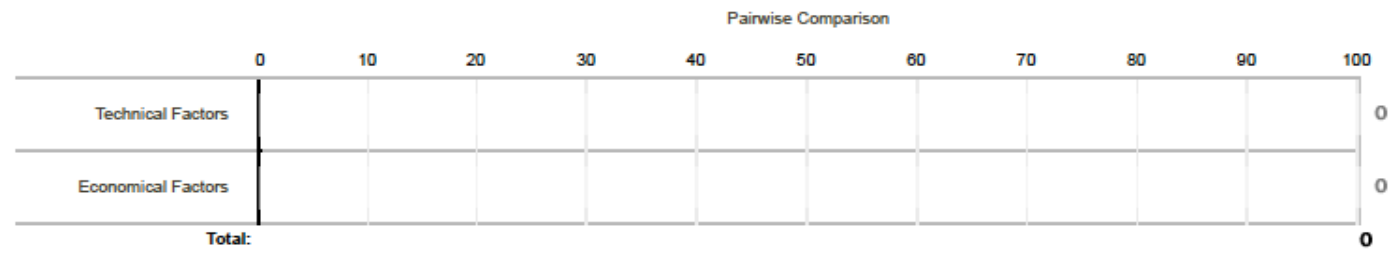

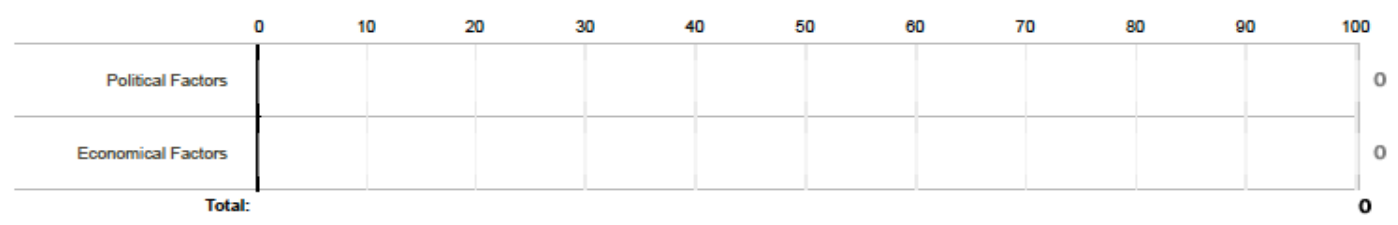

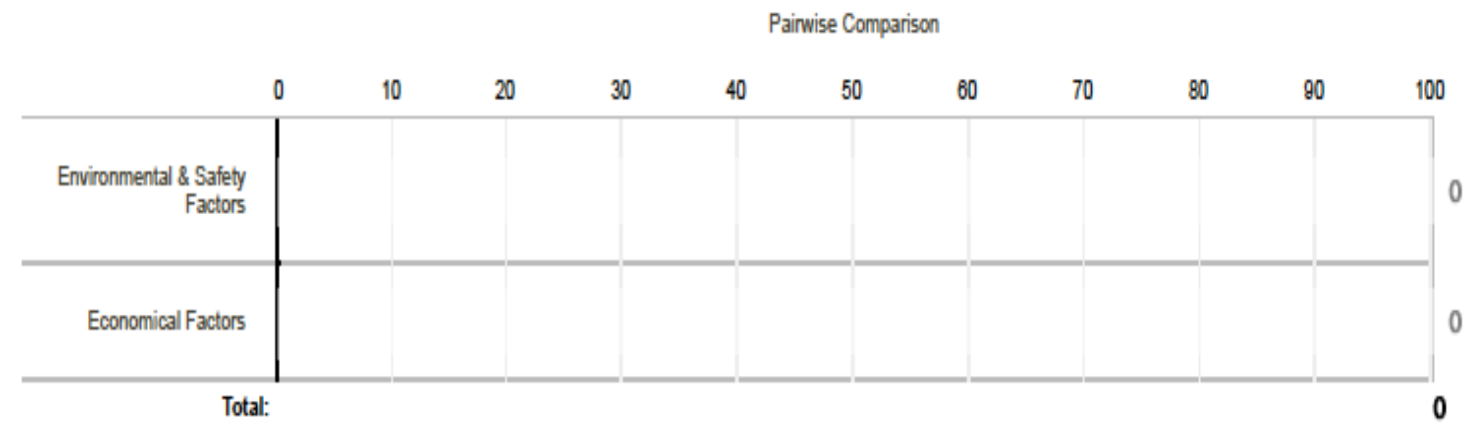




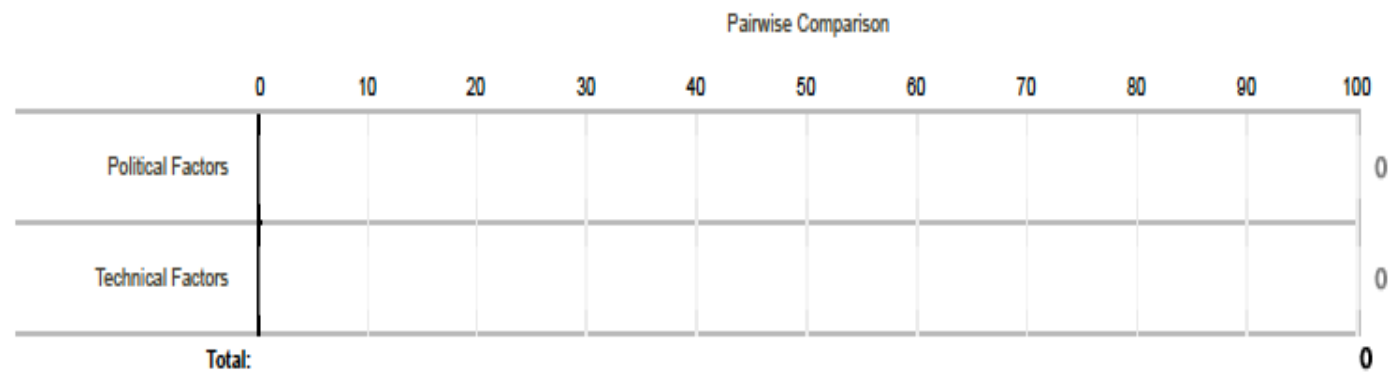

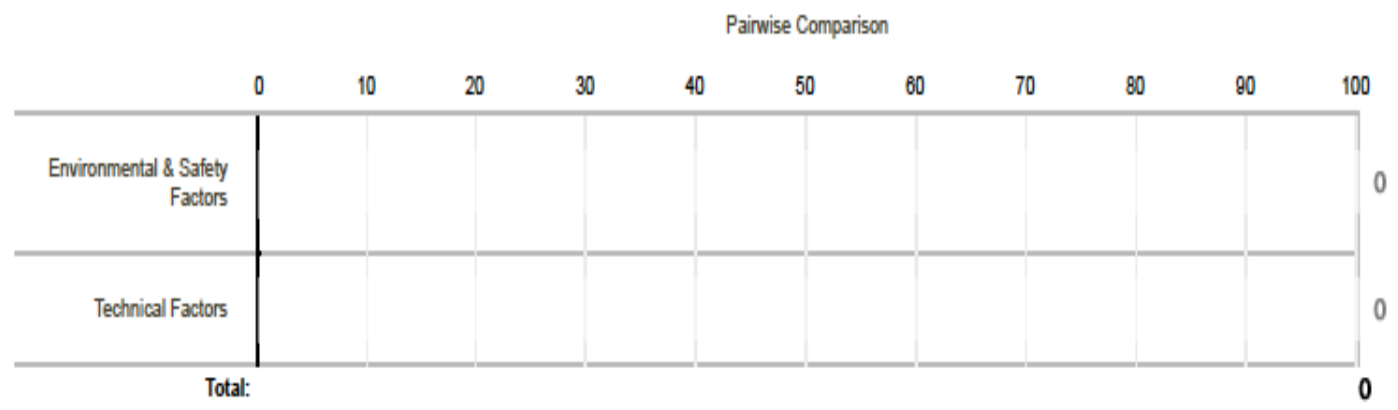

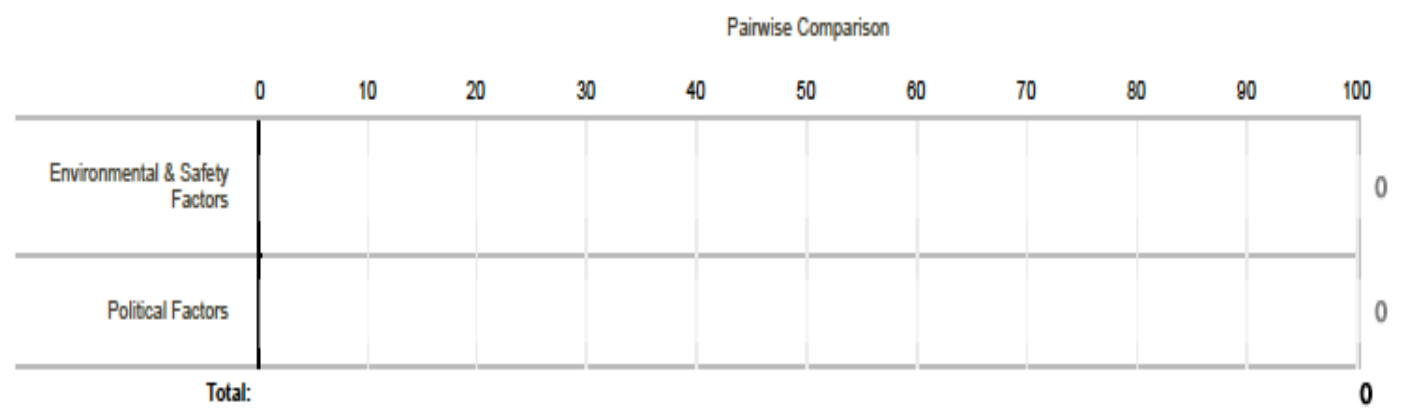

If you have comments, please provide them here: 


\begin{tabular}{|c|c|}
\hline \multicolumn{2}{|r|}{ Economical Perspectives } \\
\hline Oil Price: & $\begin{array}{l}\text { Oil Price refers to the probability of the oil price when the } \\
\text { project statst to producce oil as well as the expected change on } \\
\text { the prices during the project life cycle. }\end{array}$ \\
\hline Initial Cost: & $\begin{array}{l}\text { Offshore projects cost a huge amount of money and initial cos } \\
\text { referes to the challenging of finding the funds and how much } \\
\text { will coss the company to start-up projects. }\end{array}$ \\
\hline Operational Cost: & $\begin{array}{l}\text { Operational coss referes to the operating expenses to maintain } \\
\text { production and stay in business. Operational cost include staff } \\
\text { expenditure, subsea, pollution contro, water injection, } \\
\text { maintenance, insurance, transport chargeres, miscellaneous etc. }\end{array}$ \\
\hline \begin{tabular}{|l} 
Return on \\
Investment (ROI):
\end{tabular} & $\begin{array}{l}\text { Return on Investment measures the gain or loss generated on } \\
\text { an investment relative to the amount of money invested and } \\
\text { compares the profitabilitity as well. }\end{array}$ \\
\hline
\end{tabular}

\section{You will quantify the importance of each factor through pairwise comparisons. Please read the instructions below:}

Items will be compared against each other, in pairs, Assign the points according to your opinion. The assignment of points should reflect the importance of each item, Example: if $A$ is $3 x$ more important than B, A should receive 75 points and B should receive 25 points, Note that for each pairwise comparison, the total of points assigned must be 100 , Please try to be logically consistent in your choices,, Le, if $A$ i is better than $B$, and $B$ is better than $C_{1} A$ must be better than $C$.

\section{Note: Please refer to the above table for summary about each factor}




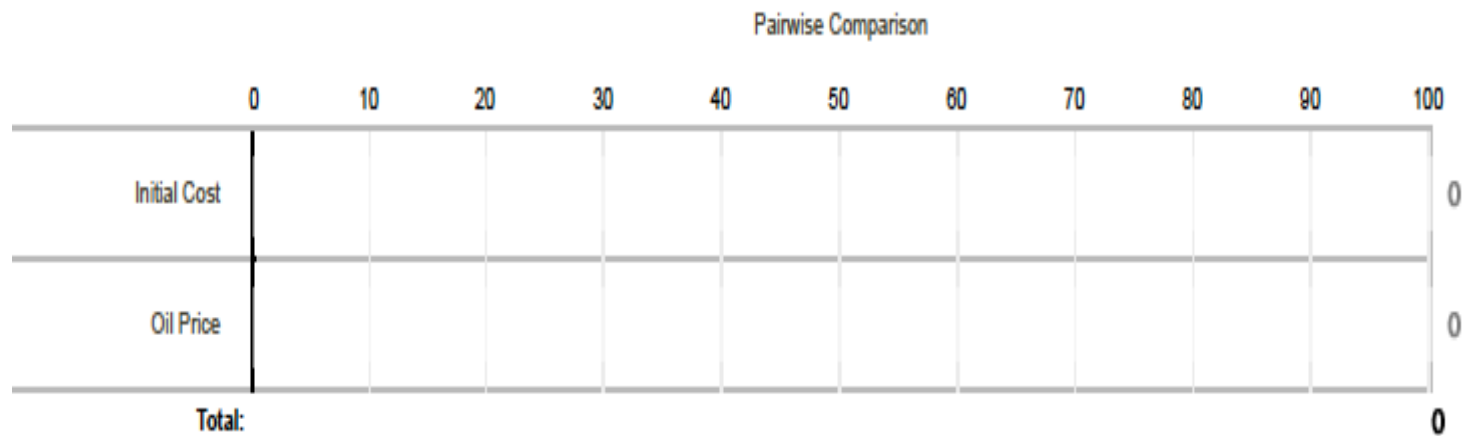

Painwise Comparison

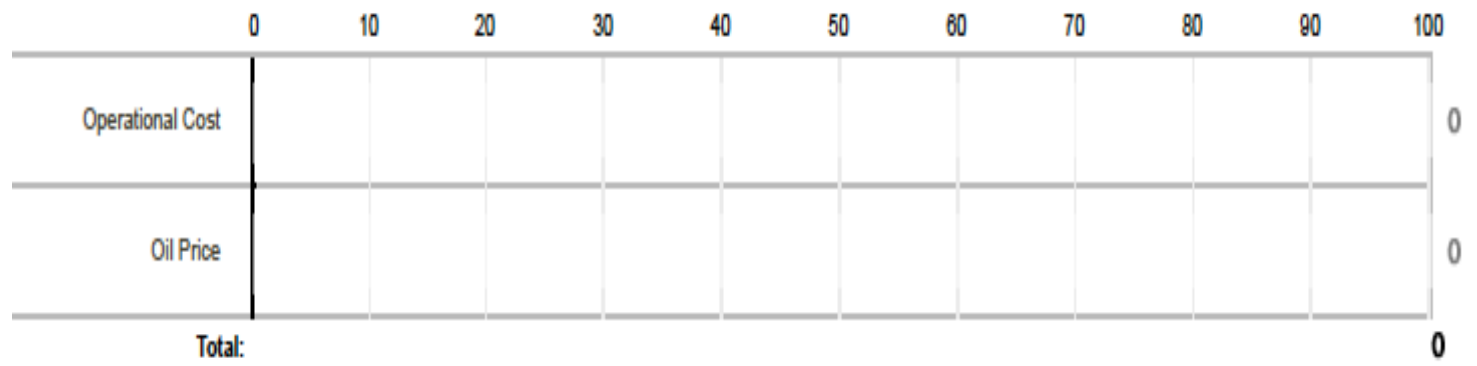

Painwise Comparison

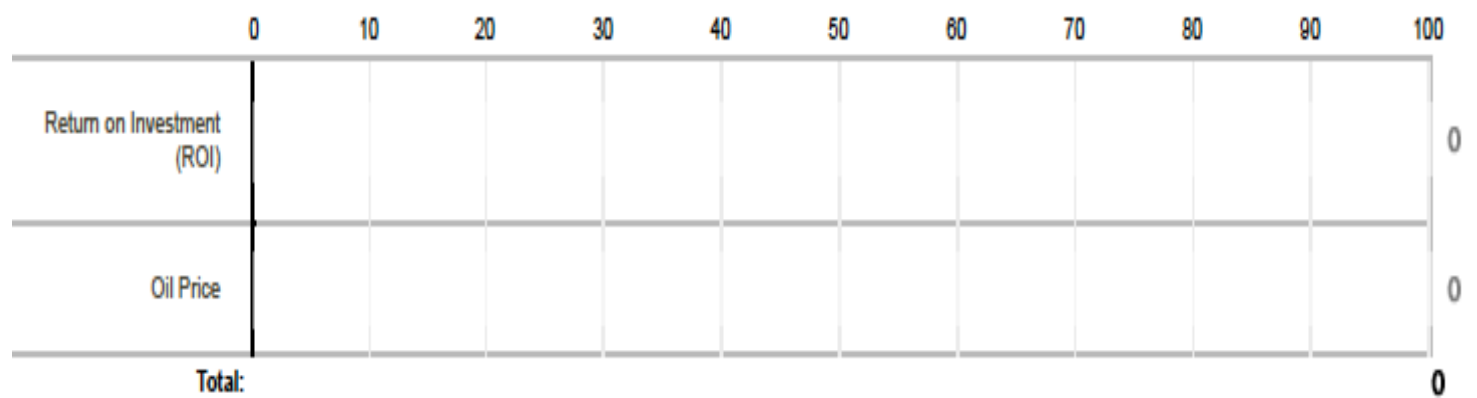




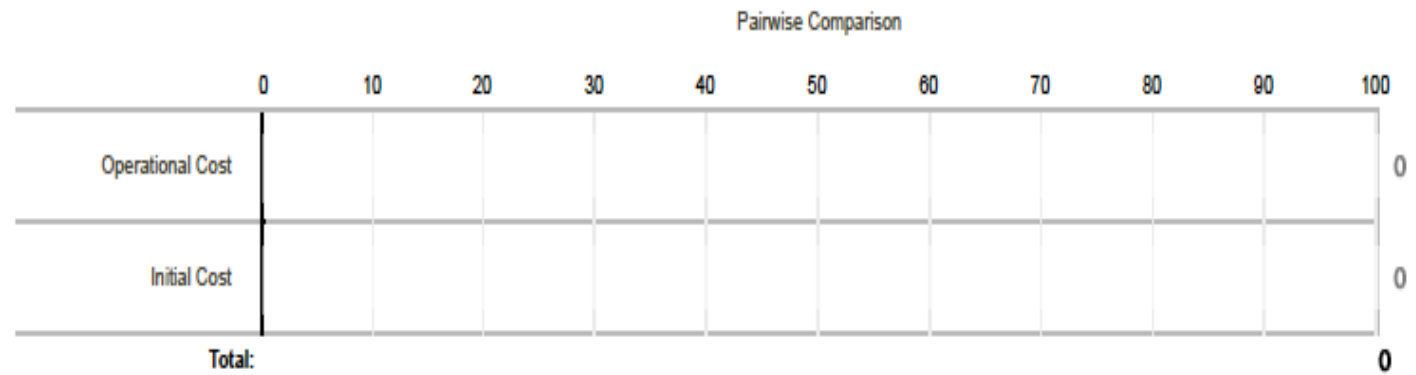

Pairwise Comparison

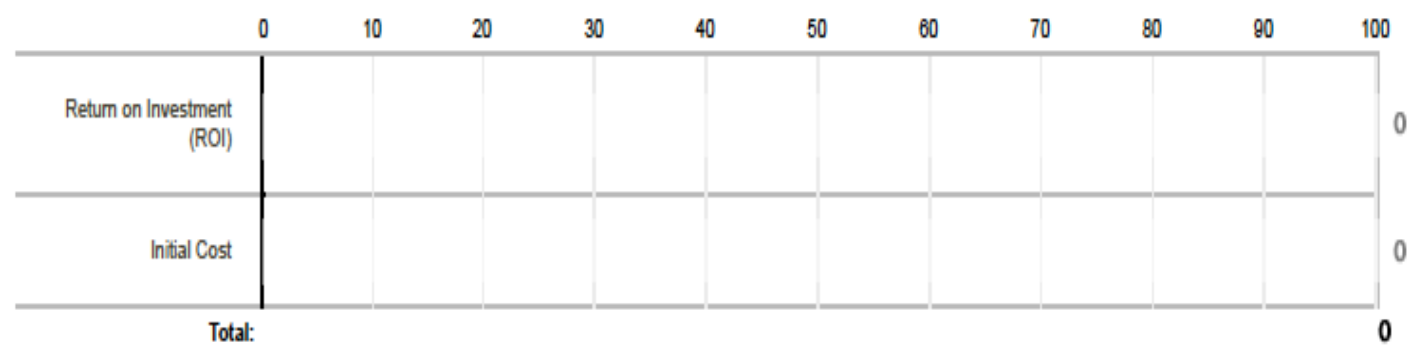

Pairwise Comparison

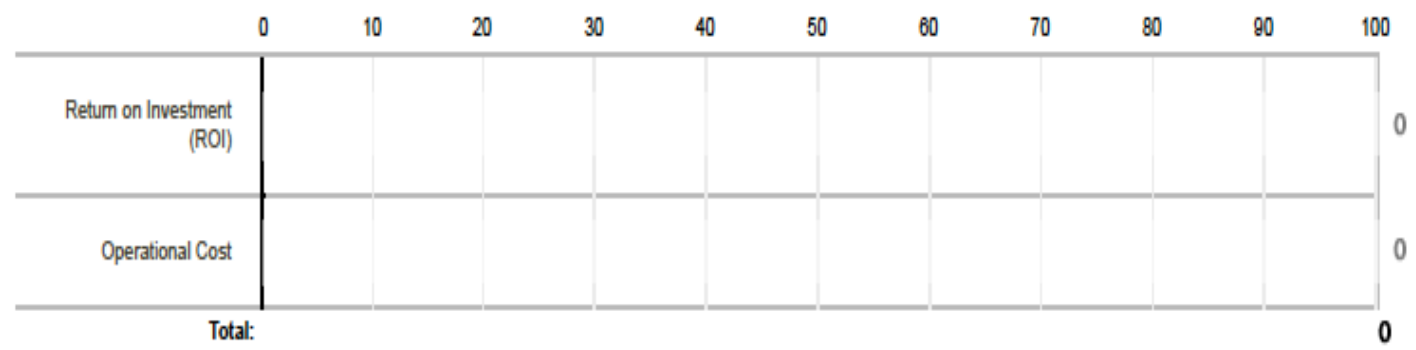

If you have comments, please provide them here: 


\begin{tabular}{|c|c|}
\hline \multicolumn{2}{|r|}{ Technical Perspectives } \\
\hline $\begin{array}{l}\text { Operational } \\
\text { Difficultices: }\end{array}$ & $\begin{array}{l}\text { Refeers to differenent types of operational difficulties projects } \\
\text { will face that will rise risks and costs such as, complex } \\
\text { working equipment, harsh weather conditions, limited access } \\
\text { to safety points, hydrocarbon releases, fire, high degrees of } \\
\text { temperature and pressure, fatigue, tec. }\end{array}$ \\
\hline Size \& Complexity: & $\begin{array}{l}\text { Refers to size of the project and risk of having a larger number } \\
\text { of sub-scopes, such as well, subsea system, production sysem } \\
\text { transportation system, etc. These individual project sub-scopec } \\
\text { are also quite large with cosst in the hundreds of millions of } \\
\text { dollars. }\end{array}$ \\
\hline $\begin{array}{l}\text { Production } \\
\text { Performance: }\end{array}$ & $\begin{array}{l}\text { Refers to risk of fallure to produce the planned production, } \\
\text { since the production volume of the oil and gas is one of the } \\
\text { key factors to determine a project's profitibility. }\end{array}$ \\
\hline \begin{tabular}{|l|} 
Reservoir \\
Uncertainty:
\end{tabular} & $\begin{array}{l}\text { Refers to the geologic and seismic uncertainty since drilling is is } \\
\text { the onlly way to confirm if an oil or gas field actually exists in } \\
\text { that location. The geologic and seismic uncertainty can cause } \\
\text { the company to lose money and waste time and resources. }\end{array}$ \\
\hline
\end{tabular}

\section{You will quantify the importance of each factor through pairwise comparisons. Please read the instructions below:}

Items will be compared against each other, in pairs, Assign the points according to your opinion, The assignment of points should reflect the importance of each item, Example; if $A$ is $3 x$ more impootant than B, A shoudd receive 75 points and B should receive 25 points, Note that for each pairwise comparison, the total of points assigned must be 100 , Please try to be logically consistent in your choices, i.e, if $A$ is better than $B$, and $B$ is better than $C_{1} A$ must be better than $C$.

\section{Note: Please refer to the above table for summary about each factor}


Please judge the importance of the following factors dividing 100 points between them. Drag the bars below assigning more points to the one you deem more important.

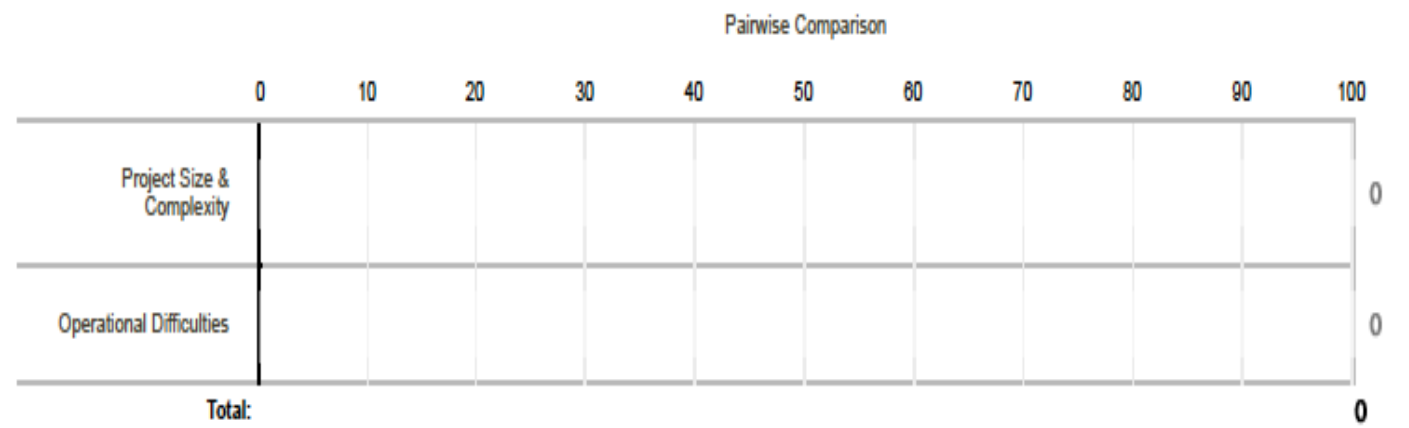

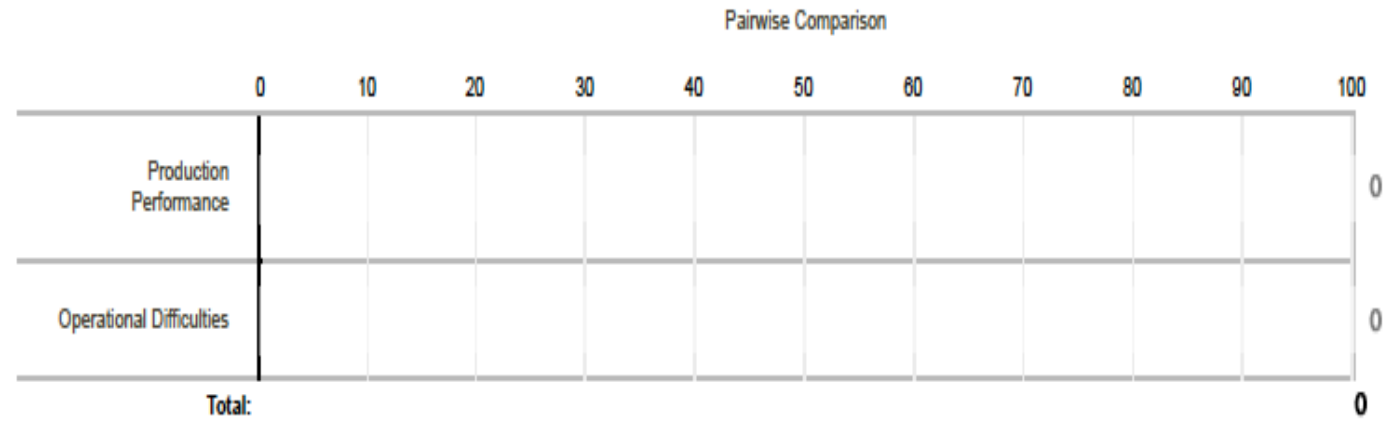

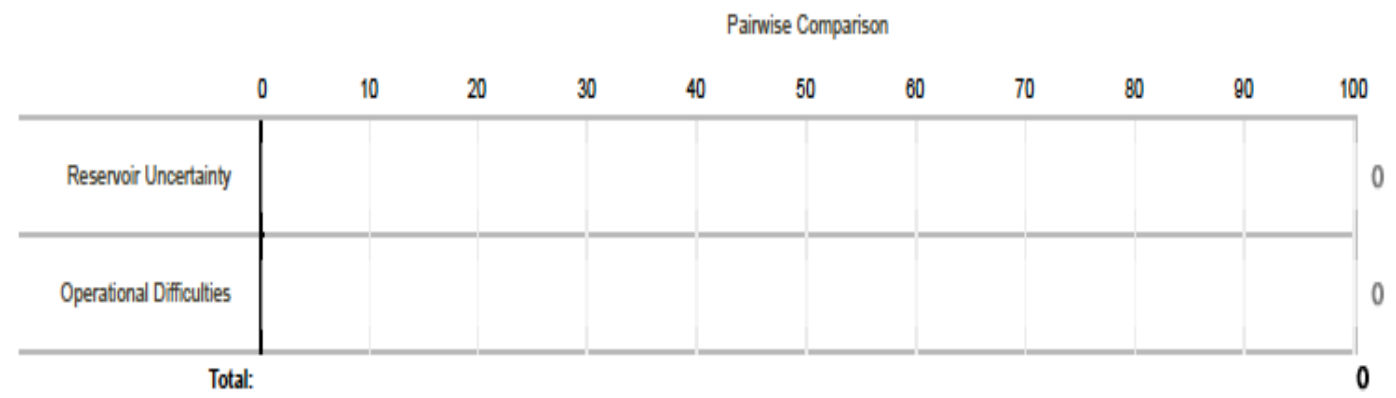




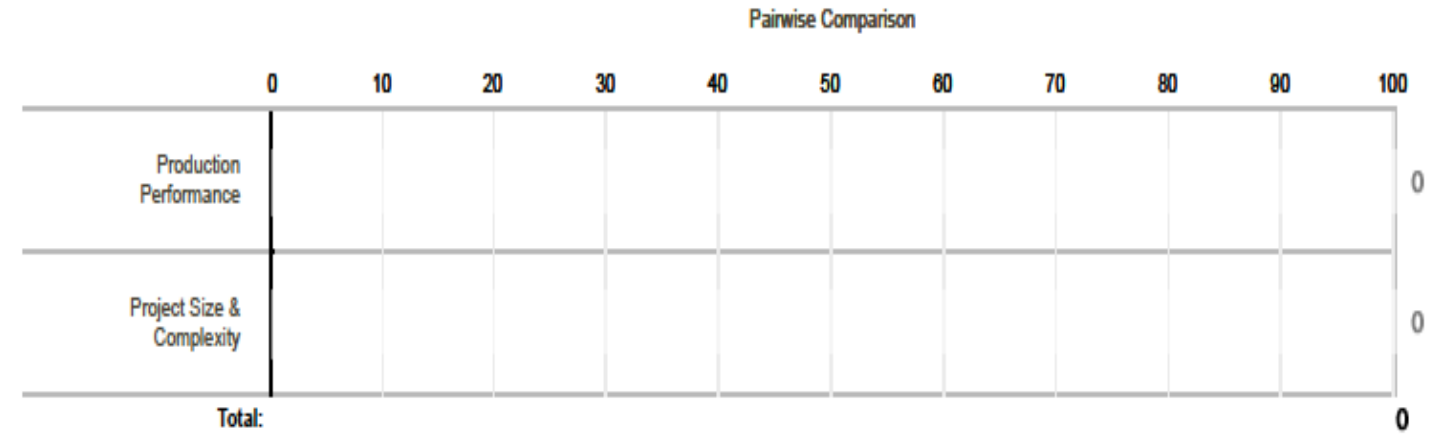

Pairwise Comparison

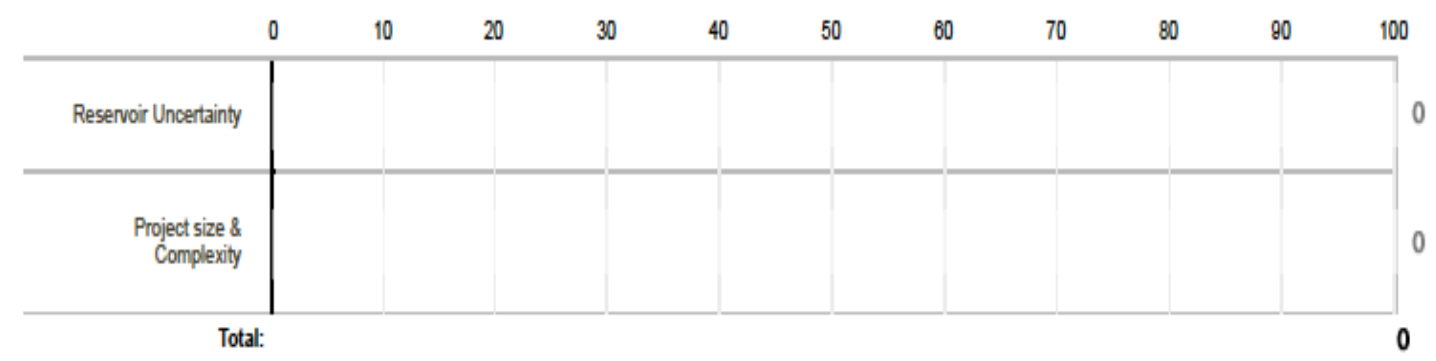

Pairwise Comparison

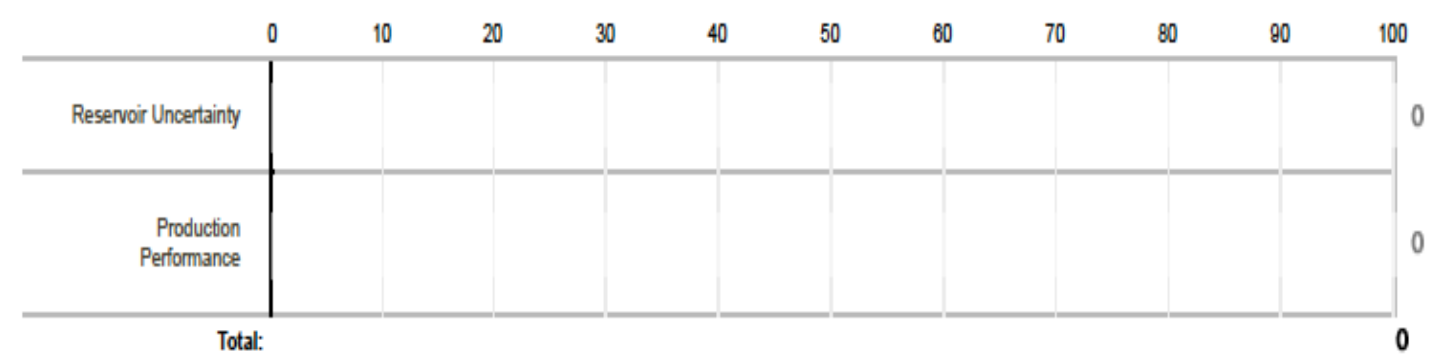

If you have comments, please provide them here: 


\begin{tabular}{|c|c|}
\hline \multicolumn{2}{|r|}{ Political Perspectives } \\
\hline $\begin{array}{l}\text { Covernment } \\
\text { Stability: }\end{array}$ & $\begin{array}{l}\text { Refers to stability of the government hosts the site. Oil and } \\
\text { Gas componiles tend to prefere countries with stable political } \\
\text { systems and a history of granting and enfocing long feerm } \\
\text { leases. }\end{array}$ \\
\hline $\begin{array}{l}\text { Conflict Over } \\
\text { Maritime Claims: }\end{array}$ & $\begin{array}{l}\text { In spite of clearly defined boundaries, martimed disputer are } \\
\text { conmmon where countries compete over ol discovery. The } \\
\text { conflict over martime most likely occurs when the hight } \\
\text { production performance has been achieved. }\end{array}$ \\
\hline $\begin{array}{l}\text { Policies, Requlations } \\
\text { \& Covernance } \\
\text { Standards: }\end{array}$ & $\begin{array}{l}\text { Refers to regulation uncertainty, such as changing taxes, public } \\
\text { service announcement terms, workplace health, safety and } \\
\text { envirommental securty,y, govermment stability in the developing } \\
\text { countries, etc. }\end{array}$ \\
\hline $\begin{array}{l}\text { Contracts } \\
\text { Complexity: }\end{array}$ & $\begin{array}{l}\text { Referes to the complexity and difficulty to implement and } \\
\text { manage multiple contractors. }\end{array}$ \\
\hline
\end{tabular}

\section{You will quantify the importance of each factor through pairwise comparisons. Please read the instructions below:}

Items will be compared against each other, in pairs, Assign the ponints according to your opinion, The assignment of points should reflect the

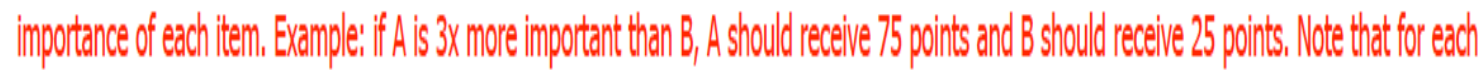

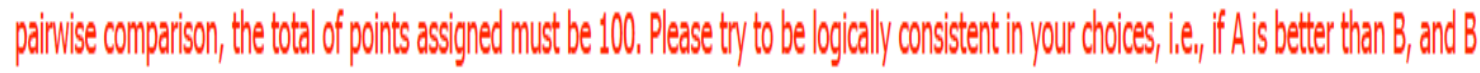
is better than $C_{1}$ A muss be better than $C_{1}$

Note' Please refer to the above table for summary about each factor 
Please judge the importance of the following factors dividing 100 points between them. Drag the bars below assigning more points tc the one you deem more important.

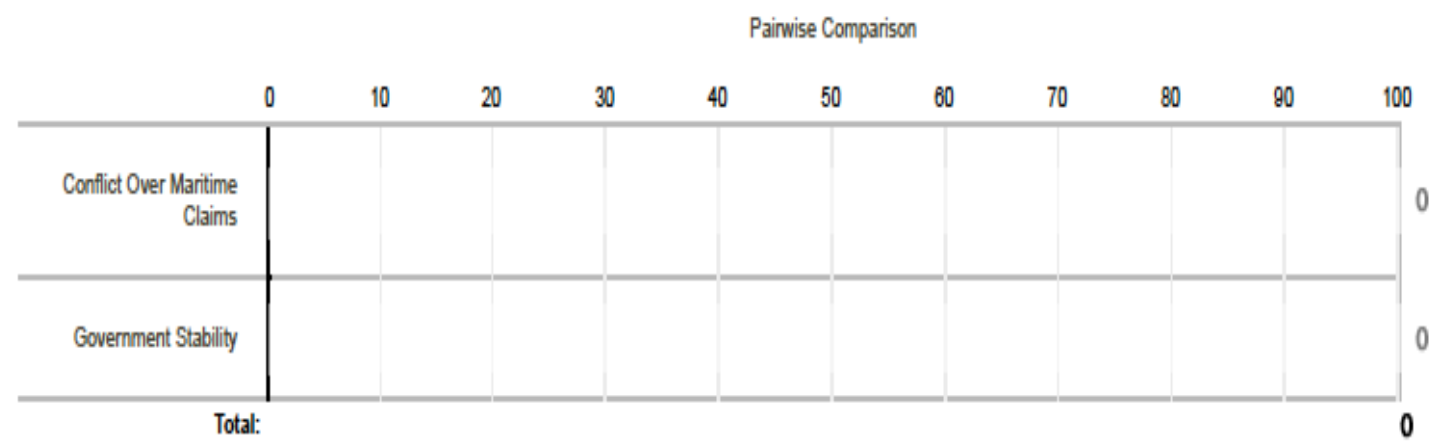

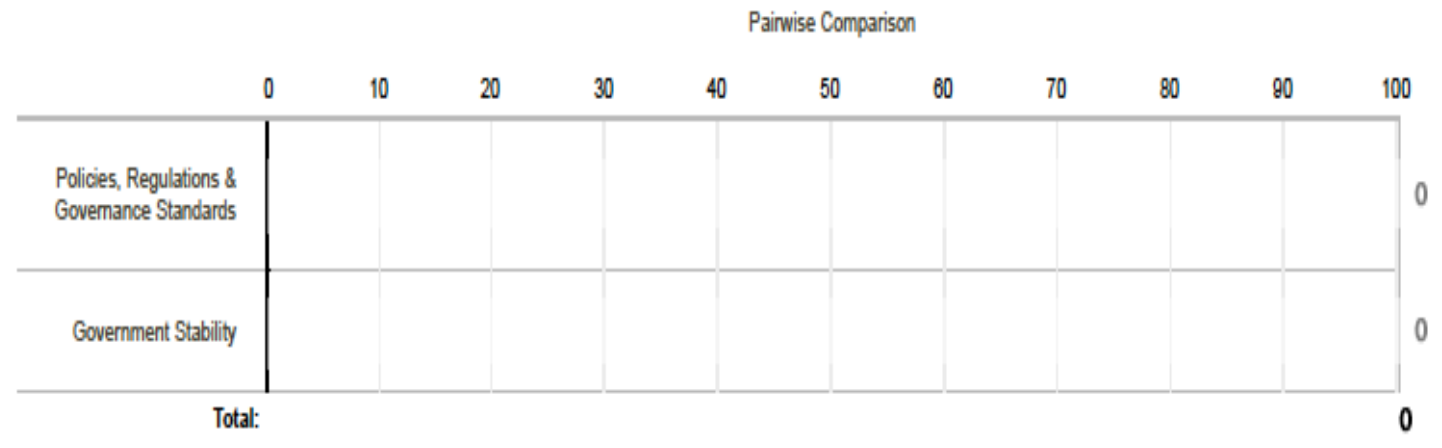

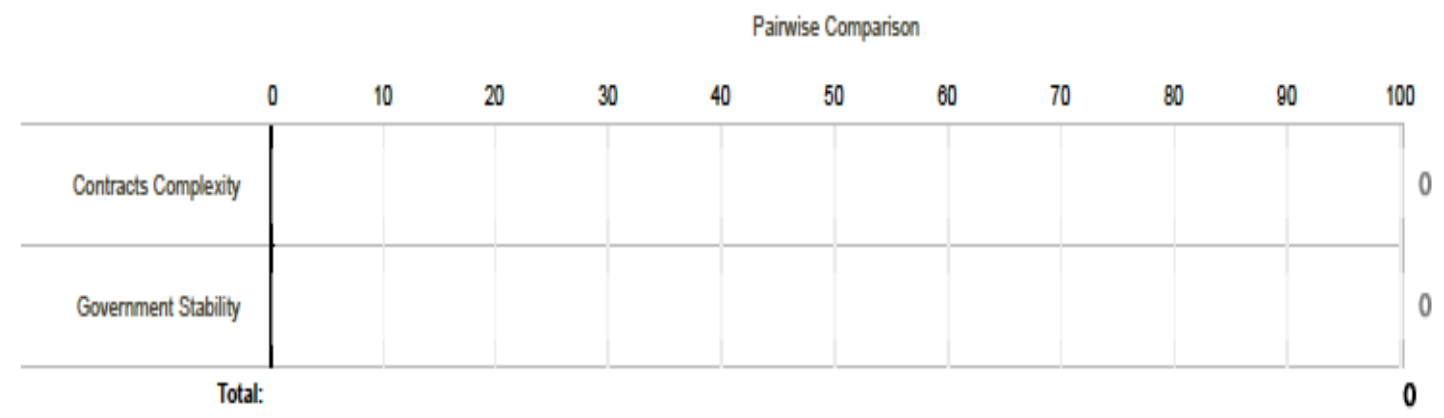




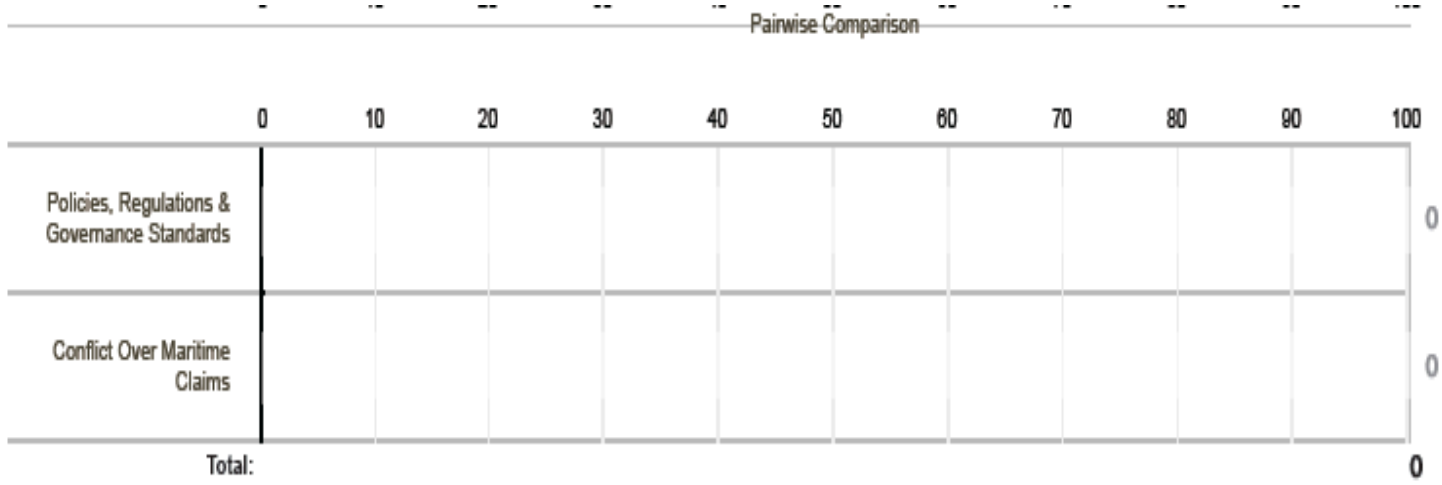

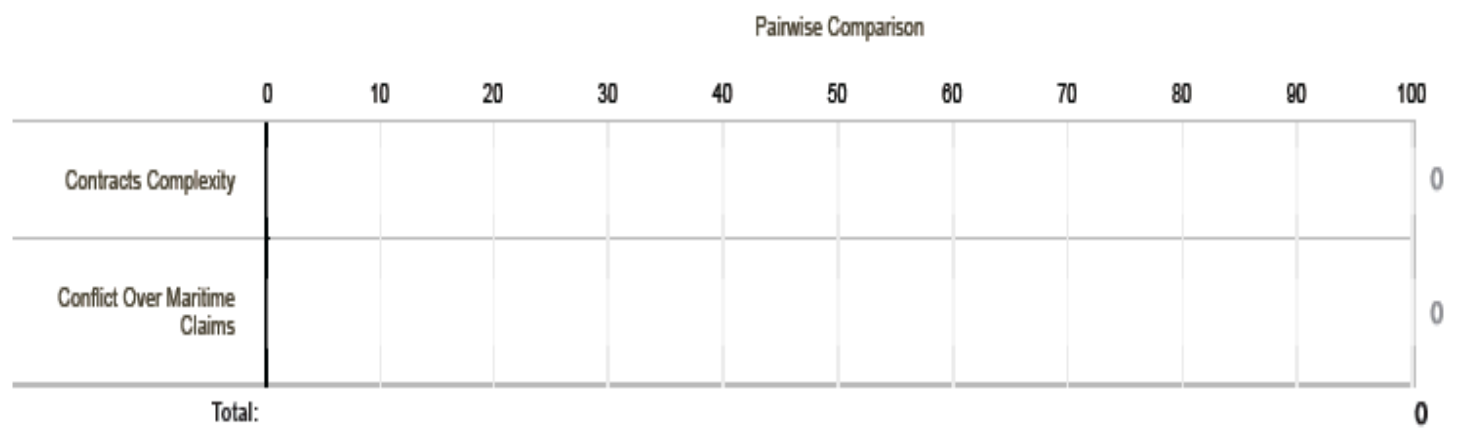

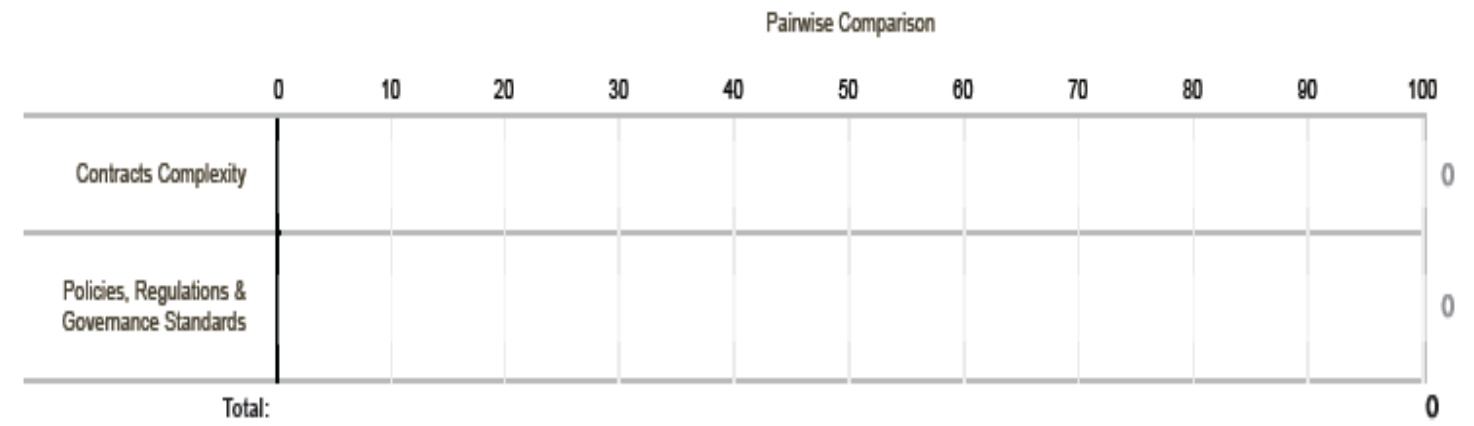

If you have comments, please provide them here: 


\begin{tabular}{|c|c|}
\hline & Environmental \& Safety Perspectives \\
\hline $\begin{array}{l}\text { Hazard } \\
\text { Identification \& } \\
\text { Risk Management: }\end{array}$ & $\begin{array}{l}\text { Refers to the identification and evaluation of any issues } \\
\text { potentially impacing safety and envirommental of the project. } \\
\text { Hazard identification is an essential step before project } \\
\text { implementation and during the project lifecycle phases. }\end{array}$ \\
\hline $\begin{array}{l}\text { Implementing } \\
\text { Health, Safety and } \\
\text { Environmental } \\
\text { (IISE): }\end{array}$ & $\begin{array}{l}\text { Refers to the ability to implement the health, safety and } \\
\text { environmental (HSE) principles. HSE principles contain the } \\
\text { performance levels and measures that are generally considered } \\
\text { to be achievable in new facilities by existing technologies at } \\
\text { reasonable costs. }\end{array}$ \\
\hline $\begin{array}{l}\text { Stringent of the } \\
\text { Local HSE } \\
\text { Standards: }\end{array}$ & $\begin{array}{l}\text { Refers to the stringent policies and regulations of the local } \\
\text { government in implementing health, saiety and environmental } \\
\text { (HSE) principles. More stringent means more money spending } \\
\text { on the project. }\end{array}$ \\
\hline $\begin{array}{l}\text { Environmental Risk } \\
\text { Management } \\
\text { Integration: }\end{array}$ & $\begin{array}{l}\text { Refers to the environmental enforcement rules that the } \\
\text { company has to conduct on the project activities. }\end{array}$ \\
\hline
\end{tabular}

You will quantify the importance of each factor through pairwise comparisons. Please read the instructions below:

Items will be compared against each other, in pairs. Assign the points according to your opinion. The assignment of points should reflect the importance of each item. Example: if $A$ is $3 x$ more important than B, A should receive 75 points and B should receive 25 points. Note that for each pairwise comparison, the total of points assigned must be 100. Please try to be logically consistent in your choices, i.e., if $A$ is better than $B$, and $B$ is better than $\mathrm{C}, \mathrm{A}$ must be better than $\mathrm{C}$.

Note: Please refer to the above table for summary about each factor

Please judge the importance of the following factors dividing 100 points between them. Drag the bars below assigning more points to the one you deem more important. 
Pairwise Comparison

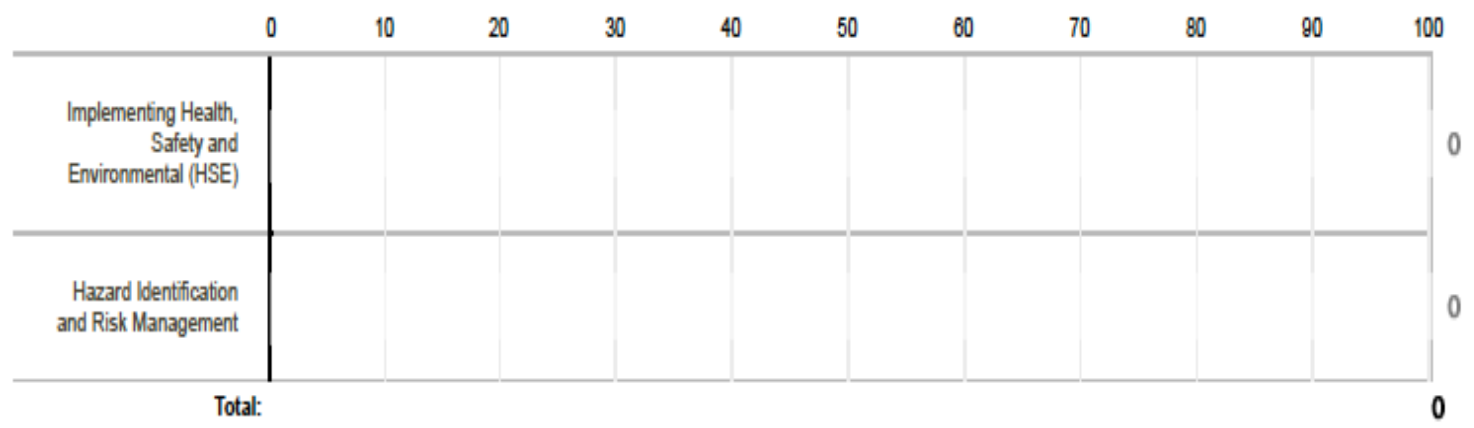

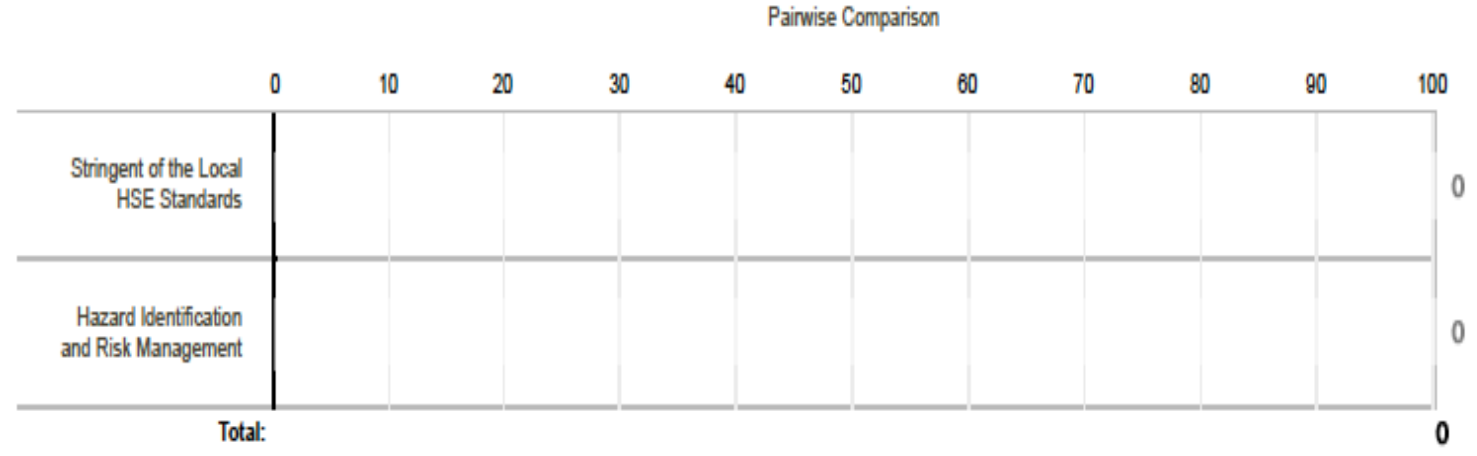

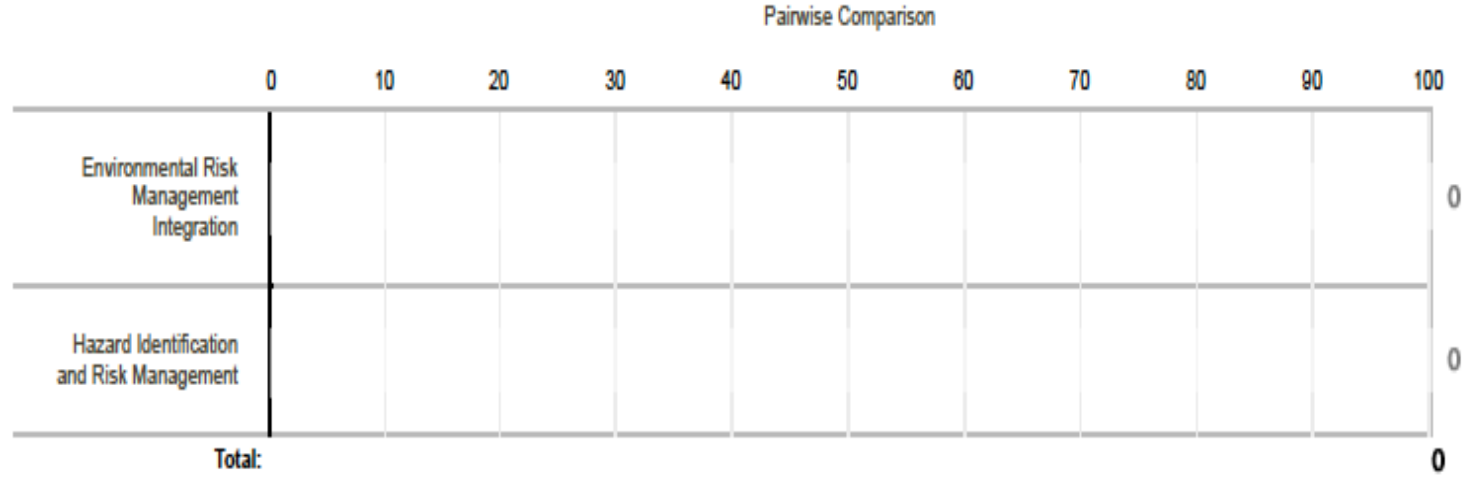




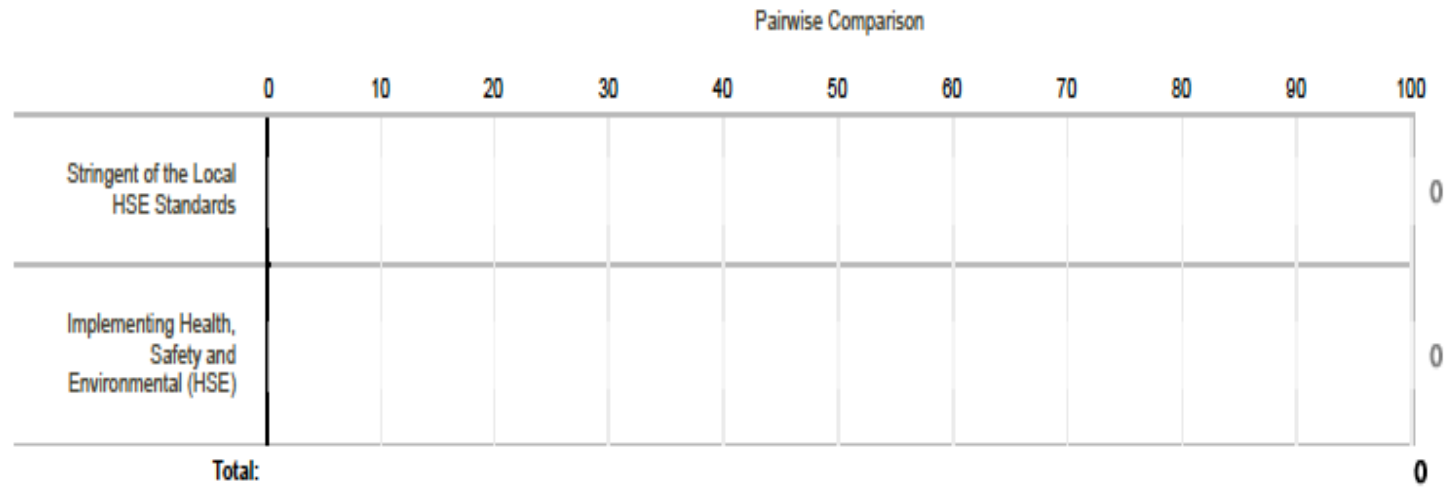

Pairwise Comparison

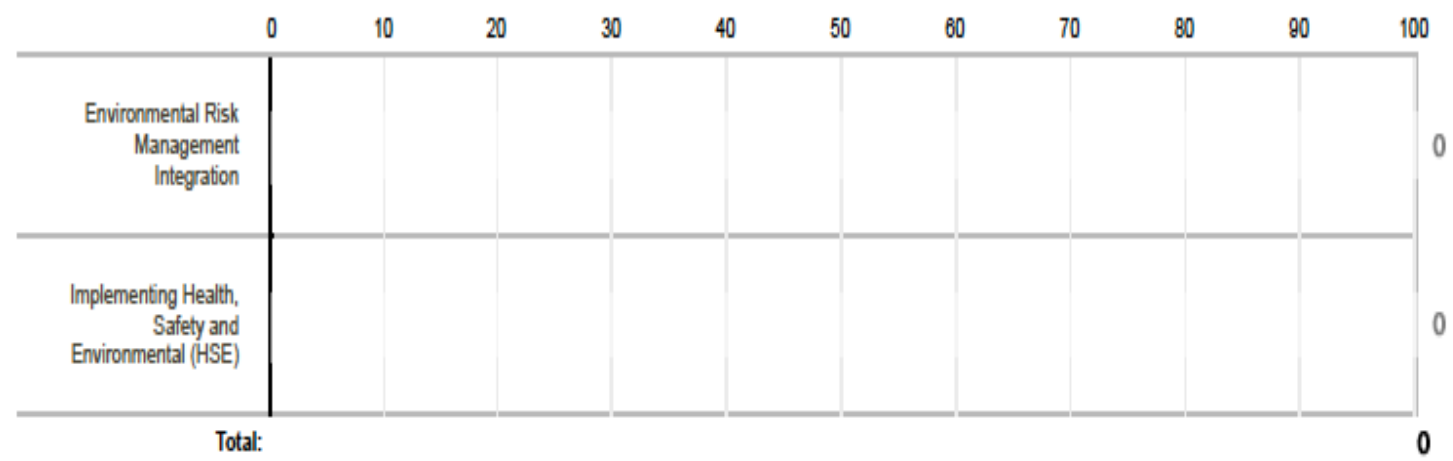

Paimise Comparison

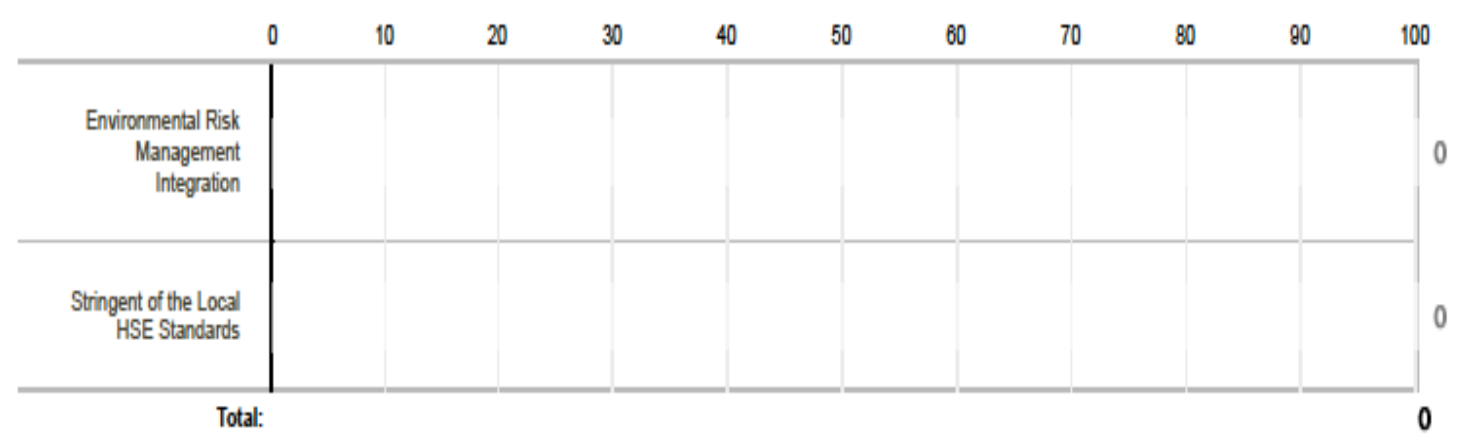




\section{APPENDIX D: QuAltrics SuRVEYS TO QuANTIFY THE DESIRABILITY CuRVE}

\section{Desirability Metrics for Oil Price Criteria:}

Please assign a value (from "0" to "100") on each metric.

At least one metric is required to be assigned as " 0 ", meaning the least desirable.

At least one metric is required to be assigned as "100" meaning the most desirable.

\section{Example:}

Expert assigned values or scores to the Oil Price based on hisher experience and knowledge as following:

\section{Value of Crude Oil Price}

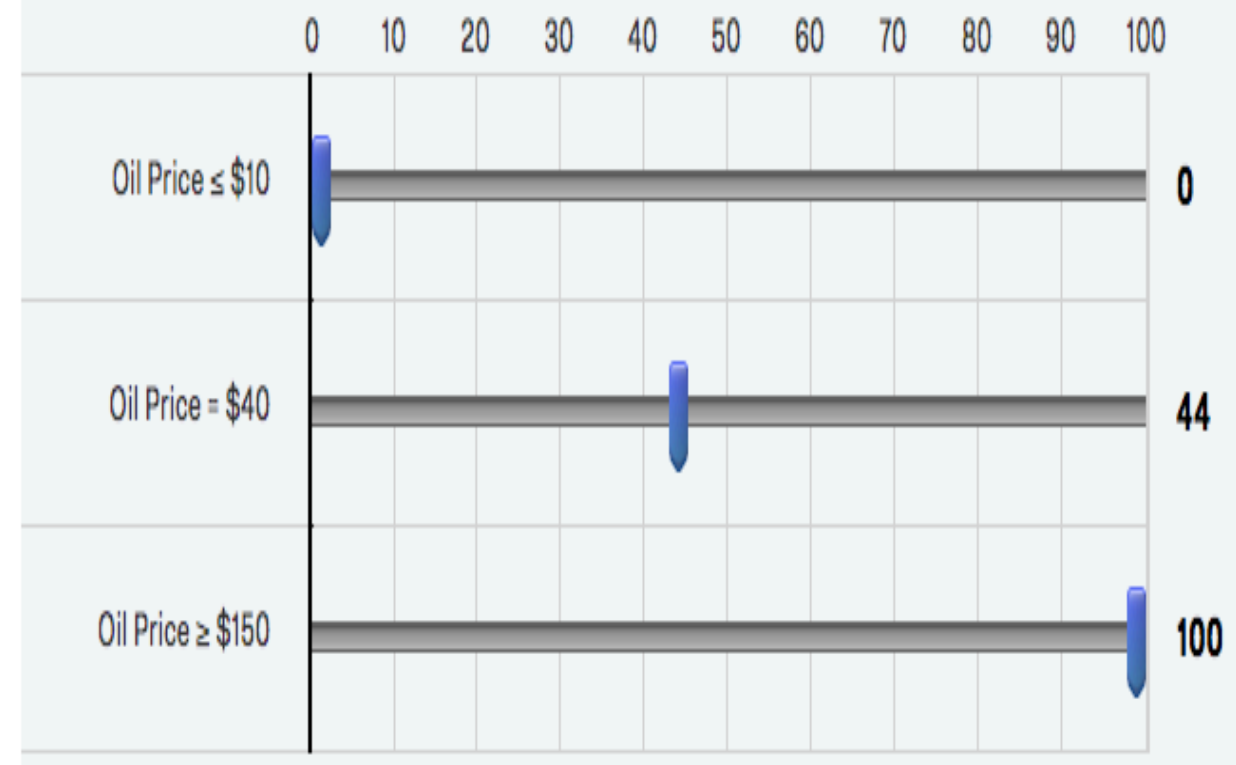


From 0 to 100 Please score and rank the desirability unit of the Oil Price?

\begin{tabular}{|c|c|c|c|c|c|c|c|c|}
\hline \multicolumn{9}{|c|}{ Value of Crude Oil Price } \\
\hline 10 & 20 & 30 & $40 \quad 50$ & 60 & 70 & 80 & 90 & 100 \\
\hline
\end{tabular}

Oil Price $=\$ 40$

Oil Price $=\$ 60$

Oil Price $=\$ 120$

Oil Price $\geq \$ 150$

From 0 to 100 Please score and rank the desirability unit of the Initial Cost?

Initial Cost

10

20

30

40

50

60

70

80

90

100

Initial Cost $\leq 500$ million

Initial Cost $=1$ Billion

Initial Cost $=10$ Billion

Initial Cost $=50$ Billion

Initial Cost $\geq 95$ Billion 
From 0 to 100 Please score and rank the desirability unit of the Return on Investment (ROI)?

\begin{tabular}{llllrrrrrrr}
\multicolumn{1}{c}{ Return on Investment (ROI) } \\
0 & 10 & 20 & 30 & 40 & 50 & 60 & 70 & 80 & 90 & 100
\end{tabular}

Negative or less than zero

ROI between 10 - 50 percent

ROI between $50-70$ percent

From 0 to 100 Please score and rank the desirability unit of the Operational Cost?

\begin{tabular}{|c|c|c|c|c|c|c|c|c|c|c|}
\hline \multicolumn{11}{|c|}{ Operational Cost } \\
\hline 0 & 10 & 20 & 30 & 40 & 50 & 60 & 70 & 80 & 90 & 100 \\
\hline
\end{tabular}

Average estimated cost of operating expenses

High estimated cost of operating expenses

Extremely high estimated cost of operating expenses 
ROI between 70 - 90 percent

ROI equal or exceed 100 percent

From 0 to 100 Please score and rank the desirability unit of the Operational Difficulties?

\begin{tabular}{|c|c|c|c|c|c|c|c|c|c|}
\hline \multicolumn{10}{|c|}{ Operational Difficulties } \\
\hline 0 & 10 & 20 & 30 & $40 \quad 50$ & 60 & 70 & 80 & 90 & 100 \\
\hline
\end{tabular}

Project expected to face low level of operational difficulties

Project expected to face medium level of operational difficulties

Project expected to face high level of operational difficulties

Project expected to face extremely high level of operational difficulties

From 0 to 100 Please score and rank the desirability unit of the Project Size \& Complexity?

\begin{tabular}{|c|c|c|c|c|c|c|c|c|}
\hline \multicolumn{9}{|c|}{ Project Size \& Complexity } \\
\hline 10 & 20 & 30 & $40 \quad 50$ & 60 & 70 & 80 & 90 & 100 \\
\hline
\end{tabular}

Average complexity

High complexity

Extremely high complexity

From 0 to 100 Please score and rank the desirability unit of the Production Performance?

0

20

30

Production Performance

$50 \quad 60 \quad 70$

80

90

100 
High Production Performance

Extremely high Production Performance

From 0 to 100 Please score and rank the desirability unit of the Subsurface \& Reservoir?

10

20

30

Subsurface \& Reservoir
40

$60 \quad 70$

80

90

100

Project has a high certainty of reservoir volume

Project has a low uncertainty of reservoir volume

Project has a average uncertainty of reservoir volume

Project has a high uncertainty of reservoir volume

From 0 to 100 Please score and rank the desirability unit of the Government Stability?

\begin{tabular}{|c|c|c|c|c|c|c|c|c|c|c|}
\hline \multicolumn{11}{|c|}{ Government Stability } \\
\hline 0 & 10 & 20 & 30 & 40 & 50 & 60 & 70 & 80 & 90 & 100 \\
\hline
\end{tabular}

High risk of instability

Some risk of instability

Stable country 
From 0 to 100 Please score and rank the desirability unit of the Contracts Complexity?

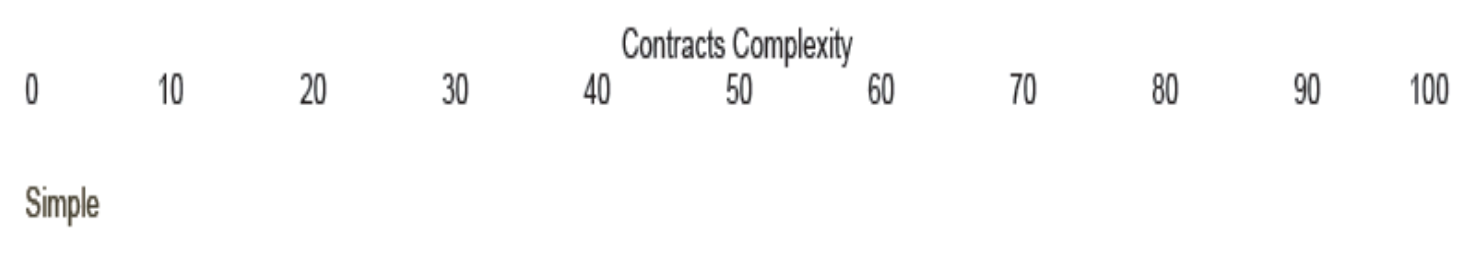

Reasonable

Complex

From 0 to 100 Please score and rank the desirability unit of the Conflict Over Maritime Claims?

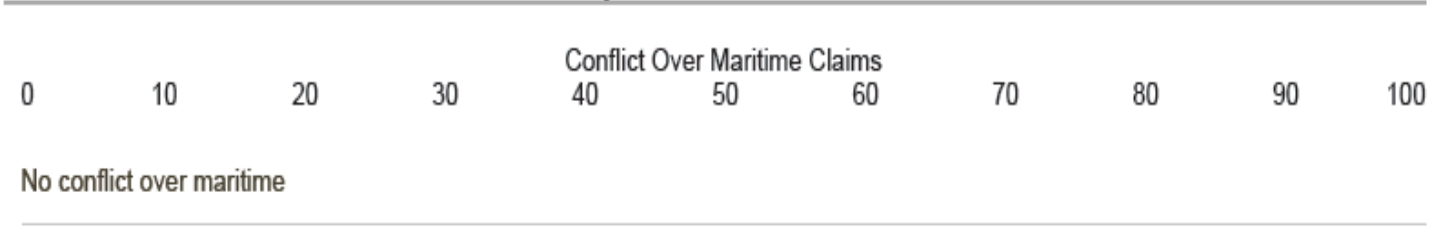

Low probability of conflict over maritime

High probability of conflict over maritime

Conflicted Area 
From 0 to 100 Please score and rank the desirability unit of the Policies, Regulations \& Governance Standards?

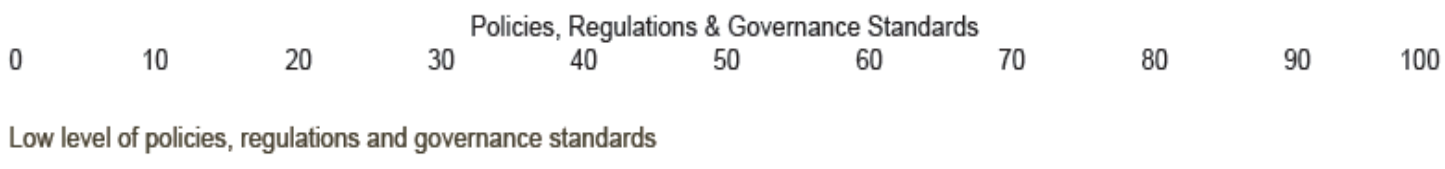

Average level of policies, regulations and governance standards

High level of policies, regulations and governance standards

Extremely high level of policies, regulations and governance standards

From 0 to 100 Please score and rank the desirability unit of the Hazard Identification \& Risk Management?

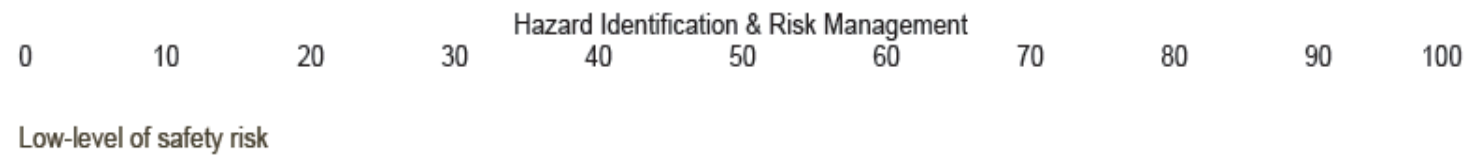

Average level of safety risk

High-level of safety risk

Extremely high-level of safety risk 
From 0 to 100 Please score and rank the desirability unit of the Implementing Health, Safety and Environmental (HSE)?

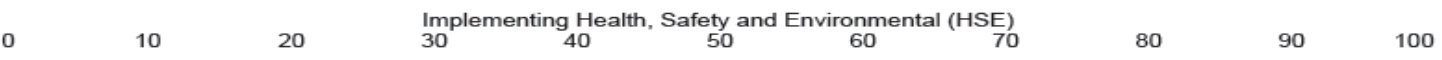

HSE easy to implement

HSE reasonable to implement

HSE complex to implement

HSE very complex to implement

From 0 to 100 Please score and rank the desirability unit of the Stringent of the Local Health, Safety and Environmental (HSE) Standards?

10

20

Stringent of th

30

40

50

60

70

80

90

100

Low stringent of local Health, Safety and Environmental (HSE) Standards

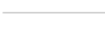

Average stringent of local Health, Safety and Environmental (HSE) Standards

High stringent of local Health, Safety and Environmental (HSE) Standards

Extremely high stringent of local Health, Safety and Environmental (HSE) Standards

From 0 to 100 Please score and rank the desirability unit of the Environmental Risk Management Integration?

$\begin{array}{llllllllll}0 & 10 & 20 & 30 & \begin{array}{c}\text { Environmental Risk Management Integration } \\ 40\end{array} & 50 & 60 & 70 & 80 & 90\end{array}$

Low level of regulation on environmental threats is required

Average level of regulation on environmental threats is required

High level of regulation on environmental threats is required

Extremely high level of regulation on environmental threats is required 
APPENDIX E: HDM SOFTWARE TOOL

Version: Beta 2.0

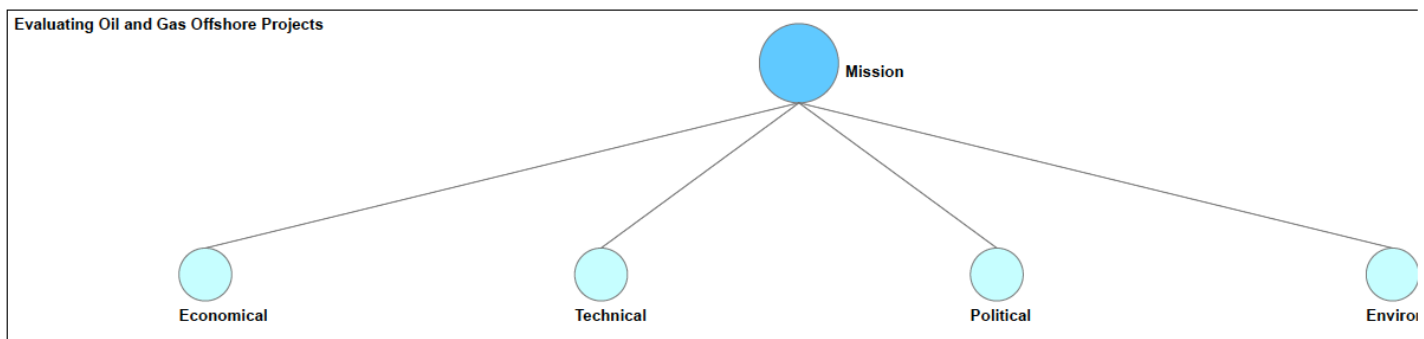

Show Instructions

Please give your judgment for each pair of nodes below toward Mission:

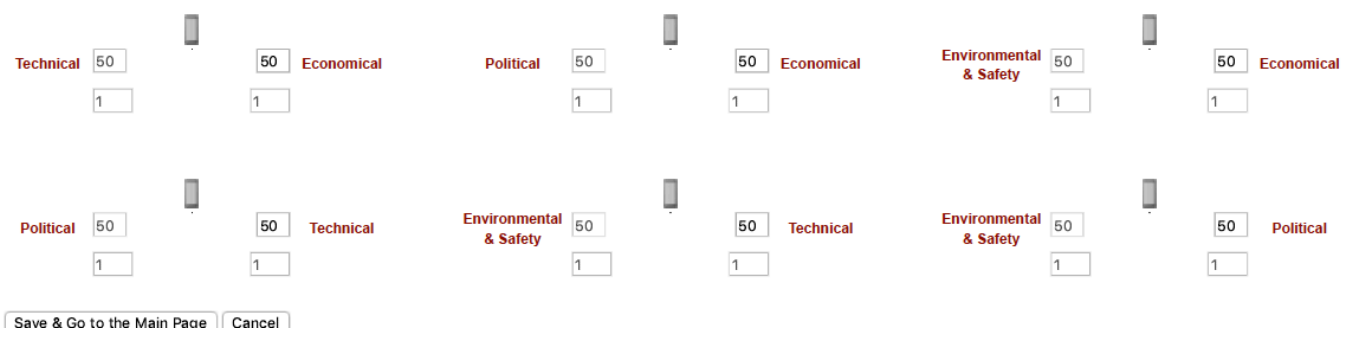

Version: Beta 2.0

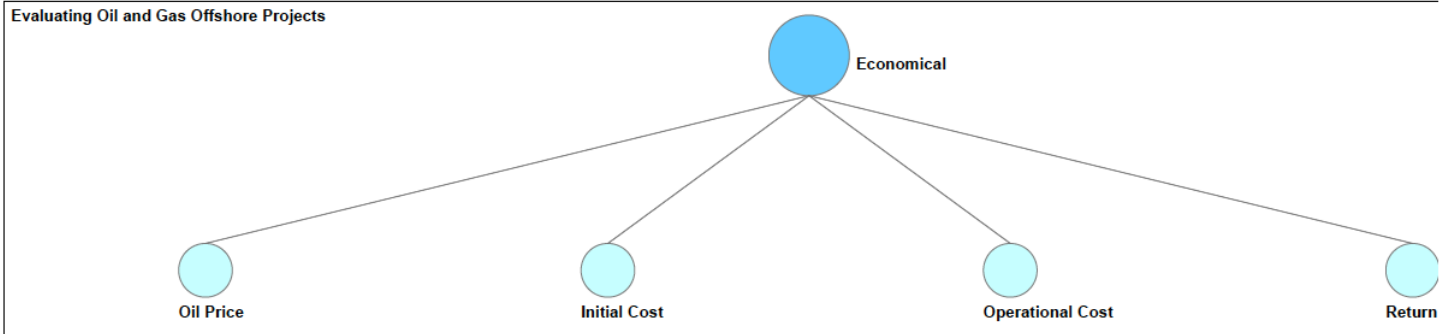

Show Instructions

Please give your judgment for each pair of nodes below toward Economical:

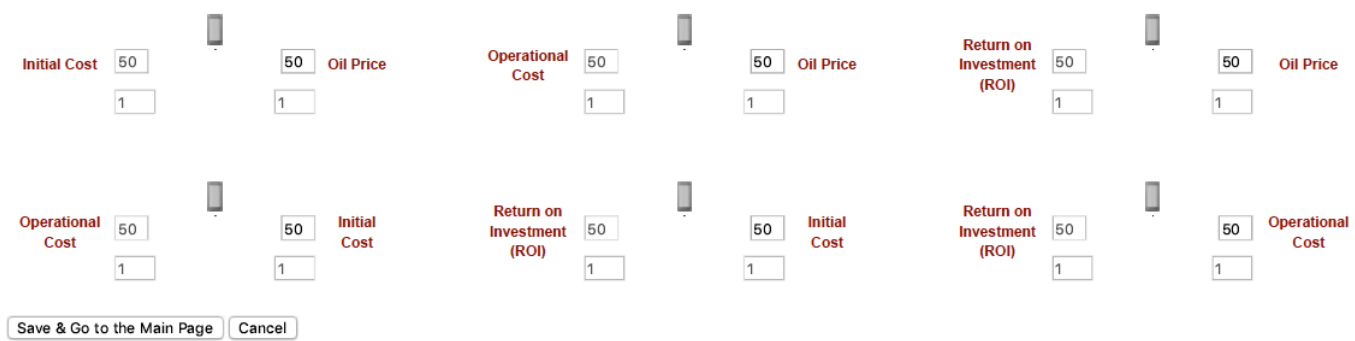

Save $\&$ Go to the Main Page Cancel 
Version: Beta $\mathbf{2 . 0}$

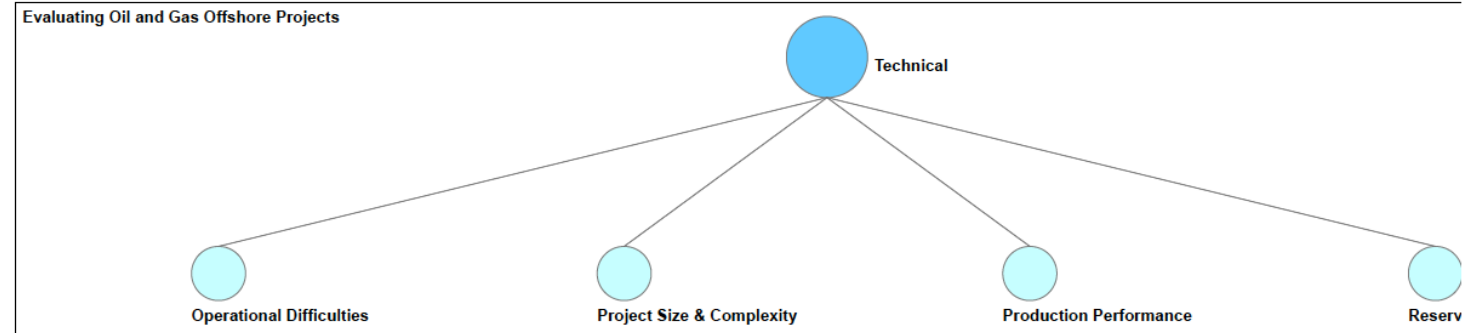

Show Instructions

Please give your judgment for each pair of nodes below toward Technical:

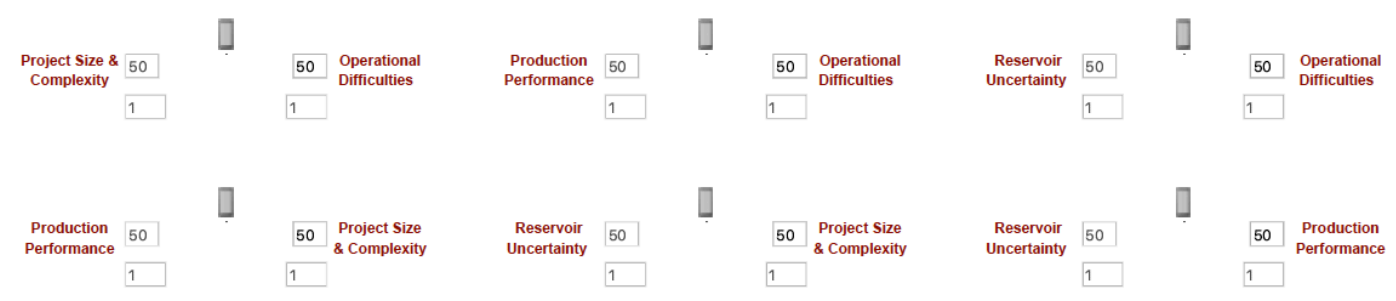

Version: Béta 2.0

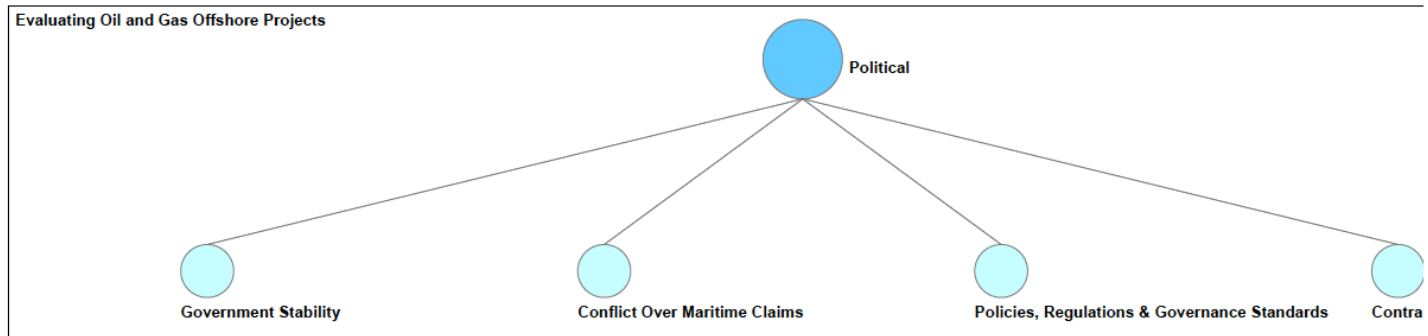

Show Instructions

Please give your judgment for each pair of nodes below toward Political

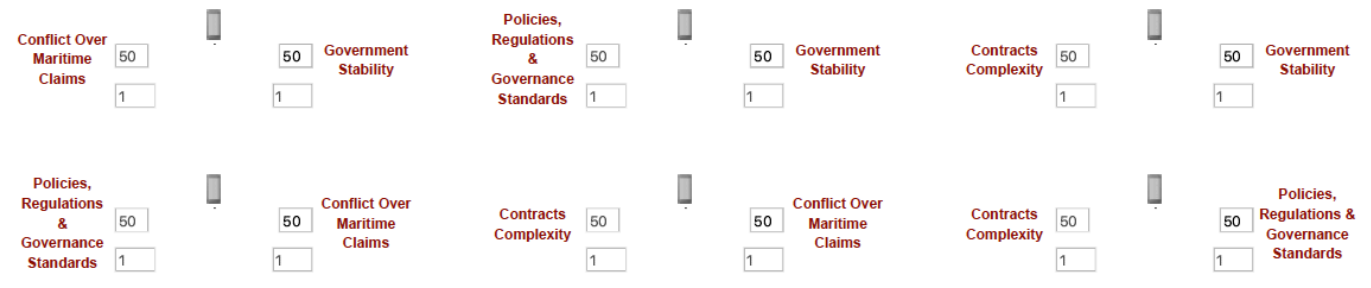

Save $\&$ Go to the Main Page Cancel 
Version: Beta 2.0

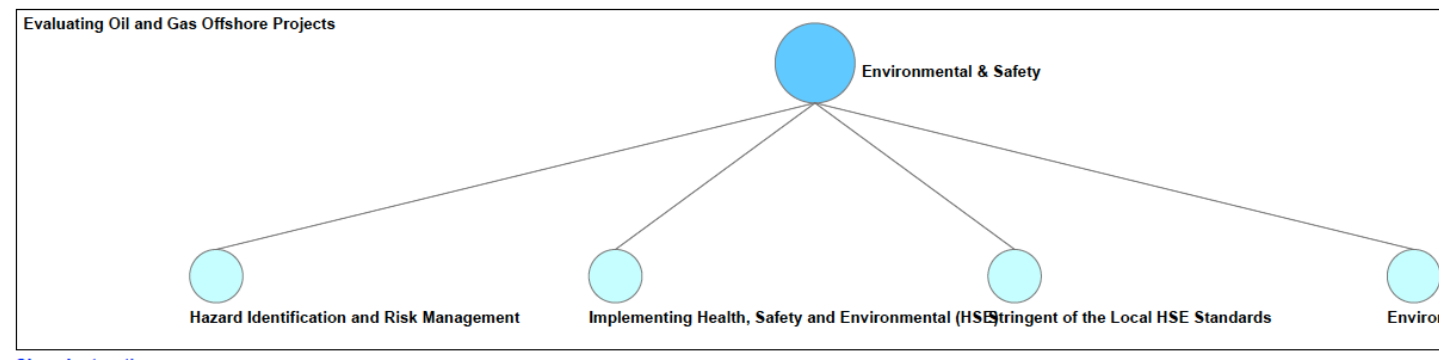

Show Instructions

Please give your judgment for each pair of nodes below toward Environmental \& Safety:

\begin{tabular}{|c|c|c|c|c|c|c|c|c|c|c|c|c|c|c|}
\hline \multirow{3}{*}{$\begin{array}{l}\text { Implementing } \\
\text { Health, Safety } \\
\text { and } \\
\text { Environmental } \\
\text { (HSE) }\end{array}$} & & \multirow[t]{3}{*}{$\square$} & \multirow{3}{*}{\multicolumn{2}{|c|}{$\begin{array}{c}\text { Hazard } \\
\text { Identification } \\
\text { and Risk } \\
\text { Management }\end{array}$}} & \multirow{3}{*}{$\begin{array}{l}\text { Stringent of } \\
\text { the Local HSE } \\
\text { Standards }\end{array}$} & & \multirow[t]{3}{*}{ 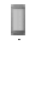 } & \multirow[b]{2}{*}{50} & \multirow{3}{*}{$\begin{array}{c}\text { Hazard } \\
\text { Identification } \\
\text { and Risk } \\
\text { Management }\end{array}$} & \multirow{3}{*}{$\begin{array}{c}\text { Environmental } \\
\quad \text { Risk } \\
\text { Management } \\
\text { Integration }\end{array}$} & & \multirow[t]{3}{*}{$\square$} & \multirow{3}{*}{\multicolumn{2}{|c|}{$\begin{array}{c}\text { Hazard } \\
0 \\
0\end{array} \begin{array}{c}\text { Identification } \\
\text { and Risk } \\
\text { Management }\end{array}$}} \\
\hline & 50 & & & & & 50 & & & & & 50 & & & \\
\hline & 1 & & & & & 1 & & 1 & & & 1 & & & \\
\hline \multirow{3}{*}{$\begin{array}{l}\text { Stringent of } \\
\text { the Local HSE } \\
\text { Standards }\end{array}$} & & ] & & $\begin{array}{l}\text { Implementing } \\
\text { Health, Safety }\end{array}$ & Environmental & & U & & $\begin{array}{l}\text { Implementing } \\
\text { Health. Safety }\end{array}$ & Environmental & & U & & \multirow{3}{*}{$\begin{array}{c}\text { Stringent of } \\
\text { the Local HSE } \\
\text { Standards }\end{array}$} \\
\hline & 50 & & 50 & $\begin{array}{l}\text { and } \\
\text { Environmental }\end{array}$ & $\begin{array}{c}\text { Risk } \\
\text { Management }\end{array}$ & 50 & & 50 & $\begin{array}{l}\text { and } \\
\text { Environmental }\end{array}$ & $\begin{array}{c}\text { Risk } \\
\text { Management }\end{array}$ & 50 & & 50 & \\
\hline & 1 & & 1 & & & 1 & & 1 & (HSE) & & 1 & & 1 & \\
\hline
\end{tabular}

Save \& Go to the Main Page Cancel 